\title{
6 Anhang: Berichte und Instruktionen im Wortlaut
}

Nation und Glaube als Identitätsmerkmale prägten schon im 16. Jahrhundert auch die Einstellung der damaligen Päpste. Unter Identität sind sechs große Felder zu verstehen, die das Bild eines Betrachters - in diesem Falle die Päpste im 16. und 17. Jahrhundert - auf den Betrachteten - die Eidgenossen - beeinflussen. Diese sechs Felder betreffen Geschlecht, Religion, Heimat (Nation), soziales Gefüge, Kultur und Aussehen. ${ }^{1}$

In den Instruktionen und Briefen an und von den Nuntien in Luzern geht es immer um Männer. Frauen werden nur als Ordensfrauen (Klöster) und als Ehefrauen von wichtigen Persönlichkeiten behandelt. Bei den bürokratischen Abwicklungen der Nuntien ging es oft um Ehedispense, was auch Frauen betraf, doch bei machtpolitischen Angelegenheiten spielten Frauen keine Rolle.

Was das zweite Feld betrifft, so geht es im Allgemeinen um Fragen der katholischen Religion. Neben dogmatischen Themen war auch die religiöse Praxis ein wichtiges Thema, das die Päpste den Nuntien ans Herz legten. Allgemein stellten die Absender aus Rom und die Adressaten - also die Nuntien in Luzern - den Gegensatz „Italiener vs. Schweizer“ in den Vordergrund, wenn auch nicht explizit. Die kulturellen Unterschiede werden in den Instruktionen als Merkmale genannt, um eine bessere Integration der Nuntien zu ermöglichen. Dies hatte wohl das Ziel, möglichst erfolgreich im Gastland aufzutreten. Ebenfalls gut aus den Instruktionen und Briefen der Nuntien herauszulesen sind die Unterschiede im Bereich des sozialen Gefüges. Sowohl die Päpste selber als auch die Nuntien allesamt gehörten dem italienischen Adel an. Diese setzten sich mit Leuten auseinander, die aus ihrer Sicht im besten Fall Patrizier waren und sich mit den adeligen Gepflogenheiten auskannten. Im kulturellen Bereich spielten auch die unterschiedlichen Sprachen eine Rolle, wobei die Nuntien auf Informanten und Gesprächspartner in der Eidgenossenschaft zählen konnten, die Italienisch sprachen. Was das Aussehen betraf, so wurden die Schweizer in keiner Instruktion oder Brief negativ dargestellt. Diese Qualitäten kamen am Rande vor, wenn es darum ging, die Schweizer als kräftige oder bäuerliche Männer zu beschreiben. Dies kam im Bereich der Söldneranwerbung durchaus vor.

Bei den folgenden Dokumenten handelt es sich um eigene Übersetzungen von Originaldokumenten, die im Apostolischen Päpstlichen Archiv (Geheimar-

1 Vgl. Kwame Anthony Appiah: Identitäten. Die Fiktion der Zugehörigkeit, Berlin 2019. Statt Aussehen verwendet Appiah das Feld „Hautfarbe“, was aber bei dieser Studie keine Rolle spielt.

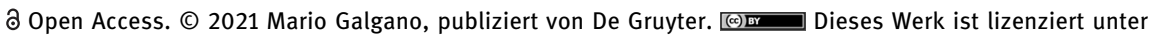
der Creative Commons Attribution 4.0 Lizenz. Weitere Informationen finden Sie unter 
chiv) zu finden sind bzw. aus anderen Publikationen, die aber zur besseren Einordnung dieser Schrift hier aufgeführt werden sollen. Anmerkungen in eckigen Klammern stammen vom Übersetzer.

\subsection{Bericht über Ottavio Paravicini (1587-1591)}

In folgender Schrift geht es um den Blick auf den Nuntius und nicht vom Nuntius. Daran ist interessant festzustellen, wie aus römischer und Schweizer Sicht der Papstgesandte in der Schweiz wirkte. Auch gibt dieser Bericht einen Einblick auf das Verhältnis und die Stimmung bei den Schweizer Katholiken und insbesondere bei den Luzernern.

\section{Monsignore Ottavio Paravicini, Apostolischer Nuntius in der Schweiz; ernannter Kardinal ${ }^{3}$}

1591 fand in Luzern ein großes und unvergessliches Fest statt. Ich will darüber berichten. Am 5. März des letzten Jahres hatte Papst Gregor XIV. ${ }^{4}$ die Würde des Kardinalats ${ }^{5}$ an Monsignore Ottavio Paravicini versprochen, der vier Jahre lang bei den katholischen Kantonen der Schweiz war. Es handelt sich um einen Prälaten, der sich durch Tugenden und Verdienste ausgezeichnet hat.

Nach dieser Ernennung sandte der Papst einen seiner Kammerherren nach Luzern. Es handelt sich um Monsignore Fausto Rebaly ${ }^{6}$, der das von Seiner Heiligkeit gesegnete rote Birett ${ }^{7}$ dem neuen Kardinal überbrachte. Dieser lebte wegen geschäftlicher Angelegenheiten seit einiger Zeit in Uri. ${ }^{8}$

2 Segreteria Stato, Svizzera, Volume Additamenta I, Busta 4. Der Originaltext ist auf Französisch verfasst. Es gibt keine weiteren Erläuterungen zum Verfasser dieses Beitrags und auch keine Angaben zum Zeitpunkt und Ort seines Erscheinens. Sehr wahrscheinlich handelt sich um eine Informationsbenachrichtigung aus der Schweiz, um die römische Kurie über das Wirken Paravicinis aufzuklären. Das könnte im Rahmen der Kardinalsernennung geschehen sein. Die Kardinalskreierung fand am 6. März 1591 durch Papst Gregor XIV. statt.

3 Urban Fink: Die Luzerner Nuntiatur 1586-1873, S. 45. Paravicini hatte ein schlechtes Verhältnis zu den Schweizer Katholiken. So konnte er froh sein, die Schweiz unbehelligt verlassen zu können, wie Fink schreibt. Die Kardinalsernennung und die Überreichung des roten Biretts „im großen Stil“ könnten dies nicht überdecken.

4 Vgl. Friedrich Wilhelm Bautz: Gregor XIV., S. 325.

5 Vgl. Jürgen Dendorfer, Ralf Lützelschwab (Hrsg.): Geschichte des Kardinalats im Mittelalter. Päpste und Papsttum 39, Stuttgart 2011.

6 Weitere Informationen über Fausto Rebaly sind nicht auffindbar.

7 Das Kardinalsgewand, die cappa magna, durfte allein von Kardinallegaten während ihrer Legation in der Farbe rot getragen werden, um symbolisch eine größtmögliche Papstähnlichkeit zu erreichen.

8 Paravicini wohnte somit eine Zeit lang nicht in Luzern. Sein Verhältnis zu den luzernischen Behörden war in jener Zeit schlecht. 
Die Nachricht über die Kardinalsernennung ging sofort nach Luzern und erreichte seine Unterkunft am Jesuitenkolleg, wo Monsignore Rebaly dann am 24. März diese Stadt erreichte. ${ }^{9}$

Nachdem die beiden Prälaten sich gemeinsam beraten hatten, teilte Seine Eminenz Paravicini dem Luzerner Herrn Ludwig Pfyffer ${ }^{10}$, der damals Schultheiß war, seine Beförderung mit und bat ihn, mit anderen Regierungsmitgliedern zu ihm zu kommen; was der Schultheiß auch sofort tat, indem er von den ältesten Ratsmitgliedern und dem Staatssekretär begleitet wurde. Sie wurden vom neuen Kardinal und dem Sondergesandten aus Rom sehr freundlich empfangen. Letzterer erläuterte in einer langen Rede den Zweck seiner Mission und versicherte wiederholt die väterliche Güte Seiner Heiligkeit gegenüber der Stadt Luzern, die dem Heiligen Stuhl mehrfach Verdienste entgegengebracht hatte. Dann präsentierte er das Schreiben des Papstes und zeigte diesen Herren das aus Rom mitgebrachte Birett und schloss das Birett in einem scharlachroten Samtbeutel ein.

Der Staatssekretär öffnete das Schreiben, las es laut vor und übersetzte es dann ins Deutsche, darin heißt es im Wesentlichen: dass Seine Heiligkeit, bewegt von den großen Tugenden und Verdiensten des Apostolischen Nuntius Ottavio Paravicini, beschlossen hatte, ihn in das Kardinalskollegium aufzunehmen, indem er ihm die mit dieser Würde verbundenen Privilegien und Vorrechte verleiht; dass ihm folglich von einem seiner treuen Kammerdiener das rote Birett geschickt wurde, und dass er sich beim Tragen daran erinnern möge, dass er immer bereit sein muss, sein Blut für die Kirche Gottes zu vergießen, usw.

Diese Lesung beendete der Schultheiß, und die Ratsmitglieder gratulierten Seiner Eminenz und wünschten ihm Glück und Wohlstand aller Art; sie fügten im Laufe der Rede ihren Dank an den Prälaten Rebaly hinzu, indem sie eine brillante Aufzählung der großen Qualitäten von Monsignore Paravicini machten. Sie baten ihn, den Heiligen Vater bei seiner Rückkehr nach Rom ihrer Treue zu versichern, was der Prälat versprach, und sie trafen am nächsten Tag wieder zusammen.

An diesem Tag - es war der 25. März, das Fest Mariä Verkündigung - präsentierte sich die Delegation des Vortages in Begleitung vieler anderer der berühmtesten Persönlichkeiten der Stadt um 7 Uhr morgens im Jesuitenkolleg, um an der Zeremonie teilzunehmen, die stattfinden sollte. Wir gingen voran, und

9 Trotz des schwierigen Verhältnisses mit den Luzernern musste die offizielle Übergabe der Nachricht aus Rom offenbar in Luzern ankommen.

10 Vgl. Stichwort „Ludwig Pfyffer von Altishofen“, in: https://hls-dhs-dss.ch/de/articles/ 014468/2010-09-28/ (31. Dezember 2020). 
die Prozession wurde von den Regierungsvertretern und ihren Gefolgen begleitet. Dann kam der Auditor des Nuntius, der eine Silberplatte trug, auf der ein karminrotes Seidentuch und das roten Birett lagen. An seiner Seite war ein Diener, der den karminroten Samtbeutel in den Händen hielt. Dem Auditor folgte Seine Eminenz, zu seiner Rechten den Monsignore, also den Außerordentlichen Gesandten Roms, und zu seiner Linken den verantwortlichen Herrn Schultheiß. Die Kanoniker des Kapitels folgten sogleich, und der Marsch wurde von den Sekretären und anderen der Apostolischen Gesandtschaft verbundenen Personen abgeschlossen.

Die Kathedralkirche war so voller Menschen, als ob niemand zu Hause geblieben wäre. Der Kardinal Nuntius stand auf seinem Platz, und neben ihm standen der Außerordentliche Gesandte aus Rom, der Auditor und einige Kanoniker; der Rest des Klerus nahm seinen Platz auf den Bänken des Chores ein.

Der Schultheiß und die Ratsmitglieder besetzten ihre gewöhnlichen Plätze, und das Birett wurde auf dem Hauptaltar neben dem Evangeliar, gegenüber dem neuen Kardinal, aufgestellt.

Nachdem alle $\mathrm{zu}$ ihren Plätzen gelangt waren, ging der Priester der Stadt zur Kanzel und sprach in seiner Predigt zunächst über das Fest des Tages, das heißt die Verkündigung Mariens; dann machte er einige Anmerkungen über den Ursprung und die Würde des Kardinalats, und von diesem Ausgangspunkt aus machte er eine Ausführung, um die herausragenden Eigenschaften des gegenwärtigen Kardinals zu erläutern.

Nach der Predigt wurde die große Messe gesungen, an deren Ende der Auditor den Schultheiß holte, um ihn zum Hauptaltar zu bringen. Hier hielt er in seinen Händen die Silberplatte, auf der das rote Birett platziert war, damit der Außerordentliche Gesandte Roms es nehmen konnte und es nach verschiedenen Formalitäten auf den Kopf des neuen Kardinals legte. Zur gleichen Zeit ging ein Pater der Gesellschaft Jesu zur Kanzel und gratulierte Monsignore Paravicini zu seiner Beförderung. Der Pater würdigte Monsignore Paravicini für seine Tugenden und Talenten und hoffte schließlich, dass Seine Eminenz sein Wohlwollen dem Senat und dem Luzerner Volk weiter erweisen möge.

Nach dieser Rede schickte Monsignore Rebaly den Pfarrer der Stadt zum Schultheiß, um ihm seinen Dank zu überbringen, dass er und der Stadtrat sich freundlicherweise bereiterklärt hatten, an dieser feierlichen Handlung teilzunehmen und ihn mit ihrer Anwesenheit zu ehren, und fügte die Bitte hinzu, ihren guten Willen gegenüber dem Heiligen Stuhl beizubehalten, und die römisch-katholische Kirche, so gut sie könnten, $\mathrm{zu}$ verteidigen und ihre ganze Kraft zum Wohl dieser gemeinsamen Bindung der Gläubigen einzusetzen.

Die Posaunen und Pauken begannen zu erklingen; das Te Deum laudamus wurde von einem brillanten Orchester gespielt und aufgeführt; und nach dem 
Te Deum-Gebet wurde für das Wohl der Heiligen Kirche, des Papstes und des neuen Kardinals gebetet, und damit diese lange und interessante Feier beendet. Sie gingen in der gleichen Reihenfolge, in der sie gekommen waren, zurück zum Jesuitenkollegium. Es wurde ein ausgezeichnetes Abendessen serviert, an dem Seine Eminenz und Monsignore Rebaly, die beiden Schultheißen, die meisten Ratsherren und die angesehensten Mitglieder des Klerus, sowohl Diözesanpriester als auch Ordensleute, aus Luzern teilnahmen. Während des Essens machte ein Jesuit in einer eloquenten lateinischen Rede eine großartige Beschreibung der morgendlichen Zeremonie. Und bis zu später Stunde wurde gesprochen. Am Schluss waren alle sehr glücklich über das Treffen.

Wenige Tage später kehrte Seine Eminenz der Nuntius in Begleitung von Herrn Rebaly nach Uri zurück, um die Angelegenheiten der Nuntiatur abzuschließen, und einige Monate später verließ er die Schweiz, um nach Rom zu gehen.

Einige Anmerkungen über Bischof Ottavio Paravicini, Bischof von Alexandria und Apostolischer Nuntius in der Schweiz.

Dieser Prälat kam Ende 1587 in der Schweiz an; und kaum betrat er das Land, da hatte er mit einigen Schwierigkeiten wegen seines Erscheinens in dieser Stadt und der Art seiner Mission zu tun. Man wollte vor allem genau wissen, woraus dieser Auftrag besteht, ob er nur als Visitator des Klerus komme, dann wäre es besser für ihn, dass er seine geplanten Reformen in Konstanz beginnen solle, wo sie viel mehr gebraucht werden als in Luzern, etc.

Während seines Aufenthaltes in der Schweiz verhandelte und erhielt Monsignore Paravicini 6000 Männer zur Unterstützung der Partei der Guises ${ }^{11}$ in Frankreich, und er bemühte sich, den Abt von St. Gallen in die katholische Liga $\mathrm{zu}$ bringen, aber es gelang ihm nicht.

Anfang September 1590 verabschiedete er sich vor dem versammelten Rat, wo er in einer langen Rede von den Vorteilen sprach, die sich aus einer ständigen Nuntiatur für die Schweiz ergeben würden. Nach Beurteilung des Inhalts seiner Rede ist davon auszugehen, dass diese Beständigkeit nicht in allen Kantonen gut aufgenommen wurde und dass Seine Exzellenz einige Unannehmlichkeiten im Zusammenhang mit diesem Anliegen hatte.

11 Der Berichterstatter bezieht sich auf den Bund, der 1584-1593 von französischen katholischen Adeligen unter Leitung von Henri I. de Lorraine, 3. Duc de Guise geführt wurde. Er hatte während der Hugenottenkriege gegen die französischen Calvinisten (Hugenotten) Partei ergriffen. Vgl. Stichwort „Heilige Liga“, in: https://hls-dhs-dss.ch/de/articles/017171/2011-03-09/ (31. Dezember 2020): „Der Begriff H. bezeichnet eine unter der Führung des Papstes Julius II. geschlossene Allianz zwischen Venedig, Spanien und England. Sie war gegen Frankreich gerichtet und bestand 1511-13.“ 
Nach der Übergabe seines Beurlaubungsschreibens blieb dieser Prälat jedoch noch fast ein Jahr in Luzern und in Uri, inzwischen war er zum Kardinal ernannt worden und verließ die Schweiz Ende Juni 1591, nachdem er eine zweite schriftliche Beurlaubung der Luzerner Regierung erhalten hatte. Es dauerte fünf Jahre, bis er in der Schweiz ersetzt wurde, denn sein Nachfolger Giovanni Conte della Torre, Bischof von Veglia, wurde erst am 13. November 1595von Papst Clemens VIII. ernannt, und kam erst Ende Oktober 1596 an seinen Wohnort.

\subsection{Instruktion für Fabio Verallo $(1606-1608)^{12}$}

Rom, 1606, [keine weitere Zeitangabe]

\section{Instruktion für Monsignore Fabio Verallo, Bischof von San Severo, bestimmt als Nuntius bei den katholischen Schweizer Herren in Luzern.}

$\mathrm{Zu}$ dem so wichtigen Dienst, den die Nuntiatur im Lande der Schweizer in der heutigen Zeit einnimmt und für den Euer Hochwohlgeboren ${ }^{13}$ von Seiner Heiligkeit bestimmt wurde, gehört für Sie die Zusicherung, dass Sie geliebt und hochgeschätzt werden und dass Ihr Werk einen guten Zweck verspricht, wenn Sie all Ihre Bemühungen dafür aufwenden, wie es sich für die Diener dieses Heiligen Stuhles gehört, die öffentliche Ruhe zu bewahren und die katholische Religion zu fördern. Euer Hochwohlgeboren wird mit Vorsicht in den für Sie bestimmten Angelegenheiten vorgehen, doch wenn Sie sich in Ihren Handlungen insbesondere von Gott leiten und von Ihm helfen lassen, werden Sie die Schwierigkeiten einfacher überwinden und Ihr Können mit größerem Gewinn für das Allgemeinwohl und den Ruhm Seiner Göttlichen Majestät erweisen.

In Luzern werden Sie Ihre Residenz haben, einer Stadt voll großer Frömmigkeit gegenüber dem Apostolischen Sitz und dem Göttlichen Kult ${ }^{14}$ sehr zugetan.

12 Fondo Borghese, I, 899, 61r-68r.

13 Zur Form der Anrede, vgl. Gerd Fritz, Manfred Muckenhaupt: Kommunikation und Grammatik, S. 191: „Nach der unglaublich raschen Verbreitung der nominalen Konstruktion Ende des 16. Jahrhunderts wurden die Pronomina der dritten Person sehr bald unabhängige Anredeformen. Die Pronomina der dritten Person Plural etablierten sich jedoch am Ende des 17. Jahrhunderts erst nach einer langen Zeit, in der sie nur kombiniert mit den abstrakten Titeln verwendet wurden, die zu dieser Zeit schon eine vierhundertjährige Geschichte hinter sich hatten. Erst im 16. Jahrhundert verdrängten die Pronominalformen der dritten Person die ursprüngliche Ihr-Formen zur Fortführung der mit abstrakten Titel gemachten Anrede; desgleichen setzten sich auch erst in diesem Jahrhundert die Pluralformen der dritten Person endgültig gegenüber den Singularformen als Formen der Fortführung von Abstrakta durch.“

14 Damit sind die Gottesdienste gemeint. 
Deshalb wird man Ihnen als Diener des Herrn sehr viele Zugeständnisse machen, da es viel Gutes in dieser Stadt gibt, das betrifft dort alle und das sagt man auch zu ihrer eigenen Zufriedenheit.

Die schlechten Seiten in jenen Gebieten gibt es in großer Zahl und auf verschiedene Weise, aber was jene betrifft, die die Gesundheit der Seele berühren, müssen Sie all Ihren Geist aufwenden, da es sehr viele Häretiker gibt, und alle sind sehr begierig darauf, von den benachbarten Bernern beschützt zu werden.

In der genannten Provinz befinden sich ordnungsgemäß die Kapuzinerpater und der Bischof von Veglia musste zusätzlich auch einige Jesuiten hinschicken, um auf diese Weise viele Seelen zurückzugewinnen, die sonst zugrunde gegangen wären, und ihnen das Licht des wahren Glaubens aufzuzeigen. Die Häretiker, die vor allem in der Stadt von Sitten und in Leue wohnen, dürfen sich nicht in dieser Provinz aufhalten, wie es eine Regelung aus dem Ort Visp vom 17. März 1604 bestimmt, doch sie wurden nicht gezwungen, ihre Wohnungen rasch zu verlassen, was nötig war, um mögliche Gelegenheiten zu Aufständen zu vermeiden.

Nun müssen sie aber den Ort verlassen, wie es die katholischen Kantone die Berner wissen ließen, dass, wenn diese den Bischof davon abhalten sollten, dass sie nicht weggeschickt werden sollten, sie ihm mit den Waffen helfen werden. Nun hoffen wir, dass man von den Häretikern befreit wird, und da müssen Sie jegliche Möglichkeiten prüfen, damit diese Herren sich auf die Seite des Bischofs stellen, um ihre Untergebenen unter Kontrolle zu halten, da sie sonst die Gelegenheit nutzen könnten, um ihren Machenschaften nachzugehen.

Die Angelegenheit zu Biel erfordert weiterhin große Aufmerksamkeit, da es sich um ein Nest jeglicher Häresie handelt, fast wie Genf. Dieses Land gehörte einst dem Bischof von Basel, doch weil diese Stadt einen Aufstand ausübte und als häretisch bezeichnet wurde, konnte sie nicht mehr unter der Kontrolle des Bischofs gehalten werden, weil sie auf die Hilfe der Berner zählen konnte und auch auf die der anderen häretischen Kantone, auch wenn der Bischof auf die Hilfe der katholischen Kantone hätte zählen können. Schlussendlich wurde ein Abkommen zwischen dem Bischof und den Bernern abgeschlossen mit der Zustimmung von Papst Clemens VIII., in dem sich alle darauf einigen, dass der Bischof den Bernern das Land von Biel überlassen sollte und stattdessen andere Gebiete erhalte, doch während man dieses Abkommen abschloss und daran war, die Vergütung zu geben, merkten die Bieler, dass sie weiterhin Untertanen blieben und Sklaven der Berner sein würden und so verhinderten sie das Wechselgeschäft und wollen nun wieder unter die Autorität des Bischofs gestellt werden. Diese Geschäftsordnung ist bereits reif dafür und bald soll es eine Lösung dazu geben, da sich bereits sechs Kommissare bei der letzten Tagsatzung dazu geäußert haben, um die Differenzen anzusprechen, und auch festgehalten wur- 
de, dass, wenn die Abmachung nicht mit ihren Mitteln erfolge, so soll sie bei der Tagsatzung ein Ende finden. Darüber können Sie mehr vom Bischof von Basel erfahren, mit dem Sie gute Korrespondenz führen sollten, um seine Angelegenheit zu unterstützen, um viele Seelen zurückzugewinnen, die auf missliche Weise verlorengehen, solange sie unter den Häretikern leben.

Der Besuch der Kapitel und der Kirchen wird einzigartige Gewinne für die Katholiken bringen, weil sie damit das Beispiel des guten Lebens vom Klerus übernehmen können, während die Geistlichen das tun, was ihnen dienlich ist, indem sie Großes leisten, in Ländern, wo so viele Freiheiten herrschen und es einfach ist, zuwiderzuhandeln. Bei Gelegenheit müssen Sie einige der wichtigsten Orte besuchen und jegliche Aufmerksamkeit bekunden, um jedem die väterliche Fürsorge Unseres Herrn mit dem Mittel Ihrer Sorge zu zeigen.

Unter Ihrem Dienstbereich gibt es viele monastische Ordensvertreter, Karmeliter, Benediktiner, Kartäuser. Über den Stand der Dinge all dieser Gemeinschaften müssen Sie sich minutiös informieren, da sie sich auf freien Gebieten befinden, können sie, wenn man sie nicht pflegt, einfach die Beachtung der Ordensregeln vergessen, und so können Skandale entstehen sowie unwiderruflicher Schaden zugefügt werden, wie das jüngste Beispiel des Kartäusers zeigt, der ein Apostat wurde.

Wandermönche dürfen Sie in jenen Gebieten ohne Bewilligung ihrer Oberen ohne weiteres nicht gestatten; rufen Sie sie auf, in ihre Klöster zurückzukehren, und falls sie nicht gehorchen, machen Sie von Ihrer Autorität Gebrauch und ermöglichen Sie, wenn Sie es für richtig halten, dass man dort Ordensvertreter hinschickt, die dazu in der Lage sind.

Es gibt von Seiten vieler häretischer Prediger in jenen Ländern große Vorhaben, sich zum Katholizismus hinzuwenden, und der Gewinn wäre sehr nützlich für die Öffentlichkeit, und deshalb müssen Sie mit den katholischen Kantonen zusammenarbeiten und mit den Geistlichen, damit diese sie aufnehmen und sie alles unternehmen, damit jene einfacher bekehrt werden können.

Sie werden mit allen möglichen Überlegungen die Gründung von Priesterseminaren ins Auge fassen, indem sie die Bischöfe und Ordenskapitel auffordern, die Befehle des Heiligen Konzils von Trient umzusetzen. Dies ist im Übrigen zu ihrem eigenen Vorteil. Vor allem hegt der Bischof von Sitten den großen Wunsch hegt, ein Seminar in seinem Bistum zu errichten, deshalb werden Sie sich mit dem Bischof und dem Klerus austauschen und sie davon überzeugen, so viel wie möglich zu tun, um dieses so heilige Werk zu vollbringen, was dem Allgemeinwohl sehr nützlich ist. 
In Locarno hatten sich bereits zu Zeiten von Papst Clemens die Patres von Somasca ${ }^{15}$ niedergelassen, damit sie neue Schulen gründen, und ihnen wurden für ihren Aufenthalt zwei Pfarreieinrichtungen (Prepositure) zur Verfügung gestellt, eine davon ist bereits wieder frei geworden. Es geht nun darum, dass die genannten Patres ihren Dienst aufnehmen können, doch weil nicht wenige hingehen wollen und die Einrichtung der leerstehenden Pfarrkirche nicht genügend Platz bietet für viele, denkt man darüber nach, irgendwie von den Herren in Locarno Hilfe $\mathrm{zu}$ erbitten, damit auch nicht die andere Pfarreieinrichtung leer wird.

Die Geschäftsordnung ist auf gutem Wege und die Patres zeigen den Wunsch auf, dort hinzugehen, und deshalb sollten Sie es nicht unterlassen, die Herren aufzufordern, einige Patres hinzuschicken, damit sie die Jugend erziehen können.

In den kirchlichen Angelegenheiten muss Euer Hochwohlgeboren all Ihre Gedanken dafür aufwenden, um sich mit den vielen weltlichen Dingen zu befassen, ohne die man nicht den öffentlichen Frieden bewahren kann, Mittel, die auch zur Verbreitung des göttlichen Kultes beitragen, wie ich Ihnen unbedingt auch sagen muss.

Da die Schweizer Herren, sowohl die Katholiken als auch die Häretiker, verschiedene Bündnisse mit verschiedenen Fürsten unterhalten und insbesondere mit Frankreich und Spanien, so entstehen auch viele Gelegenheiten für wenig Erfreuliches mit den Gesandten jener Majestäten, die die Interessen jener Fürsten vertreten, und es trennt sie auch die Haltungen der jeweiligen Schweizer Herren, die jeweils von der einen oder anderen Seite abhängig sind. In diesen und ähnlichen Gelegenheiten muss Euer Hochwohlgeboren allen Seiten mit wahrhaftiger Neutralität das Vorhaben Unseres Herrn aufzeigen, das darin besteht, die öffentliche Ruhe in ihrem eigenen Interesse $\mathrm{zu}$ bewahren und zum Wohle der Christenheit vorzugehen, und wenn es für die Sache des Herrn von Vorteil ist, dann überprüfen Sie selber, ob es nützlich ist, in Ihrem Sinne vorzugehen.

Die Herren in Graubünden haben für großes Aufsehen gesorgt, nachdem der Fürst von Fuentes eine Festung zur Grenze zum Veltlin aufbaute, die aus ihrer Sicht zur Wahrung ihrer Freiheit eingerichtet wurde. Und sie versuchten mit allen Mitteln anzugreifen, auch wenn die Kantone sie dazu ermunterten, sich zu beruhigen und sich damit abzufinden, denn ihnen wurde versichert, dass von der Festung kein Schaden ausgehen würde. Diese Geschäftsordnung könnte aber große Konsequenzen mit sich bringen, da sich verborgene Interes-

15 Vgl. P. Andrea Stella: La vita del venerabile servo d'Iddio il padre Girolamo Miani, nobile venetiano. 
sen herausstellen von jenen, die den Frieden nicht lieben. Deshalb muss Euer Hochwohlgeboren dieser Angelegenheit besondere Beachtung schenken. Deshalb müssen Sie sich mit den Herren in Luzern absprechen, damit Sie mit jener Autorität den anderen Eidgenossen aufzeigen können, welchen Nutzen dies der gesamten Nation sowie der Erhaltung einer guten Beziehung mit dem Staat von Mailand bringen kann.

Die Städte Freiburg und Bern teilen sich vier Untertanengebiete, die sie gemeinsam führen. Die Gefahr besteht darin, dass sich die dortigen Katholiken durch den Handel mit den Häretikern mit der Häresie infizieren könnten. Deshalb braucht Euer Hochwohlgeboren alle Informationen über dieses Geschäft vom Bischof von Veglia. Da müssen Sie Ihren Beitrag dazu leisten, wenn die Herren von Freiburg Sie darum bitten. Sie erhalten zu Ihren Händen ein entsprechendes Breve über diese Anordnung, die in Kopien anderen Schriften beigefügt und die man Ihnen zur Kenntnisnahme über weitere Einzelheiten geben wird.

Bereits vor vielen Jahren wurden von Ulrich ${ }^{16}$, Bischof von Konstanz, Kredite in Höhe von 500 Fiorini von Heitersheim ${ }^{17}$ und Kilchzarten ${ }^{18}$, zwei Kirchgemeinden seines Bistums, sowie von der Leitung des Klosters der Malteserritter in Freiburg aufgenommen, mit der entsprechenden Bedingung, dass die Rückgabe der genannten Summe entweder der Bischof persönlich oder das Bistumskapitel zurückzahlen würde, und die Ritter seien die Garanten der Rückzahlung, damit die Gewinne dem Bischof und seinen Nachfolgern zugutekommen. Da der jetzige Bischof und das Kapitel gemeinsam vor Jahren eine Rückzahlung getätigt haben und da dies nicht angenommen wurde, hat der Klostervorsteher beim Bischof von Veglia als Nuntius am vergangenen 8. April angefragt, über einige Möglichkeiten nachzudenken, auch wenn er bereits vor Ende des Streites etwas erhalten hat und dennoch verlangte, weitere Vorteile zu erhalten. Dasselbe werden sie deshalb auch Eurer Hochwohlgeboren anfragen, dass, wenn man das Geschäft nicht zu Ende bringt, Sie es versuchen sollen, ohne großes Aufsehen zu erregen, und falls Sie Schwierigkeiten haben, teilen Sie dies mit.

Der Großprior des Christusordens ${ }^{19}$ von Deutschland hat bereits vor einigen Monaten Unseren Herrn gebeten, dass er ihm durch die Vermittlung des Bi-

16 Vgl. Stichwort „Ulrich Pfefferhard“, in: https://hls-dhs-dss.ch/de/articles/012879/2010-0201/ (31. Dezember 2020).

17 Eine Ortschaft im heutigen Baden-Württemberg; sie war im Rahmen der Ausweitung des Malteserordens im 16. Jahrhundert zum eigenständigen Fürstentum innerhalb des Heiligen Römischen Reiches avanciert.

18 Ebenfalls in Baden-Württemberg stand der Ort seit 1500 unter der Herrschaft der Stadt Freiburg im Breisgau.

19 Es handelt sich um den portugiesischen Christusorden „Hierosolymitana“, einer Bruderschaft, die sich für den Erhalt der christlichen Weltanschauung einsetzt. 
schofs von Veglia hilft. Es geht um den Fall zwischen dieser Gemeinschaft und dem Ritter Rolio ${ }^{20}$, wie Sie aus der Kopie des Memorials ersehen können, die man Ihnen geben wird, doch da dieses Geschäft den Schweizer Herren missfallen könnte, ist es gut, wenn der Großprior zuerst mit der Behörde spricht, die ihm zugeordnet ist, und erst dann eine Lösung gefunden werden soll, wenn man Schwierigkeiten vorfinden wird. Der Bischof von Veglia schlug mit gewisser Bestimmtheit vor, dass der genannte Rolio auf Deutsch über diesen Fall schreiben soll, und aus Sicht der Gerechtigkeit und nicht wegen der Güte, wie es hingegen der Großprior gerne hätte. Deshalb können Sie sich gut darüber informieren, wenn Sie beim selben Bischof vorbeikommen und sich mit ihm darüber austauschen, da es keinen Grund für neue Streitigkeiten gibt. Lassen Sie all das zu, was sich für die Lösung des Falls lohnt.

Dem Helvetischen Kollegium in Mailand wurde von Kardinal Hohenems ${ }^{21}$, Bischof von Konstanz, eine Präpositur verbunden. Derselbe bestand darauf, dass zwei seiner nachfolgenden Bischöfe 14 Plätze in dem genannten Kollegium bestimmen dürfen, doch die Herren Schweizer verlangen nun, nachdem die beiden genannten Bischöfe mittlerweile gestorben sind, dass diese Begünstigung der 14 Plätze ihrer Nation zukomme. Mit dem Herren Kardinal Borromäus haben wir lange darüber gesprochen und es wurde festgehalten, dass Eure Hochgeschätzte Würdigkeit mit Freude den genannten Herren mitteilen kann, dass dies in Ordnung sei, falls sie es bei Ihnen anfragen. Euer Hochwohlgeboren beachte die Bulle von Papst Gregor XIII. zur Gründung des Kollegiums und die andere über das Bündnis, damit Sie verstehen, dass ihre Forderungen grundlos sind.

Über das, was ich Euer Hochwohlgeboren gesagt habe, werden Sie vom Bischof von Veglia all das erhalten, was Sie benötigen, und er wird Ihnen auch die Instruktion geben, die er zu Beginn seiner Nuntiatur erhielt. Darin werden Sie die weiteren Dinge erfahren, die Sie benötigen, und auch einige nützliche Hinweise über Ihren Dienst.

Man wird Ihnen sechs Breven geben, eines über die katholischen Kantone in Bezug auf Ihre Mission und die anderen über die fünf Bistümer, die sich in Ihrer Nuntiatur befinden, also Konstanz, Chur, Basel, Lausanne und Sitten.

Den Herren der katholischen Kantone werden sie beim Überreichen der Breven auch ein lebendiges Zeugnis der väterlichen Liebe des Heiligen Segens gegenüber diesen Herren geben und der Achtung, die man vor ihrer Würde und ihrer Frömmigkeit als gehorsame Söhne dieses Heiligen Stuhls hat.

20 Hier ist nicht klar, wen der Autor genau meint.

21 Vgl. Stichwort „Mark Sittich von Hohenems“, in: https://hls-dhs-dss.ch/de/articles/ 026330/2006-11-21/ (31. Dezember 2020). 
Dem Bischof von Basel werden Sie die Breven schicken, und weil er alt ist, werden Sie Informationen aufsuchen, um zu erfahren, wie man vorgehen soll, damit die Häretiker nach seinem Tod nicht weiter in jener Diözese vordringen und über die Katholiken herfallen.

Sie werden die Breven an den Bischof von Sitten schicken und ihn oft besuchen, damit Sie erfahren können, was in jener Provinz vor sich geht, und Sie werden ihn daran erinnern, auf seelsorgerliche Weise die katholische Religion $\mathrm{zu}$ fördern, wie er dazu bestimmt wurde und es sein inständiger Wunsch sein soll. Dies soll mit der Einbringung seiner eigenen Sachen geschehen.

Den Bischöfen von Konstanz und Lausanne gegenüber können Sie die Gelegenheit des Versands der Breven dazu nutzen, um eine gute Beziehung zum einen wie zum anderen aufzubauen.

In der Erläuterung, die Ihnen der Bischof von Veglia zukommen lässt, werden Sie die einzelnen Punkte der Verlautbarungen der Tagsatzung vorfinden und die vielen Einzelheiten, die man auf andere Weise sonst nicht erfahren könnte. Beachten Sie diese bitte auf besondere Weise, und über all jene Dinge, die Sie erfahren, machen Sie sich für die Zukunft Notizen und seien Sie erfreut darüber, dass Sie der Öffentlichkeit dienen können.

Die Briefe, sowohl die Ihrigen als auch die unsrigen, werden in Mailand durch die Hände von Fornero, genannt Todeschino, weitergereicht, und da werden Ihnen die Anordnungen bekannt gegeben und Sie müssen ihm einfach nur Bescheid geben, wenn Sie etwas mitteilen wollen.

Ihnen werden jeweils zwei chiffrierte Schriften geschickt, eine wie für alle anderen Nuntien des Apostolischen Sitzes und die andere, um die geheimen (privaten) Dinge $\mathrm{zu}$ schreiben, die Sie für wichtig erachten, indem Sie regen Austausch mit den Nuntien pflegen, mit dem Ziel, auf die beste Weise diesem Heiligen Stuhl zu dienen.

Über die öffentlichen Dinge, sei es kirchlicher, sei es weltlicher Art, habe ich meines Erachtens Euer Hochwohlgeboren das Wichtigste mitgeteilt.

Mir scheint nun, Ihnen einige wenige Dinge noch mitteilen zu müssen, die mit Ihrem Gefolge zu tun haben, auch wenn ich denke, dass dies der Qualität entspricht, die einer Person zukommt, damit sie auch anderen als Beispiel dienen kann. Ich will Sie daran erinnern, dass Sie Menschen mitbringen sollten, die wohlerzogen sind, fromm und ruhig, und dass die zwei wichtigsten Mitarbeiter, der Auditor und der Sekretär, intelligent sein müssen, und Sie müssen sie darauf aufmerksam machen, dass sie bei ihrer Tätigkeit gewissenhaft handeln, und sie an die Würde dieses Heiligen Stuhls erinnern, der nicht undankbar ist gegenüber jenen, die ihm gut dienen.

Im Namen des Herrn möge Euer Hochwohlgeboren eine gute Reise unternehmen. Mögen Sie achtgeben auf Ihre Gesundheit, schreiben Sie oft und über 
all das, was in jenem Gebiet geschieht, und in all Ihren Bemühungen mögen Sie sich immer daran erinnern, dass Sie ein Diener des Apostolischen Stuhls sind und nicht von anderen Herren.

Aus Rom, am [ohne konkretes Datum] 1606.

Kardinal Borghese ${ }^{22}$

In der Transkription im Dokument, das im vatikanischen Geheimarchiv aufbewahrt ist, steht am Schluss: „Ort und Siegel“, ohne konkretes Datum.

\subsection{Instruktion für Ladislao d'Aquino (1608-1613)}

Rom, 24. Juni 1608 - registriert

\section{Instruktion für den Bischof von Venafro, Nuntius, bestimmt für die Herren Schweizer.}

Euer Hochwohlgeboren ist zum Dienst berufen, der vor allem mit Sorgfalt auszuführen ist und Ihrer Frömmigkeit bedarf, mehr als in jeder anderen Provinz, damit jene den Gehorsam gegenüber dem Heiligen Stuhl bewahren, was Seine Heiligkeit von Ihnen erwartet und die Gelegenheit bietet, Ihre Talente und die Verdienste Ihrer Dienste zu würdigen.

Der öffentlichen Ruhe wegen, ohne welche die Katholische Religion weder bewahrt werden noch wachsen kann, muss Euer Hochwohlgeboren all Ihre Gedanken der Reform des Klerus und der Kirchlichen Jurisdiktion widmen: Das sind die Hauptziele Ihrer Mission in jenen Gebieten.

Vereint sind die katholischen und die häretischen Kantone, was die weltlichen Dinge betrifft, doch nicht vereint sind sie, was die spirituellen Dinge betrifft, was sie aber durch Interessen untereinander statt durch Liebe überbrücken.

Sieben sind die Katholischen Kantone: Luzern, Altdorf, Schwyz, Unterwalden, Zug, Solothurn, Freiburg. Zwei sind gemischt: Glarus und Appenzell. Die häretischen Kantone sind vier: Zürich, Bern, Basel und Schaffhausen. Jeder Kanton hat eine eigene Regierung, einige haben eine Aristokratie wie Luzern,

22 Kardinal Scipione Caffarelli Borghese (1577-1633) war als Kardinalnepote von Paul V. von 1605 bis 1621 faktisch der Leiter der römischen Kurie. Seine Funktion bestand darin, als Kardinalstaatssekretär die Regierung des Heiligen Stuhls zu führen. Vgl. Volker Reinhardt: Kardinal Scipione Borghese (1605-1633).

23 Fondo Borghese, I, 899, 191r-202v. Eine zweite Kopie befindet sich in: Nunziature diverse, 240, 21r-32r. 
Zürich, Bern, Solothurn, Freiburg, Basel und Schaffhausen. Die anderen Kantone sind demokratisch und behandeln die wichtigsten Angelegenheiten in Generalversammlungen, bei der jeder teilnimmt, der älter als 14 Jahre ist, und es werden Geschäftsordnungen angenommen, denen die Mehrheit zustimmt.

Die Häretiker besitzen mehr Land und mehr Untertanen und auch mehr Einnahmen, doch mächtiger und schöner sind die Katholischen Kantone.

In der helvetischen Eidgenossenschaft, allgemein auch „Eignosen“ genannt, befinden sich auch die Abtei von Sankt Gallen, Graubünden, die aus drei Bünden besteht, sowie das Bistum von Sitten, die Ortschaft von Biel, Mülhausen und Rottweil. Den Kantonen sind auf dieser Seite der Berge in Italien viele Gebiete untertan: Mendrisio, Lugano, Locarno und Valmaggia. Die Untertanengebiete sind viele und die Länder von Altdorf, Schwyz und Unterwalden herrschen in Bellinzona, wo sie drei Festungen besitzen. In über zehn Ländereien haben sie die Jurisdiktion und dazu gehören Flüsse und die Täler von Blenio. Der Rest ihres Machtgebiets ist neben dem Gotthardgebirge das Wallis, Jura und der Rhein.

Auf einem so großen Feld finden Sie viel Weizen aber auch viele Streitigkeiten. Beseitigen Sie dies mit geeigneten Mitteln der Jesuiten, der Kapuziner, fördern Sie dies mit guten Werken, die sehr viel bewirken und viel Früchte tragen werden, wie es von Ihren heiligen Bemühungen zu erwarten ist. Verhelfen Sie der öffentlichen Eintracht mit Ihren frommen Gedanken. Diesbezüglich legen Sie Ihr Augenmerk darauf und beachten Sie, dass es einen freien Handel gibt, der es einfacher macht, bei der Beauftragung von frommen Menschen mit heiligen Einstellungen den Weg unter dem Schutz des Apostolischen Sitzes zu zeigen und die Güte Unseres Herrn finden zu lassen.

Die Reform des Klerus ist sehr notwendig und besteht darin, aufzufordern und nicht zu unterbinden. Die Freiheit des Landes lässt zwar keine Zwänge zu. Die Missbräuche verblenden jedoch viele, die denken, es sei richtig, wie sie handeln, was aber nicht gestattet ist. Und die Änderung der Bräuche und der eigenen Möglichkeiten ist eine schwierige Sache. Mit sanfter Hand kann man diese Unordnung beseitigen. Möge Euer Hochwohlgeboren mit so vielen Prälaten wie möglich in Ihrem Auftragsgebiet Vertrauen aufbauen, die da wären: der Bischof von Chur, jener von Sitten und der neuernannte von Basel, jenem von Lausanne, wenn dieser bekanntgegeben wird, und die Äbte in jener Provinz.

Der Bischof von Konstanz versteht sich nicht gut mit seinem Kaplan, und die Kanzler behaupten, dass der Bischof sie zu viel beanspruche, auch wenn sie diese Anschuldigungen nicht beweisen. Diese Uneinigkeit zwischen dem Bischof und den Kanzlern verursacht viele Übel, da der Herrschende nicht richtig herrschen kann, weil die Glieder nicht gehorchen, und hinzu kommt noch, dass 
dies für übles Gerede sorgt, und im Laufe der Zeit verschlimmert sich die Lage zusehends.

Euer Hochwohlgeboren soll deshalb versuchen, die Kanzler auf ihr Fehlverhalten hinzuweisen. Sie müssen als öffentlicher Diener zwar nicht auf Sie hören, aber Sie müssen dafür Sorge tragen, dass die Würde geachtet wird und die Integrität des Bischofs vor allem, und deshalb müssen Sie sie auf jeden Fall zur entsprechenden Ehrfurcht gegenüber dem Bischof bringen, damit dies der Kirche Gutes einbringt und ihre Gewissen sich beruhigen.

Gegen den Bischof hat in den vergangenen Monaten der Baron von Walburg großen Schaden angerichtet. Dieser fordert die Reform des Klosters des Dritten Ordens des heiligen Dominikus in dem Gebiet von Ennetach, ${ }^{24}$ seinem Gebiet, und zeigt ein Breve von Papst Clemens selber, in der die Einsetzung des ehemaligen Kardinals von Österreich und Bischofs von Konstanz beschrieben wird. Der Bischof antwortet, dass das Breve nicht mehr gültig ist, und der Baron entgegnet, wie es Euer Hochwohlgeboren in der beigefügten Schrift nachlesen kann. Diese Geschäftsordnung liegt nun in der Hand des Bischofs von San Severo. Von ihm wird Euer Hochwohlgeboren all das erfahren, wie die Lage aussieht, und nach seinem Bemessen kann man dem Baron, dem man viel Achtung schenken soll, ohne den Bischof zu benachteiligen, entgegenkommen.

Der Bischof reagiert, wenn sich der Nuntius in seinen ordentlichen Amtsbereich einmischt, denn er ist für ein großes Gebiet zuständig, und insbesondere Luzern und dieselben Luzerner Herren haben schon etliche Male darauf hingewiesen, dass es ihnen nicht passt, dass die Nuntien sich in Angelegenheiten des Bischofs für diese Sache einmischen, und so wurden die Handlungsmöglichkeiten desselben Nuntius eingeschränkt und deshalb soll Ihnen auch gesagt sein, dass Sie sich davor hüten sollen, sich vom Bischof beim ersten Treffen schon befremden $\mathrm{zu}$ lassen und die Herren von Luzern $\mathrm{zu}$ beleidigen, wo Ihre Residenz sein wird, wie Ihnen der Bischof von San Severo noch genauer mitteilen wird.

Denselben Bischof soll man darauf hinweisen, dass die Menschen in Bürglen im Kanton Uri die Reform des römischen Messbuches nicht umsetzen wollen und stattdessen weiterhin einige ihrer alten Riten, die ein schlechtes Beispiel sind, weiterführen. Es wird von ihnen verlangt, dass sie die Reform akzeptieren, und wenn Ihnen das gelingt, wird Ihnen das viele Verdienste einbringen.

Vom Bischof von Chur, einem Prälaten von makellosem Leben und großer Frömmigkeit, kann Euer Hochwohlgeboren derzeit nichts anderes als Tränen und Schluchzen erwarten. Die Unbarmherzigkeit der Häretiker in Graubünden hält ihn von seiner Kirche fern. Sie haben ihm das Vaterland und die Einnah-

24 Vgl. Joseph Späth: Das Dominikanerinnen-Kloster von Ennetach. 
men geraubt, aber nicht den Kampfesgeist und die Güte. Er wurde von denselben Leuten vorgeladen, aber weil die Schweizer Katholiken in letzter Zeit ihre Botschafter in seinem Namen hinschickten und sich der französische Botschafter für ihn einsetzte, so hofft man, dass sie nicht gegen ihn vorgehen werden, wie sie gedroht hatten. Für den genannten Bischof sollen Sie sich mit den Katholischen Kantonen zusammenschließen, aber nicht schriftlich soll dies geschehen, und geben Sie immer an, dass Ihnen der französische Bischof nicht missfällt, weil dieser denkt, dass der Bischof von den Spaniern abhängig ist, hat er ihn bisher nicht unterstützt, und der Sekretär der Republik von Venedig hat versucht, ihn offenkundig zu beseitigen, falls der genannte Bischof versuchen würde, zu seiner Kirche zurückzukehren. Euer Hochwohlgeboren soll gute Korrespondenz führen, und in der Zwischenzeit trösten Sie ihn und versichern Sie ihm, dass Unser Herr alles Mögliche für ihn unternommen habe und dass es für die Zukunft nicht fehlen werde, die Angelegenheit der Rückgabe mit der Hilfe des Nuntius in Frankreich anzugehen, der diese Geschäftsordnung mit jener Einstellung behandelt, die sich geziemt, und wie man sieht, mit Erfolg.

Alle Einstellungen des genannten Bischofs sind wahrlich fromm. Sie werden aus der Kopie des beigefügten Memoriale ersehen, dass er die Idee hat, in einem bestimmten katholischen Tal ein Gericht des Heiligen Offiziums zu errichten. Sie müssen alles dafür tun, um dies umzusetzen, sobald die Konflikte zu Ende gehen, und danach soll man genauere Anordnungen geben, was Sie dafür tun sollten. Der Bischof bekundet den Wunsch, dass es im Wallis nur ein Heer von Katholiken geben soll, und falls er die absolute Herrschaft innehätte, wie zuvor, dann würde er dies auch umsetzen. Zum jetzigen Zeitpunkt kann er nicht alles haben, was er will, da seine Machtstellung von der politischen Regierung des Ministers der Stadt abhängig ist, auch wenn er zu anderen Zeiten schon durch den Eingriff der katholischen Walliser in der öffentlichen Tagsatzung Beschlüsse fassen durfte, unter Androhung harter Strafen, falls die Häretiker aus jenem Staat austreten sollten, doch - sei es wegen Interessen, sei es wegen der Schwäche des Bischofs - wurde nichts daraus. Nun soll mit der Mission der Jesuiten und der Kapuziner versucht werden, die Häresien in jener Provinz auszurotten, mit einer sanfteren Art, und das wird Früchte bringen, doch die Hürden sind hoch und das Böse hat schon Fuß gefasst, auch wenn man in kleinen Schritten vorwärtskommt, wenn auch mit Mühe. Mit dem genannten Bischof muss man ständigen Austausch pflegen, um ihn daran zu erinnern, welche Gegenmittel nötig sind, ihn dazu auffordern, den Heiligen Glauben zu verbreiten, und ihm verständlich machen, dass je größer die Heilige Religion in seiner Provinz wird, er desto mehr Macht haben und sein Verdienst ewig beachtet werden wird. 
Der besagte Bischof hat diesbezüglich in einer allgemeinen Tagsatzung einbringen können, dass fünf Teile des Landes den Gregorianischen Kalender annehmen, auch wenn sich jene in Sitten und Leutsch dagegen aussprachen. Solche Beweise der Anhänglichkeit, die jenes Volk gegenüber dem Heiligen Stuhl bewahrt, offenbart ihre Zuwendung, und das lässt für die Zukunft hoffen, da der Bischof bei seinem letzten Besuch über zweitausend Menschen die Firmung spendete.

Aus alter Gewohnheit besucht derselbe Bischof alle Ortschaften seiner Diözese, doch nun versucht er, dies in Absprache mit der Behörde dieses Heiligen Stuhls zu tun. Falls dies der Bischof von San Severo schreiben würde, dann entnehmen Sie die Informationen der Geschäftsordnung und der Verkündigungen daraus, damit sie ihm einen Gefallen tun können, ohne die Nachfolger zu schädigen. Aus den Schriften, die Sie erhalten werden, werden Sie alles erschließen können, was bisher getan wurde, und vom Monsignore von San Severo werden Sie den letzten Stand der Dinge erfahren.

Vom neuernannten Bischof von Basel kann ich nichts sagen, da ich nicht einmal die Bestätigung Unseres Herrn erhalten habe, doch wie es aussieht, soll er ein Geistlicher mit gutem Talent sein, und Sie sollen in die Fußstapfen Ihres Vorgängers treten, der den Heiligen Glauben in jenen Gebieten ausbreiten konnte, indem er die Stadt von Biel wiedereinnehmen konnte, zusammen mit vielen Orten in jener Jurisdiktion, die zuvor von Häretikern bewohnt war. Dieser hat deshalb als neuer Regierender der Kirche liebevolle Erinnerungen daran nötig. Euer Hochwohlgeboren soll ihn oft besuchen und ihm schreiben, und fördern Sie seine Meinung, dass seine Frömmigkeit durch gütige Werke und Vorsicht gestärkt werden kann.

Vom künftigen Bischof von Lausanne soll Euer Hochwohlgeboren, sobald er bekannt ist, das tun, was nötig ist im Bereich des Staates in jenem Bistum, und ihn daran erinnern, was er für die Heilige Religion unternehmen kann, da seine Residenz, wie in den vergangenen Monaten erwünscht, nach Freiburg versetzt wird. Was bisher nicht geschehen konnte, weil der Bischof in der Zwischenzeit gestorben ist.

Über einen großen juristischen Machtbereich im weltlichen und geistlichen Bereich verfügt der Abt von Sankt Gallen, der ebenfalls zur Helvetischen Konföderation gehört und hier so große Nähe dem Heiligen Stuhl gegenüber bekundet, dass er jede Dankbarkeit und Schutz verdient.

Euer Hochwohlgeboren wird ihm ein vollständiges Zeugnis des väterlichen Willens Unseres Herrn mitteilen und ihn versichern, dass seine Gnade sehr wohl bekannt ist an diesem Hof und vor allem von Seiner Heiligkeit gelobt wird. Seien jene Prälaten sehr erfreut über diese liebevollen Ausdrücke. Deshalb soll Euer Hochwohlgeboren frei sein, das zu tun, was Ihrer Seele ein Gewinn 
sein wird. Auf diese Weise können Sie aus Ihren Mitteln zum Allgemeinwohl und vor allem zur Reform in dem Staat beitragen.

Der besagte Abt erbat letztens, dass Unser Herr geruhen wolle, ein Abkommen zu bestätigen, das er im Auftrag der Regierenden der Länder von Wangensee traf und das seiner Kirche Nutzen bringen solle. Hier wird diese Geschäftsordnung gezeigt, und man kann schauen, ob man ihm den Gefallen tun kann. Dazu bedarf es Ihrer Gutheißung, die er von Ihnen hören will, insbesondere für diese Angelegenheit, damit Sie das wissen, weil es sich um seine Dinge handelt.

Dem Abt vom Benediktinerkloster Engelberg hatte Unser Herr vor einigen Monaten einige Gnadenerlasse gegeben, damit der Göttliche Dienst in jenem Ort gestärkt werden konnte. Und dieser ist sehr aufmerksam in seinen Amtsfunktionen und gibt den anderen ein gutes Beispiel, was ihm von allen Christen viel Lob einbringt.

Es wird Euer Hochwohlgeboren empfohlen, durch Ihre Frömmigkeit Werke zu vollbringen, damit dem Ruhm Gottes noch mehr entsprochen wird.

Sehr fromm ist der Abt von Einsiedeln, und er besitzt viele Privilegien vom Heiligen Vater. Er schaut nicht nur, dass Unser Herr derzeit diese bestätigt, sondern versucht auch, dass jene einschränkenden Regelungen aufgehoben werden. Ich glaube, dass es ihm in vielerlei Hinsicht schwerfallen wird, aber wenn er bei anderen Gelegenheiten getröstet werden kann, achte ich darauf, seine Sachen zu schützen und seine Frömmigkeit voll zu bezeugen. Dem Abt kann es nur sehr gut gefallen, dass er sich der Wertschätzung seiner Güte und seines Verdienstes sicher ist. Die Mönche jener Gegend brauchen Reformen, und die des Zisterzienserordens haben gezeigt, dass sie darauf bedacht sind, $\mathrm{zu}$ einer Kongregation reduziert zu werden. $\mathrm{Zu}$ diesem Zweck wurde vor kurzem ein Breve an den Nuntius geschickt, und Euer Hochwohlgeboren wird ebenfalls die gleiche Fakultät erhalten, um ihren guten Absichten mit dem Segen des Herrn zu helfen.

In den Klöstern der Nonnen wird es auch gewisse Missbräuche $\mathrm{zu}$ finden geben, und um dem abzuhelfen, werden Sie auf die Arbeit des Provinzials der Kapuziner von Helvetien zählen können, dem befohlen wurde, alles zu tun, was dem Nuntius zur Durchführung der Reform der genannten Nonnen nützlich sein wird.

Das dritte relevante Kapitel unter der kirchlichen Gerichtsbarkeit ist von großer Bedeutung. Diese Herren legen mit Freude Hand an, auch wenn sie sich als Katholiken in Angelegenheiten des Klerus einmischen und als Richter in jenen besonderen Gebieten der Katholischen Kantone betrachten, doch man muss achtgeben und nicht den Anschein erwecken, dass ihre Art zu richten als Beispiel wahrgenommen wird. 
Vor einigen Monaten gab es eine Klage vor dem Bischof von Como gegen den Erzdiakon von Locarno, aber der Kommissar dieses Ortes, der ohne Autorität ist, verurteilte den Erzdiakon dazu, abgesetzt zu werden.

Mit den Herren von Luzern traf der Nuntius eine Abmachung, und so wurde ausdrücklich angeordnet, dass der erwähnte Kommissar den Erzpriester in Locarno bleiben lässt. Herr Sorichel Veso wird Ihnen das Urteil überreichen.

Und dieser Erzdiakon, wie diese Sünder sagen, wurde aus Bequemlichkeit vom säkularen Urteil befreit, um die kirchliche Gerichtsbarkeit zu bewahren, indem ihm in dem entsprechenden Gerichtsbarkeitsbereich eine angemessene Strafe erteilt wird.

Angesichts solcher Unruhen, derer sich Euer Hochwohlgeboren bewusst wird, werden Sie Ihre Beschwerden immer mit einem lebhaften Angebot der Nächstenliebe erheben und diesen Herren den Schaden vor Augen führen, den die Katholische Religion erhalten wird, wenn sie sich zu stark an ihre weltlichen Anführern anbinden, die sich vielleicht aus privaten Interessen das aneignen, was der Autorität anderer geschuldet ist.

Mit Güte und Vorsicht wird Euer Hochwohlgeboren diese Schwierigkeit angehen können und ohne Abneigungen zu verursachen.

Es wird auch manchmal der Eindruck erweckt, dass die Bischöfe dieser Gegend in einigen Fällen bereitwillig die Autorität des Heiligen Stuhls an sich reißen, und dass insbesondere der Bischof von Konstanz die Präpositur von Berona bestätigt hat, eine Amtshandlung, die Unserem Herrn vorbehalten ist.

Der Nuntius wird unverzüglich angewiesen, den Propst durch einen Beichtvater zu ersetzen, da der Propst sich seiner Stellung nicht sicher ist, und deshalb sollte er sich an Seine Heiligkeit wenden, der ihn mit seiner üblichen Freundlichkeit trösten wird. Wenn das Geschäft in einem Zustand sein wird, in dem es einer neuen Ermahnung bedarf, können Sie an die Sorgen erinnern, damit diese Präpositur so schnell wie möglich um Bestätigung bitten kann.

Bestimmte Vermögenswerte des Klosters St. Klara in Freiburg im Breisgau wurden bereits vor vielen Jahren entfremdet, und die Genesung wäre nicht schwer, wenn der Richter dem Wunsch der Nonnen nachkommen würde. Es wurde an den Nuntius am kaiserlichen Hof geschrieben, dass er einen Brief vom Kaiser an den Erzherzog Maximilian zu ihren Gunsten erhalten solle, aber die Unruhen, die in Deutschland folgten, haben es der Heiligen Majestät vielleicht nicht erlaubt zu schreiben. Das bedeutet, dass Sie weitere Erläuterungen über die Lage der Nonnen benötigen, damit die Angelegenheit so schnell wie möglich neu verhandelt werden kann.

Zwischen dem Bischof und dem Senat von Konstanz wurde ein Geschäft mit bestimmten kirchlichen Gütern abgeschlossen, dessen Bestätigung in einem Brief an Monsignore Verallo mit den üblichen Klauseln zugesagt wurde. Es 
scheint nicht, dass er die Wahrheit der Dinge darin findet, die erzählt werden, und äußert einige Zweifel, von denen Ihnen eine Kopie zu Ihrer Kenntnisnahme mitgeteilt wird. Unser Herr hat Monsignore Hortensio, dem Sekretär der Bischofskongregation, befohlen, die Schriften wieder durchzulesen, und über die Resolution wird Euer Hochwohlgeboren zum günstigen Zeitpunkt informiert.

Die Herren von Luzern wünschen sich von den Kanonikern dieser Stadt eine Vereinbarung mit ihren Untertanen, in der sie mit einer gerechten Besoldung auf das Privileg verzichten sollten, die darin besteht, nach dem Tod des herrschenden Ratsherren das Wertvollste mitnehmen zu dürfen. An den Nuntius von San Severo wurde geschrieben, dass er Informationen aufnehmen soll, falls das Abkommen von der Kirche genutzt werden soll, und in Übereinstimmung mit dem, was die Antwort sein wird, wird die Resolution umgesetzt. In der Zwischenzeit können Sie Instanzen von diesen Herren und die Bitten der Kanoniker aus den Kopien entnehmen, die diesem Brief beigefügt sind.

Die Herren von Luzern werden ein sehr frommes Vorhaben hegen, und es besteht darin, fünf Plätze am Kollegium von Mailand für fünf Waliser bereitzustellen, die ausgewählt und vom Bischof von Sitten geschickt wurden, um Bräuche und Überlieferungen kennenzulernen. Darüber wurde mit Kardinal Borromeo gesprochen, aber nachdem der französische Botschafter dieses Geschäft zur Kenntnis genommen hatte, informierte er die Herren von Luzern, dass sein König dankbar sein würde, wenn sie das Unternehmen aufgeben würden, und bot an, dass seine Majestät acht Jugendliche in Frankreich aufnehmen würde und zwar auf seine Kosten, damit auch andere aus ihren Ländern Jugendliche zum Studieren ins Land des Katholischen Königs schicken, dieser Wunsch des Königs von Frankreich verhindert ein heiliges Werk, aber vielleicht wird es dem Herrgott gefallen, das Hindernis zu beseitigen, und die Luzerner Herren werden versuchen, dem König zu zeigen, dass es kein Vorurteil gegen Seine Majestät gibt, den Gedanken auszuführen. Euer Hochwohlgeboren hat Kenntnisse über die Geschäftsordnung und das Interesse des Königs. Es möge so regiert werden, dass die Minister Seiner Majestät nicht spekulieren können, dass Sie sich ihrem Willen widersetzen.

Die oben genannten Prior setzen sich auch für die Errichtung der Schulen ein, die der Prior von Sommasca in Lugano zum Wohle der Jugend dieser Teile eröffnen mussten, und weil die oben genannten Prior versprochen haben, sie zufriedenzustellen, erinnern wir Euer Hochwohlgeboren so schnell wie möglich daran, dass, wenn sie die Ausführung verzögern, dann sollten Sie uns dies melden, damit hier die notwendigen Befehle gegeben werden können.

Die vier gemeinsam geführten Bezirke zwischen dem katholischen Kanton Freiburg und dem häretischen Kanton Bern bedürfen vor allem einer ordentlichen Führung, der hingebungsvollen Zuneigung und dem Eindruck, für sie da 
zu sein. Denn dort gibt es viele Katholiken, aber da sie gemeinsame Untertanen haben, rücken die Berner jeden Tag weiter vor, in der Hoffnung, durch die Vervielfachung der Anzahl der Häretiker in ihnen leicht die absolute Herrschaft ohne Gegnerschaft erlangen können. Es ging um eine Angelegenheit, und jetzt geht es nur noch darum, sie zu trennen, aber für das, was beabsichtigt ist, wird dem französischen Botschafter von seinem König befohlen, dafür zu sorgen, dass, wenn die Spaltung gut verläuft, die Ausübung der Religion frei bleibt. Damit dies nicht so bleibt, ist es notwendig, dass Sie alles bei den Freiburger Herren tun, dass sie Ihnen die Täuschung der Berner aufzeigen und dass Sie sich mit leidenschaftlicher Zuneigung bekleiden, um sie zu überzeugen, was ihrem Mitleid entspricht, und mit solcher Vorsicht, dass Sie den Franzosen keinen Grund geben, sich Ihrem Rat zu widersetzen, sondern dass Sie sich absolut als wahrer Diener dieses Heiligen Stuhls erweisen, um den göttlichen Kult in diesem Land zu erhalten und Seele in jenen Gebieten von der ewigen Verdammnis $\mathrm{zu}$ bewahren.

Viele der wichtigsten Abtrünnigen aus dem Wallis haben bereits mit einem Kapuzinerpater besprochen, dass sie Katholiken werden wollen, wie Sie aus der Liste ersehen werden, die diesem Dokument mitgegeben wird. Der Bischof von San Severo hat die Möglichkeit, sie aufzunehmen und ihnen auch einige Gnaden zu erweisen, um die sie bitten. Wenn diese Geschäftsordnung bei Ihrer Ankunft in Luzern noch nicht abgeschlossen ist, helfen Sie zumindest bei der Bekehrung mit gebührendem Eifer, damit das als Beispiel für die Lösung vieler anderer Fälle dient, und denjenigen, die den gleichen Wunsch hegen, dieses erleichtert.

Im Land Graubünden geht die übliche Verwirrung weiter, und jetzt herrschen dort die Häretiker. Sie werden deshalb nicht die Möglichkeit haben, sich in ihre öffentlichen Verhandlungen einzumischen, da der französische Botschafter vielleicht versuchen wird, mit Ihnen über diese Meinungsverschiedenheiten zu verhandeln, sagen Sie immer, dass Sie keine Genehmigung dazu haben und dass Sie dem Herrgott mit dem Einverständnis zahlen [sic!], damit die Katholiken nicht unterdrückt werden, und empfehlen Sie mit aller Zuneigung unsere Religion und den Bischof von Chur, einen Prälaten, der kein anderes Ziel hat, als den Heiligen Glauben in diesen Gebieten zu stärken.

Gehen Sie im Allgemeinen vor bei Ihren Argumentationen in diesen Angelegenheiten, und gegenüber allen, da es sehr wahrscheinlich ist, dass der besagte Botschafter seine Stellung auch mit Mitteln gewinnen will, die Sie als vertrauenswürdig betrachten werden, und weil der Schaden entsteht, anhand von dem, was sie zur Festung von Fuentes sagen, deshalb hören jene nicht auf, um den Abriss zu bitten, doch machen Sie sich nicht zum Schiedsrichter, indem Sie 
Ihr Urteil über diese Angelegenheit abgeben, was nicht dem ausdrücklichen Sinn Unseres Herrn entspricht.

Die Republik von Venedig hat es durch den Sekretär Patavino ${ }^{25}$ geschafft, mit den protestantischen Kantonen ein Bündnis zu bilden, aber es wird wohl nicht möglich sein, dass sie dies abschließen können, ohne den Zuspruch des Franzosen zu erhalten, dass diese Völker sich mit anderen verbünden dürfen. Große Schwierigkeiten können entstehen, da viele Monate verstrichen sind, in denen die Verhandlungen nicht geführt werden konnten: Es hängt jedoch am Sekretär Patavino, der kürzlich nach Wien zurückgekehrt ist, falls er keine Lösung bringt, was aber nicht sehr glaubwürdig erscheint. Die Venezianer werden dieses Anliegen nicht aufgeben, vielmehr werden sie es um ihres Rufes willen am Leben erhalten.

Es ist daher notwendig, dass Sie den Fortschritt der Minister dieser Republik aufmerksam verfolgen und dass Sie mit Hilfe von Vertrauenspersonen, von denen Sie vom Bischof von San Severo informiert werden, versuchen werden, noch mehr in Erfahrung zu bringen, damit Sie daraus die Schlüsse ziehen können, deren Abschluss hauptsächlich vom Zugeständnis für den Passzugang aus Italien abhängt, der von denselben Venezianern mit allem Geschicken und allen möglichen Mitteln beschafft wurde.

Um die Intrigen der ketzerischen Bündner zu verhindern, die nicht wollen, dass die Priester des Veltlin Dispense oder Benefizbullen des Apostolischen Stuhl erbitten, dachte der Bischof von Como daran, auf seine Kosten ein Kollegium zu errichten, in dem dort junge Menschen dieses Landes ausgebildet werden können. Mit Graubünden verhandelte bereits derselbe Bischof, aber die gegenwärtigen Unruhen haben den Verhandlungsfaden verwirrt. Der Herr Kardinal Borromeo wird Ihnen in dieser Hinsicht etwas sagen, wenn Sie es mit Seiner Heiligsten Herrschaft besprechen werden, wie Ihr es müsst, und mit demselben Bischof, wenn Ihr in Como seid, dem er die Fürsorge für diese Seelen empfehlen wird, und der volles Zeugnis ablegen wird über die Meinung, welche Unser Herr von seiner Güte und der Fürsorge hat.

Für die Verteidigung anderer sind alle bisher genannten Warnungen notwendig: Es ist nun angebracht, dass Sie sich davor wappnen, um den Angriffen $\mathrm{zu}$ widerstehen, die von Seiten der katholischen Kantone an Sie herantreten werden, die ständig darauf bedacht sind, Hilfe von diesem Heiligen Stuhl für alle ihre Bedürfnisse zu erhalten, wie sie es oft mittels des Nuntius Monsignore Verallo getan haben und ein wenig auch mittels des Provinzials der Kapuziner

25 Im Text kommt dieser Begriff als Name vor, doch könnte es sich eher um die Beschreibung „aus Padua stammende“ handeln. Ein Sekretär namens Patavino wird nirgend anders aufgeführt. 
von Helvetien. Hinterlassen Sie keine schlechten Spuren, was die väterlicher Sorge Seiner Heiligkeiten schaden würde, und überbringen Sie gleichzeitig die Wünsche von Papst Clemens dem Heiligsten bezüglich des Kriegs in Ungarn, damit die Schulden dieser Angelegenheit getilgt werden, deren Zahlung weitgehend Unserem Lieben Herrn überlassen bleibt, damit die Hilfe, die Seine Heiligkeit dem Kaiser bei der gleichen Gelegenheit geleistet hat, und die jüngsten Ausgaben in den venezianischen Unruhen allesamt erschöpft sind, dass man mehr darüber nachdenken muss, zu fragen, als zu versprechen und die Schulden zu bezahlen, und nicht darüber, weitere Schulden zu machen. Aus diesen Gründen entziehen Sie sich der Begegnung und bei jeglichen Vorfällen bekunden Sie nicht die Absicht, finanzielle Hilfe zu leisten, sondern bedecken Sie die Ablehnung mit höflichen Antworten und stellen Sie sie zufrieden mit dem Ausdruck der väterlichen Zuneigung, die Seine Heiligkeit gegenüber seinen lieben Kindern empfindet, die diesem Heiligen Stuhl ergeben sind, und zeigen Sie das immer und zu allen möglichen Gelegenheiten.

Sie werden in allen Orten der katholischen Kantone in Lugano, in Bellinzona, in Altdorf, dem Hauptort des Kantons, wo es eine schöne Kirche gibt, und in Luzern mit außergewöhnlichen Zeichen der Ehrerbietung gegenüber dem Heiligen Stuhl höflich empfangen. Zeigen Sie sich allen gegenüber wohlwollend, wie Sie es gewohnt sind, und zeigen Sie jede Zufriedenstellung durch Worte und Zuneigung anhand einer sehr gnädigen Erscheinung in diesen Ländern.

Vor allem Herr Pistorius wird Ihnen gegenüber jede Art von Zuneigung bekunden. Und dies ist berühmt in diesen Gegenden: Er hat guten Eifer und ist ein Gelehrter. Allerdings ist er sehr besorgt über seine eigenen Interessen, und äußert dies bei jeder Gelegenheit, aber es kann bei den Ereignissen nützlich sein. Behalten Sie einen kühlen Kopf und versichern Sie ihm, dass hier sein Verdienst sehr berücksichtigt wird und dass Unser Lieber Herrgott ihn mit väterlicher Liebe liebt.

Auch der Erzpriester von Chiavenna, im Land Graubünden, verdient es, vom Schutz der Minister dieses Heiligen Stuhls begünstigt zu werden, denn trotz der vergangenen Verfolgung und der Unterdrückung aus neuen Gründen hält er in der Furcht vor dem Herrn die Seelen, die sich seiner Fürsorge verpflichtet haben. Tut für ihn bei dieser Gelegenheit Euren ganzen liebevollen Dienst und beschützt sein Werk, soweit Sie in ihm Angemessenheit und Glauben finden werden.

Sie erhalten die üblichen Breven für die katholischen Kantone und für die Bischöfe von Konstanz, Chur, Sitten, für den gewählten Basler Bischof und für den Abt von St. Gallen. In den Kopien können Sie deren Inhalt sehen, und in 
Übereinstimmung mit diesen werden Sie die notwendigen Geschäftsordnungen einrichten.

Sie werden auch zwei Chiffren erhalten, einerseits sollen Sie eine davon benutzen, um sich über die geheimen (privaten) Geschäfte auszutauschen, und andererseits geht es derzeit darum, dass Sie an Nuntien schreiben, mit denen Sie in Gemeinschaft stehen und die mit Ihnen gute Korrespondenz führen und Sie diese über alles informieren, was Licht in die Dinge bringen kann, mit denen sie in ihren Geschäften zu tun haben werden.

Dem Fornero, bekannt als der Todeschino, der in Mailand lebt, werden die Kopien für Sie gesandt und Sie selbst werden über ihn auf diesem Weg ihre Korrespondenz mit Rom führen.

Ich erinnere Sie nicht an die Qualität des Dienstes, den die Minister dieses Heiligen Stuhls leisten sollten, denn Ihre Umsicht und Ihr Eifer erübrigen dies. Es bereitet mir Freude, dass dadurch die Gnade Unseres Herrn erfüllt wird, der Sie mit Seinem Heiligen Segen begleitet. Aus Rom, am 24. Juni 1608.

Der Kardinal Borghese ${ }^{26}$

Loco + Sigilli

\subsection{Relation über die Nuntiatur in der Schweiz von Ladislao d'Aquino (1608-1613)}

Eine genaue Datierung dieser Schrift ist nicht bekannt. Der Vergleich des Inhalts mit den zeitlichen Geschehnissen lässt vermuten, dass d'Aquino den Bericht um 1620 verfasst hat. Es handelt sich sehr wahrscheinlich um einen Text, der nicht an seinen direkten Nachfolger, sondern an Alessandro Scappi gerichtet ist, der von 1621 bis 1628 Nuntius in Luzern war.

\section{Bericht des Bischofs von Venafro ${ }^{28}$}

\section{Die Größe der Nuntiatur}

Die Nuntiatur bei den Schweizern hat einen sehr großen Umfang, denn sie erstreckt sich nicht nur über ganz Helvetien, sondern auch über das Wallis und Graubünden sowie über fünf Bistümer und zwar Konstanz, Lausanne, Sitten

26 Vgl. Volker Reinhardt: Kardinal Scipione Borghese (1605-1633).

27 Segreteria Stato, Svizzera, Volume Additamenta I, Busta V. 42 Folien.

28 Eine Übersetzung einiger Teile und Zusammenfassung dieser Relation wurde bereits in: „Geschichte der Einführung der Nuntiatur in der Schweiz und ihre dargelegte Politik“, von Ludwig Snell veröffentlicht. Da sich jene Ausgabe an die deutsche Sprache jener Zeit richtet, wurde hier nun eine an die heutige Zeit angepasste sprachliche Übersetzung gemacht. Auch 
(Sion), Chur und Basel. Und zu Konstanz sagen einige Geographen, dass es von der Größe her nicht den Vergleich mit dem Königreich Neapel scheuen muss. Auch gehören dazu noch ein bedeutender Teil der Diözese Mailand und der größte Teil von Como. ${ }^{29}$

Die Fürsten an der Grenze zur Nuntiatur sind die folgenden: Im Süden ist der Staat Mailand, östlich ist jener von Tirol und das Haus Österreich, im Westen die Grafschaft Burgund (Franche-Comté) ${ }^{30}$ und Savoyen, im Norden das Unterelsass und die Pfalzgrafschaft am Rhein, sowie das Herzogtum Württemberg, ${ }^{31}$ das sich aber noch innerhalb der Grenzen der Nuntiatur befindet.

Die Größe und Bedeutung dieser Nuntiatur kann man durch die Anzahl der Provinzen besser verstehen, die in dem entsprechenden Gebiet $\mathrm{zu}$ finden sind und die nicht wenige oder von geringer Bedeutung sind. Helvetien allein ist zweihundertfünfzig italienische Meilen lang und achtzig breit, zur Länge zählt die Distanz vom Bodensee bis zum Genfersee und zu seiner Breite zählt die Distanz vom Rhein oder den Bergen im Jura bis zu den Grenzen der Alpen, die Helvetien von Italien trennen. ${ }^{32}$

Darüber hinaus umfasst das Gebiet die folgenden Provinzen, wie den Wallis, eine eigenständige, drei Tagesreisen ${ }^{33}$ lange Provinz, in der die früheren Bewohner die Seduner, die Riper und die Verater waren.

Die Bündner, die allgemein Rätier genannt werden, sind eine weitere Provinz, die etwa hundert Meilen lang und an manchen Stellen etwas weniger breit ist als andere Provinzen.

Die Raurakier und Sequanti Cisiurani, die von den Römern Augusta Rauracorum genannt wurden, lebten im gesamten Land von Basel.

entspricht der Text von Snell nicht ganz der im vatikanischen Archiv auf Italienisch aufbewahrten Instruktion.

29 Einerseits weist die Instruktion darauf hin, dass es ein Kernland „Helvetien“ gibt. Das ist das Synonym für die Schweiz. Wallis und Graubünden gelten bereits als zusätzliche Gebiete zum Kernland. Der Vergleich mit dem Königreich Neapel zeigt, wie d'Aquinos Weltbild doch noch von seiner süditalienischen Heimat geprägt ist. Dieser Einstieg betont somit die Bedeutung der Nuntiatur, die sich über ein großes Territorium erstreckt und andererseits auch nicht homogen ist.

30 Snell hat dies zusätzlich in Klammern eingefügt.

31 Wie Snell in einer Fußnote anmerkt, war die Nuntiatur in Luzern nie beim Herzog von Württemberg oder bei einem anderen schwäbischen Fürsten akkreditiert gewesen. Vgl. Christian Wilhelm von Glück, Ludwig Snell: Geschichte der Einführung der Nuntiatur in der Schweiz und ihre dargelegte Politik, in Authentischen Aktenstücken, Baden 1847, S. 69.

32 Dieser Absatz fehlt in Snells Übersetzung.

33 Das entspricht ungefähr 240 Kilometer. 
Der Breisgau ist jene Provinz Deutschlands, die dem Haus Österreich unterstellt ist ${ }^{34}$ und die einen Teil des Markgrafen von Baden umfasst. Die dortige Metropole ist das heutige Freiburg, genannt im Breisgau. Die Stadt war auch in der Antike der Hauptort des Landes Briaco, das ein großer und sehr mächtiger Ort war.

Das Oberelsass, eine Provinz, die so reich an Weizen und Wein ist wie keine andere Provinz Deutschlands, deren Metropole Ensisheim ist, wo sich das österreichische Regiment befindet und den Österreichern auch direkt unterstellt ist, und dort sind viele Adelsstädte wie Rouffach, Colmar, Sélestat, Guebwiller und viele andere Orte. ${ }^{35}$

Die schwäbische Provinz ist so berühmt und bekannt, dass sie in der Antike den Titel Königreich und kleines Herzogtum trug, und heute ist sie Teil des Hauses von Österreich und Teil des Herzogs von Württemberg, und einige Orte haben die Herzöge von Bayern, ebenso gibt es viele freie Städte. Die Donau durchquert diese Stadt und die wichtigsten Städte sind Konstanz, Ulm, Kempten, Memmingen, Überlingen und andere, die alle zur Nuntiatur gehören, und neben diesen gibt es Augsburg, das zu einer anderen Nuntiatur gehört. Einige Gebiete gehören noch zu Tirol, und es ist klar, dass das Vinschgau-Tal, das dazu gehört, die Autorität des Nuntius von Helvetien anerkennt.

Neben diesen großen Provinzen, gibt es weitere kleine Provinzen wie Thurgau, Zürichgau, Aargau, Wiflispurgergau, so wie Val Telina [sic!], Val Chiavenna, Val Calanca, Val Aretolina, Val di Bregno, Val Leventina, Val Maggia, Val di Lugano, das heute noch Tal der Menschen ${ }^{36}$ genannt wird, und andere, was aber zu lange ist, um hier aufgelistet zu werden.

In dieser Nuntiatur haben die Hauptflüsse Europas ihre Quellen, wie die Adda und der Ticino, die Richtung Italien fließen, und in Richtung Deutschland gibt es die Donau, den Rhein, die Rhone, den Neckar, die Limmat, die Reuß und weitere andere.

Der berühmte westliche Herkynische Wald $^{37}$ befindet sich ebenfalls in dieser Nuntiatur neben Waldshut, und wird wegen seiner schrecklichen und dunklen Seiten auch Schwarzwald genannt.

34 Damit ist das österreichische Schwaben gemeint, mit den Hauptteilen des Sundgaus (südliches Elsass) und des Breisgaus. Sitz der Regierung war Ensisheim nahe Mülhausen. Freiburg im Breisgau, das sich 1368 den Habsburgern unterstellt hatte, war das geistige und kulturelle Zentrum.

35 Vgl. Stichwort „Elsass“, in: https://hls-dhs-dss.ch/de/articles/007022/2012-11-30/ (31. Dezember 2020).

36 Im Original: „valle delli uomini“. Eine weitere Erläuterung dazu ist nicht zu finden.

37 Es handelt sich um das Mittelgebirge, welches sich nördlich der Donau und östlich des Rheins befindet. Die in der Instruktion verwendete Bezeichnung ist eine aus der Antike stammende Sammelbezeichnung für dieses Gebirge. 
Unter den dreizehn Schweizer Kantonen sind katholisch: Luzern, Altdorf, Schwyz, Unterwalden, Zug, Solothurn und Freiburg.

Es gibt vier Ketzer-Kantone: Zürich, Bern, Basel und Schaffhausen.

Und die anderen beiden bleiben gemischt, das heißt teilweise sind sie Ketzer und teilweise katholisch, aber in Glarus gibt es mehr Ketzer, und in Appenzell sind sie so geteilt, dass sie getrennt leben, und jeder Teil hat eine eigene Zuständigkeit und Herrschaft.

Innerhalb der Grenzen dieser Nuntiatur werden vier verschiedene Sprachen gesprochen: Deutsch in Helvetien, Rumantsch in Graubünden, und dies ist eine eigenartige Sprache, die sich aus Wörtern von acht oder zehn verschiedenen Idiomen zusammensetzt. ${ }^{38}$ Französisch wird im Gebiet der Diözese Basel gesprochen, in Gebieten, die im Burgund liegen, und auch an einigen Orten, die die Schweizer auf dieser Seite der Berge gemeinsam teilen; und dann gibt es auch Graubünden, das ein großes und reiches Land ist. ${ }^{39}$

Es gibt viele Kantone, viele Republiken, ${ }^{40}$ und alle haben dementsprechend in ihren Ländern die höchste Autorität inne. Nicht zuletzt wird ein Teil von ihnen aristokratisch und demokratisch regiert. ${ }^{41}$ Aristokraten regieren in Zürich, Bern, Luzern, Solothurn, Freiburg und Schaffhausen.

Vom Volk regiert sind alle anderen, nämlich Altdorf, ${ }^{42}$ Schwyz, Unterwalden, Zug, Appenzell und Glarus. Die Anführer der aristokratischen Republiken werden an einigen Orten Bürgermeister ${ }^{43}$ genannt, und diese befinden sich in Zürich, Basel und Schaffhausen. An einigen anderen Orten wird diese Autorität Schulthei $\beta^{44}$ genannt, wie in Luzern, Freiburg und Solothurn. Unter den demo-

38 Im Original: „Romantesco fra Grisoni, e questa e una fauella strauagantissima composta di vocaboli di otto o dieci idiomi tutti diuersi.“ Zit. nach: Segreteria di Stato, Svizzera, Volume Additamenta I, Busta V, Relazione della Nunziatura, p. 1v.

39 Die eigentliche Schweiz (Helvetien) ist aus römischer Sicht vorwiegend die Deutschschweiz. Was in dieser Aufzählung fehlt, ist das Wallis.

40 Die Bezeichnung Kanton war im Italienischen des 16. und 17. Jahrhundert für die Schweizer Orte gängig und wurde als Synonym für die auf der italienischen Halbinsel gängigen Republiken verwendet. Die Gleichsetzung mag in vielen Gemeinsamkeiten übereinstimmen, auch war das Verhältnis (durch den Handel) mit den norditalienischen Republiken ein Ansporn für die eidgenössischen Orte, gewisse Freiheiten und politische Strukturen nachzuahmen.

41 Die Schweizer Patrizierfamilien werden in dieser Instruktion mit der in Europa verbreiteten Aristokratie gleichgesetzt, ohne jedoch eine Gleichstellung mit dem Adel zu machen. Der Begriff „Demokratie“ wird deshalb verwendet, weil man die Landsgemeinden und Tagsatzungen als „demokratisches Rechtssystem“ betrachtete.

42 Statt Uri wird hier der Hauptort stellvertretend für den Ort genannt.

43 Im Original: „Burgermaister“. Zit. nach: Segreteria di Stato, Svizzera, Volume Additamenta I, Busta V, Relazione della Nunziatura, p. 1v.

44 Im Original: „Schultetio“. Zit. nach: Segreteria di Stato, Svizzera, Volume Additamenta I, Busta V, Relazione della Nunziatura, p. 1v. 
kratischen Kantonen werden sie Ammann oder Landammann, das heißt Beamter des Landes, genannt. Aber alle haben die gleiche Autorität, fast wie der Doge von Venedig oder die Konsuln im antiken Rom.

Diese Volksbeamten sind zwei Jahre im Amt und nicht länger, obwohl die Würde des Titels erhalten bleibt..$^{45}$ Luzern und andere Orte, an denen zwei ernannt werden, regieren sie abwechselnd je ein Jahr, bis sie wie gewöhnliche Bürger werden, doch sie können während ihrer Amtszeit aberkannt oder entlassen werden.

Ich möchte nicht weiter die Art und Weise der Schaffung von Beamten und andere allgemeine Dinge erläutern, denn es gibt so viel darüber zu berichten, ${ }^{46}$ man könnte über die Grundsätze der Bündnisse, der Freiheit und der Republik dieser Nation schreiben, was aber nicht die Mühe lohnen würde. Aber diejenigen, die sich doch damit auseinandersetzen wollen, sollen Aegidius Tschudi, ${ }^{47}$ Heinrich Loriti (Enrico Glareano), ${ }^{48}$ Franz Guillimann, ${ }^{49}$ Johannes Stumpf ${ }^{50}$ und Josias Simler ${ }^{51}$ lesen, alle modern, ${ }^{52}$ aber nicht alle katholisch.

Nach diesen Prämissen folgen nun einige Kapitel über wesentliche Dinge, die für die gute Führung der Nuntiatur notwendig sind.

\section{Von den Botschaftern der Fürsten, die hier bei den Schweizern residieren, und von ihren Zwecken.}

Bei den Schweizer Herren residieren die Gesandten der Könige von Spanien, Frankreich und des Achten Herzogs von Savoyen ${ }^{53}$ sowie ein weiterer Botschaf-

45 Damit ist gemeint, dass ein Herr auch nach seinem Mandat weiterhin mit der Bezeichnung „Schultheiß“ oder „Landammann“ angesprochen oder in Briefen so aufgeführt wird. Dies kommt in der Korrespondenz der Nuntien immer wieder vor.

46 Hier liest man zwischen den Zeilen, dass die behördliche Struktur in der Eidgenossenschaft sehr komplex ist.

47 Geboren am 5. Februar 1505 in Glarus, gestorben am 28. Februar 1572 auf seiner Burg Gräpplang bei Flums. Tschudi gilt als erster Historiker über die Schweiz. Er war politisch tätig, da er einer Glarner Landammansfamilie (Patrizier) angehörte.

48 Auch Glarean genannt, geboren 1488 in Mollis und gestorben 1563 in Freiburg im Breisgau. Er war 1516 Tschudis Präzeptor in Basel gewesen.

49 Eigentlich hieß er François Guillimat und ist 1568 in Freiburg im Üechtland geboren und 1612 in Freiburg im Breisgau gestorben. Er war wie Tschudi ein Schweizer Historiker. Auch war Guillimann als neulateinischer Dichter tätig.

501500 in Bruchsal geboren und um 1577 in Zürich gestorben, war Stumpf ein Theologe, der auch als Historiker und Chronist über die Schweiz berichtete.

511530 in Kappel am Albis geboren und 1576 in Zürich gestorben, war der Theologe Simler wie Stumpf auch als Historiker tätig.

52 Im Vergleich zum Erscheinungsjahr der Instruktion waren die genannten Schweizer Historiker fast Zeitgenossen. 
ter für Frankreich, der für Graubünden zuständig ist, daneben gibt es den Apostolischen Nuntius, der dort zu Ehren der Päpste die Beziehungen zu den Kantonen unterhält. ${ }^{54}$ Und da sieht man auch, wie sehr diese Nation von den genannten Potentaten geschätzt wird, zumal sie bei den entsprechenden Großmächten normalerweise keinen ordentlichen Schweizer Botschafter haben. ${ }^{55}$

Der Zweck, den die Päpste verfolgen, indem sie einen Nuntius zu diesen Völkern Helvetiens schicken, besteht deutlich darin, und es geht um nichts anderes als die Aufrechterhaltung des katholischen Glaubens, ${ }^{56}$ der mit so viel Wut von den hinterhältigen und bösen Ketzern in der Nachbarschaft bekämpft wird. ${ }^{57}$

Obgleich der Respekt allen Orten des Christentums gilt, die in Berührung mit den Protestanten sind; gilt dies nicht mehr und weniger auch für die Schweizer, weil sie an Italien grenzen und sogar mit einem Fuß ihrer Zuständigkeit den italienischen Boden berühren, und wenn sie alle infiziert wären, wie sie es zum Teil sind, könnten der Staat Mailand und die anderen Provinzen Italiens, die so nah beieinander liegen, in große Gefahr geraten. Das gilt auch, wenn alle Kantone der Schweiz zur Ketzerei übergehen. ${ }^{58}$ Es wäre dann fast ausgeschlossen, nach Deutschland ${ }^{59}$ zu gelangen und den Gläubigen unserer Religion dort zu helfen und andere Übel zu bekämpfen, die leicht geschehen könnten, und deshalb ist der Aufenthalt des Apostolischen Nuntius in Helvetien für diese Provinz so wichtig, denn ohne diese Hilfe, und ohne die Hilfe der Kapuziner und der Jesuiten, die dort auf Vorschlag der Nuntien eingeführt wurden, wären zu dieser Zeit vielleicht alle vom Aberglauben von Zwingli und Calvin geblendet worden, und es ist schon lange her, dass Nuntien nach Helvetien ge-

53 Um 1620 war Karl Emanuel I. Herzog von Savoyen. Vgl. Toby Osborne: Dynasty and diplomacy in the court of Savoy. Political culture and the Thirty Years' War. Cambridge 2002; Valerio Castronovo: Carlo Emanuele I, duca di Savoia, in: Alberto M. Ghisalberti (Hrsg.): Dizionario Biografico degli Italiani (DBI). Band 20: Carducci - Carusi.

54 Hier ist eine Selbstdefinition angegeben. Es wird der Schwerpunkt darauf gerichtet, dass die Schweizer sich eigentlich geehrt fühlen sollten, dass der Papst einen Gesandten zu ihnen schickt. Die anderen Gründe werden hier nicht aufgeführt.

55 Hier ist ein Hinweis darauf, dass die Eidgenossen kein Reziprozitätsprinzip bei den Gesandten und diplomatischen Beziehungen anwenden.

56 Hier ist das Hauptziel der Gesandtschaft des Nuntius angegeben. Es entspricht dem Anliegen des Konzils von Trient.

57 Der Vorwurf an die Protestanten ist also, dass sie nur Böses vorhaben und dass es sich um einen Kampf handelt.

58 An dieser Stelle offenbart die Instruktion den Grund für die Einsetzung eines Nuntius in der Eidgenossenschaft. Es geht also um die „Verteidigung“ vor den Protestanten.

59 Im Original: „Germania“. Zit. nach: Segreteria di Stato, Svizzera, Volume Additamenta I, Busta V, Relazione della Nunziatura, p. 2v. 
sandt und eingesetzt wurden, da schon in alten Schriften darüber berichtet wird, und die Entsendung des Nuntius ist sogar älter als der Bund der Eidgenossen, denn bereits um das Jahr $1228^{60}$ wurde ein Gesandter nach Luzern entsandt und das wurde auch getan, als der Ort der Eidgenossenschaft beitrat und ihre Freiheit im Jahr 1378 erlang. ${ }^{61}$

Aber mit welcher Absicht die anderen Fürsten ihre Gesandten in die Schweiz entsenden, ist nicht leicht zu erraten, da dies eines der Dinge ist, die numerantur inter arcana Imperii, ${ }^{62}$ auch wenn es aus bestimmten Gründen offensichtlich und bekannt ist, und diese sollen hier aufgezählt werden:

Der König von Spanien unterhält Freundschaften, Bündnisse und Gesandte mit den katholischen Kantonen Helvetiens und zahlt ihnen große Summen für die Sicherheit ${ }^{63}$ des Staates Mailand und für den Burgund, an den sie grenzt, und das ist keine geringe Gunst, denn nach den alten Ansprüchen Frankreichs auf die Herrschaft von Mailand, als die Schweizer nicht mit Spanien im Bündnis waren, war der Weg für die Feinde ${ }^{64}$ offen, die noch mehr hätten unternehmen können, wenn sie ihre Kräfte mit dieser reichen und kriegerischen Nation vereint hätten. Und zur Erhaltung der Freundschaft und des Bündnisses, aber auch um ihrer Stellung nicht zu schaden, wird ein Gesandter nach Helvetien geschickt. Der zweite Zweck Spaniens ist zugunsten des Zugangs nach Flandern und nach Deutschland, denn durch die Freundschaft mit der Schweiz kann Seine Katholische Majestät seine Regimenter von Italienern und Spaniern nach Flandern durch die Schweiz gehen lassen und lässt umgekehrt bei Bedarf die Landsknechte [,lanzichenecchi“ im Originaltext] nach Italien kommen, da die Schweiz der sicherste Weg ist, um die Alpen zu überqueren. Wie wichtig dieser Punkt ist, kann von denjenigen verstanden werden, die sich um den Ausgleich zwischen den großen Parteien kümmern, da der König den stärkeren Kantonen aus diesem Grund beisteht, damit die Durchreise eingehalten werden kann. ${ }^{65}$ Und aus diesem Grund lassen die Schweizer jene nicht durch ihre Gebiete, die

60 Vgl. aus: Sophronizon oder unpartheyisch-freymüthige Beyträge zur neueren Geschichte, Gesetzgebung und Statistik der Staaten und Kirchen, herausgegeben von Heinrich Eberhard Gottlob Paulus, Frankfurt am Main 1820, S. 4: „Dieser Gebrauch, Nuntien nach der Schweiz zu schicken, ist so alt, dass aus Urkunden erhellt, es seyen ihrer vor Stiftung der Eidgenossenschaftt schon dort gewesen, nemlich im Jahr 1228, und zu Luzern nach der Conföderation und Freyheit seit 1384.“

611378 starb der römisch-deutsche Kaiser Karl IV. Da seine Söhne und Verwandte nach seinem Tod sich nicht einigen konnten, ging die von Karl geschaffene Machtstellung verloren.

62 Hier wird das Römische Reich als ein für die römische Kurie fremdes Gebilde betrachtet.

63 Damit sind Söldner gemeint.

64 Damit ist Frankreich gemeint.

65 Diese Machtkonstellation machte es auch möglich, dass die katholischen Kantone, die von Spanien unterstützt wurden, sich den protestantischen Kantonen nicht unterstellen mussten. 
sie nicht wollen, denn ihre Macht besteht darin, die Tore $\mathrm{zu}$ den Provinzen jenseits der Berge zu schließen und so auch die Zugänge nach Deutschland und den Niederlanden zu versperren. Es kann noch sein, dass zu den oben genannten Gründen, die den König von Spanien dazu bringt, die Schweizer zu berücksichtigen, die Nachahmung Frankreichs ist, und damit jene Nation die Schweiz nicht dominiert und sie als Gegengewicht zur gegnerischen Fraktion betrachtet, und während die Schweizer gespalten sind, besteht dann weniger Gefahr, dass sie sich zusammenschließen können, um in Italien zum spanischen Nachteil einzufallen, indem sie den Staat Mailand angreifen, wie sie es zum Zeitpunkt des Kaisers tun wollten, um sich dann mit Frankreich zu einigen, wenn sie nicht das Hindernis vorgefunden hätten, das sie den Kragen kostete. Die Achtung vor den Getränken, vor dem Fett wie Fleisch und Käse, die sie aus Deutschland kennen und die es in Helvetien gibt, vereint sie untereinander stärker als mit anderen. Und das lässt sie sich nicht voneinander trennen und kennzeichnet sie auf besondere Weise.

Über die Könige von Frankreich sagt man, dass sie sich mit den Schweizern vereinen, weil sie ihre Tugend und Stärke bewundern, aber man sagt auch, dass Ludwig XI., ${ }^{66}$ der auf Ersuchen von Papst Eugen ${ }^{67}$ nach Deutschland gekommen war, um das Konzil von Basel $^{68} \mathrm{zu}$ verhindern, viel zu tun hatte, um nur 1500 Schweizer zu besiegen, die sich ihm widersetzten, und obwohl er eine sehr große Armee von Fußsoldaten und Reiter und Pferde hatte, starben mehr als sechstausend von ihnen bei dem blutigen Sieg. Daher sagte der König die folgenden Worte: Daturum se operam, ne deinceps cum Helvetiis pugnadum sit. ${ }^{69}$ Und so führte Ludwig XII. ${ }^{70}$ das erste Bündnis aus diesem Grund ein, um Untertanen zu gewinnen, indem er den Bauern die Waffen wegnahm, und ob das ein guter Rat ist, sollen die Staatsmänner beurteilen.

66 Ludwig XI. der Kluge, König von Frankreich von 1461 bis 1483. Er war der sechste König aus dem Haus Valois und der zweite der sogenannten Loire-Könige. Vgl. Ansgar Wildermann: Ludwig XI., in: Historisches Lexikon der Schweiz (HLS) - online, Eintrag vom 16. Juli 2008: https:// hls-dhs-dss.ch/de/articles/029212/2008-07-16/ (31. Dezember 2020).

67 Es handelt sich um Papst Eugen IV. (Gabriele Condulmaro aus Venedig), der von 1431 bis 1447 Papst war.

68 Das Konzil von oder zu Basel zählt zu den bedeutendsten Synoden im 15. Jahrhundert. Das Konzil wurde am 23. Juli 1431 von Papst Martin V. in Basel einberufen; es endete am 19. April 1449. Die Spaltung von Papst und Konzilsvätern im Jahre 1437 führte zu dem gleichzeitigen Konzil von Basel/Ferrara/Florenz.

69 Er wird alles dafür tun, damit in der Folge keine Kampfhandlung gegen die Schweizer stattfinden darf.

70 Ludwig XII. war von 1498 bis 1515 König von Frankreich und ein Angehöriger des Hauses Valois-Orléans, einer Nebenlinie des Hauses Valois. 
Und aus denselben Gründen des Heldenmutes, den man den Schweizern zusprach, sagen Historiker, dass Franz I., ${ }^{71}$ der den Herzog von Mailand und seine Schweizer Verbündeten in Marignano besiegt hat, zu bedenken gab, dass ihn dieser Sieg viel wegen des Mutes der Helvetier gekostet habe. Deshalb schloss er erneut ein Bündnis mit den Schweizern, was zuvor von Ludwig XII., seinem Vorgänger, aufgegeben worden war. Da es diese Wertschätzung gegenüber diesen Menschen gab, führte dies dazu, dass die Könige von Frankreich sich mit ihnen verbündeten, und darum kann man daraus schließen, dass sie zur Aufrechterhaltung der Freundschaft und aus Respekt ihre Botschafter und ihre Minister dorthin schicken.

Der andere Zweck, den die Franzosen mit dieser engen Freundschaft anstreben, ist die Unterstützung durch eine gute Infanterie, die sie in einem Hauch von Trommelwirbel von den Schweizer Kantonen erhalten können, und umso mehr muss dies geschätzt werden, weil die Könige von Frankreich nicht bereitwillig Fußsoldaten in ihrem Königreich stellen oder, wie ich sagte, keine Waffen in die Hände der niedrigen Untertanen geben, oder weil sie an sich nicht viele Ritter haben.

$\mathrm{Zu}$ diesen Gründen kann man noch weitere hinzufügen, die man auch vom König von Spanien kennt, nämlich jene, dass man die raue Nation der Schweizer durch die Teilung ihrer Kräfte schwächt. Weiter kommt hinzu, dass die Grenzen und Passzugänge bei jeder Gelegenheit offen bleiben sollen, um ihre Stärke zu nutzen. Auf diese Weise können sie die untergeordneten Kronprinzen in Schach halten, die sonst tumultartig handeln würden. Doch diese wissen, dass ihr König auf diese Weise sofort so viele Soldaten in den Kampf schicken kann, wie er will, denn es gibt wirklich kein Volk, das bereitwilliger in den Krieg zieht als die Schweizer, noch das mit Waffen so gut umgehen kann. Und weil sie den Krieg wie eine Kunst führen, sind sie immer danach bestrebt, ehrenhafte Taten zu vollbringen, indem sie den Verstand verachten, um ihren Ruf zu behalten, der ihnen die Herrschaft gibt. So erhalten die Fürsten einen hervorragenden Dienst. Andere spezifischere Zwecke und Geheimnisse gelten als undurchdringlich und unsicher und darum belassen wir es damit. Es ist durchaus richtig, dass der König von Frankreich aus den gleichen Gründen seinen Botschafter sowohl nach Graubünden als auch in die Schweiz schickt, und es ist nichts Besonderes dabei, außer dass er mehr Passzugänge nach Italien hat, um sich damit mit den Venezianern, den alten Freunden dieser Krone, zu verbin-

71 Der 1494 geborene François I ${ }^{\mathrm{er}}$ war ein französischer König aus dem Haus Valois-Angoulême, einer Nebenlinie des Hauses Valois. Er wurde am 25. Januar 1515 in der Kathedrale von Reims zum König von Frankreich gesalbt und regierte das Land bis zu seinem Tod 1547. 
den. Der Herzog von Savoyen ${ }^{72}$ bewegt sich nach wie vor weise für seine Zwecke, indem er die Pensionen zahlt und mit seinen Gesandten die Schweizer Nation beehrt. Er muss diese Kantone berücksichtigen, sowohl wegen der Nähe der Staaten als auch wegen der Forderungen, die viele Orte wie Bern, Wallis und die Stadt Genf haben, sowie die Grenzen zur Schweiz berücksichtigen. So muss er hoffen, von den katholischen Kantonen Hilfe zu erhalten, wenn sie beschließen, sich dafür einzusetzen. Zumindest muss er sie als Freunde pflegen, damit sie ihm gegenüber neutral bleiben, da das Herzogtum Savoyen wie zwischen einer Schere zwischen Frankreich und Spanien liegt, und so ist es eine kluge Sache, diejenigen zu berücksichtigen, die sie brauchen, weil das oft der Fall sein kann, umso mehr, als sie Nachbarn sind. Dazu kommt der Vorteil, Söldner anzuwerben, da die katholischen Kantone verpflichtet sind, ihm bei jeder Anforderung eine Anzahl von bis zu achttausend Fußsoldaten zu überlassen, und sogar mehr, wenn er will. Und man kann in der Tat sehen, wie sehr dieser Fürst auf diese Soldaten zurückgreift. Denn er hat nicht nur die gewöhnliche Wache aus Schweizern, sondern er heuert keine anderen an, ohne zunächst Schweizer Soldaten anzuwerben. Denn das ist die Frucht, die von der Eidgenossenschaft gewonnen wird. Und so schickt er seinen Minister, um ihnen seine Pensionen zu zahlen und das Wohlwollen der Herren $\mathrm{zu}$ bewahren, damit sie seinen Bedürfnissen günstig geneigt sind. Und was man noch betrachten kann, ist der Wohnsitz dieses und der anderen Botschafter, um über den Wert der Söldner informiert zu werden, die dann als Oberste oder Hauptmänner gewählt werden sollen. Denn damit können die Besten ausgewählt und der Weg zu Verhandlungen mit ihnen besser vorbereitet werden. Und so wird den Bräuchen, der Natur, den bekannten Qualitäten und anderen Besonderheiten dieses Staates mehr Gewicht verliehen, als es für die Besonnenheit der großen Fürsten nützlich ist. Und wahrhaftig, die Venezianer gelten als vorsichtig, weil sie bei den Botschaftern und in den Beziehungen, die sie eingehen, so gewissenhaft sind. Und dem gleichen Stil scheinen heute die Staaten von Holland zu folgen, und andere Fürstenhöfe von weit weg, die aber weniger eine christliche Politik pflegen.

Nachdem die Zwecke genannt wurden, bleiben noch die Anmerkungen, wie man mit diesen Botschaftern umgehen soll.

In der Stadt Luzern, wo der Apostolische Nuntius wohnt, residieren auch der Botschafter von Spanien und Savoyen und der Botschafter des Allerchristlichsten Herrschers, dem König von Frankreich, und auch in der Stadt Solo-

72 Vgl. Stichwort „Frieden von Saint-Julien“, in: https://hls-dhs-dss.ch/de/articles/017176/ 2012-09-11/ (31. Dezember 2020). 
thurn ist noch ein Gesandter Frankreichs, da der Ort den Grenzen des Königreichs am nächsten liegt. Der Nuntius muss daher eine gute Freundschaft mit all diesen Fürstendienern pflegen, denn sie können sehr viel bewirken. Sie halten mit der goldenen Kette den Willen der ganzen Schweizer Nation an sie gebunden, und man kann es mit der eigenen Hand spüren, als der Bischof von Chur nicht in der Lage war, sein Bistum zu führen und 1608 vertrieben wurde. Damit er wieder an seinen Wohnsitz gelangen konnte, wurde er von mir überredet, sich mit dem Botschafter von Frankreich anzufreunden, und so wurde er mit seiner Gunst empfangen und angenommen, und nun wohnt der Bischof wieder sehr friedlich in Chur. Mit der Hilfe desselben Botschafters holte ich mir die Zustimmung der Ketzer Graubündens ein, damit der Bischof von Como das Veltlin besuchen kann, und hoffentlich hat das Erfolg. Und es ist in Helvetien öffentlich bekannt, dass, wenn der Botschafter des Allerchristlichsten in Solothurn mir in den Geschäften des Wallis, in denen ich so viel harte Arbeit an der Sicherheit geleistet habe, geholfen hätte, dann wären alle Ketzer aus dieser Provinz vertrieben worden, und zum heutigen Zeitpunkt wären dort bereits alle Katholiken. So bedeutend und mächtig ist dieser Botschafter, wenn man seinen Dienst in den Geschäften braucht. Und deshalb ist es sehr wichtig, wie Unser Herr es in meiner Zeit oft getan hat, insbesondere Frankreich immer darum zu bitten, katholische und eifrige Diener mit einem ausdrücklichen Auftrag zu entsenden, um den Geschäften des Glaubens zu helfen und eine gute Korrespondenz mit dem Nuntius zu führen, denn auf diese Weise werden die Früchte vieler Überlegungen geerntet, wie man es jetzt beginnt zu tun, da eine wahrhaft christliche Königin regierte. Mit den in Luzern ansässigen Botschaftern wird sich öfters besprochen, und es wird dem Nuntius leichter fallen, diese erhellende Eingebungen und diese Hilfe zu haben, aber ich bin in diesen Fragen nicht so mächtig wie die anderen, weil sie an kein Bündnis gebunden sind, außer mit den katholischen Kantonen, und sie haben das weder mit dem Wallis noch mit Graubünden, wo sie es vielleicht am meisten brauchen. Es ist eine allgemeine Regel, immer neutral zu bleiben und sich nie einer Seite mehr hinzugeben als einer anderen, weder zu Frankreich, noch zu Spanien, da es die Einstellung Unseres Herrn ist, dass man alle zu seinen Freunden haben kann. Denn es ist nicht gut, sich selbst zu einem unzuverlässigen Teil zu machen. Es ist wahr, dass es schwierig ist, diese Neutralität immer aufrechtzuerhalten, so dass es keinen Verdacht gibt, aber es ist nicht unmöglich.

Über die Tagsatzungen und die Art und Weise, wie sich die Schweizer versammeln

Was die Helvetische Republik zusammenhält, ist nichts anderes als die Tagsatzung oder die öffentliche Beratung aller Kantone, denn ohne dies würde der Bund nicht bestehen, und Helvetien wäre nicht eine einzige Republik, sondern 
es gäbe so viele Republiken wie es Kantone gibt, und damit wären die Schweizer schwächer und weniger geschätzt und angesehen. Da die Tagsatzungen die Grundlage und die Basis der Wertschätzung und Freiheit ihrer Nation sind, werden im vorliegenden Kapitel einige Besonderheiten zur Kenntnisnahme dieser Angelegenheit angesprochen.

Für die Erhaltung der Eidgenossenschaft, die den Namen der Schweiz zum Verdienst hat, das heißt den der Vereinigung durch Eid, war es notwendig, einige Male zusammenzutreffen, um einige gemeinsame Gesetze für die Erhaltung des Staates zu erlassen, und die wichtigsten Dinge zu konsultieren, um gemeinsam die Erhaltung ihrer Republik zu erreichen, die sich an die Griechen anlehnte und aus mehreren Mitgliedern bestand, die alle frei und eigenständig waren, was zu einer gemeinsamen Gesellschaft führte, wie auch Guillimann in seinem Buch „de vetere Republica Helvetiorum“73 aufzeigt. Und für diese Zwecke wurde vor allem die Abhaltung der Tagsatzungen, mit denen wir uns an dieser Stelle befassen, eingeführt.

Die Tagsatzung ist daher nichts anderes als eine Kongregation der Staaten der Schweiz, um alle Fragen der Erhaltung und des Ausbaus ihrer Freiheit zu besprechen und darüber zu beraten.

Diese Tagsatzungen sind in allgemeine und außerordentliche Tagsatzungen unterteilt. Die außerordentlichen sind diejenigen, die auf Wunsch der Botschafter der Fürstenhöfe für bestimmte Verhandlungen oder für Geschäfte einberufen werden, die die allgemeine Politik dieser Nation nicht betreffen. Aber ich bezeichne als allgemeine Tagsatzungen nicht nur jene, die in der Stadt Baden im Aargau aus allen dreizehn Kantonen bestehen und bei denen sowohl die katholische als auch die protestantische Seite vertreten sind, sondern auch diejenigen Tagsatzungen, die alle sieben katholischen Kantone untereinander oder die ketzerischen Kantone untereinander bilden, denn auch bei diesen Treffen haben sie es oft mit Geschäften zu tun, die den Bund berühren und ihre Freiheit angehen.

Früher wurden diese Tagsatzungen an anderen Orten abgehalten. Es war aber nicht an einem bestimmten Ort, da man sich in Luzern, Zürich, Baden, Bremgarten und anderen Orten traf. Aber heute wird aus Bequemlichkeit für alle Kantone die Ordentliche Tagsatzung der dreizehn Kantone in der Stadt Baden durchgeführt, die mitten in Helvetien liegt. Und die Stadt ist reich an Le-

73 Es handelt sich sehr wahrscheinlich um das von François Guillimann verfasste: De rebus Helvetiorum sive antiquitatum Libri V, 1598. Darin wird die Geschichte der Schweiz bis 1315 aus katholischer Sicht behandelt, was als Gegenentwurf zur reformierten Chronik von Johannes Stumpf und Josias Simler galt. Vgl. Stichwort „Franz Guillimann“, in: https://hls-dhs-dss.ch/ de/articles/018692/2005-11-23/ (31. Dezember 2020). 
bensmitteln und guten Wohnungen. Hinzu kommt, dass sie neutral gegenüber den acht Kantonen ist, die die Stadt seit dem Jahr 1415 unterworfen haben.

Die Tagsatzungen der sieben katholischen Kantone sind in der Regel in Luzern, und so gilt das seit vielen Jahren, obwohl die anderen Kantone sich mehrmals dagegen ausgesprochen haben und darüber in die Haare geraten sind und verlangten, dass sie die Tagsatzungen von einem Ort zum anderen abhalten sollten; sie sind aber nie zum Erfolg gekommen, denn es gibt keinen für alle bequemeren Ort als Luzern und es gibt auch keinen Kanton, der die Ausgaben besser in den Griff bekommt, die anfallen, um die Boten zu entsenden. So wird der Neid einiger durch die vorteilhaften Interessen erstickt, und trotzdem geht der Streit im gleichen Stil weiter.

Die Tagsatzungen der fünf katholischen Kantone, die aus Luzern, Schwyz, Altdorf, Unterwalden und Zug bestehen und alle als ländliche Gebiete vereint sind, werden bei Bedarf durchaus auch an anderen, für alle bequem zugänglichen Orten durchgeführt. So versammeln sie sich auch in Gersau am Vierwaldstättersee, wohin jeder leicht zu Wasser kommen kann.

Die Ketzer, wenn sie sich untereinander besprechen wollen, sind es gewohnt, sich an einem anderen Ort namens Aarau im bernischen Bereich zu treffen, auch wenn man liest, dass sie, als sie über eine Einigung mit Luther sprachen, sich in Basel treffen wollten. Aber zu jener Zeit waren noch die Botschafter Straßburgs da.

Andere Tagsatzungen finden je nach der Bequemlichkeit der Kantone, und diejenigen, die von den Botschaftern der Fürstenhöfe einberufen werden, an den Orten statt, an denen sich die Botschafter treffen. In Solothurn sind häufig die von Frankreich und in Luzern die von Spanien und Savoyen. Denn dies reicht für sie aus, um den geeigneten Ort zu finden, an dem sie sich treffen.

Die Menschen, die zusammenkommen, um zu beraten, sind die Botschafter der Kantone, die dann in diesen Landtag eingreifen müssen, und diese werden in jedem Kanton vom Senat gewählt, und sie entsenden ihre Hauptoberhäupter der Republik, und weil sie die ganze Überlegenheit repräsentieren, gewährt man ihnen große Macht und erteilt ihnen schriftlich die Anweisungen, doch manchmal sind sie so frei, die Geschäfte selber fertigzustellen, manchmal müssen sie sich zunächst beraten und darüber berichten, manchmal sind sie begrenzt. Das ist je nach Bedeutung der zu behandelnden Punkte der Fall. Jeder Kanton entsendet zwei Vertreter, und so sind in der Generalversammlung von Baden die Dreizehn insgesamt mit sechsundzwanzig Senatoren vertreten, die über die Resolutionen abstimmen dürfen. Als Sekretär haben sie einen gesetzten Mann in Baden und bei den anderen Tagsatzungen außerhalb Badens nehmen sie jeweils einen aus dem Kanton, wo die Tagsatzung stattfindet, wie beispielsweise Luzern bei den Treffen der Katholiken oder Zürich bei den 
Versammlungen der Protestanten. Manchmal wieder, aber selten, liest man darüber, dass Tagsatzungen durchgeführt werden, bei denen Botschafter aller Eidgenossen, also auch der Bündner, Walliser, aus St. Gallen, Müllhausen und andere interveniert haben und alle hatten Stimmrecht, denn es ging um Frieden oder allgemeinen Krieg, der das Interesse aller berührt.

Die Zeit der Ordentlichen Tagsatzung von Baden findet um die Sonnenwende statt, nach dem Fest des Heiligen Johannes des Täufers, ${ }^{74}$ und diese Versammlung findet fraglos jedes Jahr statt und dauert fünf bis sechs Wochen oder mehr, je nach Anhäufung und Bedeutung der Geschäfte, die es gibt. Bei diesem Treffen sind alle Präfekten oder Gouverneure, die sie Vögte nennen, dazu verpflichtet, Rechenschaft abzulegen über die Orte, an denen sie gemeinsam Untertanen haben, die von den Zwölf, oder den Acht, oder den Sieben Orten geführt werden. Gleichzeitig, wenn der Landtag in Baden stattfindet, entsenden die Vertreter bequemlichkeitshalber Untertanen, die im italienischen Gebiet der Zwölf Orte sind und auf dieser Seite der Alpen liegen. Es sind zwölf Botschafter, je einer pro Kanton, um die Rechnungen der Präfekten von Lugano, Locarno, Mendrisio und des Maggiatals anzufordern, da sie auch das Recht auf Berufung haben, so wie die in Baden, und so können die Untertanen solche Berufungen an Baden selbst richten, das als ein großes und allgemeines Gericht gilt, wenn es ihnen so gefällt, auch wenn die nach Italien kommenden Botschafter das Gegenteil behaupten. Die anderen Tagsatzungen der Sieben Kantone und ähnliche wie beispielsweise die Außerordentlichen haben keine feste Zeit, weil sie den Bedürfnissen entsprechend geführt werden, und sie werden gemäß den Erfordernissen der Geschäfte einberufen. Die Einberufung der Allgemeinen und Gewöhnlichen Tagsatzung von Baden fällt den Zürchern zu, weil sie den ersten Platz unter allen Kantonen einnehmen, da Altdorf sie zur Übertragung des Primats veranlasst hat, der ihnen als Begründer der Freiheit zusteht.

Die Zürcher bezeichnen daher auf eigene Kosten brieflich und durch Postkurier allen anderen Kantonen den Tag und die Zeit, wann die Tagsatzung beginnen soll, und ob es darum geht, eine bestimmte Geschäftsordnung auszuhandeln. Bei einer außergewöhnlichen Tagsatzung informieren sie darüber, damit jeder Kanton die Kommissionen beschließen und mit ihren Botschaftern abstimmen kann. Und wenn es für einen anderen Kanton notwendig ist, sich für eine Ordentliche Tagsatzung zu bewerben, schreibt und bittet er die Zürcher, die dann wie gewohnt alle anderen dazu einladen. Die Tagsatzungen der Katholiken werden von Luzern durchgeführt, weil sie den ersten Platz unter ihnen einnimmt. Und wenn die Botschafter der Fürsten sie für bestimmte Geschäfte herbeirufen, dann können sie sie selbst einberufen, weil alles auf Kosten ih-

74 Das Hochfest der Geburt Johannes’ des Täufers (Johannistag) ist jeweils der 24. Juni. 
res eigenen Geldbeutels geschieht. Und wenn diese Botschafter in der Tagsatzung von Baden gehört werden wollen, müssen sie sich mit dem Zürcher Botschafter absprechen, der sie vorstellt und ihnen die Redemöglichkeit gewährt, und dies ist ihr Brauch, der in keiner Weise verändert werden kann.

Die üblichen Themen, die in dieser öffentlichen Tagsatzung von Baden von allen Kantonen behandelt werden, sind zahlreich, aber die wichtigsten entsprechen dem allgemeinen Staatsinteresse, das heißt all jene Punkte, die den Frieden, den Krieg, den Bund untereinander oder mit anderen ausländischen Fürstenhöfen betreffen. Bei den vorgeschlagenen Bündnissen hat jeder Kanton die Befugnis, zu widersprechen, wenn dies ihre alten Bündnisse schädigen würden, und jeder Kanton kann auch dem Bund frei beitreten oder auch nicht beitreten, je nachdem, was ihm zweckmäßiger erscheint. Es ist wahr, dass die acht ältesten Kantone mit denjenigen, die sie mögen, neue Bündnisse bilden können, sofern sie die alten nicht benachteiligen. Aber die anderen fünf Kantone können dies nicht ohne die Zustimmung und Bewilligung der anderen älteren Kantone tun, und so wurde es in diesem Jahr 1612 Basel und Schaffhausen verboten, mit dem Grafen von Baden ein Bündnis zu schließen, obwohl Zürich und Bern dies durften. Denn zu früheren Zeiten schafften es die Zürcher aus verschiedenen mächtigen politischen Gründen, sich mit König Franz I. von Frankreich zu vereinen, obwohl sich alle anderen Kantone erst im Jahr 1519 mit ihm verbündet hatten, und die entsprechenden Gründe sind weitgehend belegt durch den Siegel in seinem Buch über die Schweizer Republik.

Es obliegt dem Landtag selbst, gemeinsame und universelle Gesetze zu erlassen, die zum Wohle der gesamten Schweiz zu beachten sind. Denn wenn sich auch jeder Kanton mit seinen Gemeindegesetzen selbst frei regiert, sind die allgemeinen Beiträge zur Erhaltung der Eintracht und des öffentlichen Friedens mehr als notwendig, ohne die es Unterschiede in Sitten, Uneinigkeit, Krieg und andere unendliche Übel gäbe. Dazu gehören die Kriegsgesetze, die Art und Weise des Militärs sowie die Regel, Täter und Banditen gegenseitig nicht aufzunehmen, und nicht über Religion und dergleichen zu streiten. Aber dieser letzte Punkt berührt sie in besonderer Weise, denn das ist die letzte Vernichtung des katholischen Glaubens, weil die ketzerischen Füchse trotzdem alles versuchen, um die einfachen armen Seelen mit Gift zu infizieren, und die Unsrigen, die fahrlässiger sind - und ich weiß nicht, aus welcher Sünde heraus das geschieht oder gar wie Gott das erlauben kann -, sind damit zufrieden und äußern meistens keinen Groll, den es eigentlich geben sollte, und bei der Versammlung müsste doch darüber gesprochen werden, aber wenn es sich stattdessen herausstellt, dass ein Prälat oder ein guter Priester, der sich um die Gesundheit einer getäuschten Seele sorgt, dann kommen sofort die Minister des Teufels, die wie 
„unüberwindliche Löwen“75 sind, und schreien mit weit geöffneten Augen kontinuierlich, man möge diese Priester kreuzigen, und somit sehen Sie, dass in diesem Gebiet gilt: „prudentiones sunt filii iniquitatii““ ${ }^{76}$ da die „filii locii“"77 der Sorgfalt unterlegen sind.

Aber zurück zu den Geschäften, die den Ordentlichen Tagsatzungen entsprechen: da sage ich, dass da die Eidgenossen über Frieden verhandeln oder sich über die Entsendung der Botschafter oder ihrer Beglaubigungsschreiben beraten, oder um Hilfe bitten, oder um Krieg zu schüren, oder für ähnliche Dinge. Alles wird von den Botschaftern derjenigen, die sich in der Stadt Baden treffen, behandelt und konsultiert. Die Sorge, ob die gemeinsamen Untertanengebiete von den Regierungen gut regiert werden, liegt ebenfalls bei ihnen. In diesem Ort werden, wie bereits erwähnt, die Einlegung von Berufungen oder die schwerwiegendsten Fälle behandelt, und weil es unendlich viele Beteiligte gibt und sie sowie wenig wissen, genügt es ihnen, allgemeine Dinge festzustellen, die zum allgemeinen Interesse der Republik und der Kantone beitragen. All das, was auf dieser Tagsatzung behandelt wird, dient nur zu diesem Zweck und deshalb versammeln sie sich.

Es bleibt zu erklären, welche Ordnung bei solchen Treffen eingehalten wird. Einen Tag vor der Tagsatzung von Baden schicken die Botschafter der Zürcher einen Staatsdiener oder Beauftragten, der Unterpräfekt von Baden genannt wird, in alle Gasthäuser der Stadt, um zu wissen, welche Botschafter angekommen sind, und diese werden begrüßt. Man empfängt sie im öffentlichen Namen und lädt sie für den folgenden Tag zu einer festen Zeit am Morgen an dem üblichen Ort des Senats ein. Und wenn nicht alle am ersten Tag gekommen sind, so behandelt man jene Geschäfte, für die man nicht die Anwesenheit derer benötigt, die nicht anwesend sind. In dem ersten Treffen gibt es alle Zeremonien, Händeschütteln, Grüße und Hinweise darauf, wie es in dieser Nation üblich sei, dass sie älter und liberaler sei als jede andere auf der Welt. Und sie halten daran fest, dass auf diese Weise und durch das gemeinsame Essen oft das gegenseitige Wohlwollen bewahrt wird, welches für den Erhalt ihrer Republik so notwendig ist. Die Botschafter sitzen nach der Reihenfolge der Kantone, von Zürich, Bern, Altdorf usw. bis zum Ende. Der Zürcher beginnt alle im Namen der Vorgesetzten zu begrüßen und schlägt dann vor, was in der laufenden Tagsatzung behandelt werden soll. Und wenn man zur Diskussion über einen bestimmten Punkt kommt, spricht jeder der Reihe nach zur Anweisung über den Auftrag, so wie er es schriftlich vom Kanton erhalten hat, den dieser vertritt,

75 Im Original auf Latein: „tanquam leones“.

76 Auf Deutsch: „Umsicht ist das Kind der Unruhigen“.

77 Hiermit sind die Schweizer Katholiken gemeint. 
und man fährt mit so viel Ordnung fort, die Stimmen zu zählen, dass, während der eine spricht, die anderen ihn nicht unterbrechen dürfen. Und es gibt einen Richter, der das Amt hat, die Anordnung aller Botschafter in Frage zu stellen. Ein Botschafter darf sich dann nicht rühren, so lange der Richter ihn nicht erwähnt hat und ihm mitgeteilt hat, ob es ihm obliegt zu sprechen oder nicht. Und wenn alle ringsum ihre Dinge gesagt haben, können sie wiederum antworten, falls ihnen etwas mehr zusagt, und dann fragt der genannte Senatsrichter auch „Rothrichter“ [Ratsrichter, Anm. d. Übersetzers] genannt - sie, ob der eine oder andere in dieser Angelegenheit noch etwas zu sagen hat, und auf diese Weise kommen sehr oft mit Ordnung und Fleiß gute Dinge zusammen. Und die behandelten Themen sind Überlegungen wert, die für jeden ein weiser Rat sein sollen, und durch subtilen und einfühlsamen Einfallsreichtum kann sogar eine Sache um ein Vielfaches besser werden, wie es in diesem Fall wahr ist. Denn viele Staatsmänner sind für die Regierung besser geeignet als Subjekte mit mittelmäßigerem Einfallsreichtum. Die Stimmen aller Botschafter werden aufgeschrieben, wie sie vom Präfekten von Baden oder vom Sekretär dieses Amtes vorgetragen werden, und diese Stimmen werden nach Kantonen und nicht nach der Anzahl der Botschafter gezählt. Diejenigen, die dann noch besondere Gründe haben, bitten um eine Audienz bei den Herren von Zürich, die sich die Zeit nehmen und sie auf die Liste eintragen lassen, die dann vom Ordnungshüter, ohne Verwirrung zu stiften, aufgerufen werden soll. Alle, die bei den Tagsatzungen sprechen, auch wenn sie Senatoren sind, und auch wenn der eine ein Botschafter war, müssen ohne Hut stehen, solange der Richter nicht gesprochen hat, sonst wird es nicht angenommen. So viel Respekt wird gezollt, was zu Überlegenheit führt. Und beendet wird das Ganze, wenn sie vorschlagen, sich nach draußen zurückzuziehen. So können diese Herren konsultieren und beraten. Die Methode, die Streitigkeiten so zu beenden, mit Fairness und Natürlichkeit, aber ohne dass sie durch einige ausgehöhlt werden könnten, und dennoch wenige Treffen, die sie miteinander halten, führen dazu, dass jede Auseinandersetzung, ohne Schaden und Schadensrichter geführt wird.

Sobald dann die öffentlichen und privaten Geschäfte beendet sind, werden sie vom Sekretär mit dem Siegel des Präfekten von Baden - der „Abschied“ genannt wird - schriftlich übernommen, das heißt die Verabschiedung der Geschäftsordnungen, die als Zusammenfassung der Beschlüsse in allen Punkten aufgelistet wurden, und dies wird getan, damit man es ihren Vorgesetzten zeigen kann, und es ist wahr, dass ernste Dinge beim ersten Tag der Tagsatzung nie gelöst werden, denn in dieser Nation wird sehr lange beraten, und das dauert, da die Überlegungen von vielen Gehirnen abhängen. So heißt es im Sprichwort, wenn ein Geschäft nie zu Ende geht: Man soll es an die Tagsatzung der 
Schweizer zurückgegeben oder das Geschäft von denselben in Verabschiedung annehmen lassen. Und das ist, was ich über die Tagsatzung sagen wollte.

Über die Bergpässe, die sich in der Nuntiatur von Helvetien befinden

Der Lauf der Alpen, der durch ansässige und natürliche Weise Italien von Frankreich und Deutschland trennt, ist so lang, dass es, da es sich um mehr als zweihundertvierzig italienische Meilen oder dreitausend Stadien handelt, notwendig ist, viele Pässe zu überqueren, um den Handel mit ausländischen Nationen zu unterhalten. Denn durch diesen Handel bauten die Römer und Italiener ihre Herrschaft im Norden aus, und brachten dort die Zivilisation nach und nach und machten die enormen Gebiete Deutschlands bewohnbar und nahmen sie aus der tiefen Barbarei heraus, in der sie sich befanden.

Und dass die besagten Alpen aus dem Lateinischen „ab Albedine“ stammen, weil sie immer voller Schnee sind, oder aus dem Französischen, in dem sie hohe Berge bedeuten, oder aus dem Deutschen, weil Alp das Gleiche bedeutet wie Berg aus Sahne. Das ist uns alles egal, wir überlassen diese Debatten den Geographen, die sich damit befassen.

Dass die Menschen in der Antike auf dem Abschnitt dieser Alpen fast die gleichen Pässe hatten, wie wir sie in unserer Zeit kennen, wird von mehreren Autoren bewiesen, und zwar lagen „die Alpen am Meer, also die ligurischen Alpen, durch die Pässe des Cottas, des Graias, des Perinos, durch die hohen Alpen der lepontischen, rätischen und julischen Alpen“, ${ }^{78}$ wie dies Mercator in seinem Atlas minor in der Tafel zu Italien zeigt.

Welchen dieser Passübergänge Cäsar überquerte, um die Gallier zu erobern, und welchen Hannibal benützte, um nach Italien einzufallen, darüber gibt es eine große Debatte unter den Autoren, die für uns von geringer Bedeutung ist, aber sie wird von Tschudi im 34. Kapitel des Alpenvolkes behandelt, und von Br. Leandro Alberti ${ }^{79}$ in seinem Werk über Italien, das sich mit der Lombardei jenseits des Po-Flusses beschäftigt.

In Bezug auf unsere Rede und dem Wunsch, nur auf einige wenige Bereiche einzugehen, die für die Nuntiatur in Helvetien von Bedeutung sind, soll nicht über anderes gesprochen werden, was nichts mit unserer Relation zu tun hat.

Es gibt drei Pässe in dieser Nuntiatur, um nach Deutschland und andere Länder jenseits der Berge zu gelangen. Der erste Übergang liegt im Wallis. Der zweite ist jener des St. Gotthards und der dritte ist Graubünden; aber jeder von

78 Im Original auf Latein: „Alpes maritimas, sec ligusticas, per Cottas, per Graias, Perinos, per Alpes summas lepontias, Rheticas et Julias.“

79 Der italienische Dominikaner und Historiker lebte von 1479 bis 1552. Der Ruhm von Alberti beruht hauptsächlich auf seiner Descrizione d'Italia (Bologna 1550), einem Buch, in dem viele wertvolle topographische und archäologische Beobachtungen stehen. 
ihnen hat verschiedene Wege, die zu verschiedenen Orten führen, und sie sind so vielfältig, dass man sich erlauben kann, fast getrennt voneinander zu reisen.

Am einfachsten und am meisten durchquert wird Graubünden, der sich in drei Bereiche aufteilen lässt. Der erste Teil geht durch das Veltlin, indem man Bormio verlässt und auf dem sehr hohen Monte di Braulio geht, wo man zur „Lega Rhetica“ kommt, und das führt durch einen anderen Weg nach Österreich, und zur Donau, auf der sich viele Mailänder Händler herumtreiben, um ihre Waren in jene Gebiete zu schicken. Der zweite Teil des Bündnerpasses ist nicht weniger beliebt als der erste und führt durch das Tal von Chiavenna, und der Aufstieg nach Splügen führt in die Stadt Chur, Hauptort Graubündens, und dann zum Bodensee ins Schwabenland. Für diese Durchfahrt gibt es eine übliche Fahrt, die von Lindau bis nach Mailand reicht, und es gibt auch herkömmliche Kuriere, die den Händlern zur Verfügung stehen, und die problemlos von Nürnberg, Frankfurt, Augsburg und anderen Großstädten Deutschlands verkehren. Aber dieser Pass ist so bedeutend, dass Graubünden es mit vier Soldaten gegen jede mächtige Armee aufnehmen könnte, weil sich der Durchgang zwischen diesen hohen Bergen an einem Ort verengt, an dem es einige Schleusen gibt, die mit wenig Aufwand geschlossen werden können, und man kann sie nicht angreifen, da sie von Natur aus so gut befestigt ist. Der dritte Ort des Passes in Graubünden ist derjenige, der durch die Landschaft von Bellinzona und dann durch das Tal Mesolcina führt. Der Weg führt zum zerklüfteten Berg San Bernardino und endet in Splügen, wo er sich mit dem anderen oben genannten Pass verbindet, der dann nach Chur und somit in den Rest Deutschlands führt. Aber das kann man nicht immer benützen, da der Weg im Winter durch den Schnee nicht zugänglich ist und undurchdringlich wird.

Von diesen Teilhabern der Eidgenossenschaft könnte der König von Spanien über den Bündner Pass bequem Hilfe für die Anwerbung deutscher Soldaten und Landsknechten in Anspruch nehmen, wenn er mit ihnen ein Bündnis halten würde, und von hier aus würden sie bald in den Staat Mailand hinabsteigen, den sie nicht durch die Schweiz durchqueren, denn die Bündner befinden sich nahe an Österreich und Schwaben, also den Erbländern des Hauses von Österreich. Die Franzosen haben zu diesem Zweck ein Bündnis mit Graubünden hergestellt, um die Bequemlichkeit zu haben, nach Italien zu kommen, denn von dort aus können sie sich sofort in den Staat Mailand begeben oder einen guten Unterschlupf finden und sich auf die Venezianer freuen, die diese Krone unterstützen.

Die Venezianer wollen als Nachbarn der Bündner diese Bequemlichkeit des Passes selbst genießen, und um dies zu erlangen, sind sie nicht nur bereit, diesen Alpenvölkern zu helfen, sondern sie sind darum bemüht, mit der Hilfe der Franzosen zu rechnen, mit denen sie einen Bund halten, auf den sie in diesem 
Jahr 1612 mit Graubünden verzichtet haben, weil sie sich gegen die Republik Venedig ausgesprochen haben, wie an anderer Stelle bereits gesagt wurde.

Der zweite Hauptpass, der sich in der Nuntiatur befindet, ist der St. Gotthard, der seinen Namen von den Lepontinischen Alpen erhielt, die wegen ihrer immensen Höhe noch immer „summa Alpes“ genannt werden. Dies ist ein sehr bequemer Pass, und er ist sicherer im Winter als im Frühling, denn wenn der Schnee friert, ist es sicherer zu reisen, aber wenn die Sonne anfängt zu strahlen, dann verflüssigt sich alles und das ist eine große Gefahr für Lawinen, die an diesen Orten so genannt werden, die alles durch den Schnee ruinieren und oft auch viele Menschen unter sich begraben. Denn damit haben sie keine Zeit, sich $\mathrm{zu}$ befreien und bleiben unglücklich begraben.

Kaufleute benützen viel diesen Weg, und sie bringen die Waren von der einen in die andere Provinz. Aber die Soldaten, die von Deutschland nach Italien oder von Italien in die andere Richtung kommen und gehen, benützen diesen Weg, um in die Niederlande den Dienst an den katholischen Königen von Spanien anzugehen. Somit benützen heute alle diesen Weg, und das ist das Ergebnis der Eidgenossenschaft und der vielen Einnahmen, die an die Schweizer Nation gezahlt werden.

Dieser Pass steht in der Macht des Kantons Altdorf, der sein Besitzer ist, aber es ist besser, diesen Ort wachsam zu verfolgen, um ihn zu erhalten, denn dieses Gebirge kann einerseits von den Wallisern und andererseits von den Bündnern leicht besetzt werden, wenn man nicht wachsam ist, und Graubünden hat die Altdorfer bereits mehrmals bedroht, und so einige Forderungen des Abtes von Disentis geweckt, der sagt, er habe die Zuständigkeit in der Nähe von Ursern, ${ }^{80}$ wo der Pass sehr bedeutend ist, und deshalb verlangt er, dass ein Urteilsspruch gegen diesen Kanton gesprochen wird.

Der Ort ist so gut bewacht wie die anderen, doch er wird geschätzt, weil er uneinnehmbar ist, aber weil man damit in das Land Luzern und in die anderen katholischen Kantone kommt, reicht es dennoch nicht aus, nur mit Altdorf verbündet zu sein, man muss schon mit anderen Katholiken verbündet sein, wie der König von Spanien, der sich nicht um die ketzerischen Kantone kümmert. Die Schweiz ist für die katholischen Fürstenhöfe wegen ihrer Vielfalt der Religion abscheulich, und auch weil man sie braucht, um nach Deutschland zu gelangen.

Der dritte und letzte Pass dieser Nuntiatur ist der im Wallis, durch den zwei Straßen führen, eine aus dem Ossola-Tal des Staates Mailand und die andere aus dem Augusta-Tal oder aus Aosta im Staat Savoyen, und beide Pässe führen

80 Vgl. Stichwort „Ursern“, in: https://hls-dhs-dss.ch/de/articles/007467/2014-01-14/ (31. Dezember 2020). 
durch den Wallis im Land der Berner und dann nach Freiburg und auch an den Genfer See, auch Alemannischer See genannt.

Der Valle d'Osola geht auf diese Weise, und zwar vom Staat Mailand kommend, betritt man das genannte Tal bis nach Domo, dann besteigt man den Berg Simplon und kommt in der Mäderalp an, und steigt hinunter nach Brig, und von dort erreicht man schließlich den ganzen Wallis bis nach St. Maurice, und nach der Enge dieses Passes, wenn man es vom Wallis aus betrachtet, kommt man in das Land der Schweizer und zwar im Gebiet der Berner, und dieser Pass wird auch von vielen für den Warentransport benützt und ist $z u$ jeder Jahreszeit bequem, auch wenn der Winter sehr hart ist, und das kann es dem König von Frankreich trotzdem wert sein, als er den Mut hatte, von dort nach Italien abzusteigen, denn die Berner und die Walliser sind mit dieser Krone verbündet, aber nicht mit der Krone von Spanien.

Die andere Reise des Tals von Ossola oder Augusta ist für den Herzog von Savoyen so bequem, weil sie eben durch seinen Staat führt, und von dort aus kann man direkt nach Deutschland und Helvetien, weil man zunächst, an Ivrea vorbei, nach Châtillon gelangt und dann im Aosta-Tal am Berg St. Bernhard vorbeikommt, der großartig ist, der den Wallisern gehört, und dann Martigny im Unterwallis erreicht. Von dort geht man nach St. Maurice und dann nach Helvetien und $\mathrm{zu}$ anderen Orten, wohin man gehen will.

All dies sind die Pässe, die in den Alpen zu finden sind und die in der Nuntiatur Helvetiens liegen, $\mathrm{zu}$ denen diejenigen, die besseres und minuziöseres Wissen haben wollen, eine Reise machen sollten und eine Zeichnung davon anfertigen lassen müssen, wie es von anderen Fürsten getan wurde, denn wenn man sie so trocken beschreibt, wird es immer etwas dunkel bleiben.

\section{Spiritueller Status der Nuntiatur der Schweizer ${ }^{81}$}

Da der Hauptzweck des Apostolischen Stuhls darin besteht, die Nuntien zur Verwirklichung und Vermehrung der katholischen Religion zu entsenden, und dies nur mit Hilfe von Bischöfen, Prälaten, Priestern und Ordensleuten geschehen kann, erschien es mir angebracht, ein ganz eigenes Kapitel dem geistlichen Zustand dieser Nuntiatur zu widmen. Die fünf Diözesen mit ihren gesamten

81 Dieser Teil ist auch übersetzt worden in: Geschichte der Einführung der Nuntiatur in der Schweiz von Christian Wilhelm von Glück, Ludwig Snell, ab S. 100: https://books.google.it/ books?id=_uMAAAAAcAAJ\&pg=PA114\&lpg=PA114\&dq=fribourg+sceva\&source=bl\&ots=2gdsmo18Nv\&sig=ACfU3U14uVsWgCuFZwwv9m2Qi5sXHqNOJQ\&hl=de\&sa=X\&ved=2ahUKEwjs04e q6YnkAhUhNOwKHch-Dq4Q6AEwEHoECAcQAQ\#v=onepage\&q=fribourg\%20sceva\&f=false (31. Dezember 2020). 
oben genannten Diözesen, das heißt Konstanz, Sitten, Lausanne, Chur und Basel, werden unter diesem Blickwinkel zunächst beschrieben.

\section{Bistum Konstanz}

Konstanz hat den Beinamen „Latiscino“, weil einige Kosmographen geschrieben haben, dass dieses Bistum nicht kleiner ist als das ganze Königreich Neapel, aber nur, wenn man jene Teile miteinbezieht, die zu diesem Zeitpunkt den ketzerischen und protestantischen Fürsten unterworfen sind und die einen großen Teil des Bistums ausmachen. Hinzu kommt das ganze Herzogtum Württemberg sowie Gebiete des Grafen von Baden und der Großteil Helvetiens, was im Vergleich zu den Kantonen Zürich, Bern, Schaffhausen und anderen Orten nicht zu vernachlässigen ist, wie Botero ${ }^{82}$ im ersten Buch seiner Berichte schreibt. Die Diözese wurde unter Kaiser Sigismund gegründet, als das Konzil von Konstanz stattfand, und in dem Bistum gab es eintausendsiebenhundertsiebzig Pfarreien, 350 Klöster und 17000 Priester, und ich las in Büchern und Manuskripten, dass diese Zahl im Jahr 1429 auf 17060 Geistliche gestiegen war, wie der Bischof dieser Stadt, Otto von Rottelem, ${ }^{83}$ beschrieben hat und wie es von Botero ebenfalls berichtet wurde.

Klöster mit vielen Nonnen gibt es nach dem Wissensstand über die verschiedenen Religionen, die mir in einer Notiz mitgegeben wurden, um die neunzig. Es gibt viele Abteien, wie wir noch sehen werden, und niedrigere Klöster mit unzähligen Bettelmönchen, und dann gibt es auch noch viele Klosterkollegien.

Alle Bischöfe von Konstanz sind Fürsten des Reiches und gehören zum Kreis von Konstanz, in dem sie den ersten Platz des Kirchenstaates einnehmen. Sie besitzen zahlreiche große Ländereien, die ihnen weltlich und kirchlich unterstellt sind, wie es in Deutschland üblich ist. Der Bischof wohnt nicht in der Stadt Konstanz, weil die Stadt frei ist, sondern in der kleinen, mit einem von den Bischöfen vergrößerten Ehrenpalast geschmückten Stadt Meersburg am Bodensee, der mindestens fünfzehn italienische Meilen breit ist. Und es gibt noch weitere Besonderheiten, die von dem Kardinal Hohenems und den Österrei-

82 Giovanni Botero (1544-1617) war ein Priester und Diplomat und Sekretär von Erzbischof Karl Borromäus (1582). 1579 wurde Botero entlassen, als er in einer Predigt die weltliche Macht des Papstes kritisiert hatte. Gegen Niccolò Machiavelli trat Botero für einen Staat ein, der auf christlichen Prinzipien aufgebaut sein sollte. Vgl. Justus Nipperdey: Die Erfindung der Bevölkerungspolitik. Staat, politische Theorie und Population in der Frühen Neuzeit, Göttingen 2012. 83 Gemeint ist Otto III. von Hachberg (1388 auf der Burg Rötteln, daraus „italianisiert“ der Nuntius „Rottelem“ -1451). Dieser Bischof war Gastgeber des Konstanzer Konzils von 14141418. Vgl. Andreas Bihrer: Eine Feier ohne den Hausherrn? 
chern, die dort Bischöfe waren, eingerichtet wurden und die immer noch verantwortlich für die Insel Reichenau sind, oder, wie man den Ort auch nannte „Augia Maggiore“, oder anders gesagt [verderbt, Anm. des Übersetzers] ... und sie besitzen den Leichnam des heiligen Evangelisten Markus, der nicht nur dort, wie man sagt, gezeigt wird. Die Insel ist schön, und ihr Durchmesser beträgt ungefähr drei italienische Meilen. Dort leben Mönchen des heiligen Benedikt, die noch das Kloster führen, aber die Abtei hat sich mit dem Bistum vereinigt. Das bleibt ewig im Besitz der Bischöfe von Konstanz, die dafür dem Reich 40. [tausend?] Gulden pro Jahr übertragen. Und der Bischof ist Gönner einiger Präfekturen in der Schweiz, aber nur in weltlichen Angelegenheiten wie beispielsweise für Kaiserstuhl, der ehrenwerten kleinen Ortschaft, sowie Reichen$\mathrm{au}$, Arbon und andere Orte, aber verpflichtet ist, Schweizer Beamte einzusetzen, aus Angst vor einem Krieg mit anderen Menschen, die sich sonst in diesem Gebiet bewaffnen könnten. Die Einnahmen des Bistums Konstanz betragen um die 30 tausend Gulden, auch wenn das die Bischöfe und Prälaten Deutschlands niemals zulassen wollen, dass diese Einnahmen bekanntgegeben werden, und immer versuchen sie, dies zu verbergen als das größte Geheimnis, das sie in dieser Welt haben, und als sie einmal gezwungen waren, mir eine Liste ihres Jahreseinkommens zu geben, hat man mir nur 16 tausend und siebenhundertsiebenundsiebzig Gulden dieser Währung angegeben, was in etwa zwölftausend Scudi des päpstlichen Geldes entspricht. Der heutige Bischof Jakob Fugger ${ }^{84}$ zeigt die großen Schulden, die der Kardinal von Österreich ${ }^{85}$ ihnen hinterlassen hat, als er starb, aber sie könnten leicht beglichen werden, wenn man wüsste, wieviel das Einkommen beträgt, und so könnten die Ökonomen besser damit umgehen, ohne auf die Deutschen zu warten. Und weil dieser Bischof bei seiner Wahl den Kanonikern die Absicht kundtat, sie in irgendeiner Weise wirtschaftlich befreien zu wollen, hat er mich gebeten, das Bistum für einige Jahren um mehr als sechzig tausend Gulden zu entlasten, was keine geringe Summe ist.

In Konstanz residieren der Offizial und der Steuereintreiber am Sitz der bischöflichen Kurie, vor der alle Zivil- und Strafsachen behandelt werden, und diese beiden bilden zusammen mit zwei weiteren Kirchendoktoren der Stadt, die als kuriale Anwälte bezeichnet werden, das Konsistorium, das von ihnen so

84 Jakob Fugger, auch Johann Jakob Fugger (geboren am 18. Oktober 1567 in Meersburg (?); gestorben am14. Januar 1626 in Meersburg oder Konstanz), war Fürstbischof von Konstanz von 1604 bis 1626 .

85 Andreas von Österreich (geboren am 15. Juni 1558 auf Burg Bresnitz, Březnice, Böhmen; gestorben am 12. November 1600 in Rom) war Kardinal und Bischof von Konstanz und Brixen. Seine Eltern waren der Habsburger Erzherzog Ferdinand II., Landesfürst von Tirol, und dessen Frau, die Augsburger Patriziertochter Philippine Welser. Er war von 1587 bis 1600 Abt des Klosters Murbach. 
genannt wird, ich weiß nicht, wie bescheiden die Kongregation ist, in der sie ihre Fälle bestreiten. Diese Diener reichen bei weitem nicht aus, da die Diözese so ausgedehnt ist und sie häufig auch Visitationen durchführen und sich auch, wie es in Italien der Fall ist, um die gute Pflege der Armen kümmern müssen. Ich habe dem Bischof mehrmals vorgeschlagen, dass er zusätzlich zu dem besagten Offizial noch einen Geistlichen haben sollte, der als Visitator die Diözese besucht, sich um die Schulden kümmert, doch wegen des Mangels an ehrenhaften Männern, so sagt er, sei es in Deutschland nicht möglich, besonders wegen fehlender kirchlicher Kanonisten, die ja Geistliche sein sollten. ${ }^{86}$

Er hat einen Weihbischof, der die bischöflichen Funktionen wahrnimmt, und er hätte die Möglichkeit, die Diözese zu besuchen, aber tut dies nicht, zumindest nicht, wie er sollte, und als man es ihm in Erinnerung rief, zeigte er nur in Worten die Bereitschaft dazu. Aber in Wirklichkeit hat er sich ... [verderbt] mit Priestern abgesprochen, und hat sogar Zeugenaussagen beschafft, die besagten, dass die Pfarreien gut geführt würden und dass [verderbt, Anm. des Übersetzers] weitere Visitationen unnötig seien. Dies sind alles Entschuldigungen, um mein Vorhaben zu untergraben [verderbt, Anm. des Übersetzers], und um die Verantwortung von seinen Schultern loszuwerden. Und da der Bischof auch darauf hinweist, dass sein Bistum groß und er arm und verschuldet sei, so könne er deshalb nicht die Kosten einer Visitation übernehmen, doch trotzdem bleibt die Entschuldigung anmaßend, weil ich ihn im Namen Unseres Herrn gnädig darauf hingewiesen habe, dass mit den Visitationen die Strafen der Verurteilten formell umgewandelt werden könnten, um durch die Einnahmen der Strafgebühren die Visitationen zu finanzieren, was sicherlich eine nennenswerte Hilfe wäre. Darüber hinaus habe ich ihm entsprechende Breven geschickt, damit er mit größerer Achtung und Autorität diese Aufgaben erfüllen konnte, um einmal alle Klöster der Nonnen des heiligen Franziskus und des heiligen Dominikus zu besuchen, ${ }^{87}$ auch wenn es noch gar nicht so viele in seiner Diözese gibt. Aber selbst von diesem Gefallen wollte er nichts wissen.

Der Bischof von Konstanz hat viele weltliche Amtsträger um sich und hat häufiger mit ihnen als mit den Kirchenräten zu tun, wobei die Prälaten aus Deutschland eher weltliche als geistliche Fürsten sind, wenn man bedenkt,

$86 \mathrm{Ab}$ diesem Abschnitt beginnt eine Auflistung von konkreten Kritikpunkten am Bischof von Konstanz, Bischof Mark Sittich Kardinal von Hohenems (1561-1589).

87 Die Franziskaner und Dominikaner waren nördlich der Alpen noch nicht zahlreich vertreten. Es kam erst mit Giovanni della Torre (1595-1606), Fabrizio Verallo (1606-1608) und Ranuccio Scotti (1630-1639) zur Gründung neuer Klöster und Ordensgemeinschaften. Vgl. Michael F. Feldkamp: Die europäischen Nuntiaturen in der frühen Neuzeit unter besonderer Berücksichtigung der Luzerner Nuntiatur, in: Zeitschrift für schweizerische Kirchengeschichte, Band 88, 1994, S. 43. 
dass sie Fürsten und gleichzeitig auch Bischöfe sind, und dass sie meist Privatmänner ${ }^{88}$ sind, wenn sie nicht die bischöfliche Würde angenommen hätten. Der weltliche Rat besteht daher aus einem Kanzler, der den ersten Platz einnimmt, und aus mindestens zwei oder drei anderen Beratern, alle Doktoren der Gesetze, die eine Ehefrau haben und die nicht folgen, wenn man sie nicht mit hohen Löhnen und Provisionen überschüttet. Der Bischof benutzt den Kanzler als Oberhaupt des Staatsrates und hat es zu einem festen Brauch gemacht, dass dieser den Fürstenhöfen Briefe über ernste Dinge schreiben darf, und entsendet ihn zu den anderen Ratsmitgliedern der kaiserlichen Kreise, zu den Landtagen und anderen Botschaftstreffen. Von diesen wissen wir von vielen wichtigen Anliegen, die von der kaiserlichen Kammer an den Bischof von Konstanz delegiert wurden, wie es bei allen Fürsten des Reiches der Fall ist, und zusammenfassend lässt sich sagen, dass alle Diener des Bischofs in weltlichen Verhandlungen mit solcher Sorge und solchen Kosten miteinbezogen sind, dass, wenn wir die geistliche Betreuung der Seelen mit einer solchen Sorge ausstatten würden, die Dinge viel glücklicher laufen würden, als sie es tun. Der Bischof kauft viel für diese Botschaft beim Reich ein, schickt Provisionen, die er zahlt, und entrichtet Spenden, die an diese und andere Amtsträger geleistet werden müssen, und trägt jedes Jahr mehr als zweihundertvierundvierzig Gulden zum schwäbischen Kreis bei, denn als Fürst trägt er für die Erhaltung der Kanoniker von Konstanz im Reich bei, die 28 Mitglieder zählen sollten, hat aber nicht mehr als achtzehn Mitglieder und einige wenige andere, die nicht in Deutschland aufgewachsen sind.

Die Zusammenstellung dieser Mitglieder ist nicht Aufgabe des Bischofs, sondern des Kapitels während der bischöflichen Versammlungsmonate, und wenn es in ihrer Verantwortung liegt, dann wählen sie nur Adlige, nicht Doktoren des Rechts, weil der Adel anders ist als die Rechtsgelehrten, denn sie sind der Ansicht, dass dieser vom Grad des Blutes klar abweicht. Wenn Unser Herr in den besagten Monaten keine ausgebildeten Kanoniker ernennt, dann würden die Adligen, die jetzt schon die Mehrheit der Stimmen in diesem Kapitel haben, die absolute Macht an sich reißen und würden sich nicht unter den anderen einreihen wollen, wie es immer der Fall ist, doch die besten Untertanen, die weiterhin für das Gute einstehen, sind meist Rechtsgelehrte, die so nötig wären. Deshalb sollte der Apostolische Stuhl bei den Versammlungen mit offenen Augen vorgehen und der Nuntius soll sie eindringlich warnen, wenn sie versuchen, diesbezüglich Neuerungen einzuführen, denn es ist nicht gut, dass der gewöhnliche Adel so mächtig ist. Man soll ihnen stattdessen so viel Beachtung

$\overline{88}$ Die auf die eigenen Interessen bedacht sind. 
schenken, wie nötig, wie es in einigen Diözesen der Fall ist, wo die Kanoniker Grafen und Barone sein müssen, wie in Köln, Straßburg und Bamberg.

Es gibt die Würde des Propstes, der im Konstanzer Dom lebt und einen guten Ruf genießt, da er jährlich um 8 tausend Scudi Einträge erhält, und darüber hinaus viele Vorteile und Befugnisse über verschiedene Orte besitzt. Es gibt dann noch die Würde des Dekans und anderer, aber sie sind nicht so sehr von Bedeutung, und im Allgemeinen sind alle Kanoniker aus Deutschland einfache Adlige und nicht betitelt. Meist sind es sogar arme Menschen und von gewöhnlichem Stand. Auch wenn sie behaupten, dass sie dem katholischen Glauben viel Nutzen bringen können und dass sie eine Unterstützung für Deutschland darstellen, scheint mir dies alles nur Eitelkeit zu sein, denn sie können es nicht, machen es auch gar nicht, sondern sie konsumieren das Einkommen, indem sie luxuriös leben, und lassen auch an vielen Orten die Gewohnheit beiseite, das Kleid des Klerus zu tragen. ${ }^{89}$

Der Bischof von Konstanz hat keine Ansammlung von Privilegien, denn einfache Kirchenmänner findet man in großer Zahl in Deutschland, doch die Pfarrer besitzen alle Macht und gehören entweder Privatpersonen oder Adligen, Republiken und freien Städten an, ebenso gilt dies für die Kanoniker. Damit er diejenigen, die ihm dienen, einzig durch sein eigenes Einkommen entlohnen kann, ist es kein Wunder, dass ein paar tapfere Kirchenmänner nach [verderbt] kommen, wenn es ihm an guten Untertanen mangelt.

In Helvetien weiß ich nicht, ob durch Privileg oder alten Brauch alle Pfarreien und [nicht leserlich] von den gleichen Herren der Republiken versorgt werden oder, wie in einigen Kantonen wie Schwyz und Appenzell, bis hin zu den Pfarrern von den Landsleuten bedroht und vertrieben werden können, wenn sie mit einem Priester unzufrieden sind, was sie auch tatsächlich tun. Daher ist der arme Priester manchmal gezwungen, Unwürdigkeiten zu begehen, um geliebt und bestätigt zu werden, und aus dieser Quelle geht hervor, dass es in diesen Gebieten keine guten Untertanen gibt, die einem dienen wollen, aber der Mangel ist zwar bedauerlich, jedoch nicht heilbar.

Bei dieser Gelegenheit ist über dieses Thema zu sagen, dass es das Gerücht gibt, in Helvetien gebe es Simonie, und das ist wahrscheinlich wegen der Gier der weltlichen Herrscher, die keinen ordentlichen Priester bevorzugen, ohne an ihre Interessen zu denken.

Im ersten Jahr haben die Kanoniker weder Wohnsitz, noch erhalten sie Einkünfte von den Einnahmen, aber das genannte Jahr dient vor allen Dingen dem Aufbau und anderen Bedürfnissen der Kirche.

89 In diesem Abschnitt wird vor allem auf Deutschland eingegangen. Die Schweizer kommen nicht vor. 
Derselbe Bischof von Konstanz hegte eine uralte und schmerzliche Feindschaft mit dem Herrn Grafen Hohenems, als dieser für diese Kathedrale verantwortlich war, und alle Kanoniker und Kapitelmitglieder hielten sich mehr an diesen Herrn als an den Bischof wegen eines Streits eines Kanonikers, der durch das Kapitel ernannt wurde und ein unfähiger Adliger war, doch da es sich um ein priesterliches Amt handelte, und der Bischof wandte sich an Rom, was aber zu einem sehr bösartigen und hartnäckigen Streit führte. Diese Auseinandersetzung war so weit gewachsen, dass es jeden Tag öffentliche Skandale gab, und fast ganz Deutschland sprach darüber, und was noch schlimmer ist, nachdem eine Einigung von mehreren Prälaten und anderen Nuntien versucht worden war, konnte nur ein Schlussstrich gezogen werden, dass die Einigung für alle unmöglich war. Nachdem auch ich mich entschlossen hatte, diesen Gordischen Knoten zu lösen, ging ich persönlich nach Konstanz, und nachdem ich an einem anderen Ort untergebracht war, um meine Neutralität zu zeigen, bildete ich nach vielen Wochen mit der göttlichen Gunst ein Kapitel und schlug dem Bischof und den Kanonikern vor, sich öffentlich mit allgemeinem Applaus zu entschuldigen, und zwar nicht nur bei der Stadt und der Diözese, sondern in allen Teilen der Nuntiatur, was dann die Rückkehr der Eintracht hervorbrachte, mir andere ihre Wertschätzung zeigten, und dies geht zur Zufriedenheit beider Seiten weiter.

Einige andere Differenzen wurden von mir kurz zuvor festgestellt, die derselbe Bischof mit dem Senat von Konstanz wegen einiger Einkünfte hatte, weil der genannte Senat ein benediktinisches Schottenkloster besaß, das zum Zeitpunkt der Ketzerei verlassen wurde, und weil ich die Vereinbarung mit der Bewilligung Unseres Herrn getroffen hatte, bestätigte ich sie erneut, und ich hätte auch auf die völlige Ruhe des Bischofs einwirken sollen, der einen alten Streit mit dem Abt von St. Gallen hatte, wenn es keine anderen Schwierigkeiten gegeben hätte, die wir an anderer Stelle behandeln werden.

\section{Bistum Sitten}

Das zweite Bistum ist jenes von Sitten von der Stadt Sion, Hauptort und Metropole im Wallis, einem Tal zwischen den Alpen, das bei St. Gotthard beginnt und unweit des Genfer Sees endet und von einem Ende zum anderen an der Rhone vorbeiführt, die ihn teilt. Diese Völker wurden früher Seduni genannt, aber heute noch gehören dazu die „Viberi“ und die „Veragri“.

Der Bischof führt den Titel des Grafen und Präfekten des gesamten Wallis, weil er sein Herrscher ist, da Karl der Große es dem heiligen Theodor, ${ }^{90}$ dem

90 Vgl. Kirsten Groß-Albenhausen: Theodor, S. 881-884. 
Bischof von Sitten, und seinen Nachfolgern geschenkt hat, und die Schenkung wurde mehrmals bestätigt, und zuletzt auch von Karl V. zugunsten von Kardinal Matthäus Schiner, ${ }^{91}$ der Bischof derselben Kirche und vor allem ein Berater dieses Kaisers war. Aber heute, aufgrund schlechter Regierung und überwältigender Fahrlässigkeit, ist das Volk frei geworden, und es wird wie eine Republik regiert, dem Bistum bleibt nur der Titel.

Diese Diözese war bis vor wenigen Jahren ganz katholisch, aber heute gibt es im Unterwallis viele Ketzer, und diese Plage wurde von den benachbarten Bernern gebracht, die nichts anderes anstreben, als überall ihre Pest zu verbreiten. Darüber hinaus hat die Armut in dieser Provinz dazu geführt, dass es weniger Priester und Ordensleute [unklare Worte] für die Verbreitung des Guten gib, da sie nicht in diese Gegend gehen wollen, unter fast wilden Menschen, die misstrauisch und stolz sind, um dann an Hunger und Entmutigung zu sterben, und indem auch noch die geringe Zahl der regulären Ordensleute hinzu kommt, die sich im Wallis befinden. Es gibt nichts anderes in so viel Raum im Land, als ein schlecht geführtes Kloster der Karmeliter. Es wundert nicht, dass dieser allgemeine Mangel an Dienern im Laufe der Zeit leicht zu untergraben war, und viele unwissende Menschen wurde mit Leichtigkeit in der Lehre getäuscht, so dass die eigentliche Ursache für den Ruin dieser Provinz die Armut ist. Es liegt an der Armut, am Mangel an Priestern und an der mangelnden Entschlossenheit der Ordensleute, die wie gute Bauern vorgehen sollten, um die besagten Weinberge des Herrn von Dornen zu reinigen.

Um diese Probleme zu lösen, wurde im Jahr 1533, als die Ketzerei anfing, Beute zu machen, ein ausgezeichnetes Gegenmittel gefunden, und zwar durch einen gegenseitigen Bund, der in Freiburg zwischen den sieben katholischen Kantonen gebildet wurde. Der Sittener Bischof Adrian ${ }^{92}$ hatte mit allen Wallisern, um den römisch-katholischen Glauben zu verteidigen, die Schweizer dazu verpflichtet, ihnen bei der Bewahrung der besagten katholischen Religion im Wallis zu helfen. Und umgekehrt waren sie verpflichtet, in jenen Kantonen den heiligsten und frömmsten Gedanken zu verteidigen, doch von den Schweizern wurde die Umsetzung nur schwächer durchgeführt, als es nötig gewesen wäre.

Heutzutage wurden durch den Fleiß der Apostolischen Nuntien, die den Bischof angespornt und die Katholiken aufgefordert haben, die wenigen Ketzer, die da sind, ausgerottet. Es wurde ein öffentliches Dekret erlassen, wonach jene, die nicht katholisch leben wollen, unter Androhung von sehr schweren

91 Vgl. Stichwort „Matthäus Schiner“, in: https://hls-dhs-dss.ch/de/articles/021447/2012-1120/ (31. Dezember 2020).

92 Vgl. Stichwort „Adrian I. von Riedmatten“, in: https://hls-dhs-dss.ch/de/articles/021483/ 2010-10-21/ (31. Dezember 2020). 
Strafen aus dem Land vertrieben werden sollen. Und es wurde auch befohlen, dass niemand in der Stadt und den Orten der Ketzer studieren oder seine Kinder dorthin schicken darf. Aber es wurden schwerwiegende Hindernisse für diese Einrichtung gefunden, denn die Infizierten, wenn auch nur wenige, waren die Hauptoberhäupter des Landes und genossen die Unterstützung von Bern, und noch während der Herrschaft von Heinrich IV. von Frankreich erhielten sie durch seine in der Schweiz ansässigen Minister Unterstützung, die aus welchem Grund auch immer gezeigt haben, dass sie die Ketzer schüren und die Zahl der Katholiken in diesen Gebieten senken oder vernichten wollen. Deshalb ist der genannte Bann nie in Kraft getreten, und auch in meiner Zeit habe ich viel Arbeit daran geleistet, wie die öffentlichen Briefe bezeugen, all das habe ich durch meinen Fleiß und das Mitleid des Bischofs geschafft, der sich meist als sehr eifrig erwiesen hat. Das hat aber nicht gereicht, um es richtig zu machen. Aber jetzt, da sich der Zustand der Dinge geändert hat und die heutige Königin von Frankreich andere Zwecke entdeckt und mit anderen Prinzipien regiert, darf man das Vorhaben nicht aufgeben, sondern muss es weiterführen, bis man sein gewünschtes Ende sieht, was in diesem Gebiet den Fleiß der ketzerischen Gegner widerspiegelt, die das Unternehmen nie aufgeben, auch wenn sie es sehr schwierig finden. Deshalb habe ich vor kurzem an den Botschafter der genannten Krone geschrieben und ihn um Hilfe gebeten, und ich habe auch den Herrn Kardinal-Patron zu überzeugen versucht, dass es sich lohnt, einen Antrag bei der Königin zu stellen, damit sie ihren Ministern befiehlt, bei Verhandlungen die Frommen zu bevorzugen, und dann habe ich einen Teil davon an Monsignore Nuntius von Paris übergeben, damit er bei jeder Gelegenheit die Notwendigkeit in Erinnerung ruft und die Anträge stellen kann, die dazu notwendig sind.

Zur Lösung der anderen Probleme dieser Provinz wurden zu meiner Zeit sehr geeignete Mittel ausprobiert, die weiterhin von großem Nutzen sind. Und immer wieder versuchte ich, die Kantone Luzern und Altdorf in die Verteidigung des Wallis einzubinden, indem ich ihnen neben der Verpflichtung des Bundes auch zeigte, wie viel Schaden ihren Kantonen zugefügt würde, wäre das Wallis ketzerisch geblieben, weil es an der Grenze zum St. Gotthard mit Graubünden liegt, und es gibt in der Mitte nur den Pass, der die Macht der Herren von Altdorf ausmacht und der aus diesem Grund von den Päpsten so hoch geschätzt wird. Doch falls diese Walliser sich Graubünden anschließen würden, was sie auch tun würden, und alle Ketzer wären, dann würde Altdorf durch diesen Pass eingeschlossen bleiben. Sie hätten keine Hoffnung auf Hilfe und Rettung, da sie keine Größe mehr hätten, die ihm alle Kantone für die Bedeutung des St. Gotthard-Passes beimessen. Diese Überzeugungen und die Realität der Gründe fand ich bei den Herren in Altdorf und in Luzern immer als Gegenstand einer lebhaften Diskussion vor, um alle Anliegen des katholischen Glaubens im 
Wallis zu bevorzugen und diesbezüglich Verhandlungen zu erleichtern. Doch in den Republiken waren die Absprachen sehr ermüdend, da sie den Abgeordneten wie eine Last vorkamen, da sie ihnen sehr viel abverlangten. So ließ ich es einrichten, dass man in Luzern Herrn Oberst Rudolf Pfyffer ${ }^{93}$ den Auftrag geben sollte, ... [verderbt, Anm. des Übersetzers] und in Altdorf ließ ich dasselbe einrichten mit Herrn Emanuel Bessler, ${ }^{94}$ beide wertvolle und fromme Männer, [verderbt], und da ich hoffte, Gutes daraus zu gewinnen, wenn die Pest mich nicht daran gehindert hätte, so hoffe ich, dass meine Nachfolger diesbezüglich große Fortschritte machen werden, indem sie diese oder ähnliche Anliegen in diesem Geschäft nutzen.

Als Gegenmittel gegen den Priestermangel gibt es verhältnismäßig gute Lösungen, da der König von Frankreich durch die Verpflichtung seiner Liga gezwungen war, von Anfang an Schüler dieser Nation in Paris zu halten, und dann wiederum auf Antrag des heutigen Bischofs Hadrian von Matten verpflichtet war, sechs weitere in Ternen zu behalten, die von den Jesuiten begleitet werden und die acht Schüler umfasst, je einer aus jeder Gegend, also aus den sieben Kantonen, und ein anderer, den dieser Bischof von Sitten ernennen darf; Es wäre eine größere Hilfe und ein Vorteil, wenn die Schüler gezwungenermaßen Priester würden und man keine Weltlichen aufnähme, was man fördern sollte, denn es würde dem Wallis wenig Nutzen bringen, wenn einige Laien lesen und schreiben können, doch der Kirche nicht dienen und beim Katechisieren der einfachen und ignoranten Armen nicht helfen. Im Helvetischen Kollegium von Mailand haben sie zwei gewöhnliche Plätze, auch wenn sie den Anspruch auf insgesamt fünf haben, was sehr notwendig wäre, da diese Orte die Pflicht hätten, sich kirchlich zu verbessern, und mit ein wenig Sorgfalt des Nuntius könnten sie das auch hinbekommen.

Es war im Wallis üblich, dass, beim Tod eines Priesters, der Bischof ihm alles wegnahm, doch den Priestern gefiel das immer weniger. Nachdem mir berichtet worden war, dass dies die Konsequenz des Übels sei, und dass der Bischof so sehr gehasst wurde, und dass sowieso sehr wenig Vergütung aus der genannten Wegnahme floss, arbeitete ich mit der guten Gnade Unseres Herrn hart daran, so dass ich, nachdem ich angekommen war, mit dem Bischof über die Steuereinnahmen verhandelte, und so eine Übereinkunft aushandelte, die in dieser Provinz sehr dankbar aufgenommen wurde, und bald werden wir ih-

93 Vgl. Stichwort „Rudolf Pfyffer von Altishofen“, in: https://hls-dhs-dss.ch/de/articles/ 024146/2010-09-28/ (31. Dezember 2020).

94 Vgl. Stichwort „Emanuel Bessler von Wattingen“, in: https://hls-dhs-dss.ch/de/articles/ 015493/2002-09-17/ (31. Dezember 2020). 
ren großen Nutzen sehen, und so werden in Zukunft viele des Landes bereitwilliger der Kirche dienen.

Ferner wurde von mir aufgetragen, dass einige Priester aus Luzern „ad tempus“ dorthin geschickt wurden, um diesen Gebieten zu helfen, und es wurde fruchtbar durchgeführt, aber es kann nicht allzu oft geschehen, weil Helvetien seine eigenen Bedürfnisse abdecken muss und die guten Priester wegen der Armut und des schlechten Lebens, die sie in dieser Provinz finden, nicht dorthin gehen wollen, und selbst wenn sie dorthin gehen, wollen sie nach kurzer Zeit wieder weggehen.

Und weil im Oberwallis, das ganz katholisch ist, doch so viel Unwissenheit herrscht, kann man nichts mehr hinzufügen. Es reichte nicht aus, die Hilfe von Priestern zu haben, die oft noch nicht sehr gebildet sind, eine weitere fruchtbarere, aber schwierigere und gefährlichere Hilfe wurde gefunden, indem einige Jesuitenväter auf eine Mission geschickt wurden, wo sie mit ihrem Wert unendlich gute Arbeit geleistet haben, und wenn sie weiterhin die Dunkelheit der Unwissenheit beseitigen, dann werden sie diesen armen Bauern das wahre Licht unseres Glaubens aufzeigen können. Ich musste sehr darum kämpfen, dass der Bischof einige dieser Ordensleute bei sich behält, aber der bisherige Versuch war vergeblich, denn der Prälat ist arm und flieht vor den Kosten, sowie blieb er von der bischöflichen Stadt fern, in der er eigentlich wohnen sollte, die jedoch mehr infiziert von der Ketzerei ist als jeder andere Ort, und er zweifelt an dieser Neuerung, sodass diese Patres sich in einem anderen Ort aufhalten, der nicht weit weg ist und wo sie Schulen eröffnen können, um vielen Schülern zu helfen, und gute Erfolge stellen sich ein, wenn sie bevorzugt und beschützt werden, wie es bisher der Fall war und wie ich es immer getan habe.

Im Oberwallis gibt es insgesamt 300 Pfarreien und im Unterwallis um 20 oder 24. Von den weltlichen Dingen dieser Provinz findet man etwas ganz Besonderes im unteren Kapitel.

Der heutige Bischof von Sitten muss sehr höflich behandelt werden, denn die Nation ist grob und misstrauisch. Er ist als Person fromm und eifrig, aber schüchtern und unentschlossen und sagt, dass er es mit mehr Schwierigkeiten zu tun hat, als er ausdrücken könne. Man soll ihn mit liebevoller Freundlichkeit oft anschreiben, um ihn zu gewinnen, und er spricht einem nie eine vernünftige Gunst ab, und die üblichen Anfragen aus dieser Provinz soll man ihnen kostenlos gewähren. Das nützt dem Bischof auch, um seine Freundschaft zu gewinnen, indem ich dem Kanzler befohlen habe, nichts für seine Dienste entgegenzunehmen.

Ich wurde bei der Unterstützung dieser Provinz stark behindert durch eine List der Ketzer, die zwischen den Wallisern und den katholischen Kantonen Zwist gesät haben, indem sie behauptet haben, dass die Schweizer im Schatten 
der Liga und durch die Aufrechterhaltung des katholischen Glaubens diese Orte in Besitz nehmen wollten, und sie deshalb so schlecht in ihrem Land aufgenommen würden, was es schwierig mache, mit ihnen $\mathrm{zu}$ verhandeln und ihnen $\mathrm{zu}$ helfen. Auch die Mittel und Briefe des Nuntius gelten aus anderen Gründen als verdächtig, nachdem sie das Gerücht verbreitet haben, dass die Botschafter Frankreichs zur Zeit des Nuntius-Bischofs von Veglia ${ }^{95}$ im Schatten geistlicher Dinge um Bündnisse mit Spanien verhandelten und weltliche Dinge förderten, was dazu führte, dass sie noch in meiner Zeit demselben Neid verfallen sind, und es ist fast unmöglich, sie mit der Wahrheit aufrichtig $\mathrm{zu}$ behandeln, und ich sehe keine anderen Mittel, als dass diejenigen, die Böses getan haben, das heißt der Botschafter von Frankreich, sich darum bemühen sollten, das Vertrauen wieder herzustellen und auch zur Hilfe dieser Provinz beizutragen; Denn wenn dies in kurzer Zeit geschehen sollte, dann würde ganz Wallis wieder katholisch sein, da sich dann alle der Vorgaben ihrer politischen Anführer folgen würden, über die ich schreibe, und das ist die allgemeine Meinung, weil der genannte Minister wegen der Renten viel Macht über diese Leute ausübt.

Da das Bistum Sion besondere Hilfe braucht, habe ich nicht nur den allgemeinen Zustand dieser Kirche im Auge gehabt, sondern auch die Zukunft, und es scheint mir, dass, wenn dieser Bischof sterben wird, es keinen Kanoniker gibt, der diesem Amt überhaupt gewachsen ist, so meine ich, dass es eine gute Idee wäre, sich einen Koadjutor [Weihbischof, Anm. des Übersetzers] vorzustellen, doch als es Hoffnung gab, ihn von seine Zustimmung dazu zu überzeugen, kam es leider nicht dazu, dieses Anliegen so zu beschließen, wie ich es mir gewünscht hatte, weil ich mich nie mit dem Bischof darüber auseinandersetzen konnte, obwohl ich mehrere Bitten gestellt hatte, so überlasse ich diesen Gedanken dem Nachfolger, der mit Geschicklichkeit vielleicht ein Mittel für die so große, aber auch so trostlose Kirche finden kann.

In der Provinz Wallis befindet sich an der Stelle von Gerunden/Géronde ${ }^{96}$ ein Kloster der Karmelitermönche, das in der Vergangenheit der Auflösung nahestand, und ich hatte daran gedacht, dass es fruchtbarer wäre, es mit dem Jesuitenkolleg zu verbinden, sobald sie dort gut Fuß gefasst hätten und mir Unser Herr die Gnade dazu verliehen hätte. Aber vor kurzem, nachdem ich von Vätern die Anfrage erhalten hatte, ob Unbeschuhte Karmeliten an diesem Ort eingeführt werden können, fand ich es schwieriger als ich dachte, weil das Volk die Karmeliter nicht kennt und deshalb nicht leicht zustimmen will, sowie weil der Priester derer, die jetzt dort sind, nachdem er auf seinem Vertrag pocht, persön-

95 Nuntius Giovanni della Torre (1595-1606).

96 Vgl. Stichwort „Gerunden“, in: https://hls-dhs-dss.ch/de/articles/008222/2005-11-14/ (31. Dezember 2020). 
lich gekommen ist, um eine Reform durchzuführen, und er hat auch noch die Gnade des Bischofs und der Nation erworben. Da es keine besseren Möglichkeiten gibt, glaube ich jetzt nicht, dass es etwas Besseres abzuschließen gibt, denn in meinen Briefen gab ich den Gönnern darüber Auskunft, und damit reicht es, den geistlichen Zustand des Bistums Sion und der Walliser beschrieben zu haben.

\section{Bistum Lausanne}

Das dritte Bistum der Nuntiatur in der Reihenfolge ist jenes von Lausanne, das nach der gleichnamigen Stadt am Ufer des Alemannensees benannt ist. Dieser See wird heute Genfersee genannt. Der Bischof dieses Ortes war einst sehr mächtig, denn er war nicht nur Fürst des Reiches, sondern auch weltlicher Machthaber über fast das gesamte Gebiet der Diözese und erkannte keinen anderen Oberen als den Apostolischen Stuhl und das Römische Reich an und hatte, wie es geschrieben steht, mehr als hunderttausend Seelen, die seiner zeitlichen Herrschaft unterlagen und innerhalb der Grenzen des gesamten Landes Waadt lebten, auf das der Herzog von Savoyen Ansprüche erhebt. Aber die religionsbedingten Turbulenzen in Helvetien haben alles anspruchsvoll gemacht, was nicht nur die Stadt Lausanne betrifft, sondern die gesamte Diözese, mit Ausnahme des Teils, der dem Schweizer Kanton Freiburg gehört und in die Gewalt der bernischen Ketzer fiel. Diese haben die Kirchen befallen und all diese unglücklichen Untertanen ins Verderben geführt, indem sie die guten Katholiken zu bösen Protestanten gemacht haben, und die Stadt Lausanne, die früher Bischofssitz war, ist jetzt Sitz der Pest, weil sie [nicht leserlich] das Studium von Fehlern. Und zwischen dieser Stadt und Genf gibt es so viel Eintracht, dass sie [verderbt] das Gift verbreiten, um gemeinsam verschiedene Provinzen zu infizieren.

Deshalb bleibt der schönen Diözese von Lausanne heute nur noch das Gebiet von Freiburg, und ich weiß nicht, ob Freiburg kleiner ist als die Stadt Solothurn, aber sie ist so einkommenslos, dass seit vielen Jahren dort nicht mehr als etwa 100000 Seelen überleben, wie etliche mir sagen; Über die Katholiken in diesem Bistum ist zu sagen, dass die Bischöfe noch weiterhin mit den Ansprüchen an die von den Bernern besetzten Güter beschäftigt sind, denn für den öffentlichen Frieden, der hier landsfreid [Landfrieden, Anm. des Übersetzers] ${ }^{77}$ genannt wird, gilt, was beschlossen wurde, und zwar dass künftig kein Zweifel mehr an der Herrschaft geäußert werden darf über die Güter, die sowohl katholische als auch ketzerische Kantone besitzen. Das gilt zwar auch für kirchliche

97 Vgl. Arno Buschmann, Elmar Wadle (Hrsg.): Landfrieden. 
Güter, aber nicht für jene des Bistums Lausanne, was nicht in diesem öffentlichen Abkommen einbezogen wurde. Denn die Berner selbst konnten es, wie alle anderen Kantone auch, nicht leugnen und mussten dies eingestehen. Wenn nun die Bischöfe, wie sie es zumindest in Freiburg verhindern konnten, denselben Geist für Lausanne anwenden würden, dann müssten sie die Berner rechtlich nach den besetzten Gütern anfragen, was mehr als 30000 Scudi jährlich an Einnahmen bedeuten würde. Und dieses Vorhaben ist nicht unmöglich, weil die zwölf Kantone in Baden ihr gerecht werden müssten. Die Katholiken würden das Vorhaben sicherlich bevorzugen, weil sie dem Basler Bischof gegen die Basler aus dem gleichen Grund geholfen haben und ihn dazu gebracht haben, Biel gegen den Willen der Bieler zurückzugeben, was ein weiteres Beispiel dafür ist und etwa dem entspricht, was unseren Fall in der Größenordnung betrifft, und auch die Gründe sind ähnlich in beiden Fällen. Aber die Berner, die diesen Gefahren aus der Ferne folgen, kämpfen dennoch unter anderen Decken, damit die Freiburger Herren dem genannten Bischof nicht erlauben, in ihrer Herrschaft und Stadt zu wohnen, denn durch die Abwesenheit des Hirten werden sie von dieser Eifersucht befreit, und zu diesem Zweck haben sie vor einigen Jahren Botschafter in den Kanton Freiburg gesandt, um die Herren dort zu bitten, die Rückkehr des Bischofs nicht zuzulassen, und sie sagten, dass der Bischof sonst tausend Dinge ruiniert hätte, die Rückerstattung von Gütern gefordert hätte, die die Kirche für sich in Besitz genommen hätte, und viele Privilegien annulliert hätte, die im Besitz der Freiburger sind, und mit ähnlichen Kniffen verdeckten die Ketzer ihr eigenes Interesse, indem sie die Parteinahme anderer vorgaben. Trotzdem wurden durch die harte Arbeit der Apostolischen Nuntien die Trugschlüsse entdeckt und auch veranlasst, die Aufnahme ihres Bischofs zum Wohle des katholischen Glaubens zu gewähren, um die Verwirrung der Ketzerei und den Ruf ihrer Stadt, dieses sehr wandlungsfähigen Kantons, zurechtzubiegen.

Aber um diese Herren von jeglichem Verdacht einer Auseinandersetzung zu befreien, hat Bischof Jean Doroz, ${ }^{98}$ der 1601 Bischof dieser Kirche war, bei der Einsetzung des Bischofsvorsitzes bei den Herren im Kanton Freiburg angefragt, was alles nötig sei, damit er die Kirche von Lausanne übernehmen könne, und insbesondere waren sie auf diese Weise miteinander verbunden geblieben und ganz klar gingen sie davon aus, das dieser genannte Ort Gegenstand seines Bistums sei, und dass er auf die Einnahmen bestehen würde, mit Abzug der notwendigen Ausgaben. Das wären nach römischem Brauch hundertfünfzig golde-

98 Vgl. Stichwort „Jean Doroz“, in: https://hls-dhs-dss.ch/de/articles/026382/2005-02-08/ (31. Dezember 2020). 
ne Scudi camerali. ${ }^{99}$ Auf der Sitzung zeigte der Senat von Freiburg auf, wie auch zum Zeitpunkt der Revolutionen um des Glaubens willen Käufe getätigt werden konnten, zeigte auch die gemachten Verbesserungen, die Ausgaben für Bauarbeiten von Klöstern, sowie die Bitte an Unsere Liebe Frau von Thonon für die Bekehrung der Ketzer und den Bau eines großartigen Jesuitenkollegs in der Stadt Freiburg, welches auf Zureden des Nuntius Bischof von Vercelli ausdrücklich begonnen wurde, um eben die Gemüter zu beruhigen, da sie so wenige Güter im Bistum Lausanne besaßen, und mit diesen Anweisungen wurde beschlossen, dass man ihn nicht zwingen konnte, für seine Schulden nochmals zu bezahlen, selbst wenn sie es wollten, dass er seine Schulden nochmals zurückzahlen sollte, und so wurde einerseits vereinbart, dass der Bischof auf jegliche Ansprüche verzichtet, die er in dieser Gerichtsbarkeit besaß und die gegen diesen Kanton gerichtet waren, und andererseits verpflichteten sich die Freiburger Herren, den Bischof in ihrer Stadt aufzunehmen, ihm ein komfortables Haus mit Garten zu bauen und einen bestimmten Zehnten Teil in Höhe von 400 Dukaten zu überlassen als jährliches Einkommen, das auf siebzig Säcke aller Weizenarten aufsteigt, sowie zur Verpflichtung für den Bischof, die Kartäuserabtei namens Partii Dei, unweit von Freiburg zu unterstützen. Dieser Vereinbarungsvertrag wurde 1602 von den Stellvertretern beider Parteien abgeschlossen, und was die apostolische Genehmigung betrifft, so wurde in Rom damit begonnen, diese Bestätigung zu behandeln. Es wurde jene Sorgfalt angewandt, die ein solches Unterfangen erfordert. Von Rom aus war der damalige Nuntius, der Bischof von Veglia, damit beauftragt, Informationen zu sammeln, und im Jahr 1606 wurde der Bericht erstellt, dass die Dinge wahr seien, und dass sie gerechtfertigt waren, und dass sie für die Kirche nützlich sein würden, wenn sie abgeschlossen wurden um [verderbt] Früchte hervorzubringen, die von der Residenz des Bischofs in Freiburg erhofft wurden.

Monsignore Doroz starb in der Zwischenzeit, und diese Kirche blieb etwa zweieinhalb Jahre lang vakant, da sie sich nicht leicht dem Druck auf diese Gebiete unterzuordnen hatte, wie es immer noch von einigen Ansprüchen des Herzogs von Savoyen gesagt wird. Zu meiner Zeit war es in Helvetien so, dass das Bistum keinen Bischof hatte, und der Vertrag blieb bis zur Neuwahl eines neuen Bischofs ausgesetzt.

In der Zwischenzeit hatte ich stets Briefe und Ordnungsanträge an das Bistum gerichtet, und eine der besonderen Sorgen, der ich mich in der Nuntiatur annahm, war die um dieses Bistum, wo der Bedarf größer war und der Verdienst und die Frucht viel sicherer. Ich benutzte den Generalvikar Antonius von Paseva [nicht bekannt, wer das ist, Anm. des Übersetzers], einen sehr liebens-

99 Vgl. Carlo M. Cipolla: Money in Sixteenth-Century Florence. 
würdigen und eifrigen Menschen. Ich rief ihn ein paar Mal zu mir, ich gab ihm Anweisungen, ich drängte ihn zu vielen guten Geschäften, und dank seines Fleißes entwurzelte ich die Dornen, die in dieser Diözese entstanden waren. Ich habe kraft der apostolischen Autorität befohlen, jenen Teil des Kantons Solothurn zu fördern, der in diesem Bistum schweigt, weil ich wusste, dass es hundertfünfzig Jahre her war, dass es nicht mehr offiziell von den früheren Bischöfen besucht wurde, und dies ist mit unendlicher Frucht geschehen. Dieser Generalvikar wurde inzwischen wegen seiner Güte zum Abt von Hauterive gewählt und ist daher ein religiöser Zisterzienser geworden, nicht aus diesem Grund wollte ich, dass er auf den Titel des Vikars verzichtet, weil ich sah, wie hilfreich seine Autorität, sein Rat und seine Umsicht in diesen Teilen waren, und ich teilte es Seiner Heiligkeit mit, der meine Meinung bestätigte, und auf diese Weise wurde er durch einen Vikar namens Jakob Kammerling ersetzt, der ihm mit viel Güte folgte, und mehrmals sollte ich mich persönlich für mehrere Geschäfte einfinden, und ich habe ihn so gut wie möglich angesprochen, so dass es immer noch von dem neuen Bischof Jean de Watteville ${ }^{100}$ bestätigt wurde, der kürzlich für diese Kirche gewählt wurde.

Derselbe neue Bischof wurde von mir unzählige Male gebeten, persönlich nach Freiburg umzuziehen, um den Zustand seiner Kirche zu sehen und die Geschäfte fortzusetzen, die sein Vorgänger unvollkommen hinterlassen hat, und der Majestätischste Herr ist ein Zeuge, der ihn väterlich zum selben ermahnte, aber er befindet sich als Abt im Burgund. Und da er in diesen Gebieten keine Einrichtung für sein Essen zur Verfügung hat, hat er sein Kommen bisher aufgeschoben, da er durch viele Fälle eingeschränkt sei, und versprach, in kurzer Zeit persönlich zu kommen und mit all seinen Bemühungen für die Wiederherstellung dieser Kirche $\mathrm{zu}$ arbeiten. Und ich habe bei der Versammlung alle Anstrengungen unternommen, dass die Freiburger Herren sich auf sein Kommen vorbereiten, um auf ihn zu hoffen, ihn zu empfangen und ihn zu ehren, wie ich weiß, werden sie es sicherlich aus Liebe $\mathrm{zu}$ mir tun, da sie von mir zu diesem Zweck bei jeder Gelegenheit beschenkt wurden und es so für sie von bemerkenswertem Nutzen war, und sie sich nicht nur aus Frömmigkeit beugten. Die Unterstützung bei der Etablierung dieses Bischofs von Lausanne und eines der wichtigsten Geschäfte dieser Nuntiatur für die oben genannten Folgen würde es erforderlich machen, dass der Nachfolger Nuntius nach der Ankunft des neuen Bischofs mit besonderer Begeisterung auf Sie wartet und sich persönlich in diese Teile begibt, um diesem und anderen sehr wichtigen Geschäften, die dem katholischen Glauben dienen, ein Ende zu setzen, und das genügt, um vom Bistum Lausanne zu sprechen.

100 Bischof von Lausanne von 1609 bis 1649. 


\section{Bistum Chur}

Das vierte Bistum ist Chur, der Hauptort Graubündens, der früher Curia genannt wurde, weil dort im Jahr 157 der römische Kaiser ${ }^{101}$ beim Krieg gegen die Deutschen anhielt und die Stadt erbauen ließ. Im Jahr 495 hatte der Kaiser ${ }^{102}$ den ersten Bischof eingesetzt, und im Jahr 744 wurden den Bischöfen jene Privilegien gewährt, wie beispielsweise Geld zu schlagen oder als Richter für die gesamte Alpenrepublik Rätiens vorzustehen, was noch immer der Fall ist, und andere Besonderheiten, die durch die Besetzung mit weltlichen Herrschern verlorengegangen sind. Seither haben die Churer Bischöfe viele Freiheiten verloren, und sie sind der weltlichen Macht unterworfen worden, als die Stadt Chur und fast ganz Graubünden sich der Bosheit Zwinglis und Calvins unterwarf. So wurde ein Großteil dem römisch-katholischen Glauben abtrünnig. So litt das altehrwürdige und edle Bistum Chur, aber auch ein Großteil der großen Stiftungen. Denn neben der Betreuung des gesamten alpinen Rätiens, dem heutigen Graubünden, zählten auch noch einige Teile Tirols dazu, wie das Vintschgau und andere dem Haus Österreich unterstellten Orte. Der Churer Bischof musste viele Revolutionen und Verluste erdulden, die zu Usurpationen der Ketzer geführt haben. Seine Residenz ist ein Schloss in Chur, wo er für sich selbst und alle Domherren Platz hat, doch mehr gilt dies für die Fürstenburg in Tirol, wodurch er auf mindestens 4 tausend Dukaten Einnahmen zählen kann, die im Vergleich zum alten Reichtum nichts sind. Das ist auch wenig im Vergleich zu den großen Einkünften anderer deutscher Bischöfe, was für den wirtschaftlichen Alltag nicht ausreicht und wegen des Schutzaufgebots an Truppen schnell aufgebraucht wird.

In der Zeit des neuen Bischofs von Chur namens Johannes hat das Bistum mit einigen Herausforderungen zu kämpfen. Die Gefahr, durch die Einnahme Graubündens völlig usurpiert zu werden, falls der Bischof stillschweigende Informationen mit dem König von Spanien weiterleiten sollte, mit dem sie kein Bündnis teilen, und eine Kapitulation vor dem Staat Mailand, der sie eigentlich überfallen und mit bestialischen Erfindungen an sich reißen wollte, und in seiner Abwesenheit verhängten sie einen ungerechten Beschluss, in dem sie den Bischof am 29. Juli 1608 verurteilten. Die Richter Graubündens verkündeten,

101 Der Autor schreibt namentlich „Kaiser Konstantin“, was von der Zeitangabe her nicht möglich sein kann. Vielmehr meinte er Marc Aurel.

102 Auch an dieser Stelle gibt es einen zeitlichen Fehler, weil der Autor Kaiser Karl den Großen nennt. Vgl. Stichwort „Chur (Diözese, Fürstbistum)“, in: https://hls-dhs-dss.ch/de/articles/011403/2020-01-09/ (31. Dezember 2020): „451 unterschrieb der Bischof von Como einen Synodalbrief des Bischofs von Mailand an Papst Leo I. auch für den abwesenden Bischof Asinio von Chur (,pro ... Asinione ecclesiae Curiensis primae Rhaetiae episcopo'). Das hier erstmals bezeugte Bistum Chur wurde vielleicht schon im 4. Jahrhundert gegründet.“ 
dass er sich nie wieder in die Geschäfte des Landes einzumischen habe, und 600 Scudi als Bestrafung für die begangenen Taten zu zahlen habe, und dieser antwortete, dass er diese Strafe nicht akzeptieren würde und dass beabsichtigt wurde, ihn seines Bistums zu berauben, und den Kantonen befohlen wurde, die Wahl eines anderen an seiner Stelle durchzuführen, so sein Vorwurf. Da die Gegner zersplittert waren, nahmen sie den Bischof wieder auf. So durfte er wieder an seinen Wohnsitz zurückkehren, und sein Einkommen wurde zurückgegeben, weil ihm in der Tat alles weggenommen worden war. Indem ich mich der Autorität Unseres geliebten Herrn bediente, habe ich so viel mit den Schweizer Kantonen und dem Grafen von Fuentes, ${ }^{103}$ dem damaligen Gouverneur von Mailand, unternommen, dass sie drohten, den Verkehr des Staates nach Graubünden zu erschweren, wenn man den Bischof nicht unterbrächte. Dem Antrag wurde stattgegeben, aber allen war bewusst, dass die Schwierigkeit von höherer Stelle kam, da der dort lebende Botschafter Frankreichs den Bischof als zu spanischfreundlich betrachtete und als Feind seines Königs. Und so forderte ich den Botschafter und den Prälaten auf, sich hinzusetzen, um der Kirche und den Seelen der Katholiken in jener Diözese nicht zu schaden und sich auf diese Weise cessauit quallatio zu versöhnen. Und so kehrte der Bischof wieder nach Chur zurück, erhielt sein Schloss Fürstenburg samt Einkommen zurück. Von nun an kann er hoffen, mit meinem Beirat und in gutem Verhältnis zum französischen Gesandten, ungestört sein Amt wahrzunehmen.

Es ist wahr, dass bei dem streitbaren Charakter des Volkes, welches sich souverän fühlt, der Bischof in ständiger Lebensgefahr schwebt, denn wenn er den ketzerischen Predigern ein wenig Abscheu entgegenbringt, dann machen sie Lärm. Der Bischof würde in Kürze und schutzlos vertrieben, falls die Menschen wütend werden. Er wohnt mitten unter grausamen und barbarischen Feinden. In Chur selber gibt es nur die Katholiken, die im bischöflichen Hof leben. Und wenn es nicht daran gelegen hätte, dass durch den Bundesvertrag die Bündner verpflichtet sind, das Bistum und dessen Einkünfte aufrechtzuerhalten, dann wäre eine Kapitulation nicht zu verhindern. Sie fürchten aber eine Revolution von Katholiken, denn diese können genauso mit ihren Bündnissen mit Schweizern und Fürsten in der Nachbarschaft rechnen. Wäre dies nicht der Fall, dann gäbe es zu diesem Zeitpunkt keine Kirche mehr im Bistum, noch Gläubige der alten und wahren katholischen Religion.

Im Bistum Chur sind noch folgende Gebiete katholisch: das gesamte Tal im Vintschgau in Tirol, fast das gesamte Graubünden, das gesamte Mesolcina-Tal

103 Eigentlich Pedro Henriquez de Acevedo y Toledo, Conde de Fuentes (1525 oder in älteren Quellen auch 1560 geboren und gestorben am 22. Juli 1610 in Mailand). Er war ein spanischer Feldherr und Staatsmann. 
und dann andere Orte, die im Gotteshaus- und Zehngerichtsbund verstreut sind. Der große Priestermangel, den Pfarreien fühlen können, zwingt den Bischof oft, Wanderpriester aufzunehmen oder entlaufene Mönche, die gern in diese Gebirge fliehen. Dies wird gemacht, um den katholischen Glauben nicht verblassen zu lassen. Der jetzige Bischof hat jedoch große Anstrengungen unternommen, um meinem Rat zu folgen, von solchen Apostaten keinen Gebrauch zu machen, und wenn er Ordensleuten eine Pfarrei übertragen will, so muss er vom Apostolischen Stuhl eine Lizenz erfragen. Ich selbst habe ihm einige Male dabei geholfen, weil der Bischof mich darum bat. Es ging darum, für den Seelendienst und für das Gebet desselben Bischofs zur Linderung dieser Hungersnot und für die Hilfe des genannten Bistums zu helfen. Graubünden hat Plätze im Helvetischen Kollegium Mailand erhalten, indem es wie jeder der drei Bünde je zwei Plätze stellt, wie es immer noch jedem katholischen Kanton zusteht. Weitere acht Plätze werden den Untertanen Graubündens gewährt, nämlich sechs aus dem Veltlin und zwei für das Tal Chiavenna, weil diese Täler der Diözese Como angehören und nicht dem Bistum von Chur.

Zusätzlich zu dieser Hilfe hat der Apostolische Stuhl auf Bitten des Bischofs im päpstlichen Kollegium in Dillingen vier Plätze für junge Leute aus Graubünden gewährt. Der Kardinal-Patron hat sogar auf meine Anfrage hin die Möglichkeit offengelassen, dass es noch mehr sein könnten, wenn zu gegebener Zeit dies erfragt werden sollte. Die wäre sehr wünschenswert, denn gute Priester sind die beste Waffe gegen die Ketzer. Um den Bischof in diesen und anderen Dingen zu unterstützen, möge der Nuntius in ununterbrochenem Briefwechsel mit dem Bischof stehen.

Diese Hilfsmittel können als die Etablierung des katholischen Glaubens in diesen Teilen bezeichnet werden, denn da die Unwissenheit der Priester unendliche Übel verursacht, werden mit der Lehre und dem guten Beispiel dafür die Überreste bewahrt und der totale Ruin der Religion vermieden.

Und es würde die Bündner bremsen, wenn die Schweizer Katholiken ihnen drohen und keine Neuerungen zulassen würden. Der Versuch, den katholischen Glauben dort zu untergraben, muss sofort dazu führen, mit den katholischen Kantonen zusammenzuarbeiten, damit diese die Bündner warnen, nicht weiter zu gehen. Was die Katholiken machen können, ist ihnen zu drohen, den Handel mit ihren Ländern aufzuheben und die Zufuhr von Getreide und Früchten aus dem Staat Mailand zu verbieten, der durch das Tal von Mesocco eingeführt wird, und ohne das sie nicht überleben könnten.

Die hartnäckigen Bemühungen der Ketzer, das Mesolcina-Tal mit Ketzerei $\mathrm{zu}$ infizieren und dort einen Prediger zu platzieren, waren unsäglich, und ich musste zehn ganze Jahre lang dagegen arbeiten, um ihre Pläne zu verhindern, wie die Herren Patrone sich aus den ständigen Mitteilungen erinnern werden, 
in denen ich von dem Vorhaben berichtet habe. Am 24. November 1608 wurde auf Antrag des Tals von Mesocco an die drei katholischen Urkantone, die durch die Vogtei Bellinzona ihre Nachbarn sind, ein Dekret erlassen, in dem festgeschrieben wurde, dass sie katholisch leben und sterben sollen und niemals ketzerische Prediger empfangen sollen. Es wurde im Gegenteil beschlossen, den Ketzern mit aller Kraft zu widerstehen. Das führte dazu, dass die bösen Ketzer nicht zum Schweigen gebracht wurden, und nachdem sie großen Lärm wegen eines solchen Dekrets gemacht hatten, bei der Versammlung der Drei Bünde, kam es zum Glück nicht zu einem schlimmen Ausgang. Das lag daran, dass ich die Schweizer Kantone aufgerufen habe, den Bündnern $\mathrm{zu}$ drohen. Und wenn ich nicht mit Erlaubnis Seiner Heiligkeit den Gouverneur von Mailand, den Grafen Fuentes, bewogen hätte, die Getreidezufuhr und den Handel nach Graubünden zu unterbinden, dann hätten die Dinge nicht sofort eine bessere Wendung nehmen können. Bei diesen so wirksamen Mitteln nahmen die Dinge plötzlich eine andere Gestalt an. Übrigens geben die Ketzer einen einmal gefassten Plan nicht leicht auf. Sie wissen wohl, wie wichtig es für sie wäre, in einem Tal, das eigentlich zu Italien gehört, Fuß zu fassen. Gelänge es ihnen, so würden sie das Tal als Eingang zu noch weiteren Erwerbungen benutzen wollen. Aber der Nuntius kann dem durch erhöhte Wachsamkeit entgegensteuern. Er kann dies durch die Benutzung der erwähnten Mittel tun und durch die beständige Verbindung mit den angesehensten Katholiken von Mesocco, Calanca und Roveredo. Das können sie besonders mit den Priestern tun, die vom Eifer der Glaubensverteidigung beseelt sind. So lange der Minister Gioieri ${ }^{104}$ von Mesocco, Savo und Roveredo, sowie der weltliche Vikar von Bellinzona und der Geistliche Vito Pellicani, die mir immer geholfen haben, da sind, wird es am besten sein, sich ihrer zu bedienen, da sie die Verhältnisse kennen und sehr eifrig sind, den katholischen Glauben in diesen Gebieten zu fördern.

Kardinal [Federico, Anm. des Übersetzers] Borromeo hält dieses MesoccoTal unter seinem besonderen Schutz, und für dessen Hilfe schickt er ihnen oft einige seiner Oblaten auf Mission, die dort erfolgreich sind, und oft ist es notwendig, dass der Nuntius die Fortsetzung der Rettung mit diesem Herrn fortführt, deshalb ist es notwendig, ein gutes Einverständnis ihm zu haben.

Es gab früher noch eine weitere geistliche Hilfe, die von großer Bedeutung war, und die jetzt verlorengegangen ist und ein Vermächtnis von Herrn Kardinal von Alessandria war, der die Notwendigkeit für dieses Land kannte. Er gründete eine Art Kollegium im bündnerischen Disentis für 34 Schüler und gewährte eine Rente von vielen hundert Dukaten, aber weil er das Geld in die

104 Mehr über ihn steht in der Instruktion nicht. Es ist auch nicht klar, um wen es sich konkret handelt. 
Hände dieser Herren Katholiken schickte, die schlecht damit umgingen, stellte er die Hilfe ein. Während er nachforschte, wie das Geld sicherer zu verwenden sei, starb er. Nach seinem Tod versuchte man vergeblich, ein so nützliches Vorhaben fortzuführen.

Die Verbindung, die ich vor kurzem begonnen habe, zwischen Schweizer Katholiken und Bündner Katholiken zu fördern, ist von großer Bedeutung, denn wenn sie in den Drei Bünden so minderwertig behandelt werden, wie es für die Katholiken der Fall ist, so sind sie auf eine Hilfe angewiesen, die diese Lage ausgleicht. Ansonsten werden sie immer darunter leiden und ihren Staat verlieren. Auswärtige Hilfe ist unentbehrlich und selbst der Abschluss eines förmlichen Bündnisses würde keine übermäßige Aufregung verursachen. Das gilt sogar, wenn ein solches Bündnis nicht geheim gehalten würde. Die Walliser, die früher mit den Bernern verbündet waren und diesen Bund auflösten, haben sich mit den sieben katholischen Kantonen verbündet, um der Erhaltung der römisch-katholischen Religion willen, und es folgte keine Änderung. Die ketzerischen Bündner selbst haben vor wenigen Jahren ein besonderes Bündnis mit den anderen Schweizer Ketzern geschlossen, weil diese ihnen nahestehen und es von den Katholiken nicht verhindert wurde. Auch den Katholiken soll dies also möglich sein. Sie haben ein ebenso gutes Recht dazu, und wenn sie Mut fassen, so könnte dies auch gelingen. Deshalb darf man den Mut nicht verlieren, sondern muss mit Geschicklichkeit und mit so viel Konsequenz weitermachen, um den Feinden nicht aus Mangel an Sorgfalt zu unterliegen. Ich füge noch hinzu, dass ich weitere Einzelheiten zusätzlich berichten werde, nämlich über die Herren Florini in Disentis, Gioieri aus Calanca und andere Herren aus Graubünden, und unter den Schweizern über Amadeus Besler, ${ }^{105}$ der das Amt eines umsichtigen Ministers innehat. Auch berichte ich noch über die neuen Bündnisse und die enge und freundschaftliche Union, und das wird wohl von großer Bedeutung sein.

Und das ist alles, was mir in den Sinn kommt, über den geistlichen Zustand der Diözese Chur und wie ich Ihnen helfen kann.

\section{Bistum Basel}

Das letzte Bistum, das der Schweizer Nuntiatur unterstellt ist, und das nach der Stadt Basel benannt wird, ist durch den Fluss Rhein geprägt, der das Bistum in zwei Teile teilt und ein wichtiger Handelsweg ist. Die Stadt befindet sich an einem sehr komfortablen und schönen Ort. Diese Stadt ist sehr alt und das Jahr ihrer Gründung ist, wenn man so will, in römischer Zeit zu suchen, als an jenem

105 Es handelt sich um einen politischen Herrn aus Altdorf. 
Ort ein Vorläufer des heutigen auf deutschem Boden gründete. Andere behaupten, dass diese Stadt nach der Zerstörung der römischen Stadt Augusta Raurica aufgebaut wurde, die nicht weit davon entfernt war. Es gibt bedeutende Untersuchungen, die von Papst Pius II. im Jahr 1459 durchgeführt wurden, und berühmt wurde die Stadt durch das Konzil von Basel, ${ }^{106}$ das dort wegen des Schismas mit Eugen IV. gehalten wurde, als er von Felix V. ${ }^{107}$ als Gegenpapst ersetzt wurde. Und diese Reichsstadt grenzt in Helvetien an die Provinz der Rauracher. Die Bischöfe hatten die Herrschaft über die kleine Stadt, den so genannten kleineren Teil jenseits des Rheins, und waren reich an anderen Gerichtsbarkeiten und traten gegen die Mutation der Religion ein, wurden aber später aus der Stadt vertrieben, und der größte Teil des Eigentums wurde von den sehr schlechten Ketzern beraubt, die durch Johannes Oekolampad ${ }^{108}$ pervertiert wurden. Im Jahr 1529 wurde dann ein neuer Bischof ihrer Stadt ernannt, doch fielen die Basler in einen Abgrund endloser Irrtümer, und so wurde jenes Jahr zum endgültigen Augenblick ihres Glaubensabfalls. In der Hauptstraße zur Kathedralkirche haben sie auf einer Tafel jenen Augenblick mit diesem berüchtigten Spruch unten dargestellt.

Ecce annum, quo pulsa fuit caligo.

Papam et vite ettleucit sol. Basel sili. ${ }^{109}$

Es stimmt, dass sie, als sie ihren Glauben wechselten, weder den Bischof noch die Domherren, die weiterhin als Herren des großen Gebäudes neben der Hauptkirche lebten, gewaltsam verdrängt haben, noch den anderen Herrn, ${ }^{110}$ den wir in einem vorgenannten Kapitel behandelt haben, aber der Bischof von Basel hielt nicht daran fest, um nicht so viele Gräuel mitansehen zu müssen. Und so wird er heute beschuldigt, durch seine Abwesenheit vieles verursacht zu haben, und vielleicht hätte er mit der Zeit durch seine Anwesenheit die Stadt

106 Das Konzil von oder zu Basel zählt zu den bedeutendsten kirchlichen Ereignissen im 15. Jahrhundert. Das Konzil wurde am 23. Juli 1431 von Papst Martin V. in Basel einberufen; es endete am 19. April 1449. Die Spaltung von Papst und Konzilsvätern im Jahre 1437 führte zu dem gleichzeitigen Konzil von Basel/Ferrara/Florenz.

107 Dieser war von 1383 bis 1451 Papst.

1081482 bis 1531 in Basel. Auch latinisiert Oekolampadius genannt, war er ein Theologe, Humanist und der Reformator von Basel.

109 Eigentlich stand auf der Inschrift: „Ecce annum, qua pulsa fuit caligo papatus ac vitae affulsit sol, Basilea, tibi - Siehe, Basel, das ist das Jahr, in welchem die Finsternis des Papsttums vertrieben wurde und die Sonne des Lebens dir zu leuchten begann." Vgl. Andreas Pronay: Die lateinischen Grabinschriften in den Kreuzgängen des Basler Münsters, S. $43 \mathrm{f}$.

110 Damit ist der Bischof von Konstanz gemeint. 
zurückerobert, wie es der Bischof von Konstanz tat, der seine Stadt nie ganz im Stich gelassen hat.

In dem großen Münster ist bis heute unter einer eisernen Tür der kirchliche Schatz mit Kelchen, Reliquien und ähnlichen alten Ornamenten zu finden, und wenn man sie darüber befragt, dann antworten sie, dass sie nicht wissen, ob vielleicht ihre Nachfolger zum alten Glauben zurückkehren wollen, also zu jenem papistische Glauben, wie sie sagen. Das sind offensichtliche Zeichen dafür, dass sie nicht stabil sind, und Zweifel haben, und so zum Teil ihre Fehler einsehen.

Die Architektur der Kirche ${ }^{111}$ ist wirklich erstaunlich, und außen hat sie marmorne Glockentürme mit sehr edlen Schnitzereien, die einen schönen Anblick bieten. Es gibt ein Kloster mit einem Friedhof, auf dem unter anderem Erasmus begraben liegt. Die Orgel der Kirche ist unversehrt erhalten und wird immer noch von Ketzern verwendet. Sie erhalten dafür von anderen Respekt, scheint es mir, da diese Einrichtung großes Staunen auslöst.

Lasst uns diese Ausführungen nun verlassen und zurück zum Bischof und zur Diözese kommen. Der Basler Bischof residiert in einem großen Land an der Grenze zum Burgund namens Pruntrut, ${ }^{112}$ wo die allgemeine Sprache Französisch ist, obwohl Deutsch sehr vertraut ist. Hier ist er weltlicher Herr und wohnt in einer schönen Festung. Weil aber der Ort dem Erzbischof von Besançon unterstellt ist, kann man sagen, dass dieser Bischof keinen richtigen Wohnsitz hat, was auch für mich sehr unangenehm ist. Deshalb habe ich mit dem entsprechenden Prälaten darüber verhandelt, um Abhilfe zu schaffen, und es wird vorgeschlagen, dass es besser wäre, einen Austausch mit dem genannten Erzbischof von Besançon zu machen, unter der Bedingung, dass er Pruntrut der Diözese Basel überlässt, und ich schlug ihm vor, ihm andere gleichwertige Orte, die zu diesem Bistum Basel gehören und an Burgund grenzen, zu überlassen. Schon hatte ich den zuständigen Herren davon berichtet, indem ich ihnen die vielen Vorteile mitteilte, die sich aus diesem Wechsel ergeben würden, als sie in Rom bereits über den Erzbischof in Erfahrung kamen. Es wurde uns empfohlen, alles in einem Vertrag zu regeln, mit viel Hoffnung auf einen guten Abschluss, aber seit die Pest gekommen ist, wurde alles ausgesetzt. Somit wird ein anderer Nuntius bei der Verhandlung mit beiden Prälaten, die daran interessiert sind, die letzten Hürden überschreiten.

Das Domkapitel desselben Bistums befindet sich noch immer außerhalb der Diözese, und sie wohnen in der Stadt Freiburg im Breisgau in der Diözese Kon-

111 Damit ist das Basler Münster gemeint.

112 Vgl. Stichwort „Pruntrut (Gemeinde)“, in: https://hls-dhs-dss.ch/de/articles/003003/201203-30/ (31. Dezember 2020). 
stanz. Ich wunderte mich doch sehr, als ich die Korporation dieser Kirche an so vielen fernen und unterschiedlichen Orten getrennt gesehen habe. Der Bischof befindet sich in einem Teil. Das Kapitel befindet sich in einem anderen, und der Vikar mit der bischöflichen Kurie in einem anderen Ort, und selbst in der Diözese mangelt es nicht an großen und ansehnlichen Ortschaften, in denen sich jeder mit mehr Ansehen und persönlichem Vorteil beteiligen könnte.

Die Diözese Basel ist sehr ausgedehnt, denn sie erstreckt sich nicht nur im Kanton Basel, der ketzerisch ist, sondern zum Teil auch im Kanton Solothurn, dann in einigen Orten des Burgunds und weithin im gesamten Oberelsass, wo es viele Ehren- und Großstädte, reiche Klöster und eine große Anzahl von Adligen und Fürsten gibt, und es ist fast der fruchtbarste Teil Deutschlands mit sehr guten Weinen und reich an Getreide und Weizen.

Der jetzige Bischof ${ }^{113}$ ist $\mathrm{zu}$ meiner Zeit bestätigt worden, und ich selbst habe ihn in Pruntrut auf Anordnung meiner Herren geweiht, und sein Name ist William Ringg in Badenstain, eine gottesfürchtige Person. Er ist ein höchst eifriger Mann, und um es mit einem Wort zu sagen, was ich in meinen Briefen auch schon geschrieben habe, ruft er viel Lob hervor, und er ist einer der besten Prälaten ganz Deutschlands.

Der Vorgänger ${ }^{114}$ des jetzigen Prälaten gab viel Geld für die Gründung eines Kollegs der Jesuiten in seinem Land von Pruntrut aus. Die Kirche, das Kolleg, die Schule und das Seminar sind alle von Grund auf in schöner Form aufgebaut worden, und heute gibt es viele Adlige, die dort studieren, und es gibt große Früchte.

Der Basler Bischof hat sich mit den sieben katholischen Kantonen verbündet, und es lag an diesen, ihn mit einem gewissen Aufwand an Spenden auch mit den ketzerischen Kantonen zu verbünden. Damit verbunden sind große Kosten, die sie an die Botschafter aller Kantone leisten, damit ein solcher Bund möglich ist. Aber diese Eidgenossenschaft ist für die Bischöfe sehr gewinnbringend, weil sie über hohe Einnahmen aus dem ketzerischen Land verfügen können. Wenn sie nicht mit diesen Kantonen verbunden wären, würde ihnen drohen, alles zu verlieren, und wenn sie nicht jene auf ihrer Seite hätten, die ihre Gründe verteidigen, und zwar schon seit 25 Jahren, in denen wir effektiv gesehen haben, wie die Schweizer Katholiken die Einnahmen des Bistums in großen Mengen verbessert und viele Waren zurückgewonnen haben. Das sieht man

113 Wilhelm Rinck von Baldenstein (1566-1628), vgl. Stichwort „Wilhelm Rinck von Baldenstein“, in: https://hls-dhs-dss.ch/de/articles/017055/2010-03-22/ (31. Dezember 2020).

114 Jakob Christoph Blarer von Wartensee (1542-1608), vgl. Stichwort „Jakob Christoph Blarer von Wartensee“, in: https://hls-dhs-dss.ch/de/articles/017030/2004-08-11/ (31. Dezember 2020). 
auch an der Gerichtsbarkeit von Biel, die ihnen von den Bernern gegeben wurde, wie oben erwähnt, und es ist zu hoffen, dass sie auch andere Einkäufe mit der Geschicklichkeit und Wachsamkeit des jetzigen Bischofs erlangen werden und sogar noch mehr getan wird, wenn die Nuntien ihre Augen für diesen Bischof öffnen und ihm helfen, wie ich es immer versucht habe.

Die Basler Bischöfe selbst haben viele Präfekturen unter ihrer weltlichen Herrschaft, wo die Völker allerdings Ketzer sind, und es wird alles getan, damit diese in den Schoß der Kirche zurückkehren, auch wenn die Berner, die sie in Schutz genommen haben, versuchen, sich dagegen zu wehren. Mit all dem machen wir langsam etwas Gewinn, und der jetzige Bischof hat Erfolg trotz derer, die die Messen an vielen Orten nicht einführen wollten, und wir hoffen, mehr und allgemeine Zugeständnisse in sehr kurzer Zeit umzusetzen, und weil er persönlich viele Besuche unternimmt, und wir hätten in diesen Jahren viel mehr tun können, wenn die Pest uns nicht davon abgehalten hätte, wie sie auch mich noch gehindert hat.

Die ketzerische Stadt Biel verweigerte in den Jahren 1608 und 1609 dem Bischof den üblichen Treueeid, ${ }^{115}$ und die Berner hatten sie ermutigt, das Joch des katholischen Fürsten abzuschütteln, aber letztendlich konnte dies mit meiner und der Hilfe der katholischen Kantone verhindert werden.

Der Bischof, der das Seminar zugunsten der Diözese errichtet hat, verlangt ausreichende Einnahmen, aber er muss mit der Verschuldung des Bistums kämpfen, da alle regulären Prälaten, die zahlreich sind und vom Konzil von Trient davon ins Benehmen gesetzt wurden, einen Beitrag dazu zu leisten, dieser Anordnung jedoch widersprechen. Der einzige Weg ist, sie zu dieser Bezahlung zu zwingen, auch wenn sie das nicht für richtig halten, und nach Rücksprache habe ich den Bischof daran erinnert, vor allem die Erklärung der Heiligen Kongregation des Konzils zu erfragen, damit er immer mit klaren und gerechtfertigten Bedingungen vorgehen kann.

Nach den großen Unruhen im Jahr 1612 in Deutschland durch den jülichklevischen Streit gaben die Prälaten des Elsass sehr viel Geld aus, um sich vor den vielen ungezügelten Soldaten zu schützen, die herumplünderten. So unternahmen sie große Anstrengungen und forderten dann, dass der ganze Klerus zum Teil das Gewicht des Schadens spüren sollte, was dazu geführt hat, dass der Erzherzog Maximilian mir geschrieben hat, ich möge Seine Heiligkeit bitten, beim Klerus eine Sammlung von einem Prozent für die Wiedergutmachung des Schadens zu verlangen. Dies sollte den regulären Prälaten zum Wohle der Allgemeinheit aufgezwungen werden, aber nachdem der Basler Bischof davon ge-

115 Der Treueeid wurde verweigert, weil der Basler Bischof einen Statthalter einsetzen wollte, der von den Bürgern mehrheitlich nicht angenommen wurde. 
hört hatte, nannte er mir viele Gründe, die ich Seiner Heiligkeit habe zukommen lassen. Das bewirkte, dass bis jetzt die Sache noch nicht entschieden ist. Auch die von dem genannten Maximilian empfohlene Bitte ist bisher noch ausgesetzt.

Der Bischof wird immer noch stark von den Deutschordens- und Johanniterrittern unter Druck gesetzt, damit dieser seine Priester besuche und gegen die Gegner des Heiligen Konzils vorgehe. Das war ein Anliegen des früheren Großpriors aus Deutschland. Nun ist aber ein diskreterer Mann gefolgt, deshalb hoffen wir auf eine ruhige Zukunft. Die Verhandlungen sind bereits im Gange. Der Bischof hat mir mitgeteilt, dass er mit der Diskussion begonnen hat, und ich habe ihm mitgeteilt, dass er mir Auskunft geben soll über jeden Punkt und dass er nichts ohne die Zustimmung des Apostolischen Stuhls abschließen soll, damit er nicht in irgendeiner Weise in schädliche Angelegenheiten verwickelt werde. Er hat mir versprochen, diesbezüglich so vorzugehen, und man muss ihn wohl kaum mit diskreten und liebevollen Worten daran erinnern.

An der bischöflichen Kurie in Altkirch ${ }^{116}$ gibt es einen ausgezeichneten Pfarrer, der auf meine Bitte hin anstelle eines anderen dort eingesetzt wurde. Der andere hatte nämlich einen schlechten Ruf. Durch die Gnade Gottes entwickeln sich dort die Gerichtsprozesse sehr gut. Leider gibt es viele Fälle von Simonie und eine Vielzahl von Konkubinaten und so werden viele Strafen verhängt. Das sind die Früchte der Frömmigkeit des Bischofs und seines persönlichen Besuchs, den er in der Diözese macht, und zwar mehr als die anderen Bischöfe Deutschlands. Es ist gut und wahr, dass er mit mir bei seiner Weihe vereinbart hat, all die oben genannten Dinge zu tun, da er dies mit viel Eifer getan hat, und sich dann gefreut hat, von mir schriftlich viel Lob erhalten zu haben, seine gute Führung der Seelen betreffend. Derselbe Bischof wurde von mir aber auch gedrängt, persönlich nach Rom zum Ad Limina Besuch zu gehen. Er zeigte anfangs Widerwillen, indem er vorgab, es sei in Deutschland nicht üblich. Er wolle nicht der Erste sein, der dieses Eis brechen sollte, doch schließlich wurde er von der Vernunft überzeugt und entdeckte seinen großen Wunsch, diesen Besuch in Gehorsam zu machen. Leider verhinderte bisher die Pest, diese Reise zu unternehmen. Er wird sich ohne Zweifel noch auf den Weg machen.

Die Einkünfte dieses Bischofs sind nicht hoch, aber er kann sie auch nicht genau kennen, und ich habe herausgefunden, dass es nicht weniger als 20 tausend oder mehr als 30 tausend Scudi sein können, aber es ist viel Geld, und ein Teil sind auch Schulden. Dennoch ist genug da für den Bischof von Basel.

116 Das Kloster Altkirch war ein Benediktinerkloster im Elsass. 


\section{Ordensleute}

Für das Verständnis des geistlichen Zustands dieser Nuntiatur werde ich nun auf die wesentlichen Dinge der Religion und der Kirchenvertreter eingehen, die sich dort befinden, abgesehen von den Besonderheiten, die sie betreffen. Diese lassen wir beiseite, um den Umfang dieser Erläuterungen nicht zu sprengen.

\section{Benediktiner}

Innerhalb der Grenzen der Nuntiatur der Schweizer gibt es keine größere Ordensgemeinschaft als jene des Ordens des heiligen Benedikts. Sie besitzen nicht nur etliche Abteien, die sich durch ihre altehrwürdige Gründung auszeichnen, sondern sind auch bekannt für ihren Reichtum und ihre Gerichtsbarkeit. Der Abt von Kempten [Campidonense im Originaltext] ${ }^{117}$ und der Abt von Murbach [Murbacense im Originaltext] ${ }^{118}$ gehören zu den vier Äbten des Reiches. Sie sind Fürsten und befehligen die Stadtfestung und andere Orte mit viel Würde und Ruhm.

Der Abt von St. Gallen ${ }^{119}$ in der Schweiz kann im Land in acht oder zehn Tagen 12 tausend Fußsoldaten aufstellen, so dass es in Bezug auf die Stärke keinem katholischen Kanton unterlegen ist.

Der Abt von St. Blasien ${ }^{120}$ im Schwarzwald soll rund 150 tausend Gulden Jahreseinkommen haben.

Der Abt von Ochsenhausen ${ }^{121}$ hat Einkünfte, die mehr als 30 tausend Gulden betragen. Jene von Weingarten entsprechen in etwa demselben Rahmen. Die Äbte von Muri, Fischingen, Rheinau, Einsiedeln und viele andere hatten nicht weniger als zehn oder 19 tausend Gulden Einkünfte im Jahr.

117 Vgl. Stichwort „Kempten, Fürstabtei: Territorium und Verwaltung“, in: https://www.historisches-lexikon-bayerns.de/Lexikon/Kempten,_F\%C3\%BCrstabtei:_Territorium_und_Verwaltung (31. Dezember 2020).

118 Murbach liegt im Département Haut-Rhin im Osten Frankreichs. Die Abtei in der Gemeinde Murbach, nahe der elsässischen Gemeinde Guebwiller (auf Deutsch: Gebweiler), wurde 727 vom heiligen Pirminius gegründet. 1548 verlieh Kaiser Ferdinand I. der Abtei den Rang einer Fürstabtei mit Sitz und Stimme im Reichstag. Vgl. Philippe Legin: Die Abteikirche von Murbach im Oberelsass.

119 Vgl. Stichwort „St. Gallen (Fürstabtei), in: https://hls-dhs-dss.ch/de/articles/008394/ 2017-03-16/ (31. Dezember 2020).

120 Vgl. Stichwort „St. Blasien“, in: https://hls-dhs-dss.ch/de/articles/007111/2011-01-11/ (31. Dezember 2020).

121 Die Reichsabtei Ochsenhausen war von 1090 bis 1803 ein Kloster der Benediktiner in Ochsenhausen in Oberschwaben, das zum Schwäbischen Reichskreis gehörte. Vgl. Max Herold (Hrsg.): Ochsenhausen. 
Diese Benediktinerklöster sind in reformierte und nicht reformierte Abteien unterteilt. Jene, die sich als reformiert bezeichnen, sind Teil einer Kongregation. ${ }^{122}$

Es gibt nur wenige nicht reformierte Benediktiner und sie sind fast nur auf die beiden Fürstabteien von Murbach und Kempten beschränkt. Das liegt daran, dass es in diesen Abteien Schwierigkeiten gibt, ein gutes Ordensleben zu führen. Denn sie sind nicht in der Lage, streng vorzugehen, da viele Adelige ihnen beigetreten sind. Der Kardinal-Patron wird sich sicherlich daran erinnern, welche großen Anstrengungen unternommen wurden, um die Zahl der Mönche der berühmten Abteien von Murbach und Ludens ${ }^{123} \mathrm{zu}$ vergrößern, indem sie miteinander vereint wurden. Das betraf jene Abtei des früheren Murbach, die im Jahr 727 von Abt Pirminius gegründet wurde, wie von Guillimann in seinem Werk „Habspurgiaco“ berichtet wird. Und ich setzte mich dafür ein, dass der jetzige Abt in anständiger Kleidung herumläuft sowie die Regeln des Ordens und andere Dinge beachtet, und ich muss zugeben, dass der Abt seine Bereitschaft und seinen Wunsch zeigte, das auch zu tun, was er mir versprochen hatte. Aber wegen der Kälte und der weiten Entfernung von Luzern hat er mich immer hingehalten, bis er wegen der Pest gezwungen war, auf sein Versprechen vollends zu verzichten, um der Gefahr der Ansteckung zu entkommen. Was den Abt von Kempten betrifft, so gibt es sogar noch mehr Schwierigkeiten, denn die Entfernung ist groß und er ist übermütiger als der andere, den ich genannt habe. Aber auch bei ihm habe ich es versucht, in der Hoffnung, gute Früchte hervorzubringen.

Unter den nicht reformierten Abteien befindet sich jene von Disentis ${ }^{124}$ in Graubünden, die sehr edel und sehr alt ist, und die alten Äbte hatten ein „Jus cudende monete“ [Münzrecht, Anm. des Übersetzters] und die erste Stimme in Graubünden. Aber heute befindet sich dieses Kloster wegen der Missregierung dieser Prälaten in einem schlechten Zustand. Es geht nun darum, die Vernichtung dieses Klosters zu verhindern. Deshalb versucht man jetzt den heutigen Abt zu überzeugen, der reformierten Kongregation der Äbte Helvetiens beizutreten. Und ich habe ihm mit lebhaften und herzlichen Ermahnungen dazu angeraten und hoffe, dass dieses Vorhaben auch gelingen würde. Wenn es nämlich an diesem Ort gute Mönche gäbe, könnte man auf einen großen Erfolg gegen die Ketzer in Graubünden hoffen, und man hätte auch einen Vertrauten mehr in

122 Bei den sogenannten „reformierten Benediktinern“ handelt es sich um Zisterzienser, die in der Tradition der Gründer des Klosters Cîteaux ihr Ordensleben führen.

123 Murbach-Ludens: Es ist nicht klar, was der Autor hier mit Ludens meinte.

124 Vgl. Stichwort „Disentis“, in: https://hls-dhs-dss.ch/de/articles/011490/2010-03-17/ (31. Dezember 2020). 
der Provinz Graubündens; denn dieses Kloster ist heute in der Tat so arm an Untertanen, und der jetzige Abt ist so schwach, dass es nach seinem Tod schwierig ist, ihn durch jemanden zu ersetzen, der dann auch noch erfolgreich wäre. Es wäre also gut, bei Zeiten darüber nachzudenken und sich mit den Herren Florin ${ }^{125}$ auszutauschen, von dem einer in Altdorf ist und der sich an der Rettung des Klosters beteiligen möchte. Gemeinsam könnte man Mittel finden, damit die edle Abtei nicht untergeht, und das kann mit einer Bedingung verknüpft werden, dass es mögliche Verdienste geben könnte. Aus der Aufforderung an den Abt, gute Mönche zu wählen und sich mit der genannten Schweizer Kongregation $\mathrm{zu}$ vereinen, was von mir bereits angesprochen wurde, wurde bisher nichts, denn die Qualität der Mönche und die Art der Menschen dort ist schwierig. Sie sind phlegmatisch und misstrauisch.

Wir kommen nun zu den reformierten Klöstern, das heißt zu denen, die in einer bestimmten Kongregation zusammengeführt sind. Ich bezeichne diese als reformiert im Vergleich zu den anderen, weil sie ein gemeinschaftliches Leben führen, die Gottesdienste bei Tag und bei Nacht versehen, wie es in Italien geschieht, kein Eigentum besitzen und die Klausur ehrenhaft beachten. ${ }^{126}$

Es kommen hier zwei Kongregationen in Betracht, und zwar auf der einen Seite jene aus Helvetien und auf der anderen Seite jene aus Schwaben, wobei diese älter und die andere jünger, aber zahlreicher anzutreffen ist.

Diese Kongregationen sind vom Papst mit Lob anerkannt und unter dem Schutz des Apostolischen Stuhls angenommen worden. Sie treffen sich jährlich in einer anderen Abtei, und es gibt Ordnung und Eintracht. Sie schlagen Wege vor, um Fortschritte im monastischen Leben zu erzielen, indem sie jeweils immer zwei neue Äbte wählen, die alle Klöster während des Jahres besuchen. Auf diese Weise kann alles in guter Ordnung gehalten werden. Mit harter Strafe gehen sie gegen Gegner vor und die Verurteilten werden in ihren eigenen Räumen festgehalten.

Diejenigen Klöster in Savoyen und in der Schweiz gehen mit großer Sorgfalt vor, so dass vor einigen Jahren alle eine gemeinsame Form des Breviers nach dem römischen Gebrauch mit ihren eigenen Heiligen zusammengestellt haben und in Rom überarbeiten ließen. Das wurde nicht nur von der Heiligen Kongre-

125 Vgl. Stichwort „Florin“, in: https://hls-dhs-dss.ch/de/articles/021908/2017-03-10/ (31. Dezember 2020). Es könnte sich um Paul Florin handeln, der ab Ende des 16. Jahrhunderts alle wichtigen Landesämter Graubündens innehatte. Die Familie Florin erreichte im 17. Jahrhundert ihre höchste politische Einflussnahme.

126 Somit meint der Autor nicht die eigentliche Unterscheidung mit den Zisterziensern, sondern allgemein die Unterscheidung zwischen guten (reformierten) und „liberalen“ (nicht reformierten) Abteien, die sich sozusagen eigene Regeln vorgeben. 
gation des Konzils, sondern auch noch vom ehrwürdigen Bellarmin ${ }^{127}$ genehmigt. Es wurde auch die Erlaubnis erteilt, dass es gedruckt werden darf, so wie es geschehen ist, und es wurde beabsichtigt, dass es noch andere Kongregationen in anderen Provinzen übernehmen dürfen.

\section{Schwäbische Kongregation}

Die Schwabenkongregation wurde von Papst Clemens VIII. im Jahr 1603 bestätigt und den Äbten wurde befohlen, sich in jeder Not an den Nuntius bei den Schweizern $\mathrm{zu}$ wenden. Dieser Kongregation steht der Abt von Weingarten [Veringartense im Originaltext] ${ }^{128}$ vor. Dieses Kloster hat Würde und ist eines der schönen, gut gebauten Klöster, die in ganz Deutschland zu finden sind. Zusätzlich zu einer großen Anzahl von Mönchen, die alle gelehrt und qualifiziert sind, nimmt der jetzige Abt normalerweise auch eine Anzahl Schüler auf, die bei den Jesuiten in Dillingen studiert haben, was ihm einen beständigen Zuwachs an guten Studenten ermöglicht.

Von Schönheit ist im Kloster Weingarten vor allem das Kirchengebäude, das wert ist, besichtigt zu werden. Alles ist neu und in gutem Zustand und außerdem gibt es dort eine Holzdecke, die so schön geschnitzt ist, wie man es sich nur wünschen kann. Der Abt namens Georg ist einer der hochverehrten und angesehenen Prälaten, die sich in diesen Teilen des Landes befinden, und dies muss man berücksichtigen.

Er hat kürzlich gesagt, dass die Abtei Weingarten die Komturei Feldkirch den Malteserrittern abgekauft hat, die diesen Ort wenig berücksichtigten. Es wurden 60 tausend Gulden dafür bezahlt. $\mathrm{Zu}$ diesem Kauf gibt Seine Heiligkeit jetzt eben sein Placet, in Erwägung der Verdienste des Abtes, der einwirkenden Umstände und meiner demütigen Fürbitte und Bereitschaft, ihnen wohlwollend Gnade zu erweisen. Es wurde damit sehr gute Arbeit geleistet und wird wohl auch sehr gut arbeiten, denn an jenem Ort soll ein Priorat mit geachteten Mönchen gegründet werden, die in der Nähe der Ketzer viel Nutzen bringen und endlose Bekehrungen fördern werden.

127 Vgl. Thomas Dietrich: Die Theologie der Kirche bei Robert Bellarmin (1542-1621).

128 Der Abt des Klosters war seit 1555 einer der festgeschriebenen Vertreter bei einem Ordentlichen Reichsdeputationstag. Das Kloster war durch seinen großen Landbesitz von zuletzt 306 $\mathrm{km}^{2}$ mit etwa 11000 Einwohnern, der sich vom Allgäu bis zum mittleren Bodensee erstreckte und viele Wälder und Weingüter umfasste, eines der reichsten Klöster in Süddeutschland. Vgl. Hans Ulrich Rudolf, Anselm Günthör: Die Benediktinerabtei Weingarten zwischen Gründung und Gegenwart. 
Die Abtei von St. Marienberg ${ }^{129}$ im Vinschgau im Tirol ist der gleichen schwäbischen Kongregation eingegliedert, und obwohl der Bischof von Chur die Zuständigkeit für diesen Ort beansprucht hat, hat der ehemalige Nuntius, Monsignore von Veglia, sie von dessen Ordinariat eximiert, da der Bischof das Kloster selten besucht hat. Kraft des oben genannten Breves von Papst Clemens seligen Angedenkens untersteht sie nun unmittelbar dem Apostolischen Stuhl. Auch ich habe diesen Beschluss bestätigt, als ich wegen anderer Streitigkeiten und Kontroversen zwischen dem genannten Bischof und dem jetzigen Vorgesetzten dieser Abtei zu vermitteln hatte.

\section{Helvetische Kongregation}

\section{Kloster St. Gallen}

Den ersten Platz unter den Äbten der Kongregation in der Schweiz belegt zu Recht der Abt von St. Gallen, denn die Abtei ist sehr altehrwürdig und sehr berühmt. Der Heilige Gallus, ${ }^{130}$ der sie gründete, kam aus Schottland und war ein Schüler des Heiligen Kolumban, ${ }^{131}$ der 16 Jahre lang gegen Götzendiener predigte und sie bekehrte, und durch die Großzügigkeit des Königs von Burgund erhielt er im Jahr 644 an dem Ort, an dem wir heute die Stadt St. Gallen am Bodensee erblicken, sein Kloster. Er hatte zunächst den Titel Abt vom Herrscher Pippin erhalten, dem Sohn von Karl Martell. Der Heilige nahm mit seinen Mönchen die Regel des Heiligen Benedikt an und mit heiligem Leben bewohnte er das umgebende Land, das voller dunkler Wälder war, und allmählich vervielfachten sich die Privilegien durch Lehen, Gerichtsbarkeiten und Titelzuweisungen, und so wurden sie Fürsten des Reiches. Unter dem Schutz der Kaiser lebten sie und hielten sie lange Zeit an ihrer Stellung fest.

Die Ruhe dieser Äbte dauerte nicht allzu lange, denn im Jahre 759 versuchte Sidonius, ${ }^{132}$ Bischof von Konstanz, die Abtei und all ihre Gerichtsbarkeiten sei-

129 Die Klosterkirche stammt aus dem späten 12. Jahrhundert. Sie ist eines der größten Zeugnisse romanischen Kunstschaffens im Alpenraum, wie es in der Informationsbroschüre des heutigen Klosters heißt. Vgl. https://www.marienberg.it/de/kloster/kirche-krypta.html (31. Dezember 2020)

130 Vgl. Stichwort „Gallus“, in: https://hls-dhs-dss.ch/de/articles/010216/2006-11-20/ (31. Dezember 2020).

131 Vgl. Stichwort „Kolumban“, in: https://hls-dhs-dss.ch/de/articles/010215/2007-08-23/ (31. Dezember 2020).

132 Sidonius von Konstanz († 4. Juli 760 auf der Insel Reichenau) war von 746 bis 760 Bischof von Konstanz. Vgl. Stichwort „Sidonius“, in: https://hls-dhs-dss.ch/de/articles/012970/201604-13/ (31. Dezember 2020). 
nem Bistum zu unterwerfen, und nach ihm wiederholten andere Bischöfe diese Aufforderung mit Waffengewalt, so dass gefährliche Kriege mit sehr unterschiedlichen Erfolgen entstanden, die hier auszuführen zu langwierig wäre, aber auch das Wissen, dass die Äbte sich immer selbst verteidigt haben und großzügig waren und bis heute so viel an weltlichen Dingen besitzen, lässt uns verstehen, welchen Stellenwert der Streit hat, mit dem sich jetzt in Rom die heilige Rota beschäftigt. Seit mindestens 19 Jahren wird darüber gestritten. Ursprünglich wurde dieser Streit auf weltlicher Ebene ausgetragen, und jetzt auf kirchlicher Ebene. Der Bischof von Konstanz verlangt, dass er im ganzen Land des Abtes regieren darf und dass dieses Gebiet intra fine der Diözese liege, ${ }^{133}$ und andererseits setzte sich der Abt dafür ein, dass alle Gerichtsbarkeiten, die seine Priester betreffen, von ihm ausgeübt werden, und forderte für sich „Jurisdictione separatam et quasi episcopalem“. ${ }^{134}$. Das Ende dieses Streits wäre sehr fruchtbar, denn der siegreiche Abt würde sanftmütiger regieren als der Bischof. Auch erhöhen sich die Ausgaben und öffentlichen Skandale, die sich jeden Tag aus einem so langen Streit ergeben. Für dessen Beilegung habe ich auch sehr hart gearbeitet. Ich hatte gehofft, in wenigen Monaten eine Lösung zu finden, und so hatte ich die Verhandlungen ausgearbeitet, aber dann wurde ich durch einen weiteren Unfall verhindert, so dass ich es nicht für unmöglich halten würde, irgendwelche Schwierigkeiten zu überwinden, wenn mein Nachfolger meine Gedanken anwenden würde.

Dieselbe Abtei kämpfte lange Zeit gegen die Appenzeller, die Untertanen des Klosters waren, und die Vorwände der Rebellion war der Name Appenzell, das Abbatiscella ${ }^{135}$ bedeutet. Die schwere Last des Aufstands zwang die Äbte dazu, sieben Jahre lang mit Hilfe der Österreicher, des Kaisers Friedrich Stauffer, des Grafen von Württemberg und anderen vorzugehen. Appenzell trennte sich von der Stadt St. Gallen, da es in der Stadt ebenfalls Aufstände gegen das Kloster gab. Doch dann kam es zum Bund mit vielen Schweizer Kantonen. Am Ende des Jahres 1408 wurden die Differenzen von Kaiser Ruprecht ${ }^{136}$ beigelegt, und wie die Appenzeller heute behaupten, hätten sie den genannten Äbten für ihre Freiheit einen hohen Preis gezahlt. Nun seien sie im freien Besitz davon. Deshalb besteht Helvetien seit dem Jahr 1513 aus 13 Kantonen. Die Stadt St. Gallen war zuvor lange Zeit den rechtmäßigen Herren ihres Klostergründers unter-

133 Der Bischof von Konstanz wollte somit, dass St. Gallen territorial zum Bistum Konstanz gehört.

134 Gemeint ist, dass der Abt dieselben Rechte wie ein Bischof haben soll.

135 Auf Deutsch: „kleine Abtei“.

136 Ruprecht (1352-1410) aus der Dynastie der Wittelsbacher war von 1400 bis 1410 römischdeutscher König. Vgl. Historisches Lexikon Bayerns: https://www.historisches-lexikon-bayerns.de/Lexikon/Startseite?title=Hauptseite (31. Dezember 2020). 
worfen gewesen, aber bereits unter Kaiser Friedrich II. fiel sie durch die Forderungen der Rebellion, die vom Kaiser gutgeheißen wurden. Die Stadt schloss sich dann den Schweizer Kantonen mit einem engen Bündnis an, das die katholische Religion verbot und stattdessen den skandalösen Fehler machte, die Zwinglianer anzunehmen, die ihre Nachbarn sind.

Die Äbte, die sich von Feinden umgeben sahen und sich nicht verteidigen konnten, weil sie sonst den Ort und ihr Leben verloren hätten, hatten sich bewusst mit den Kantonen verbündet, und so stehen sie an erster Stelle unter den Eidgenossen, wenn es um ihre Verteidigung geht.

Die Macht des Abtes wird sehr hoch geschätzt, da man sieht, dass er in acht oder zehn Tagen etwa 12 tausend Infanteristen im Land zusammenstellen kann, obwohl er oft von den benachbarten Zürchern beneidet und schikaniert wird, die ihm aufgrund ihrer Religion sehr feindlich gesinnt sind. Dazu kommt noch die weitere Belästigung durch die Luzerner, Schwyzer, Glarner neben den genannten Zürchern. Die Beschützer des Klosters möchten sich nicht einmischen. Deshalb versuchen die Gegner, wo sie Feld gewinnen, so viel wie möglich davon an sich zu reißen.

Das Territorium dieser Abtei ist so groß, dass sie 50 gute Pfarreien umfasst. Diese Gerichtsbarkeit ist in eine alte und eine neue Jurisdiktion aufgeteilt, und diese wurden drei Jahre lang kontinuierlich von Ketzern tyrannisiert, als die Schweizer ihre Religion wechselten, ${ }^{137}$ aber die Äbte haben in kurzer Zeit vieles zurückgewonnen, so dass in der alten Gerichtsbarkeit, in der sie die absoluteste Herrschaft haben, die Todesstrafe vorgesehen ist, wenn jemand nicht katholisch sein will. In dem neuen Herrschaftsgebiet, das am sogenannten „landsfreiden"138 teilhat, gibt es die Freiheit, die Religion, die man will, auszuwählen, und es gibt dort eine große Anzahl von Ketzern. Auch wenn sich jeden Tag durch den jetzigen wachsamen Abt Bernhard ${ }^{139}$ eine große Anzahl von Pfarreien durch die Bekehrung zum wahren Glauben erweitert hat und da die Heilige Messe in zahlreichen Pfarreien wieder eingeführt wurde. Die Priester werden dort aus der eigenen Geldbörse des Abtes bezahlt. Aus diesem Grund müssen die Nuntien ihn als Verfechter der wahren Lehre und des vollkommenen Ansehen immer begünstigen, da er unmittelbar dem Apostolischen Stuhl untersteht.

137 Damit ist die Zeit der Reformation gemeint. Vgl. Stichwort „Reformation“, in: https://hlsdhs-dss.ch/de/articles/013328/2013-01-29/ (31. Dezember 2020).

138 Vgl. Stichwort „Landfrieden“, in: https://hls-dhs-dss.ch/de/articles/008951/2010-05-20/ (31. Dezember 2020).

139 Vgl. Abt Bernhard Müller von St. Gallen (1557-1630): „Als überzeugter Anhänger der Jesuiten wirkte Müller im Geiste des tridentinischen Konzils.“ Zit. nach Stichwort „Bernhard Müller“, in: https://hls-dhs-dss.ch/de/articles/021735/2011-01-13/ (31. Dezember 2020). 
Und mit St. Gallen schloss sich eine weitere Abtei namens St. Johann im Thural $^{140}$ im Kreis Toggenburg an. Das ist vor nicht vielen Jahren geschehen. Dort leben vor allem Bauern und noble Herren.

Der jetzige Abt will vom Grafen Sulz die Grafschaft Vaduz und das Gut Schellenberg an der Grenze zu Graubünden, wo eine komfortable Festung steht, kaufen. Es handelt sich um einen Durchgang zu anderen Orten, der von großer Bedeutung ist. Der Preis wurde auf 207 tausend Rheinische Gulden festgelegt. Die Verhandlung ist bereits abgeschlossen, aber jetzt scheint es, dass der Graf von Altemps ${ }^{141}$ als Dompropst von Konstanz und Erzbischof von Salzburg ebenfalls Interesse am Kauf geäußert habe, und so ist die Sache bis jetzt noch offen, da der Graf von Sulz als Verkäufer den Vertragsabschluss in die Länge zieht, auch wenn er sein Wort gegeben hatte.

Und da ich anscheinend viel vom Abt von St. Gallen berichtet habe, möchte ich im Kompendium auch über andere Äbte der helvetischen Kongregation desselben Ordens des heiligen Benedikts ein paar Worte sagen.

\section{Kloster Einsiedeln}

Der Abt von Einsiedeln hatte noch das Privileg des Reichsprinzips, welches von einigen Kaisern in Bezug auf die berühmte und hochverehrte Marienkapelle vergeben wurde. Diese befindet sich in der Kirche dieses Klosters und wurde im Jahr 948 zur Zeit des Papstes Agapitus II. ${ }^{142}$ in Anwesenheit von Konrad, ${ }^{143}$ Bischof von Konstanz, geweiht. Auf die Fürsprache vieler Heiliger und Engel des Paradieses ereigneten sich bemerkenswerte Wunder, die dieser Muttergottes zugesprochen wurden und die von Papst Leo VIII. ${ }^{144}$ anerkannt und beglaubigt wurden, dem Papst, der wie Otto, der Große Kaiser, und andere Fürsten an ein solches Wunder glaubte. Er glaubte der Tatsache, dass damals durch unzählige Wunder bewiesen wurde, wie bedeutend jener Ort war, da es jeden Tag von

140 Vgl. Stichwort „Sankt Johann im Thurtal (Kloster)“, in: https://historisches-lexikon.li/ Sankt_Johann_im_Thurtal_(Kloster) (31. Dezember 2020).

141 Nicht zu verwechseln mit der italienischen Familie Altemps. Der Autor verwendet die italienische Version für die Grafen von Hohenems, denn ursprünglich hießen die italienischen Altemps „Alta Emps“, was die wörtliche Übersetzung von Hohenems ist. Die italienische Familie ist ein Nebenzweig der 1759 ausgestorbenen Familie von Ems zu Hohenems, ursprünglich aus dem heutigen Hohenems in Westösterreich (Vorarlberg).

142 Agapitus II., auch Agapet II. († 8. November 955), war Papst vom 10. Mai 946 bis zu seinem Tod. Vgl. Friedrich Wilhelm Bautz: Agapitus II., S. 52-53.

143 Vgl. Stichwort „Konrad (Heiliger)“, in: https://hls-dhs-dss.ch/de/articles/010204/2016-0413/ (31. Dezember 2020).

144 Leo VIII. war ab 4. Dezember 963 Papst. Zwei Jahre lang amtierte er auf dem Stuhl Petri. Vgl. Harald Zimmermann: Leo VIII., S. 1442-1443. 
Gott auf die Fürbitte der Königin des Himmels und seiner heiligsten Mutter bezeugt wurde. Daher gehört der Ort zu den berühmtesten in Deutschland ${ }^{145}$ und hat eine Sakristei mit wertvollen silbernen Verzierungen und Perlen, die ebenfalls von großem Wert sind und den Gaben, die die Fürsten des gesamten Christentums ihr gebracht haben, zu verdanken sind. Diese Abtei hat sehr viele Privilegien und wurde vor langer Zeit in die Zuständigkeit der Konstanzer Bischöfe aufgenommen, und sie behält auch heute noch die weltliche Zuständigkeit in dem Dorf in der Nähe des Klosters und an anderen nahe gelegenen Orten.

Aufgrund der Größe des Bistums Konstanz und der Anzahl der Menschen, die $z u$ diesem heiligen Ort beitragen, hat Seine Heiligkeit dem jetzigen Abt von Einsiedeln, genannt Augustinus, ${ }^{146}$ einem frommen und heiligen Mann, die Würde des Titularbischofs vergeben. Damit verbunden ist die Befähigung, in seiner Kirche $\mathrm{zu}$ bestimmten Zeiten des Jahres das Sakrament der Firmung zu erteilen. Schon hatte ich den Auftrag erhalten, den Prozess „de vita et moribus“ einzuleiten, als aber der Bischof von Konstanz sich dem widersetzte, da er befürchtete, dass die Schweizer, die sich diesem neuen Titularbischof anschließen, versuchen würden, sich zum Nachteil seiner Kirche vom Bistum zu distanzieren. Und so arbeitete er daran, dass alles zum Schweigen gebracht wurde, und dem Abt blieb der Verdruss darüber, dass diese Angelegenheit unter die Leute verbreitet wurde, ehe sie überhaupt entschieden worden war.

\section{Kloster Muri}

Der Abt von Muri ist ebenfalls Mitglied derselben helvetischen Kongregation und hat ein ehrenvolles und reiches Kloster, das einen halben Tag von Luzern entfernt liegt. Das Kloster wurde von Radbots von Habsburg ${ }^{147}$ von Österreich im Jahr 1026 gegründet, einer der ältesten und königlichsten Familien. Dieses Kloster steht wie das von Einsiedeln unter dem Schutz des Apostolischen Stuhls. Der jetzige Abt regiert sowohl im Geistigen als auch im Weltlichen mit großer Umsicht, Güte und Verdiensten.

145 Im Original: „de più celebri di Germania“.

146 Vgl. Stichwort „Augustin Hofmann“, in: https://hls-dhs-dss.ch/de/articles/025727/200801-08/ (31. Dezember 2020): „1600 zum Abt gewählt. Hofmann reformierte die Klosterverwaltung, festigte das monastische Leben (Chorgebet, Einhaltung der Klausur) und beteiligte sich maßgeblich an der Gründung der Schweiz. Benediktinerkongregation (1602 in Einsiedeln).“

147 Vgl. Stichwort „Muri (Kloster)“, in: https://hls-dhs-dss.ch/de/articles/011496/2010-09-02/ (31. Dezember 2020). 


\section{Kloster Rheinau}

Die Abtei von Rheinau ${ }^{148}$ befindet sich mitten im Rhein, in einer sehr reizvollen Lage. Der Abt hat wie die anderen genannten Äbte viele Privilegien. Seine weltliche Herrschaft erstreckt sich über ein großes Land, das ebenfalls Rheinau genannt wird. Aber mit all dem, was mit der Ketzerei eingetreten ist, kam es, dass Katholiken von dort vertrieben wurden. Der jetzige Abt tut alles, um den katholischen Glauben auch vor dem Hintergrund verschiedener Streitigkeiten wiederherzustellen. Bei den Streitigkeiten geht es um Auseinandersetzungen, die in Baden mit den Zürchern stattgefunden hatten. Durch meine Hilfe haben die katholischen Kantone in diesem Jahr 1612 die Abtei vor ihren Gegnern beschützt, und wir haben erreicht, dass die Heilige Messe nach 90 Jahren Verbot wieder eingeführt wird.

\section{Kloster Engelberg}

Die Abtei Engelberg befindet sich auf dem Gipfel der Alpen innerhalb der Grenzen des Kantons Unterwalden, und in der Antike war sie sehr edel und hatte eine große Anzahl an Mönchen. Heute aber ist diese Abtei die ärmste von allen, obwohl sie Herrschaft und Gerichtsbarkeit im Tal besitzt. Trotz seiner Überlegenheit und des Schwertes an seinem Wappen kam es durch ständige Streitigkeiten mit seinen Nachbarn von Unterwalden dazu, dass diese Macht verlorenging. Es geht um Steuereintreibung und Grenzfragen. Der jetzige Abt sieht ein, dass diese Herren darauf aus waren, ihm nach und nach alle Gerichtsbarkeiten $\mathrm{zu}$ entziehen, die sie in diesem armen Tal hatten. So wurde von mir versucht, alle Streitigkeiten in Anwesenheit einiger Abgeordneter aus Luzern und Schwyz beizulegen, aber danach sind wieder andere Differenzen entstanden, die jetzt mit meiner Hilfe aufgearbeitet werden.

Dieser jetzige Abt ist der einzige in Helvetien, der keinen Bischofshut trägt, aber ihm gefällt, dass seine alten Vorgänger die Mitra trugen. Nachdem er also durch mich die Gnade erbeten hatte, hegte er die Absicht, ebenfalls einen bischöflichen Titel zu erhalten, doch erschrocken von den großen Kosten, blieb er noch im Zweifel, ob er diesen Antrag stellen will.

In der Nähe dieser Abtei gibt es ein altes Nonnenkloster an einem verlassenen Ort, das der Fürsorge des Abtes empfohlen wird, aber es scheint mir, dass zu viel Nähe Anlass für einen Skandal sein könnte, da ich manchmal versucht habe, diese wenigen Nonnen in andere, weniger gefährliche Klöster zu versetzen und nach ihrem Aussterben die entsprechenden Einkünfte zu einem anderen frommen Werk hinzuführen. Da es jedoch zwischen dem Abt und dem Kan-

148 Vgl. Stichwort „Rheinau (Kloster)“, in: https://hls-dhs-dss.ch/de/articles/011596/2011-1223/ (31. Dezember 2020). 
ton Unterwalden zu Schwierigkeiten bei diesem Antrag kam, blieb dieses Vorhaben ausgesetzt. Es muss dies aber künftig getan und dafür gesorgt werden, denn es wird nicht sehr schwierig sein, es erfolgreich durchzuführen. Wenn es möglich wäre, mit dem Einkommen dieser Nonnen ein Benediktinerkloster am Grabe des Seligen Einsiedlers Nikolaus ${ }^{149}$ zu gründen, auf dessen Fürsprache so viele Wunder in diesem Kanton Unterwalden geschehen, wie berichtet wird, dann wäre es ein sehr großzügiges und frommes Werk. Umso mehr wäre das gut, da es um die Heiligsprechung des Heiligen Mannes geht. Schon andere Male wurde es auf Antrag Roms versucht, und es mangelt an nichts, außer daran, das zur Kanonisation nötige Geld aufzubringen.

In derselben Schweizer Kongregation gibt es noch die Abtei Fischingen ${ }^{150}$ und die Abtei Pfäfers ${ }^{151}$ in Graubünden. Sie sind ebenfalls angesehene Klöster und stehen unter ehrenwerten Äbten. Aber da keine weiteren Einzelheiten wichtig sind, über die zu berichten wäre, wollen wir mit anderen Klöstern fortfahren, die übrigbleiben.

\section{Kloster St. Blasien}

Der Abt von St. Blasien im Schwarzwald ist zwar noch Benediktiner und lebt nach der reformierten Regel, doch gehört das Kloster nicht mehr der Schweizer Kongregation an, weil der Abt Reichsfürst ist und sich der Ort außerhalb Helvetiens befindet, wo sich die Schweizer dem Kaiser widersetzen würden. Ein Beitritt zur Schweizer Kongregation würde Misstrauen gegen ihn erregen. Auch der Kongregation von Schwaben kann der Abt nicht beitreten, da sie zu weit von dieser Provinz entfernt liegt.

Die Einnahmen an diesem Ort sollen etwa 100 tausend Scudi betragen. Das Kloster ist wunderschön, befindet sich aber in bitterer Einsamkeit, und fast in der verstecktesten Einsiedelei des Schwarzwaldes, der wegen der Dunkelheit und der Dichte der Bäume, die sich dort befinden, Schwarzwald genannt wird.

Es war Monsignore Portia, ${ }^{152}$ Nuntius für Deutschland, der schöne Befehle für die Reform dieses Ortes gegeben hatte, aber es gab zu dieser Zeit viele Schwierigkeiten und an vielen Orten herrschte Lauheit. Der jetzige Abt namens

149 Vgl. Stichwort „Niklaus von Flüe“, in: https://hls-dhs-dss.ch/de/articles/010224/2017-0928/ (31. Dezember 2020).

150 Vgl. Stichwort „Fischingen (Kloster)“, in: https://hls-dhs-dss.ch/de/articles/000301/200501-19/ (31. Dezember 2020).

151 Vgl. Stichwort „Pfäfers (Kloster)“, in: https://hls-dhs-dss.ch/de/articles/011595/2010-0118/ (31. Dezember 2020).

152 Vgl. Stichwort „Bartolomeo Portia“, in: https://hls-dhs-dss.ch/de/articles/017914/201005-25/ (31. Dezember 2020): „1571 sollte Portia als Nuntius in die Schweiz reisen, doch kam der Besuch wegen des Widerstands der Eidgenossenschaft nicht zustande. ... Anders als in 
Martin $^{153}$ rief mich herbei und ich erteilte neue Befehle, bestimmte die Grenzen und reformierte den Ort, damit wieder Frieden und Zufriedenheit für all diese Mönche einkehre, und tröstete sie mit Ablässen und einem von unserem HerrnPatron gespendeten Altar.

Von allen Abteien des Heiligen Benedikt kann ich im Allgemeinen sagen, dass ich große Anstrengungen unternommen habe, damit die Mönche auf dem richtigen Weg der Ordensregeln wandelten. Denn ich fand dort besonders großen Missbrauch vor. So trugen die Mönche nicht den Ordenshabit, sondern benutzten ein anderes Gewand und kleideten sich wie Priester. Und schließlich gab ich ihnen zu verstehen, dass die Form der Ordenskleidung wesentlich ist, und das gilt besonders für die Kapuze, die zur Geduld veranlasst, und so tragen sie jetzt die eigentümliche Kapuze ihrer Ordensgemeinschaft, was jetzt beachtet wird.

Ich entdeckte noch einen weiteren Abgrund, als ich Mönche außerhalb des Klosters in Pfarreien der Präfekturen und der Gerichtsbarkeit vorfand, die dort beschäftigt waren, und als ich von dem Übel hörte, dass sie dort sehr häufig auftraten und das auch fortzuführen gedachten, unternahm ich große Anstrengungen, von ihren Äbten die Zusage zu erhalten, dass sie alle an das Kloster gebunden bleiben sollten und nicht mehr in solchen Lasten der weltlichen Menschen beschäftigt werden dürfen. Sie dürfen keine Verpflichtung außerhalb des klösterlichen Lebens haben. Dazu sollen Diözesanpriester eingesetzt werden, welche kein Klostergelübde abgelegt haben. Aber ich habe meine gesamte Absicht noch nicht erreicht, obwohl ich auch den Abt von Weingarten und den von St. Blasien daran erinnert habe. Daraufhin rief der Abt von Weingarten all jene Mönche, der von St. Blasien wenigstens die meisten wieder ins Kloster zurück, und so sollte vorgegangen werden.

Es gibt noch viele andere Klöster und Abteien des Ordens des Heiligen Benedikt im Gebiet der Nuntiatur, aber da sie nicht von Belang sind und um den Umfang dieser Schrift nicht zu vergrößern, wollen wir diese beiseitelassen.

\section{Zisterzienser}

Nach den Benediktinern kommen die Zisterziensermönche an erster Stelle in dieser Position, und auch sie haben dort gute und edle Abteien.

den deutschen und österreichischen Gebieten blieb dem bedeutenden Reformnuntius Portia der Erfolg in der Schweiz versagt.“

153 Martin Meister, auch Martin I. (um 1560-1625) wurde im September 1596 zum 36. Abt des Klosters St. Blasien erwählt. Mit großem Aufwand bemühte er sich um eine ansehnliche Bibliothek. Vgl. Stichwort „St. Blasien“, in: https://hls-dhs-dss.ch/de/articles/007111/2011-01-11/ (31. Dezember 2020). 
1606 erhielt der Nuntius und Erzbischof von Veglia von Seiner Heiligkeit durch ein Breve den Auftrag, alle Zisterzienserklöster der gesamten Nuntiatur in einer reformierten Kongregation zu vereinigen. Und mir wurde ebenfalls ein Breve mit demselben Auftrag gegeben, so dass ich lange daran gearbeitet habe, das Ansinnen Seiner Heiligkeit auszuführen, aber es gibt noch mehr Schwierigkeiten als bei den Benediktinern, da sie keinen Ordensgeneral anerkennen und keinen Vorsteher haben. Daher ließen sich die Benediktiner dagegen auch so leicht in eine Vereinigung zusammenführen. Aber die Zisterzienser, die ihrem französischen General gehorchen, wollten nicht so leicht unserem Ansinnen zustimmen, aus Angst, dass bei einem Scheitern des Anliegens der Vorgesetzte gegen sie vorgehen würde, als wären sie für die Neuerungen nicht geschaffen. Auf diese Weise haben sie sich aus der Sache herausgehalten, und in letzter Zeit haben sie nach einigen Bedingungen gefragt, aber weil sie mir übertrieben erschienen, musste ich ihre Vorschläge zurückweisen.

Dennoch kann man nicht sagen, dass diesen Klöstern die Reform zuwider ist, denn sie leben ohne Skandale. Sie werden von einem der vier Assistenten des Ordens besucht, und einige von ihnen leben mit der nötigen Strenge und ihre ehrenhafte Einhaltung ist lobenswert.

\section{Wettingen}

Wettingen ist eine Viertelmeile von Baden entfernt. Es handelt sich um eine alte und sehr edle Abtei, die von Heinrich, ${ }^{154}$ Graf von Rapperswil, gegründet wurde und vom Grafen von Habsburg, dem Oberhaupt des Hauses Österreich, erweitert und ausgestattet wurde, was durch Geschichte, Gebäude und Grablegen belegt wird, die sich in diesem Kloster befinden, das auf Latein „Maris Stella“(155 genannt wird. Das Kloster steht unter dem heutigen Abt nach der Reform keiner Benediktinerabtei nach. Er forderte, dass sein Kloster einem kleinen Priorat eingegliedert werden soll, das nach dem Heiligen Wilhelmsorden von Sion heißt. Der Grund des Anspruchs waren einige Vorschläge der Kantone, die ihre Beschützer sind, aber nachdem ich die Abtei mit eigenen Augen gesehen hatte, stellte ich fest, dass die Vereinigung nicht existierte und dass das Priorat einer anderen Religion zugehörig ist. Die Mönche gehörten in keiner Weise der oben genannten Abtei von Wettingen an, so dass ich eine Absage erteilte. Mit Hilfe des Bischofs von Konstanz übergab ich ihm Mönche von St. Blasien. Ich gab ihnen die Anordnung, die man Reformen nennt, obwohl es auf der Seite der Schweizer Fürsten gab, die sich dem Abt nicht beugen wollten und behaupte-

154 Vgl. Stichwort „Wettingen (Kloster)“, in: https://hls-dhs-dss.ch/de/articles/012147/201310-28/ (31. Dezember 2020).

155 „Stern Mariens“ auf Deutsch. 
ten, ihre alten Zugeständnisse für immer beibehalten zu haben. Viele Schwierigkeiten gab es, aber ich bin jetzt informiert worden, dass dieselben Herren, die zum St. Wilhelmsorden von Sion wollten, mit dem von mir eingesetzten Prior sehr zufrieden sind, weil er wirklich eine fromme Person mit guter Regierungsführung und besonderem Eifer ist. Er war so tüchtig und fromm, dass er schon sechs Priester und andere Ordensleute in das Kloster eingeführt hat, welche dem Gottesdienst vorstehen. Wäre es Sion einverleibt worden, so könnte von alledem nicht die Rede sein und das angesehene Kloster wäre verloren gewesen.

Dieser Abt von Wettingen kümmert sich um sieben oder acht Klöster von Nonnen seines Ordens, und er hat alles auf sehr lobenswerte Weise reformiert. In Kenntnis dieses Eifers habe ich ihm somit auch noch die Fürsorge des Klosters Olsberg ${ }^{156}$ anvertraut, das überhaupt nicht eingerichtet war, weil man dort nicht so fleißig mit der Visitation des Abtes von Lützel ${ }^{157}$ umgegangen ist, doch heute ist der Ort in gutem Zustand, und sie leben dort auf fromme Weise.

\section{St. Urban}

Die Abtei von St. Urban gehört dem Zisterzienserorden an und befindet sich ebenfalls im Gebiet Luzerns an der Berner Grenze. In diesem Kloster herrschte früher große Lockerheit, so dass meine Vorgänger ihm die Aufsicht über die beiden Nonnenklöster von Rathausen ${ }^{158}$ und Eschenbach ${ }^{159}$ bei Luzern entziehen mussten. Aber nachdem ich dann zu meiner Zeit entdeckt habe, dass dort ein besseres Leben geführt wurde, und nachdem sie die von mir geforderte Reform in den wesentlichsten Dingen durchgeführt hatten, gab ich dem Abt bei meinem Besuch die Klöster wieder zurück, indem ich die Beichtabnahme den Jesui-

156 Vgl. Stichwort „Olsberg (Kloster)“, in: https://hls-dhs-dss.ch/de/articles/011160/2016-1110/ (31. Dezember 2020): „Die auf Betreiben Erzherzog Ferdinands berufene Äbtissin Katharina von Hersberg (1558-86) sollte das Kloster wiederbeleben; aber die Vorschriften des tridentinischen Konzils bezüglich des Verzichts auf persönliches Eigentum und der Einhaltung der Klausur wurden offenbar weder von ihr noch von ihren Nachfolgerinnen durchgesetzt. Auch wirtschaftlich gelang der Aufschwung nicht.“

157 Vgl. Stichwort „Lützel“, in: https://hls-dhs-dss.ch/de/articles/012144/2009-11-26/ (31. Dezember 2020): „Im 17. Jahrhundert trat Lützel der oberdeutschen Zisterzienserkongregation der gemeinen Observanz bei. Der Abt wurde Ordensvisitator für die Provinz, die das Elsass, die Schweiz und den Breisgau umfasste.“

158 Vgl. Stichwort „Rathausen“, in: https://hls-dhs-dss.ch/de/articles/012158/2010-07-28/ (31. Dezember 2020): „Nuntius Ottavio Paravicini ließ 1588 die vier luzernischen Frauenklöster, die alle von der Auflösung bedroht waren, in Rathausen und Eschenbach zusammenfassen. Da St. Urban damals nicht in der Lage war, die Frauenseelsorge auszuüben, setzte der Nuntius Jesuiten als Beichtväter ein, was schließlich zum sogenannten Beichtigerhandel führte.“

159 Vgl. Stichwort „Eschenbach (Kloster)“, in: https://hls-dhs-dss.ch/de/articles/012150/ 2004-11-03/ (31. Dezember 2020). 
ten überließ, die das aber höchst ungern taten, da es ihrer Ordensregel zuwiderläuft, es aber aus Demut gegenüber Seiner Heiligkeit dann doch übernahmen. Der Papst hat, um den Herren von Luzern zu gefallen, auch gestattet, dass ich den Jesuiten dieses Geschäft auch auf weitere fünfzig Jahre übertragen darf.

\section{Hauterive}

Die Abtei Hauterive ${ }^{160}$ der Zisterzienser hat ihre Abtei bei Freiburg in der Schweiz, und es war ein Ort, der im Verborgenen liegt und früher keinerlei Reform beachtete, da die Abtei weit weg von den Augen des Nuntius war, aber nachdem zu meiner Zeit der zum Abt postulierte und treffliche Herr Anton de Panna, ${ }^{161}$ Generalvikar von Lausanne, ein Mann von exzellenten Gepflogenheiten, das Kloster sofort reformiert hat, leben die Ordensleute jetzt dort in exemplarischer Weise wie jeder andere geordnete Ort.

\section{Salem}

Die Abtei von Salem, ${ }^{162}$ bekannt als schwäbische Abtei, ist einen halben Tag von Konstanz entfernt und die wichtigste und vornehmste dieser Ordensgemeinschaft in der Schweizer Nuntiatur, und das gilt auch für den Abt, der Reichfürst ist. Der Wormser Übereinkunft zufolge hat das Kloster 392 Gulden Abgabe zu bezahlen und sieben Pferde und 67 Fußsoldaten. Seine Einkünfte betragen aber 60 tausend Gulden im Jahr. Es handelt sich um eines der großen und leistungsfähigen Klöster, die in all diesen Gebieten zu finden sind.

Dieser Abt hat viele Nonnenklöster unter seiner Obhut, da er der Herr seiner eigenen Ordensgemeinschaft ist, und der jetzige Abt hat viel Barmherzigkeit gezeigt, indem er sie fast alle reformiert hat, weil sie in großer Not waren. Noch muss er das Kloster Gutenzell ${ }^{163}$ reformieren, wo alle Nonnen Adlige sind, doch sie widersetzten sich dem Orden und die schwäbischen Herren lehnten sich dagegen auf und sandten eine Bitte zusammen mit einer kaiserlichen Empfehlung an Seine Heiligkeit. Mir wurde dann der Auftrag erteilt, die Angelegenheit dahingehend zu leiten, den Nonnen zu gewähren, dass ihnen, solange sie dort leben, und vor allem denen, die sich jetzt im Kloster befinden, die Regeln nicht verschärft werden, und mit dieser Gnade gaben wir nach. Wohl aber muss die nächste Generation sich an die Reform halten. Aber der Abt ist nicht still geblie-

$\overline{160}$ Vgl. Stichwort „Hauterive (Kloster)“, in: https://hls-dhs-dss.ch/de/articles/012142/200711-29/ (31. Dezember 2020).

161 Der Name des Generalvikars ist unklar. Bei Snell wird er „Antona Pascua“ genannt. 162 Vgl. Stichwort „Salem“, in: https://hls-dhs-dss.ch/de/articles/007110/2011-02-04/ (31. Dezember 2020).

163 Vgl. Otto Beck, Ludwig Haas (Hrsg.): Gutenzell. 
ben, da er sein Bestes in dieser Angelegenheit gibt, und jeden Tag versucht man ihm neue Schikanen aufzubürden. Doch er will nicht, dass diese Nonnen das Zugeständnis genießen, das Seine Heiligkeit zur Überwindung großer Unannehmlichkeiten gewährt hat.

Die Äbte von Hauterive und von Lützel bleiben von diesem Orden, aber jener des letztgenannten Klosters, das sich an den Grenzen des Burgunds in der Diözese Basel befindet, wird in keiner Weise von seinen Mönchen gewürdigt. Von mir wurde er ermahnt und er war bereit, sich zu reformieren. Doch aus Angst vor der Gewalt der anderen Mönche bat er mich, ich solle mit der apostolischen Autorität langsam die Maßregeln befehlen. Das wurde auch so ausgeführt, und es bleibt ihnen die letzte Hürde zu überqueren, um, wie es sich gehört, die so heilige Vollkommenheit zu erreichen, was leicht durch die Erfolge erreicht werden kann, indem man dem Abt drängt, und das genügt, um die Lage der Zisterzienser zu erläutern.

\section{Prämonstratenser}

Die Prämonstratenser haben in dieser Nuntiatur noch einige Niederlassungen, wie in der Diözese Basel das Kloster Bellelay ${ }^{164}$ und in dem von Konstanz das von Weißenau, ${ }^{165}$ Rot an der Rot, ${ }^{166}$ Schussenried, ${ }^{167}$ Obermarchtal ${ }^{168}$ und andere, aber sie stören den Nuntius nicht sonderlich, weil sie wenige sind und zurückgezogen leben und sehr ordnungsgemäß geführt werden.

In Bellelay wurde kürzlich wegen des Todes des Abtes ein Nachfolger gewählt, aber weil er der Sohn eines Ketzers war, musste man notwendigerweise eine Dispens beschaffen. Man kann in Deutschland, wo so große Verwirrung in religiösen Angelegenheiten herrscht, die nötigen Kirchenregeln unmöglich genau beachten.

164 Im Original steht: „Ballilea“. Vgl. Stichwort „Bellelay“, in: https://hls-dhs-dss.ch/de/articles/008492/2012-05-31/ (Version vom 31. Mai 2012):

165 Das Kloster Weißenau hieß früher auch Minderau, während die lateinische Bezeichnung für dieses Kloster Augia Minor lautete und vom Autor auch so verwendet wurde. Die Abtei war ein reichsunmittelbares Chorherrenstift der Prämonstratenser wenige Kilometer südlich der ehemaligen Freien Reichsstadt Ravensburg in Oberschwaben. Es bestand von 1145 bis zur Säkularisation 1802/1803. Vgl. Helmut Binder (Hrsg.): 850 Jahre Prämonstratenserabtei Weißenau.

166 Es handelt sich um eine Reichsabtei, die früher auch nur Roth genannt wurde. Der Autor hat auch diese Bezeichnung für das in Oberschwaben liegende Prämonstratenserkloster verwendet.

167 Diese ehemalige Reichsabtei in Oberschwaben hat eine ähnliche Struktur wie Rot an der Rot und Weißenau.

168 Auf Latein: „Abbatia Marchtallensis“. Es liegt im Alb-Donau-Kreis. In der Nachbarschaft liegt der Ort Untermarchtal mit dem gleichnamigen Kloster der Vinzentinerinnen. 


\section{Regulierte Augustiner}

Die regulierten Augustiner haben in jenem Gebiet noch wenige Abteien und außerhalb von Konstanz haben sie die Abtei in Kreuzlingen, ${ }^{169}$ die sehr edel und altehrwürdig ist.

Diese Äbte verkauften einige Besitztümer in der Diözese Chur mit Gewinn, wie es von ihrem Kloster heißt, aber da es kein apostolisches Einverständnis für den jetzigen Abt gab, hatte ich versucht, ihm eine Bewilligung zu verschaffen, damit das Geschäft auch möglich sei. Ich glaube, dass er es verdient.

An das Bistum Konstanz ist eine weitere Abtei desselben Ordens namens Egnau angebunden, ${ }^{170}$ wo es noch viele Ordensleute gibt, und das reicht zur Erwähnung dieses Ordens aus.

\section{Bettelorden}

Was die Bettelorden betrifft, so gehören vor allem die Kapuziner dazu, die sich in kurzer Zeit an jedem Ort der Nuntiatur verbreitet haben. In Helvetien hat jeder katholische Kanton sein eigenes Kloster, und außerdem befinden sich weitere Klöster in Länder und Orten, die in Schwaben und im Elsass von Bedeutung sind. Sie sind sehr beliebt und werden zu neuen Ansiedlungen aufgefordert.

Angesichts der religiösen Bedrängnis in diesen Gebieten Deutschlands wurde den Kapuzinern das Beichthören gewährt, und niemand kann leugnen, dass seit ihrer Ankunft die Frömmigkeit gewachsen ist und dass die Dinge des Glaubens jetzt ganz anders vorangehen, als dies früher der Fall war.

Bisher gab es in der gesamten Provinz eine große Anzahl italienischer Kapuziner, und in ihren Händen befanden sich alle Angelegenheiten und Dinge, die mit der Strenge der Disziplin zu tun hatten. Aber jetzt, da die Zahl der deutschen Kapuziner gestiegen ist, ziehen sich die Italiener, teilweise des Misstrauens dieser Nation gegen die Fremden müde, mehr und mehr zurück. Ich glaube, dass dies großen Schaden und große Lauheit zur Folge haben wird, denn die Deutschen sind von Natur aus zum bequemen Leben aufgelegt und befolgen gewiss bald nachlässiger die frommen Regeln, wenn nicht Strenggesinnte sich um die Beichte und weltliche Geschäfte kümmern. Wenn dies überhaupt in einem Teil von Deutschland gilt, dann hier, wo die ursprüngliche Strenge dieser Ordensbrüder zuerst nachgelassen hat. Deshalb halte ich es für unumgänglich und notwendig, dass die italienischen Kapuziner die Schweiz nicht verlassen, sondern unablässig tüchtige und strenggläubige Männer hinschicken, um die

169 Vgl. Stichwort „Kreuzlingen (Stift)“, in: https://hls-dhs-dss.ch/de/articles/011409/201709-19/ (31. Dezember 2020).

170 Vermutlich handelt es sich um das Kloster Öhningen im Landkreis Konstanz. Die Bezeichnung des Ortes könnte sich auf Hegau nordwestlich des Bodensees beziehen. 
Regel aufrechtzuerhalten. Auch müsste schon aus diesem Grund immer eine gewisse Anzahl Italiener in diesem Land bleiben, weil der Nuntius wenigstens die Kapuziner, ohne Verdacht $\mathrm{zu}$ erregen, überall herumschicken kann, denn die Deutschen sind für wichtige Angelegenheiten, wie beispielsweise $\mathrm{zu}$ Klosterreformen - und da insbesondere bei Nonnenklöstern - kaum zu gebrauchen. Ich habe mich deshalb schon an Seine Heiligkeit und an den Ordensgeneral gewandt, und mein Nachfolger wird dies wohl auch so sehen, dass es für ihn am besten ist, wenn auf diesem Weg fortgeschritten wird.

Ich fürchte aber, die guten Väter schaden sich selbst durch ein allzu starkes Bestreben, sich in jeder noch so kleinen Ortschaft anzusiedeln. Die Orte sind meist arm, ihre Kräfte reichen kaum aus, und so müssen die Kapuziner, statt beim Beten im Chor zu bleiben, den ganzen Tag betteln gehen.

Die Franziskaner-Konventualen ${ }^{171}$ und die Barfüßer ${ }^{172}$ haben ebenfalls viele Klöster, aber es wäre besser, wenn sie keine hätten, denn sie sind alle der Regel untreu und geben Anlass zum Skandal, wo immer sie sich befinden, und, was schlimmer ist, es ist schwieriger, sie zu reformieren, als hundert Äbte anderer Ordensgemeinschaften.

Sie kümmerten sich um viele Klöster von Nonnen ihres Ordens, aber die glichen mehr Hurenhäusern ${ }^{173}$ als Klöstern. Diese Aufsicht habe ich den Mönchen deshalb fast überall entzogen, um sie anderen Orden oder Weltgeistlichen zu übertragen. Auf diese Weise habe ich mich um den Lärm, der deswegen entstand, nicht mehr kümmern müssen. Ich bitte meinen Nachfolger, ihnen auch die Versorgung der noch übrigen Nonnenklöster zu entziehen. Das Kloster Gutenzell in Schwaben und die Ursache, warum es nicht reformiert werden sollte, habe ich bereits oben erwähnt, als ich über den Abt von Salem als dessen Visitator sprach.

Die Ordensleute des Heiligen Dominikus und des Heiligen Augustinus beobachten nirgends die Abgeschiedenheit, und der Bischof von Konstanz, der die meisten unter sich hat, entschuldigt sich damit, dass die Klöster so arm sind, dass sie kaum geschlossen werden können.

In diesen Teilen Deutschlands gibt es noch eine andere Art von Frauenklöstern, und zwar jene, die Kongregation der weltlichen adeligen Jungfrauen genannt wird, ${ }^{174}$ und von denen es in der Diözese Konstanz das Kloster von Bad

171 Es handelt sich um die Minoriten, nach der Farbe ihres Habits auch „schwarze Franziskaner“ genannt.

172 Der Autor bezeichnet sie als „Zoccolanti“, also „Unbeschuhte“, die der Reformbewegung des Franziskanerordens im 16. Jahrhundert folgten.

173 Im Originaltext schreibt er von „portibolio“, also einem Ort, der zum Galgen führt.

174 Im Original heißt diese Kongregation: „Congregatione de Nobili vergini secolari“. Es handelt sich um die sogenannten Adeligen Chorfrauenstifte. Die Beschränkung der Aufnahme auf 
Säckingen, ${ }^{175}$ Lindau ${ }^{176}$ und Buchau ${ }^{177}$ gibt, in der Diözese Straßburg gibt es Andlau, ${ }^{178}$ und im Bistum Basel noch ein weiteres, aber diese haben keine Profess, außer für die Äbtissinnen, die an einigen Orten auf meinen Befehl ihre Gelübde abgelegt haben. Sie leben nicht in Abgeschiedenheit, schmücken sich prunkvoll mit Gold, verwenden edle Vorhänge und kleiden sich schön, und jedes dieser Stifte hat eigene Einkünfte. Die Mitglieder dieser Orte sind normalerweise Prinzessinnen des Kaiserreichs, und alle unterstehen eigenen Gerichtsbarkeiten.

Von den Kongregationen der Schwestern des Dritten Ordens des Heiligen Franziskus und der Heiligen Klara gibt es eine unendliche Anzahl in dieser Nuntiatur. In Helvetien hat jeder Kanton sein eigenes Kloster, und sie sind beliebt, weil sie als Institution die Kranken besuchen und die Toten zur Bestattung geleiten. Sie stellen Wachskerzen und andere Dinge her. Sie kümmern sich um jene, die wegen ihrer Armut die Klausur nicht beachten können. Allein im Bistum Konstanz gibt es rund 30 solcher Klöster.

Der am meisten reformierte Ort aller genannten Schwesterklöster des Heiligen Franziskus ist das Kloster namens Pfanneregg, ${ }^{179}$ und auf dessen Beispiel hin wurden viele andere reformiert. Und die Reform wird auch fortgeführt, dank der Bemühungen, die ich während meines Aufenthalts unternommen habe. Es wurden sieben Klöster reformiert, und die meisten von ihnen habe ich aus den Händen der Barfüßer und Konventualen entfernt, da sie die Konservativen gegen jegliche Änderungen waren, und sie gaben mir viel zu tun. Doch in Solothurn haben sie viel unternommen, dass nicht alle Nonnen reformiert wur-

schwäbische Gräfinnen ist bis zum Ende des Stifts strittig und wird seitens des Stifts immer wieder durchbrochen. Der Autor schreibt im italienischen Original auch von „Canonesse“, also Kanonissen.

175 Es handelt sich um das adelige weltliche Chorfrauenstift St. Fridolin Säckingen. Das Kloster blühte zwischen dem 10. und 12. Jahrhundert. Die Abtei besaß ab dem 14. Jahrhundert viele Ländereien auf schweizerischem Gebiet, die dann infolge der Auseinandersetzungen zwischen dem Haus Habsburg (Österreich) und der Eidgenossenschaft verlorengingen.

176 Obwohl sich die Stadt Lindau der Reformation anschloss und 1530 in der benachbarten Stefanskirche den protestantischen Ritus einführte, blieben die Stiftsdamen dem katholischen Glauben treu. Vgl. Stichwort „Lindau“, in: https://hls-dhs-dss.ch/de/articles/007076/2008-0124/ (31. Dezember 2020).

177 Eine päpstliche Urkunde von 1417 regelte grundlegend die Verfassung des Stifts. Danach ist Buchau ein weltliches Stift, gegründet für eine Äbtissin, zwölf Chorfrauen, vier weltliche Chorherren und zwei ständige Kapläne. Vgl. Bernhard Theil: Das (freiweltliche) Damenstift Buchau am Federsee.

178 Vgl. Christian Wildsdorf: Andlau, in: Lexikon des Mittelalters (LexMA).

179 Vgl. Stichwort „Pfanneregg“, in: https://hls-dhs-dss.ch/de/articles/011996/2009-08-05/ (31. Dezember 2020). 
den. Dort wurde nur ein einziges Frauenkloster reformiert. Deshalb wurde beschlossen, dass sie in zwei Kongregationen aufgeteilt werden sollten, auch wenn es sich um nicht reformierte Klöster handelt, die sich nicht entsprechend der Regel anziehen. Die Reform besteht aus einem engen und groben Habit, die von den Visitatoren überreicht wurden. Man darf sie nicht ohne Begleitung herumgehen lassen, und wenn doch, dann nur wenn es nötig ist. Sie sollen sich stattdessen im heiligen Leben und in der begonnenen Einfachheit üben. Bisher haben sie ein großes Beispiel gegeben, sind aber in großer Gefahr, da sie nicht in Klausur leben. Es ist auch zu hoffen, dass mit zunehmendem Einkommen viele dieser Klöster nicht mehr gebraucht und deshalb geschlossen werden, damit dann die Nuntien die Anliegen Seiner Heiligkeit umsetzen können, wie er sie dem Nuntius in einem Breve über die Pflege dieser Schwestern anvertraut hatte. Denn sie stehen unmittelbar unter seinem Schutz. Und die Kapuziner können durch die Beichte und die Unterstützung der Nonnen dabei helfen, weitgehend die Leiden der Nuntien zu verringern.

Aber um nicht weiter mit so weitreichendem Gerede über Mönche und Nonnen zu langweilen, möchte ich kurz auf die Diözesanpriester eingehen, die damit als Letzte in Bezug auf den geistlichen Zustand der Nuntiatur zu nennen sind.

\section{Diözesanpriester}

Es ist schön, die Anzahl der Kollegiatskirchen zu betrachten, auch das Alter der Stiftskirchen, die Anzahl der Kanoniker und die Qualität der Privilegien ist zu beachten, die sich alle in der gesamten Nuntiatur befinden und sich durch viele Anzeichen der Vergrößerung hervorheben, aber sich auch durch die großzügige Frömmigkeit der alten Deutschen kennzeichnen, die nicht nur freiwillig, sondern auch reichlich an die Kirchen gespendet und die Klöster bereichert haben.

Die Zahl der Kollegiaten, die sich allein in der Diözese Konstanz befinden, übertrifft die Zahl [keine Ziffer wird genannt, Anm. d. Übersetzers], wie sie am Ende der Synode zur Wirkungszeit von Kardinal Altemps zu sehen war. In Helvetien hat die Kollegialkirche von Berona, ${ }^{180}$ allgemein bekannt als Beromünster, die sehr altehrwürdig ist und bewundert wird und die vor über sechshundert Jahren von den Grafen von Lenzburg ${ }^{181}$ gegründet wurde, über viele Einnahmen verfügt, über die sie heute nicht mehr verfügt. Beromünster verfügt nur noch über die niedere Gerichtsbarkeit über den gleichnamigen Ort, was vom Apostolischen Stuhl bestätigt werden sollte, aber die Bischöfe von Konstanz

180 Die alte Bezeichnung für Beromünster. Vgl. Stichwort „Beromünster (Stift)“, in: https:// hls-dhs-dss.ch/de/articles/012007/2011-03-03/ (31. Dezember 2020).

181 Ebd. 
verlangen den Besitz dieses Klosters. Deshalb kämpft er mit dem jetzigen Propst darum, also soll er sich an den Apostolischen Stuhl wenden, und er ist entschlossen, dies zu tun, fürchtet aber den Urteilsspruch, weil ich ihm geschrieben habe, dass es an ihm liegt zu zeigen, ob ihm das Kloster wirklich zusteht. Und nachdem Seine Heiligkeit die Absicht erklärt hat, das juristisch oder gemäß den Regeln der Kanzlei zu prüfen. Der Bischof antwortete mir immer mit guten Worten, aber er hatte dennoch dem Propst befohlen, sich an keine andere Stelle als das Gericht in Konstanz um seine Bestätigung zu wenden, so dass ich aufgrund des Rufs der Person, die ich vertrete, angehalten wurde, dies anzuprangern und ihn einerseits daran zu erinnern, dass die Angelegenheit mit dem Propst nur in Rom zu behandeln sei, und andererseits dafür zu sorgen, dass Seine Heiligkeit ihnen die Gnade erweist, die Kosten für die Bullen zu erlassen, wie er es bei mir anfragte, und ich erwarte, dass er sich daran hält, wie er mir gütig versprochen hat, und auch die Herren in Luzern, die sich um meinetwillen nicht widersetzen, sondern ihn sogar ermahnen, gehorchten mir, wie ich selbst versichere.

Die Chorherren dieser Stiftskirche wie aller anderen in Helvetien werden von den Schweizer Herren, die dieses Privileg haben, ernannt, und zwar nach dem alten Vorrecht der Regierung. Nur der Propst wird von den Chorherren gewählt, jedoch unter Zuziehung einer gleichen Anzahl Ratsherren.

Die Stiftskirche St. Leodegar ${ }^{182}$ in Luzern, die ebenfalls altehrwürdig und sehr edel ist, aber früher Teil der Abtei Murbach war, und es gibt noch Benediktinermönche jener Abtei dort sowie acht weitere Chorherren-Stifte wie St. Urs in Solothurn, in Freiburg in der Schweiz, in Zurzach und anderen Ortschaften, die sich in dieser Provinz befinden. Überall bestätigt der Apostolische Stuhl die Pröpste. Die Chorherren nehmen mindestens zweihundert Scudi Einkünfte im Jahr ein.

Diese Fülle an reichen Privilegien und gleichzeitig die kleine Anzahl an Priestern macht es möglich, dass ein Priester sofort ein ehrliches Gehalt erhält sowie eine angenehme Unterkunft, um ein sehr komfortables Leben führen zu können.

Es mag erstaunen, dass in Helvetien von allen Einkünften der Chorherren viele Abgaben an die Herren der Kantone entrichtet werden müssen. Und es mag auch ein starker Missbrauch scheinen, dass der Chorherr die Einkünfte des ersten Jahres selber gar nicht genießen kann, obschon er sein Amt an Ort und Stelle versieht. Aber man wird das, was einmal nicht zu ändern ist, damit entschuldigen, wenn man bedenkt, dass dies ein althergebrachter Brauch ist, und dass die Einkünfte eines Jahres zur Erhaltung der Kirche verwendet werden.

182 Vgl. Stichwort „St. Leodegar“, in: https://hls-dhs-dss.ch/de/articles/012236/2011-02-22/ (31. Dezember 2020). 
In der Diözese Konstanz gibt es noch weitere zahlreiche Stiftskirchen, die alle unterschiedlich, aber sehr einkommens- und privilegienreich sind, von denen zwei in Konstanz selbst unter dem Titel „Johannes, der Ikone“183 und die andere unter dem Heiligen „Stephanus“184 stehen. In Freiburg im Breisgau leiten die Chorherren der Stiftskirche ihren Gottesdienst im gleichen Chor, wo ihn auch die Basler Domherren verrichten. Diese haben sich dort im Zuge der Reformation mit Zustimmung des Bischofs von Konstanz zurückgezogen. Ich lasse die Erläuterungen des Kollegs von Überlingen und von Rapperswil und vieler anderer, die sich mit der genannten Diözese Konstanz befassen, außer Acht.

Im Bistum Basel gibt es noch reiche Kirchen. Eine ist jene in Ensisheim und eine weitere in Delsberg, ${ }^{185}$ in Thann ${ }^{186}$ und anderswo. In derselben Diözese gibt es in Lautenbach ${ }^{187}$ Chorherren mit vielen päpstlichen und kaiserlichen Privilegien, aber da es zu meiner Zeit einen Propst gab, der wegen zahlreicher öffentlicher Sünden diffamiert wurde, habe ich einen Prozess gegen ihn geführt, und mit legitimen Mitteln habe ich ihn nach langer und reifer Prüfung seines Amtes enthoben und befohlen, dass ein neuer Nachfolger gewählt wird, doch erst nachdem der Schuldige eines natürlichen Todes gestorben war. Nachdem dieser verstarb, sind heute die Dinge in einem besseren Zustand, was vorher nicht der Fall war.

In der Diözese Chur gibt es nur wenige Chorherrenstifte. Allein in San Vittore $^{188}$ im Mesocco-Tal liegen viele Stifte, aber sie befinden sich in einem schlechten Zustand.

183 Es handelt sich um das ehemalige Chorherrenstift St. Johann in Konstanz aus dem Jahr 1266. Ab 1550 jedoch musste die inzwischen habsburgisch gewordene Stadt auch mit St. Johann Restitutionsverhandlungen führen: Sie gestand eine Entschädigung, die Instandsetzung der Kirche, die Wiederaufnahme des Gottesdienstes und die Rückkehr der Chorherren zu. Dessen ungeachtet wurde nur ein Teil der Stiftsgüter tatsächlich restituiert, das Kollegiatstift blieb in der Folgezeit äußerst finanzschwach. Gegen Ende des 16. Jahrhundert verfolgten mehrere Bischöfe den Plan, das verarmte Stift aufzuheben, um mit dessen Kirche, Kurien und Gütern ein Jesuitenkolleg einzurichten. Vgl. Konrad Beyerle: Die Geschichte des Chorstifts und der Pfarrei St. Johann zu Konstanz.

184 Vgl. Theodor Humpert: Chorherrenstift, Pfarrei und Kirche St. Stephan in Konstanz.

185 Vgl. Stichwort „Delsberg (Gemeinde)“, in: https://hls-dhs-dss.ch/de/articles/002938/ 2009-06-25/ (31. Dezember 2020).

186 Die Stiftskirche befindet sich im Elsass und gehört zu den Hauptwerken gotischer Bauund Ausstattungskunst am Oberrhein.

187 Die Stiftskirche befindet sich ebenfalls im Elsass, ist jedoch eine romanische Kirche im Gegensatz zu jener in Thann.

188 Vgl. Stichwort „San Vittore“, in: https:/hls-dhs-dss.ch/de/articles/001563/2011-02-03/ (31. Dezember 2020). 
Im Bistum Lausanne gibt es nichts anderes als das im Schweizer Freiburg und in Solothurn, die ich oben bereits erwähnt habe, und im Wallis gibt es in diesem Bereich keine nennenswerte Kirche.

In den Diözesen Mailand und Como, auf dieser Seite der Berge in den Teilen Italiens, besitzt allein Como fünfzehn Stiftskirchen, die in der Schweizer Nuntiatur liegen, und im schweizerischen Teil des Erzbistums Mailand gibt es noch zwei oder drei.

$\mathrm{Zu}$ San Lorenzo ${ }^{189}$ in Lugano gibt es acht Chorherren und einen Erzpriester. Sie alle erhalten viele Einnahmen. Bekannt ist der lange, skandalöse, tief verwurzelte Hader zwischen diesem Stift und der Stadt Lugano. Ich trat als Vermittler auf und legte allen Streit völlig bei. Die Bedingungen der Aussöhnung sind seinerzeit dem Kardinal-Patron mitgeteilt worden.

Im Veltlin sind die Erzpriester, die Leiter der Stifte sind, fast alle Doktoren in Theologie und Säulen des katholischen Glaubens in diesen Gebieten, insbesondere gilt das für Herrn Nicolò Rusca, ${ }^{190}$ Erzpriester von Sondrio; Herrn Prospero Peranda ${ }^{191}$ von Bormio; Stupano von Mazzo, ${ }^{192}$ der viele Bücher druckte, und andere. Aber der von Chiavenna, der Paravicini heißt und als ein sehr eifriger Mann galt, hat jetzt viel Anerkennung verloren. Das lag daran, dass er mit wenig Umsicht vorging, um die Errichtung einer Stiftskirche in Plurs ${ }^{193}$ zu verhindern, sein Ehrgeiz entdeckt wurde sowie sein Gebrauch illegaler und indirekter Wege, um sein Ziel bei Gefahr schwerer Skandale und Verluste von unendlich vielen betroffenen Seelen zu erreichen.

Über die Stifte von Locarno, Bellinzona, Agno, Riva, Balerna, Mendrisio und anderen Ortschaften füge ich nichts mehr hinzu, außer dass sie ehrenwerte Erzpriester haben, die zum größten Teil gelehrt und intelligent sind. Der Nuntius wird sich aber nur wenig mit ihnen beschäftigen, weil sie Bischöfe in der Nähe haben, die zögern und es nicht gerne sehen, dass sich der Nuntius in ihre

189 Es handelt sich um die heutige Bischofskirche in Lugano, die 1078 in eine Kollegiatskirche umgewandelt wurde. Zuvor war sie 818 unter dem Patrozinium des heiligen Laurentius als Pfarrkirche errichtet worden. Vgl. Stichwort „Lugano (Gemeinde)“, in: https://hls-dhs-dss. ch/de/articles/002177/2017-06-26/ (31. Dezember 2020).

190 Der Erzpriester (1563-1618) von Sondrio studierte am Helvetischen Kollegium in Mailand und gilt als Anhänger des Mailänder Kardinals Karl Borromäus. Rusca wurde 2013 seliggesprochen. Vgl. Stichwort „Nicolò Rusca“, in: https://hls-dhs-dss.ch/de/articles/025290/2012-01-05/ (31. Dezember 2020).

191 Über ihn ist wenig bekannt. Es fehlt bisher ein Eintrag im HLS.

192 Gemeint ist Giovanni Pietro Stupano, Theologe und Erzpriester von Mazzo, der unter anderem Bücher über den heiligen Karl Borromäus veröffentlichte.

193 Die Ortschaft heißt auf Italienisch Piuro und befindet sich in der Provinz Sondrio in der Lombardei. Der Ort gehörte im 11. Jahrhundert zum größeren Chiavenna. Im 15. Jahrhundert erlangte Plurs oder, wie der Ort auf Rätoromanisch genannt wird, Plür, die Selbständigkeit. 
Angelegenheiten einmischt, auch wenn sie zu Recht der Nuntiatur unterstellt sind. Deshalb soll man vorsichtig sein, um sie nicht anzufeinden.

Nachdem ich die Stiftskirche behandelt habe, will ich einige Worte über die Domherren der Kathedralen verwenden. In Konstanz müssen sie entweder Adlige oder Doktoren in Theologie sein, aber das Domkapitel dort zählt weit mehr Adelige als Doktoren. Und man möchte gerne, dass bloß erstere den Bischof wählen sollten. Aber wenn der Papst eine Stelle zu vergeben hat, so ernennt er meistens einen Doktor, was immer wünschenswert wäre, da die Adeligen meist nichts wissen und nicht viel mehr taugen. Man sollte die Domkapitel höchstens einigen Fürsten vorbehalten, denn wie die Sache jetzt steht, so nimmt der gewöhnliche Adel, der sich für die Stütze Deutschlands hält, obschon er eher nur dessen Verderben ist, eben die Stellen in Beschlag. Auf diese Weise könnte man stattdessen viele der gelehrtesten Leute versorgen. So nimmt die Zahl der Geistlichen ab. Die Kirchen werden schlecht bedient und man denkt an alles außer an den Gottesdienst. Wären die Güter der Kirche gleichmäßiger verteilt, so würde auch die Wiederbekehrung der verlorenen Seelen besser vonstattengehen, als dies jetzt der Fall ist. Man bedenke, dass der Dompropst von Konstanz etwa 8 tausend Scudi im Jahr bezieht.

Unter den Konstanzer Kanonikern gibt es keinen Mann von besonderem Wert unter den Adligen. Von den Doktoren des genannten Kapitels sind der Generalvikar Jakob Raßler ${ }^{194}$ und Doktor Hager ${ }^{195}$ zu nennen, die als sehr intelligent gelten.

Was den Basler Domherrn für das Domkapitel in Freiburg im Breisgau betrifft, so geht man, wie oben erwähnt, mit den gleichen Begriffen wie Adel und Doktoren um, doch anstelle des Dompropstes nimmt der Domdekan die erste Würde ein. Zu meiner Zeit war das Herr Georg Hänlin, ${ }^{196}$ ein gutgesinnter und

194 Vgl. Generallandesarchiv Karlsruhe 5 Nr. 896: Konstanz-Reichenau (Hochstift Konstanz, Kloster Reichenau) / 950-1807: „Jakob Rassler wird auf Grund einer päpstlichen Provision in das Konstanzer Domkapitel aufgenommen. 16. September 1605.“ Zit. nach: https://www2.landesarchiv-bw.de/ofs21/olf/struktur.php?bestand=10707\&sprungId=8208818\&syssuche=jakob +rassler\&logik=or\&letztesLimit=suchen (31. Dezember 2020).

195 Vgl. Generallandesarchiv Karlsruhe 5 Nr. 9484: Konstanz-Reichenau (Hochstift Konstanz, Kloster Reichenau) / 950-1807: „Stiftung eines ewigen Jahrtags und eines Almosens durch den Konstanzer Domherrn Johann Christoph Hager bei St. Stephan in Konstanz. / 6. Juni 1626.“ Zit. nach: https://www2.landesarchiv-bw.de/ofs21/olf/struktur.php?bestand=10707\&sprungId $=8217266 \&$ syssuche $=$ christoph + hager + johann\&logik $=$ or\&letztesLimit=suchen $(31$. Dezember 2020).

196 Der katholische Theologe (1556-1621) war eine führende Persönlichkeit der katholischen Reform (Gegenreformation) und war am Collegium Germanicum in Rom. Er errichtete 1619 eine Stiftung für Arme und eine weitere für Studenten der Theologie. Vgl. Tilo Huber: Dr. theol. 
gelehrter Theologe von großem Verdienst und als Person von Eifer und einzigartiger Güte geprägt.

Die Churer und Sittener Domherren sind ohne Bedeutung, sie wählen aus ihrem Domkapitel ihre Bischöfe. Der Bischof von Lausanne, der fast vernichtet wurde und keinen Wohnsitz hat, kann auch gar nicht von Domherren gewählt werden, weil es dort kein Domkapitel mehr gibt. Man glaubt, dass man mit der Errichtung der Residenz dieser Stiftskirche in Freiburg und mit der Anbindung derer in Solothurn zu einem ehrenvollen Domkapitel zurückkehren könnte.

\section{Über Priester und ordentliche Pfarrer}

Ich habe nichts anderes anzufügen, als dass ich die Bischöfe und Nuntien in Deutschland sehr ermahnen muss, die Priester in Schach zu halten und ihnen wegen der Nüchternheit so weit wie möglich den Besuch der Wirtshäuser zu verbieten, denn von dieser Wurzel aus treiben die Zweige aller anderen Misserfolge. So tief dieser Hang in der Natur dieser Leute liegen mag, so kann man, wenn man will, doch nach und nach weit kommen. So haben sich viele Priester auf meine gütliche Ermahnung hin von diesem skandalösen Unwesen ziemlich gut ferngehalten.

Mit den Priestern der italienischen Schweiz hatte ich viel $\mathrm{zu}$ tun, weil sie mich sehr belästigten, so dass ich mich in unzählige Angelegenheiten einmischen musste, die im Kompetenzbereich der Nuntiatur lagen. Aber ich hatte immer das besondere Ziel vor Augen, sie wieder an den Bischof zurückzuverweisen. So habe ich wegen dieser Kompetenzen mit den Bischöfen manches Unangenehme zu tun gehabt, und es dann endlich aufgegeben, mich außer bei dringenden Fällen in ihre Angelegenheiten einzumischen.

Ich habe oben vergessen, als die Jesuiten behandelt wurden, zu erwähnen, dass sie in diesem Jahr 1612 verbannt wurden. Das bündnerische Veltlin hat sie unter dem Vorwand der Ketzer, der auf offensichtlichen Verleumdungen beruht, ausgeschlossen, weil sie behaupteten, dass es sich bei diesen Ordensleuten um Spione des Papstes handelt, was weit von der Wahrheit entfernt liegt. So haben ihre Prediger bei den Anführern ihrer Sekte Zweifel geweckt, da die Jesuiten so viele geistliche Fortschritte in der katholischen Religion erzielt hatten. Sie wussten auch allzu gut, dass ich alles daran setzen würde, ein so schlechtes Verbot $\mathrm{zu}$ verhindern. Und ich habe weder Kosten noch Fleiß gescheut, wie der Provinzialpater und der Rektor von Como von dieser Ordensgemeinschaft wissen. Ich drängte die Schweizer Katholiken, ihren Mut unter Beweis $\mathrm{zu}$ stellen, und bat den Gouverneur von Mailand, sie zu unterstützen. Ich

Georg Hänlin (1556-1621), Freiburger Diözesan-Archiv 125. Band, Dritte Folge - Siebenundfünfzigster Band, 2005. 
richtete die Bitte auch an den französischen Botschafter, und ich vergaß nicht, an den Nuntius von Paris zu schreiben und auch überall dort hin, woher man Hilfe erwarten konnte. Aber einige unglückliche Worte, die von einem Kanzler aus dem Veltlin indiskret verbreitet wurden, und weil er eben Katholik ist, haben die Gemüter erhitzt und alle Hoffnungen, die durch unser Vorgehen geweckt worden waren, beschnitten. Noch immer geht diese Geschichte weiter, und damit es dennoch zu einer positiven Wende kommen kann, braucht es Sorgfalt bei den Katholiken und Klerikern des Tals und bei den Jesuiten, die an die Bemühungen erinnern können, wie sie den Menschen geholfen haben. Und hier kommt das Ende dieser Erläuterung des geistlichen Zustands dieser Nuntiatur.

\section{Aufgabe des Nuntius, um dem geistlichen Zustand zu helfen, und wie dies auf beste Weise geschehen kann}

Nachdem ich im vorherigen Kapitel einen ausführlichen Bericht über den Stand der geistlichen Angelegenheiten der Nuntiatur vorgelegt habe und auf die wesentlicheren Punkte eingegangen bin, die ich schriftlich dargelegt habe, bleibt es mir nun übrig, die möglichen Wege zu erläutern, die meiner Meinung nach die besten sind, um den katholischen Glauben zu verbreiten und die oben genannten geistlichen Angelegenheiten zu unterstützen.

Die Wirkungen meiner Tätigkeit haben mir gezeigt, dass es nicht gut ist, dass sich der Nuntius in die Dinge einmischt, die die Bischöfe des Ortes erledigen können, und dass dies dem Diözesanbischof obliegt. Man soll ihnen nur als Hilfe dienen und nur bei wirklicher Notwendigkeit eingreifen, denn wenn man sich in alle Angelegenheiten einmischt, ohne nach Wichtigkeit und Bedeutung $\mathrm{zu}$ unterscheiden, dann werden die Bischöfe die Nuntien nicht nur verachten, sondern sich auch immer und jeder Anstrengung des Apostolischen Amtes widersetzen sowie gegen den Willen Seiner Heiligkeit und des Kirchenrechts. Das gilt insbesondere, wenn man sich in ihre Gottesdienste einmischt. Da soll der Nuntius nur gesandt werden, um zu helfen, und nicht die Autorität des Bischofs beschädigen. Ich möchte hinzufügen, dass die Reformen der Nuntien größtenteils nicht so nachhaltig sind wie die der Bischöfe, und sie gelingen nicht so leicht, denn die Deutschen haben nicht das gleiche Vertrauen zu den Italienern wie gegenüber den Menschen ihres eigenen Landes. Und weiter gilt, dass die Bischöfe dafür sorgen, dass sie das ganze Jahr über den Gläubigen beistehen können und keine Vorfälle stattfinden, die das Handeln der Nuntien rechtfertigen würden. Das wäre meiner Meinung nach der beste Weg, um diesen Gebieten nützlich zu sein und den Zusammenhalt mit den Bischöfen zu fördern. Es geht nicht nur darum, die Bischöfe immer nur an das eine oder andere zu erin- 
nern, wozu sie verpflichtet sind, sondern auch darum, dass sie es akzeptieren, denn dafür haben sie die Weihe erhalten. Und das scheint mir der Hauptzweck der Nuntien zu sein, dass sie insbesondere darauf achten müssen, dass die Bischöfe ihr Amt ausüben. Denn wenn dies erreicht wird, dann wird der Bischof in einem Monat das tun, was der Nuntius in einem Jahr mit all seinen Bemühungen nicht erreichen wird, wenn der Nuntius Visitationen vornimmt. Und es ist wichtig, dass die weltlichen Herrscher nicht argwöhnen, dass der Nuntius zu einem anderen Zweck als jenem der Unterstützung zu Besuch kommt. Auch würde der Nuntius von den Prälaten schlecht angesehen. Auch weil er die Sprache nicht versteht und seine nur von wenigen gesprochen wird. Und wenn die Frucht, die mit der Ermahnung des Nuntius und mit seiner Stimme einhergeht, verhindert oder verzögert wird, dann hat mir meine Erfahrung gezeigt, dass es nicht unmöglich ist, die Bischöfe mit liebevoller Güte und anhaltenden Gebeten auf ihre Fehler hinzuweisen. Auf diese Weise habe ich den Bischof von Konstanz zu offiziellen Visitationen überredet, sowie zur Durchführung von Diözesansynoden, die dort seit Kardinal Hohenems nicht mehr stattgefunden hatten. Und ich habe eine erfreuliche Tatsache damit erreicht, da bei einem einzigen Besuch des Bischofs mehr als 16 Personen von ihm gefirmt wurden. Ich habe den Bischof von Basel das ausführen lassen, was ich wollte, und zwar, dass er persönlich seine Diözese besucht, trotz der Tatsache, dass das in fast ganz Deutschland nicht üblich ist. Und so hat jener Bischof das Land von Konkubinaten und endlosen Fällen von Simonie abgehalten und bemerkenswerte Bekehrungen und andere edle Handlungen vorgenommen, die des ewigen Gedenkens würdig sind, ja mir als Apostolischer Delegierter mehr gedient haben, um auch selber einige Klöster zu besuchen, bei denen Männer und Frauen in Gerichtsverfahren verwickelt waren. Der Bischof von Chur gehorchte mir immer auf jegliche meiner Hinweise, indem er Visitationen vornahm, Strafurteile verkündete und in der Fürsorge für die Seelen seines Bistums tätig war. Der Bischof von Sitten tat dasselbe, und in Lausanne, da es dort keinen Bischof gab, setzte sich der Generalvikar mit meinen Befehlen für das ein, was nötig war. Und sonst wäre dort nichts geschehen. Auf diese Weise haben wir mindestens die Hälfte des Möglichen geschafft, wenn ich an den eingeschlagenen Weg einiger meiner Vorgänger denke, die es für notwendig hielten, dass der Nuntius alles selber tun sollte, und es für unnötig hielten, den Diözesanbischöfen bei der Ausübung ihres Amtes des guten Hirten beizustehen.

Das sehe ich als Hauptgrundlage für die geistliche Leitung der Schweizer Nuntiatur, und zwar, dass man Verständnis für die Zusammenarbeit mit den Bischöfen hat. Und so ist es wichtig, dass man ihnen regelmäßig schreibt, sie nicht ärgert und sie das tun lässt, was dem Amt, das sie ausüben, angemessen ist. 
Es besteht ein großer Mangel an deutschen Bischöfen in der Betreuung der spirituellen Dinge, weil sie sich alle für Fürsten halten, so dass sie mehr weltliche Geschäfte betreiben als geistliche Fürsorge. Indem man ihnen jedoch zu verstehen gibt, dass sie Fürsten sind, weil sie Bischöfe sind, und dass sie private Ehrenmänner und sogar zum größten Teil arme Menschen wären, wenn sie nicht dieses Amt innehätten, dann würden sie sich dazu durchringen, etwas Gutes zu tun, wie ich es selber erfahren habe.

Der Nuntius muss sich ständig bemühen, formelle und strenge Visitationen zu machen. Sie müssen auch die Diözesen in Dekanate aufteilen, weil sie meist zu groß sind, so dass jeder Teil seinen eigenen Visitator hat, wie das Bistum Mailand mit dem schönen Orden des heiligen Karl. ${ }^{197}$

Er muss dafür sorgen, dass in den Bistümern Synoden stattfinden, die unter dem Antrieb der Herrlichkeit Gottes durchgeführt werden, was den Prälaten zugutekommen wird. Denn der Geistliche wird damit den Ruhm Gottes vermehren, und es wird für alle mit viel Erfolg verbunden sein. Der Bischof von Basel hat mir versprochen, es seinem Amtsbruder in Konstanz gleichzutun, und wir müssen abwarten und schauen, ob er das so bald wie möglich auch tut.

Mit dem Bischof von Konstanz muss der Nuntius die Errichtung eines Seminars vorantreiben, was zur Zeit des Kardinal Hohenems ${ }^{198}$ hätte geschehen sollen, und es ist eine große Schande, wie ich an anderer Stelle sagte, dass das Bistum grundsätzlich kein eigenes Priesterseminar hat. Basel hat sein Seminar in Pruntrut errichtet, das eine sehr edle Einrichtung ist. Auch die anderen Bischöfe sollten die Möglichkeit nutzen, solche Institute zu errichten.

Folglich müssen die Nuntien die ketzerischen und misstrauischen Bücher aus dem ganzen Land verbannen, denn in diesen Gebieten gibt es sehr schlaue Ketzer und diese verursachen großes Übel, indem sie unter den niedrigen Menschen unter einer Art Mitleid ihre Druckwaren, kleine Geschichten, Bilder und Lieder verbreiten, die alle voller teuflischem Gift sind. Sie tun alles, um die einfachen Menschen zu täuschen. Nachdem ich selber davor gewarnt wurde und mit eigenen Händen diese Wahrheit berührt habe, hatte ich begonnen, die Buchhandlungen $\mathrm{zu}$ besuchen. Ich habe an verschiedenen Orten viele Feststellungen von diesen üblen Machenschaften gemacht. Auch hatte ich die Unterstützung der weltlichen Herrschaften, da ich sie darauf hinwies, dass man etwas nicht drucken durfte, wenn es vorher keine Lizenz von den Behörden erhalten hätte. Aber da nicht an jedem Ort gute Ordnung herrscht, ist es wichtig, dass die Nuntien weiterhin ein wachsames Auge darauf werfen und sich da-

197 Hier ist Karl Borromäus gemeint.

198 Hier ist Kardinal Markus Sittikus von Hohenems (1533-1595) gemeint. 
für einsetzen, dass die Bischöfe ihre Augen öffnen, so dass kein größerer Schaden mehr entstehen mag.

Das Verbot von Bibeln und Stundenbüchern auf Deutsch, die Frauen in ganz Deutschland benutzen, wurde von mir eingebracht, und Seine Heiligkeit befahl, dass dies von den Bischöfen behandelt werden sollte, so wie es getan wurde, aber ich fand es unmöglich.

Den Gelehrten und Absolventen dürfen Buchlizenzen nicht verweigert werden, aber sie dürfen nicht aus Neugierde und Gleichgültigkeit vergeben werden, weil der eine gerne Bücher seines Faches liest, der Philosoph die seines eigenen und der Theologe die seines eigenen Bereichs. Das soll zu diesem Thema ausreichen.

Der größte Erfolg, der in der Nuntiatur zu erwarten ist, ist ohne Zweifel die Bekehrung der Ketzer, und deshalb sollen die Nuntien in allen möglichen Teilen des kirchlichen Amtes den Menschen jene Möglichkeit bieten, um sie zu versöhnen und ihnen zu vergeben. Es geht aber darum, jene einzuladen, die zur Ablegung von Irrtümern bereit sind. Dazu brauchen wir entschiedenere Menschen, denn viele wenden sich ab, da von katholischer Seite nichts getan wurde. Die Almosen sind gering, sie sind auch wenig dauerhaft und unsicher.

Der Nuntius muss alle bereitwillig empfangen und sie auf größere Weise unterstützen als diejenigen, die ansonsten versuchen, die Seelen anderer zu fangen. Ich habe in all der Zeit, in der ich in Luzern war, viele Bekehrte ständig begleitet, indem ich ihnen zum Teil eine gewisse Summe Geld pro Monat für ihren Unterhalt gab, und in der Zwischenzeit ließ ich sie von Jesuiten unterrichten, was sehr erfolgreich war und viele weitere Bekehrungen mit sich brachte. Da ich nur begrenzte Mittel zur Verfügung hatte, bat ich die Prälaten darum, dies um meinetwillen zu übernehmen.

Die Errichtung Unserer Lieben Frau von Thonon bei Genf war für diese Art von Bekehrungen eine große Hilfe, denn diejenigen, die zur katholischen Religion zurückkehrten, konnten dort empfangen werden, und nach der Überlegung, dass ich die Gründung einer ähnlichen Einrichtung an anderen Orten der Nuntiatur mit gleichem Erfolg für machbar hielt, und in diesen Gebieten die Nachfrage wuchs, begann ich, das Vorhaben anzugehen, aber wegen der Pest wurde das Projekt unterbrochen. Ich hinterlasse den Nachfolgern diesbezüglich ein sehr großes Feld, um eine der einzigartigen Handlungen zu vollziehen, die für den Schutz des katholischen Glaubens in Helvetien in Frage kommt.

Wenn ein oder mehrere Aufnahmehäuser nicht wie das von Thonon errichtet werden können, so könnte man zumindest eine gute Kasse mit Geldbeiträgen bilden, die die Äbte jedes Jahr leisten sollten; Viele von ihnen wurden bereits von mir angefragt und hatten schon zugesagt, und so kann man jetzt mit den Prälaten zum Einsammeln übergehen, damit der Beauftragte dann zu den 
Bekehrten gehen kann, um sie finanziell zu unterstützen. Auf diese Weise wird man die Form finden, wie man mit den Bekehrten umgehen soll. Falls man die Umsetzung $\mathrm{zu}$ weit ausdehnt, könnten uns einige angebliche Bekehrte täuschen, aber trotzdem muss alles getan werden, damit die nötige Arbeit zur Bekehrung durchgeführt werden kann.

Die Hilfe der Kapuziner bei der Durchführung vieler geistlicher Handlungen ist notwendig, weil diese Ordensleute in der gesamten Nuntiatur Klöster haben. Sie verkehren ohne Misstrauen mit jedem, und sie bewegen sich ohne Unannehmlichkeiten von einem Ort zum anderen, und sie sind wirklich wie so viele gute Verwalter des Apostolischen Dienstes, wenn sie Menschen mit spirituellen Werten sind. Aber es ist notwendig, dass sie Italiener sind, und dass sie an bestimmten Orten eingesetzt werden, wo sie erfolgreicher sind. Den Deutschen ist absolut nicht zu vertrauen, weil sie ihrer Nation folgen und sich meist den Vorgaben und Bräuchen des Landes beugen. Der Nuntius muss in jedem Teil der Nuntiatur noch eine besondere kirchliche Vertrauensperson haben. Denn überall dort, wo es keine Kapuziner gibt, kann man ihm durch Mitteilungen helfen. Und mit dieser Hilfe bei der Arbeit und bei dem guten Vorgehen kann man erfolgreich sein und werden solche Vertrauensleute nicht fehlen, wenn sie gnadenreich vergütet werden, weil jeder die Güte des Nuntius beanspruchen will, um bei Gelegenheit einen Gefallen zu erhalten, und ich hielt in jedem Kanton eine Ansprechperson, die üblicherweise die besten Priester waren, und dasselbe hatte ich in Schwaben, im Breisgau und im Elsass. Bei Vorfällen habe ich die intelligentesten unter ihnen delegiert, um Prozesse zu betreiben. Ich hatte auch Nonnen als Vertrauenspersonen und so weiter, und ich habe einen nützlichen und profitablen Dienst erhalten.

Die reformierten Äbte des heiligen Benedikt sind bei dieser Verwendung sehr nützlich und setzen sich gerne für die Dinge ein, die dem Nuntius zugutekommen, so dass man, um sie liebevoll auf diesen Dienst vorzubereiten, die eigene Feder oft benützen muss, weil man allen oft und vertrauensvoll schreiben muss, denn diese zwielichtige Nation, die sich selbst in Schutz nimmt, braucht ähnliche Hingabe unsererseits, was Liebe und Wohlwollen betrifft.

Die Wahrung der kirchlichen Gerichtsbarkeit ist einer der weiteren Punkte, die vor allem an den Amtsträger des Apostolischen Stuhls gerichtet werden müssen, um den Ruf einer besonderen Geschicklichkeit zu erlangen. Die Missbräuche und Abkehr vom katholischen Glauben sind nicht so sehr wegen des Anspruchs auf Privilegien der Schweizer Fürsten entstanden, auch wenn es üblicherweise in den Republiken solche Unruhen und Usurpationen gibt und vor allem in den Volksrepubliken, wo die niederen Nationen nicht zwischen Zuständigkeit und Gerichtsbarkeit unterscheiden. Die Abkehr ist hauptsächlich auf die Fahrlässigkeit der Bischöfe und Prälaten bei der Verteidigung des Glaubens zu- 
rückzuführen. Es wäre ihre Aufgabe gewesen, den Glauben zu verteidigen. Das beste Mittel, das ich für die Umkehr dieser Fälle empfehle, ist, Visitationen durchzuführen und ihr bischöfliches Amt in vollem Umfang auszuführen. Am Ende widersprechen die Schweizer, wenn man sie mit liebevoller Freundlichkeit angeht, einem nicht, der mit Vernunft und gutem Eifer auf sie zugeht. Wir müssen uns aber darauf einigen, was das Ziel unseres Vorgehens sein soll, um zu zeigen, dass das, was wir tun, nur dazu dient, der Nation zu helfen und ihre Seele zu retten. Es geht also nicht um den Ruf ihres Landes, und auch nicht um Überheblichkeit oder persönliche Interessen. Wenn man sich darauf einlässt, so kann man langsam die Resultate sehen, die man sich erhofft. Es ist klar, dass mit freien Menschen und Menschen aus dem Norden nicht mit Härte, sondern mit Liebe verhandelt werden muss.

Der Nuntius muss der Vermittler zwischen dem Bischof und den staatspolitischen Herren sein, aber mit ihnen muss er immer klar vorgehen, da der Nuntius von Seiner Heiligkeit dort hin entsandt wurde, damit er als Beschützer der Nation die Privilegien der Bischöfe bewahren soll und fast ein Mitglied der Bischöfe sein könnte, denn mit diesem Vertrauen gehen die Bischöfe und die Gewissenhaftesten auf den Nuntius zu, wenn sie sehen, dass das, was die Republik verlangt, nicht mit ihrem Glauben übereinstimmt. Das ist der Fall, wenn es um Zensur und Sittenverfall geht. Etliche von ihnen begnügen sich oft damit, den Apostolischen Amtsträger in Verhandlungen zu schicken, ohne sich selber einzubringen. Das habe ich bei verschiedenen Gelegenheiten erlebt, und deshalb bezweifle ich nicht, dass Gefälligkeit der wahre Weg und der rote Faden der Tätigkeit eines Nuntius ist, um daraus erfolgreich herauszukommen.

$\mathrm{Zu}$ früheren Zeiten war es notwendig, dass sich der Nuntius an verschiedenen kirchlichen Angelegenheiten in Helvetien beteiligte, weil sich die Schweizer im Umgang mit den Bischöfen wenig auskannten. Das lag an der Feindschaft mit den Bischöfen und mit der schwäbischen Nation. Aber auch aus anderen Gründen war dies der Fall. Es ging darum, die eigene Zuständigkeit nicht zu verlieren und mit weltlichen Herren zu besetzen, die nicht nach Konstanz gehen wollten. Es war notwendig, alles direkt zu behandeln, aber heute sind die Bedingungen anders, und es gibt eine ausgezeichnete Korrespondenz zwischen dem Bischof und den Kantonen, und sie haben es ihm ermöglicht, zur freien Ausübung seiner Gerichtsbarkeit zurückzukehren, in der sie mit allen möglichen Anstrengungen zu erhalten sind.

In einigen Einzelfällen, in denen es schwierig war, Kenntnis von bestimmten kontroversen Punkten zu erlangen, sah ich die Hartnäckigkeit der Kantone, die ich wegen der einen oder anderen Streitpartei anfragte. Um Vorurteilen vorzubeugen und die Angelegenheiten nicht aus dem Ruder laufen zu lassen, habe 
ich jeweils eingegriffen. Auf diese Weise habe ich ihnen die unterschiedlichen Positionen dargelegt, damit sie die Gefahren verstehen. Das tat ich einige Male.

Die Privilegien gingen in früheren Zeiten in diesen Provinzen Deutschlands zu weit und waren die Ursache für große Schätze und Vorteile, die die Schweizer in ihrem Land angehäuft haben. Das war auch der Anlass zu vielem Kirchenraub. Das führte auch zu Fällen, bei denen gegen die Gerichtsbarkeit vorgegangen wurde, weil die bösartigsten Priester völlig von den weltlichen Fürsten abhängig waren, und zum größten Teil sind sie es noch. Denn diese Herren geben den Beschuldigten aus privatem Interesse $\mathrm{zu}$ verstehen, dass die Fürsten dies und das andere tun können, was aber falsch ist. Und dann wird es schwieriger, dieselben Fürsten von jener Auffassung zu befreien, die sie für die Gerechtigkeit halten, während sie von ihren Priestern anerkannt sind. Aber es gibt auch gute Priester. Man muss sie einfach oft besuchen, damit sie lernen, auf ihren eigenen Füßen zu stehen und die Autorität der Bischöfe anzuerkennen.

Und in Helvetien und fast ganz Deutschland wird das Kirchenrecht wenig beachtet. Das liegt an ihrer Unwissenheit, und so gingen sie gegen die Gerichtsbarkeit vor, und ich habe oft darüber nachgedacht und festgestellt, dass dies der Fall ist. Die Schweizer sind sehr eifersüchtig auf ihre eigene Autorität bedacht, und weil sie nichts gelernt haben, regieren sie nach dem, was sie verfolgen, so dass sie einfach das Vorgefundene ohne nachzudenken übernehmen. Es ist schwierig, ihre Meinung zu ändern, und das gilt umso mehr, als sie misstrauisch sind. Sie argwöhnen immer, getäuscht werden zu wollen, und dass wir sie untergraben wollen, aber die Umsicht eines Nuntius kann alle diese Felsen überwinden, und so weit hat sich die Situation verbessert, dass man sagen kann, dass die richtige Gerichtsbarkeit zu vernünftigen Bedingungen gefunden wird, und das genügt, um die Gerichtsbarkeit erwähnt zu haben.

Die Reform der Nonnen ist eines der großen Unternehmen, die in dieser Nuntiatur angegangen werden sollen, weil es viele Nonnen gibt und sie sehr entschlossen sind. Es ist nicht einfach nur ein Spruch zu sagen, dass es notwendig ist, ein wachsames Auge auf die Visitatoren $\mathrm{zu}$ halten und jene $\mathrm{zu}$ entfernen, die gefährlich sind, denn ,casus cascum ducit, improbrii improbum, similis similem“. ${ }^{199}$ Was die Konventualen und Barfüßer betrifft, so müssen wir jene Ärgernisse langsam beseitigen lassen, denn es ist nicht ihre Sache, Nonnen zu leiten, und Gott weiß, wie viele Übel sie tun, wo sie Aufsicht haben.

Die Regelung der Abgeschiedenheit, soll, wo dies immer möglich ist, vom Nuntius bestimmt werden, denn „magno fomentù ad improhortando est occa-

199 Auf Deutsch könnte man dies mit dem Spruch übersetzen: „Wie man sich bettet, so liegt man." 
sio“, ${ }^{200}$ und es wird nicht schaden, Sorgfalt walten $\mathrm{zu}$ lassen. Im schlimmsten Fall soll man Klöster schließen, wie dies schon getan wurde, und es gibt durchaus noch etliche Klöster, die man bald schließen sollte.

Um geistlichen Erfolg $\mathrm{zu}$ erzielen, ist es meiner Meinung nach nicht gut, dass der Nuntius immer an einem einzelnen Ort bleibt, denn bei dieser Nation mit unterschiedlicher Landschaft hat man Angst vor den Entfernungen und glaubt als Nuntius, nur das Nötige tun zu müssen. Doch so entzieht er sich der Hilfe, die er ihnen geben könnte, aber wenn er die verschiedenen Orte besucht, gibt er vielen Mut. Die Angelegenheiten können so besser verstanden werden und man gewinnt Selbstvertrauen und die liebevolle Freundlichkeit der Menschen in dem Land. Auf diese Weise wird das Ansehen des Nuntius davon profitieren, da die Menschen von ihren Vorurteilen befreit werden und er auch bei ihnen bekannt wird. Wichtig ist, dass diese Besuche ohne großen Aufwand erfolgen. Wer so vorgeht, bedenke aber, dass man immer guten Mutes voranschreiten und keine Geschenke annehmen soll. Es ist meines Erachtens eine gute Sache, wie ich selber festgestellt habe, selber Geschenke $\mathrm{zu}$ verteilen, denn Zuneigung erwirbt man durch das Geben und den Hass durch das Nehmen.

Die Hilfe, die ganz Deutschland vom deutschen Kolleg „Germanicum“201 in Rom und dem helvetischen Kolleg „Helveticum“202 in Mailand erhält, ist von großer Bedeutung. Denn sie sind wie eine Rüstkammer, in der es geistliche Waffen gibt, das heißt dort werden die guten Diener geschmiedet, die für alle diese Gebiete nützlich sind, weil sie sie sehr brauchen. Aber nachdem ich immer wieder darüber nachgedacht habe, dass die Deutschen eigentlich gar nicht bereit sind, auf italienische Art zu leben, und weil sie in den Kollegien leiden, kehren sie meist in einem sehr schlechten Zustand in ihr Land zurück. So nährt sich die natürliche Abneigung dieser Völker von neuem Gift. Dann folgen die Auswirkungen des schlechten Willens, und sie unternehmen wenig dagegen. Mir war in den Sinn gekommen, dass es vielleicht nützlicher wäre, wenn ein Teil des Einkommens des Kollegs von Rom dazu verwendet würde, einige in verschiedenen Teilen Deutschlands zurückzuhalten, um wenige Dutzende gezielt zu fördern, ohne ihnen aber das Geld in die Hände zu legen, sondern es ihnen nur am Ende eines jedes Semesters zu zahlen. Denn die Deutschen wären damit zufriedener. Sie würden auch den Hass auf Italien beiseitelegen und fühlten sich

200 Hier bedeutet der Spruch auf Latein, dass es besser ist, wenn man selber bestimmt, was gut ist.

201 Vgl. Peter Schmidt: Das Collegium Germanicum in Rom und die Germaniker.

202 Vgl. Stichwort „Collegium Helveticum“, in: https://hls-dhs-dss.ch/de/articles/010430/ 2010-03-11/ (31. Dezember 2020). 
dem Apostolischen Stuhl mehr verpflichtet. Die Apostolischen Nuntien könnten als Paten den Studenten zur Seite stehen, sie besuchen und die Fortschritte mit eigenen Augen begutachten, die sie gemacht haben. Es wäre jedoch hinderlich, sie während ihres Studiums argwöhnisch zu überwachen und sie auf ihre Gelder warten zu lassen. Man soll sich vor solchen Einstellungen hüten und beim Umgang mit den Studenten immer reife Überlegungen walten lassen.

Das Helvetische Kollegium in Mailand ist von großem Nutzen, und vor allem für die Entwicklung des Veltlins, denn alle Priester dort waren zuvor in diesem Kollegium und fast alle sind Doktoren in Theologie. Der ewige Schutz dieses Ortes obliegt den Erzbischöfen von Mailand, und die Schweizer Herren haben bei der Revision der Kassen nichts zu suchen, noch bei sonst was. Denn auch wenn sie bisher solches verlangt haben, ist seit diesem Jahr 1612 klar, dass sie bei diesen Anforderungen unrecht haben.

Die Einnahmen des Kollegiums betragen 6600 und mehr Scudi in etwa, aber es gibt dort viele Ausgaben. Die neun katholischen Kantone, inklusive noch Glarus, haben dort Anrecht auf je zwei Plätze, und ein Platz hat das Land von Baden im Aargau. Aber insgesamt sind es also achtzehn Plätze. Je ein Platz steht den Orten auf dieser Seite des Berges zu, und das sind vier, nämlich Lugano, Locarno, Mendrisio und Bellinzona. Die Walliser haben zwei Plätze. Graubünden hat für jeden der drei Bünde zwei Plätze zur Verfügung, wie die übrigen Kantone, so dass sie als Dreier-Bund insgesamt sechs Plätze haben. Das bündnerische Veltlin hat sechs Plätze. Das Tal von Chiavenna hat Anrecht auf zwei Stellen. Dann gibt es die finanzielle Unterstützung von Kardinal Hohenems, der für zwölf weitere Orte Studienplätze für die Schweizer Kantone zur Verfügung stellt, und ebenso viele für die Schwaben, an denen auch einige bestimmte Familien beteiligt sind, denen einer dieser Plätze durch ein Privileg vorbehalten war, und auf diese Weise kann man die Berechnung des genannten Kollegs durchführen. So sollten durchgängig etwa sechzig Schüler dort sein. Das ist eine sehr große Zahl, aber viel weniger als der Bedarf jener Provinz.

Das genügt, um die Wege zur Unterstützung des geistlichen Zustandes der Nuntiatur zu erörtern. Es kommt jetzt darauf an, wie vorsichtig der Nuntius ist, um mehr Erfolg durch gezielte Handlungen und mit gutem gnädigen Eifer zu erreichen.

\section{Wie der Nuntius die weltlichen Belange in der Nuntiatur zur Zufriedenheit angehen soll.}

Der Gesandte eines Fürsten kann sich nicht das Wohlwollen derjenigen erwerben, mit denen er verhandelt, wenn er deren Wesen nicht im Voraus kennt und sich damit abfindet. Deshalb ist es zu diesem Zweck wichtig, dass wir auf einige 
Details eingehen, die für den Apostolischen Nuntius von Belang sein können, damit er Menschen, die so viele von den Italiener unterschiedliche Bräuchen haben, dennoch Befriedigung geben und solche auch von ihnen erhalten kann.

Die Schweizer Herren sind stolz auf ihre Freiheit und auf ihre Macht und halten viel von sich selbst, so dass sie sehr gierig nach den Dingen der anderen sind, wie Tacitus in seinem Werk „de moribus Germanos“203 sagt. Sie waren immer gierig, aber heute ist dies sogar noch gewachsen. Und durch die zu große Rücksichtnahme der Fürsten ihnen gegenüber werden sie ständig mit Besoldung und mit Spenden gemästet, so dass es dem Nuntius besser geht, wer auch er diesen Weg oft einschlägt, oder zumindest mit großen Gaben auf sie zugeht, wenn er das gewünschte Ziel seiner Verhandlungen ehrenhaft erreichen will.

Um ihre Zuneigung zu gewinnen, muss man sich ihren Stimmungen anpassen, und vor allem, um den natürlichen Stolz und die Eitelkeit der Männer der Republik zu überwinden, muss man mit allen Menschen umgehen, sie begrüßen, ihnen die Hand geben, wie es in dem Land Brauch ist. Und wenn die regierenden Herren in die Stadt gehen, soll man ihnen mit Höflichkeit begegnen und mit dem Hut grüßen, und umso mehr gilt das gegenüber den Anführern. Denn diese untätigen und verdächtigen Menschen beobachten alle Handlungen eines Fremden und eines Gesandten ganz genau, um ein zu schnelles Urteil über ihre Neigung zu fällen. Bei den regierenden Herren, und insbesondere jenen aus diesen Republiken, ist es besser, sehr menschlich zu ihnen zu sein, damit die einfachen Menschen dann nicht sagen, was bereits ihre Herren zuvor mehrfach gesagt haben, nämlich dass die Italiener sie nicht sehr schätzen. Diese bösen Meinungen schaden den Geschäften oft mehr, als man sich das vorstellen kann. Ich sage aber nicht, dass die Menschlichkeit des Nuntius zu sehr Betroffenheit ausdrücken soll und er sich von der Pflicht entmutigen lassen soll, aber es ist zum Teil notwendig, den Anstand aufrechtzuerhalten, und gleichzeitig ist es notwendig, unter dem Volk und den nicht sehr edlen Menschen, wie es die meisten von ihnen in Helvetien sind, auf diese Weise vorzugehen.

In den Anhörungen und in den Verhandlungen parteiisch zu sein, ist notwendig und wichtiger als die anderen oben genannten Vorgehensweisen, denn ich weiß nicht, welche andere Nation träger und mühsamer im Umgang mit Geschäften wäre als diese. Das ist ein wahres Ergebnis der Dummheit und Unwissenheit, so dass sie oft eine ganze Stunde damit verbringen, bei der Diskussion über Präambel, Titel, Ehrerbietung und Beantwortung derselben Frage zu verbleiben und so mehr als viermal mehr Zeit als üblich zu verbrauchen. „Naturale

203 Vgl. Die Germania des Tacitus. Deutsche Übersetzung von Dr. Anton Baumstark, ordentlichem Professor der Universität zu Freiburg. Freiburg im Breisgau 1876. https://de.wikisource. org/wiki/Die_Germania_des_Tacitus (31. Dezember 2020). 
enim est ut affectare uelint defectu natione, copia uerbos“, wie Plinius sagt. Den Faden ihrer Abfolge abzuschneiden ist unmöglich, ohne sie zu entsetzen, und man darf es auch gar nicht versuchen, außer in bestimmten außergewöhnlichen Fällen und auch nur bei ganz gemeinen Menschen; denn bei vornehmen Leuten ist es besser, das Gegenteil zu zeigen und so zu tun, als hätte man besonderes Wohlgefallen und Vergnügen an ihren Redensarten und Bräuchen. Nur durch solche Aufmerksamkeit lässt sich der Ruf von Leutseligkeit und Güte erwerben. Nur so verstehen sie sich zu einem Umgang, der von Nutzen und günstiger Nachrede sein kann; daher passt das Gebot von Solon, der will, dass „magistratum gerens audiat juste et injuste“, und dass er „patientissimis auribus" sei. ${ }^{204}$

Unter wütenden und eitlen Menschen kann nichts Besseres unternommen werden, um ihr Wohlwollen zu erlangen, als zu zeigen, dass man ihre Geschichten gelesen hat und die Loblieder auswendig kennt, die in Büchern geschrieben stehen; indem man ihre Siege, ihre Eroberungen, ihre Triumphe und ähnliche Dinge zu rezitieren weiß, wodurch man Hinweise darauf gibt, auf ihrer Seite zu stehen und sie für ihre besonderen Verdienste zu schätzen, weil sie auf diese Weise allmählich mit dem fremden Minister vertrauter werden, als wäre er ein Mitglied ihrer Republik, und seine Zuneigung erwidern. Im Übrigen hat es nicht den besten Klang der Welt, das eigene Lob anzustimmen.

Häufig in der Kirche gesehen zu werden, um die Heilige Messe zu feiern oder sie zu hören, auch wenn man eine Kapelle zu Hause hat, wird für die Menschen dort eine Befriedigung sein. Sich an den großen Festen zu beteiligen, um an den Tagesgottesdiensten und den Prozessionen teilzunehmen, ist sehr notwendig und wird von den Herren gewünscht, und darüber hinaus soll die ganze Dienerschaft öffentlich an der Kommunion teilnehmen, weil man sonst in dieser sehr frommen Nation sehr viele schockieren würde, und sie erwarten, dass die Diener der Nuntien sehr zurückgezogen leben. Tun sie dies nicht, so nehmen diese Leute großes Ärgernis daran, und was bei anderen Völkern nur eine lässliche Sünde wäre, das betrachten sie dort als Todsünde der Dienerschaft des Nuntius; es ist daher sorgfältig darauf zu achten, dass man in allen Details mit gutem Beispiel vorangeht.

Das viele Trinken und das Vergnügen an häufigen Trinkgelagen ist ein Merkmal aller nördlichen Völker, und man sollte nicht überrascht sein, da es eine natürliche Sache ist. Denn das Trinken ist bei ihnen notwendig, da sie alle reich an innerer Hitze sind, und so müssen sie, um sie zu löschen, wie Bodinus behauptet, häufig und viel trinken, und zwar mehr als die Südländer. So sagte

204 Dass also der Gesandte sowohl die gerechten als auch die ungerechten Leute anhört und dabei auch Geduld walten lässt. 
Tacitus über diese Menschen: „Diem continuare nulli probum“. Und derselbe Bodinus fügte hinzu, dass ,illa sc. potandi forma qua Germani utuntur, nullis unque temporibus, aut legibus potuti emendari“. Es ist daher so, dass das häufige Bankett eines der notwendigsten Dinge und das mächtigste Mittel ist, um das Wohlwollen der Schweizer Herren zu gewinnen, die allen diesen sinnlichen Genüssen ergeben sind. Man sollte in keiner Weise den von den Nuntien selbst eingeführten Missbrauch auslassen, jede Woche und an jedem Fest einen anderen Herrn einzuladen und zu treffen. Insbesondere muss der Nuntius zu Beginn seiner Amtszeit in Luzern oftmals nach und nach sämtliche Herren des Kleinen Rates einladen. Denn in Luzern kann man es sich nicht leisten, sich mehrmals nicht $\mathrm{zu}$ treffen, und die Herren des Kleinen Rates, der etwa vierzig Herren zählt, regieren die Republik. Und dann gibt es noch die anderen Herren des Großen Rates, die viel zahlreicher sind. Und weil sie sonst schmollen und die Vernachlässigten sich beleidigt fühlen würden, soll man aus diesem Grund auch sie einladen. Man soll sich Notizen von allen Herren machen, sie gemäß ihrer Rangordnung zu sich rufen und ehren. Den Rang beobachten sie streng in all ihrem Tun. Nach dieser Weise habe auch ich mich stets gerichtet.

Wohl darf ich hier noch auf einige andere Einzelheiten hinweisen, die viel dazu beitragen können, sich das Wohlwollen dieser Nation zu erwerben. Die wiederholten Einladungen allein würden nicht helfen, wenn man den Gästen nicht das Vergnügen machte, mit ihnen mindestens drei bis vier Stunden lang am Tisch bei Banketten zu verbringen. Auch soll man nach ihrem Brauch viele Lebensmittel zubereiten lassen und Weine nach ihrem Geschmack anbieten. Aber für diese Zeremonien soll es den Nuntien nicht an Tischmeistern fehlen, die ihm helfen. Auf diese Weise wird der Nuntius durch die tägliche Übung selbst alles lernen.

Da in Luzern häufig die Zusammenkunft der Tagsatzung aller Botschafter der Kantone stattfindet, darf bei dieser Gelegenheit nicht versäumt werden, die Herren einzuladen, um ihr Wohlwollen zu erwerben, und so wird der Ruf der Höflichkeit des Nuntius überall verbreitet. So wächst das Vertrauen, das für die Verhandlungen so nützlich sein wird, und diese öffentlichen Zusammenkünfte müssen durchgeführt werden, auch wenn bei den Tagsatzungen gerade nichts Besonderes behandelt wird, was also die Arbeit des Nuntius nicht besonders berührt. Denn es gibt immer etwas $\mathrm{zu}$ empfehlen und $\mathrm{zu}$ erinnern, um ihre Freundschaft liebevoll zu bewahren, wie die Zuneigung zum Apostolischen Stuhl. Deshalb müssen diese Bankette sehr großartig und sehr üppig ausfallen, denn seit einiger Zeit kennen auch diese Herren die Freuden des Gaumens und die wertvollen Speisen der anderen Nationen. Und von der Pracht der Zubereitung schließen sie auf die Achtung, die man ihnen erweist. Bei diesen Gelegenheiten darf man nicht vor fünf Stunden von Tisch aufstehen. Mit den Trinksprü- 
chen fängt man gewöhnlich bei denjenigen an, die die ersten Sitze einnehmen, und so fährt man der Reihe und Ordnung nach weiter und befolgt immer die Reihenfolge.

Um öffentlichen Beifall zu erwerben, können Sie, wie es sich früher gehörte, auch einige Male im Jahr alle Handwerker einladen, die für Ihr Haus arbeiten, indem sie separat in einem besonderen Zimmer und reichlich essen, denn dann werden sie viel zufriedener sein und bei Ihnen bleiben.

Es ist auch nützlich, um den vielen Angelegenheiten $\mathrm{zu}$ folgen und sich mit wichtigen Dingen zu befassen, die Einladung zum Bankett manchmal auf die Jesuiten, Kapuziner und wertvollen Priester auszuweiten, denn dadurch werden sie nicht nur freundlich gestimmt, sondern sie gewinnen auch Vertrauen und sind dann bereit, dem Nuntius mit all ihrer Kraft zu helfen, und das, was sich nicht am Esstisch herausfinden lässt, ist trotz aller Sorgfalt auf anderen Wegen fast unmöglich zu entdecken. Deshalb muss man sich dieser Gelegenheit zum allgemeinen Nutzen bedienen.

Wenn andere besondere Herren aus anderen Kantonen nach Luzern kommen, um sich mit den Nuntien über Geschäftsordnungen auszutauschen, so ist es üblich, sie entweder zu Tisch einzuladen oder sie im Gasthaus mit Wein oder irgendeiner anderen Aufmerksamkeit und Freundlichkeit zu ehren. Hält man sich an diesen Brauch, kann man mit ihrer Freundschaft rechnen. Dies möge nun genügen, um von den Einladungen und Gastmählern zu sprechen.

Der persönliche Auftritt des Nuntius in der öffentlichen Ratsversammlung, um mit der Herrschaft zu verhandeln, wird nur selten für öffentliche Geschäfte und nur in sehr wichtigen Angelegenheiten erforderlich sein. Denn diese Herren sind gewöhnlich bereit, beim kleinsten Zunicken in das Haus des Nuntius zu kommen. Auch erfordert es viel Umsicht, an solche Orte wie die Ratsversammlung zu gehen. In diesen Fällen muss man sich der Anrede „Erlauchteste und Mächtigste“ ${ }^{205}$ bedienen, wie es heutzutage in jenen Republiken Sitte ist.

Bei den Schweizern ist es notwendig, sich stets geneigt zu zeigen, ihre Privilegien, die sie vom Apostolischen Stuhl erhalten haben, eher zu vermehren als zu vermindern; weil sie sehr eifersüchtig darauf bedacht sind, und sie suchen in dieser Beziehung die Gesinnung des Gesandten auszuforschen, ob er nicht die Absicht habe, ihre Rechte in Zweifel zu ziehen und zu widerrufen. Aber bei all dem muss man sehr wachsam sein, dass sie sich nicht in kirchliche Angelegenheiten einmischen und die Missbräuche alles noch komplizierter machen, indem sie sich mit Dingen befassen, die ihnen nicht zustehen, wie anderenorts bereits gezeigt wurde.

205 Im Original: „Illustrissimi e Potentissimi“. 
Das Lob der Freiheit und des Staates der Republiken gefällt den freien Menschen, und im Gegensatz dazu macht sie zu viel Lob der königlichen Regierung argwöhnisch, so dass man gut daran tut, mit diesen Begriffen vorsichtig umzugehen und zu zeigen, dass man die umsichtige Regierung ihrer Kantone besonders schätzt und ihnen wünscht, dass sie an Größe und Festigkeit zunehmen.

Besondere Höflichkeit ist noch bei Korrespondenzen zu beachten, und dies soll man nicht übersehen, dass man ohne Zögern und auf das Freundlichste allen antworten soll, weil nichts so beleidigend ist wie die Verweigerung einer Antwort an einen, der um Hilfe ansucht. Dazu gehört auch, eine nüchterne Besonnenheit und Klugheit bei den Versprechen $\mathrm{zu}$ beachten. Man mache keine große Hoffnung auf Dinge, die man nicht mit Gewissheit einhalten kann oder die nicht gewiss sind. Denn es gibt keine andere Nation in der Welt, die einen kleinen Wink sofort als verbindlich und als eine Verpflichtung gegenüber anderen betrachtet, wie diese. Glauben sie einmal, man habe ihnen das Wort gegeben, so verlangen sie, dass man es halte. Es entspricht sowieso der Würde und Ernsthaftigkeit des Nuntius, immer weniger zu versprechen als er vermag, so dass er durch sein Worthalten sich immer mehr Kredit erwerben kann und mit größerem Ruhm handeln kann.

Die Schweizer bekennen sich zu dem Satz: „olim dulcissimus et accipere“, ${ }^{206}$ und daher nehmen sie gerne Geschenke an, wie sie es immer getan haben, wie sie sehr gierig nach anderen Dingen sind, wie Tacitus von allen Deutschen behauptet. Deshalb muss auch der Nuntius diesen Weg oft einschlagen, wenn er vollkommen zufrieden sein und Ehre in den Geschäften erreichen will. So wird der Nuntius zu den Hochzeitsfeiern der vornehmen Herren eingeladen, und auch wenn er solche Einladungen selten annimmt, so soll er es wenigstens als seine Pflicht ansehen, der Braut immer einen Ring mit einem Juwel oder eine andere Freundlichkeit aus Gold oder ein Seidentuch zu schicken. Nachdem ich ein paar Mal zu Tauffeiern eingeladen worden war, konnte ich meinen Ruf nicht anders retten als durch die Ausgabe vieler Scudi. Wie ich es gewohnt war, musste ich auch den Schultheißen, die die Republik regieren, entweder Silberbecher oder andere ähnliche Dinge zum Geschenk machen, um ihr Wohlwollen und Vertrauen $\mathrm{zu}$ gewinnen. Jeglicher andere Weg ist viel weniger fruchtbar und selten erfolgreich.

Die Tatsache, dass ich einigen der führenden Herren den Rang eines Ritters vom Goldenen Sporn verschafft habe, hat sie mir auf ewig verpflichtet, weil sie ihre Würde schätzen, besonders wenn die Ehre mit einer goldenen Halskette oder zumindest einer Medaille einhergeht, wie es bei dieser Nation üblich ist, und Seine Heiligkeit hat mir bedeutet, dass ich manchmal zu großzügig bin,

206 Der Spruch bedeutet, dass die Schweizer etwas, was sie mögen, auch gerne annehmen. 
was eine ausgezeichnete Sache wäre, um diesen Ehrentitel selber zu erhalten. Aber dieser Titel verliert von Tag zu Tag an Wert, da die Ehre an jede Art von Person verliehen wird. Um den Titel wieder zu stärken, müsste man die Ehre mit einiger Vorsicht und als eine besondere Aufmerksamkeit und Auszeichnung den Schweizern zukommen lassen. Dies wäre zugleich ein Mittel, sich diese von Natur hochmütige und stolze Nation verbindlich an sich zu binden, denn eine solche Gnade sollte man nicht umsonst vergeben. Man könnte mit den damit verbundenen Vorteilen bei den Verhandlungen gewinnen und gleichzeitig ihre Abhängigkeit erlangen.

Schließlich ist noch $\mathrm{zu}$ empfehlen, keinen von ihnen $\mathrm{zu}$ beschuldigen und ihre Einrichtungen nicht zu tadeln, während man unter ihnen lebt. Auch wenn sie sich in ihrer Kleidung, ihrem Essen und Schlafen und in ihren Bräuchen völlig von den Italienern unterscheiden und zudem in manchen Dingen von der guten Lebensart der Zivilisation weit entfernt sind, muss man diese Warnung insbesondere der Dienerschaft einschärfen, damit sie beim Reden achtgeben. Denn die Worte des Dieners sollen den guten Werken des Herrn keinen Schaden bringen.

Alle diese Besonderheiten soll man in der Schweiz beachten. Mit anderen weltlichen Herren der Nuntiatur ist es nicht notwendig, sich zu befassen, außer brieflich, und mit den deutschen Grafen und Baronen, die zahlreich sind, ist es leicht, zurechtzukommen. Und es gibt keine solchen Rücksichtnahmen wie bei den Schweizern, die man besonders einhalten sollte. Überdies ist dies nicht notwendig, da es keine öffentlichen Geschäfte gibt, die eine solche Umsicht erfordern.

\section{Kompendium dessen, was der Bischof von Venafro bezüglich seiner Instruktion getan hat}

Obgleich ich an verschiedenen Stellen dieses Berichts bereits über meine Zeit in der Nuntiatur berichtet habe, will ich dennoch, um mehr Klarheit und Wissensvermittlung zu verschaffen, mich auf den Zustand der bisherigen Geschäfte beziehen, die ich in einem Kompendium erstellt habe, mitsamt der Daten, die ich von den Kardinal-Patronen erhalten habe, und halte es für gut, eine Kopie meiner Schrift meinem Nachfolger zu übersenden, damit er besser verstehen kann, weil zwei Sichtweisen besser sind als nur eine. Und wenn ich darin einige Dinge geschrieben habe, die an anderer Stelle ebenfalls genannt werden, dann ist die Wiederholung ein Zeichen dafür, dass es wert ist, darüber zu sprechen. 


\section{Anhang Graubünden}

Die Bündner leben im gebirgigen Teil des alten Rätiens, der früher weitaus größer war. Sie stammen von Toskanern ab, und Reto, ihr Hauptmann, gab der Nation den Namen, falls die Historiker nicht lügen.

Sie teilen sich in drei Gebiete auf, die sie Bünde nennen, und das sind die Drei Bünde. ${ }^{207}$ Dazu gehören: der Graue Bund, ${ }^{208}$ der Gotteshausbund ${ }^{209}$ und der Zehngerichtenbund. ${ }^{210}$ Was besondere Beschlüsse, die Wahl von Richtern und dergleichen betrifft, so gibt es nicht nur die drei genannten Republiken, sondern viele mehr und zwar so viele, wie es dort Gemeinschaften gibt. Denn jede Gemeinschaft dort ist sowohl in eine bürgerliche als auch in eine gemeindliche Gesetzgebung getrennt. Das Ganze regiert sich selbst, aber dennoch bilden alle diese Mitglieder eine einzige gemeinsame Republik, denn in den ernsten Dingen, die sie alle vereint, teilen sie viele Gemeinsamkeiten. Sie betrachten vereint die Dinge des Staates, des Krieges, der Bündnisse, der Sicherheit usw. Diese Angelegenheiten werden nirgendwo anders behandelt als in den von ihnen so genannten öffentlichen Tagsatzungen, so wie es die Schweizer tun. Die gesamte Regierung Graubündens ist demokratisch und vom Volk getragen. Jeder Bund erkennt einen bestimmten Führer für die Geschäfte und Urteile ihrer Provinz an. Sie warnen vor gefährlichen Ereignissen und sind für die Versammlungen der Gemeinden zuständig, bei denen die Bedürfnisse der Öffentlichkeit besprochen werden. Der Titel dieser Führer lautet jeweils anders, denn im Grauen Bund heißt er Landrichter, im Gotteshausbund heißt er Bürgermeister und im Zehngerichtenbund nennt man ihn Landammann. Sie sind alle offiziell für ein oder zwei Jahre im Amt. Jeder von ihnen hat eine Stimme in der Tagsatzung, und unter ihnen hat der Landrichter des Grauen Bundes den Vorrang, aber die Tagesgeschäfte der Drei Bünde werden vom Bürgermeister des Gotteshausbundes vorgelegt, weil er in Chur wohnt, wo sie ihre Versammlung durchführen.

Der Graue Bund hat achtzehn Gemeinschaften, und in der öffentlichen Tagsatzung hat er einundzwanzig Stimmen, darunter elf Katholiken. In diesem Bund gibt es das Schloss Rozumo, ${ }^{211}$ das dem Haus Österreich gehört, aber als

207 Vgl. Stichwort „Drei Bünde“, in: https://hls-dhs-dss.ch/de/articles/026840/2004-04-14/ (31. Dezember 2020).

208 Vgl. Stichwort „Grauer Bund“, in: https://hls-dhs-dss.ch/de/articles/017158/2010-01-14/ (31. Dezember 2020).

209 Vgl. Stichwort „Gotteshausbund“, in: https://hls-dhs-dss.ch/de/articles/017154/2007-1219/ (31. Dezember 2020).

210 Vgl. Stichwort „Zehngerichtenbund“, in: https://hls-dhs-dss.ch/de/articles/017163/201501-25/ (31. Dezember 2020).

211 Es sollte sich um die Anlage von Rhäzüns handeln. Vgl. Stichwort „Rhäzüns (Herrschaft)“, in: https://hls-dhs-dss.ch/de/articles/008080/2017-03-10/ (31. Dezember 2020). 
Mitglied des Titels wegen gehalten wird, und einige des habsburgischen Hauses fordern, dass das Schloss renoviert werden soll.

Der Gotteshausbund umfasst die Stadt Chur und die Täler Engadin und Bregaglia sowie andere Ortschaften. Er hat sechzehn Gemeinschaften, und in den Tagsatzungen hat er sechsundzwanzig Stimmen, darunter nur vier Katholiken und fünf gemischtkonfessionelle. Alle anderen Stimmen sind böse Ketzer.

In diesem Bund verfügt das Österreichische Haus mit dem Schloss in Frops $^{212}$ über eine starke Position mit der Bereitstellung von vierhundert Soldaten.

Der Zehngerichtenbund befindet sich in Deutschland und grenzt an das Land Tirol, ${ }^{213}$ enthält Ländereien, und verschiedene Täler gehören auch darunter. Dieser Bund besteht aus zehn Gemeinden und hat fünfzehn Stimmen in öffentlichen Versammlungen, darunter nur zwei katholische, zwei gemischtkonfessionelle, und die anderen Stimmen gehören Ketzern.

In acht Teilen dieses Bundes hat das Haus Österreich die oberste Gerichtsbarkeit bei Blutangelegenheiten inne und verfügt über einen Offizial im Schloss Castelforte, ${ }^{214}$ der sehr kompetent überwacht wird. Alle zusammen befinden sich auf der anderen Seite des Gebirges. Ihnen unterworfen ist die Gemeinschaft von Maienfeld, ${ }^{215}$ die einem bestimmten Grafen gehörte, aber auf der italienischen Seite des Gebirges ist ihnen das Veltlin, Bormio, Chiavenna und Plurs unterworfen.

Das ganze Land ist im Besitz von Graubünden und hat keine Untertanen. Es ist etwa hundertzehn Meilen lang, und in der Breite dehnt es sich um etwa sechzig Meilen aus. Es hat neunzig Pfarreien. Sie behaupten, dass sie für die Binnenkriege 50 tausend Mann haben und dass sie den Fürsten ohne Probleme zwölftausend davon geben können. Sie sind Frankreich wegen des Bundes

212 Damit ist sehr wahrscheinlich das Schloss Tarasp in der Gemeinde Scuol gemeint. Vgl. Stichwort „Tarasp“, in: https://hls-dhs-dss.ch/de/articles/001524/2017-07-12/ (31. Dezember 2020).

213 Vgl. Stichwort „Zehngerichtenbund“, in: https://hls-dhs-dss.ch/de/articles/017163/201501-25/ (31. Dezember 2020): „Als Rechtsnachfolger der Vazer waren die Toggenburger zu Territorialherren über die nordalpinen Talschaften Prättigau (inklusive Chorherrengericht Schiers), oberes Albulatal (Belfort), Churwalden, Schanfigg und die Herrschaft Maienfeld geworden.“

214 Es könnte sich um die Burg Festenstein im heutigen Südtirol handeln.

215 Vgl. Stichwort „Maienfeld (Gemeinde), in: https://hls-dhs-dss.ch/de/articles/001606/ 2017-03-10/ (31. Dezember 2020): „Von ca. Mitte des 10. Jahrhunderts bis Mitte des 12. Jahrhunderts regierten die Grafen von Bregenz in Maienfeld. 1270/75 errichteten die von Aspermont die Burg Maienfeld, die später von Friedrich VII. von Toggenburg und um 1465 von den Brandis ausgebaut wurde und heute das Wahrzeichen von Maienfeld ist. ... 1509 kauften die Drei Bünde die Herrschaft Maienfeld den letzten Erben von Brandis ab.“ 
verpflichtet, bis zu zehntausend Mann zu überlassen, aber auf jeden Fall nicht weniger als dreitausend Mann. Venedig, als sie noch verbündet waren, mussten sie höchstens fünftausend Soldaten überlassen, aber nicht weniger als zweitausend, und bei den Treffen überreichten die Venezianer jährlich den Bündnern dreitausend Scudi und sechzig Moschettoni, ${ }^{216}$ aber in diesem Jahr 1612 wurde der Bund nicht abgeschlossen, obwohl der aus Padua stammende Sekretär der Venezianer alle Anstrengungen unternommen hatte, um das Bündnis zu erneuern, und eine große Menge Geld für alles ausgegeben hatte, was gegen Frankreich gerichtet war. Die Gründe, die diese Herren motivierten, diese Konföderation aufzugeben, waren viele, aber vor allem, weil sie erfahren hatten, dass die Venezianer keine Hilfe anbieten wollten, um Getreide und Wein zu liefern, wie sie ihnen am Anfang versprochen hatten. Und darüber hinaus war ein weiterer Grund, dass sie sahen, dass ihre Freundschaft mit den Venezianern den König von Spanien und den Staat Mailand verärgerten, von denen sie einen Großteil ihrer Nahrung in ihrem Gebiet beziehen.

Das Veltlin beginnt am Comersee und endet in Bravio. Es gibt dort viele Pässe, die von Italien nach Deutschland führen, und eines der schönen Täler, die man dort finden kann, ist sechzig Meilen lang und nicht breiter als vier, aber an vielen Orten ist es noch enger.

Es gibt dort hundert und zehn Länder, und einige sind groß und reich. Sie befinden sich auf der Seite der Hügel, die auf die mittleren Täler hinunterschauen. Sie produzieren vollmundige und exquisite Weine. Auf der anderen Seite der Hügel nicht. Das Tal gehört der Diözese des Bischofs von Como, aber er kann dort wenig tun, weil die Bündner es nicht zulassen, dass er die Gerichtsbarkeit besuchen und ausüben kann. Der jetzige Bischof sagte, er wolle versuchen, jene Orte zu besuchen, und schrieb Seiner Heiligkeit, der mir befahl, ihm $\mathrm{zu}$ helfen, und ich begann dies in der Hoffnung, das Unternehmen zu gewinnen, aber der Bischof zog sich vom Vorhaben zurück, und ich weiß nicht, aus welchem Grund. Es gibt viele Ketzer im Tal und in Sondrio, ${ }^{217}$ in Traona ${ }^{218}$ und insbesondere in Teglio. ${ }^{219}$ Die Katholiken werden von den bündnerischen Herren sehr tyrannisiert, und sie erlauben ihnen nicht, ausländische Priester zu

216 Hier ist nicht klar, ob es sich um eine Währung handelt oder um eine Anzahl bestimmter Söldner.

217 Vgl. Stichwort „Sondrio“, in: https://hls-dhs-dss.ch/de/articles/007064/2012-01-04/ (31. Dezember 2020).

218 Vgl. Stichwort „Traona“, in: https://hls-dhs-dss.ch/de/articles/007091/2012-11-01/ (31. Dezember 2020).

219 Vgl. Stichwort „Veltliner Mord“, in: https://hls-dhs-dss.ch/de/articles/024652/2013-02-21/ (31. Dezember 2020). 
Hilfe zu nehmen, so dass sie oft unter fehlenden Dienern leiden, und noch mehr würden sie leiden, wenn es die sechs katholischen Schweizer Orte nicht gäbe. So können sie am Helveticum in Mailand Priesterkandidaten haben, aus denen wertvolle Priester für das Volk werden, aber auch Theologen, die ,pondus diei et aestus“220 in dieses schöne Tal gebracht haben. In letzter Zeit waren dort einige Jesuiten vorgestellt worden, die ihren Sitz in Bormio errichtet hatten. Davon erhofften sie sich viel Freiheit und Privilegien in diesem Ort. Mit dem Kollegium in Mailand hätte man viel erreichen können, aber die bösen Prediger, ${ }^{221}$ die von ihrem Teufelsvater angestiftet wurden, sich den Prinzipien dieses guten Samens entgegenzustellen, noch bevor die Ernte eingebracht wurde, haben so gearbeitet, dass die Ketzer Graubündens die besagten Jesuiten verboten haben. Sie hatten beschlossen, dass niemand ihrer Untertanen in ihre Schulen gehen darf, obwohl dieser Beschluss für den Teil des Gebiets galt, wo die Jesuiten gar keine Schulen hatten. Ich habe dann versucht, die totale Wiederherstellung der Zulassung zu erreichen, wie die Kardinal-Patrone wissen, aber mehr konnte ich nicht tun.

Dieses Tal produziert so wenig Getreide, dass es höchstens für ein halbes Jahr reicht. Deshalb braucht es die Hilfe der Fremden, und dies wird vom Vinschgau in Tirol oder vom Staat Mailand bereitgestellt. Nirgendwo anders ist eine Unterstützung zu finden.

Die Grafschaft von Chiavenna ist etwa zwanzig Meilen lang und acht Meilen breit. Sie besitzt elf Ländereien, und die wichtigsten sind Chiavenna und Plurs, wo sehr angesehene Händler sind, und sie sind geistreich und sehr fleißig. Es leben dort mehr als 20 tausend Seelen, davon sind vielleicht 2000 Ketzer. Das Tal ist arm, und es gibt dort weder Getreide noch Wein für ihre Ernährung, höchstens in kleinen Mengen. Sie werden vom Staat Mailand unterstützt, ebenso vom Veltlin.

Die Bündner sind geduldig und ausdauernd, aber sie sind rauer und barbarischer als die Schweizer, leben an raueren und faszinierenderen Orten, wo sie sehr einfach leben, mit Ausnahme von Chur, Maienfeld, dem unteren Engadin in Richtung Mesocco und Rogoredo. Der Rest produziert weder Weizen noch Wein oder Kastanien und hat nur Wiesen, Vieh, Milch und Käse, so dass diejenigen jenseits von Splügen gezwungen werden, Weizen aus dem Hause Österreich in Tirol zu holen oder von den reichen Klöstern der schwäbischen Mönche oder aus Zürich oder aus Mesolcina. Und vom Staat Mailand bis hin zum Lago Maggiore beziehen sie den Großteil des Weins aus Italien.

220 Auf Deutsch: „Gewicht und Warmherzigkeit“.

221 Damit sind die Protestanten gemeint. 
In Disentis führte Kardinal Alessandrino 222 ein Priesterseminar auf seine Kosten mit 34 jungen Männern, und es war eine Aktion, die von anderen Kardinälen nachgeahmt werden sollte, aber nachdem er gestorben war und bevor sie das Einkommen ausgeglichen hatten, das vom Abt dieses Ortes und anderen Abgeordneten schwer betroffen war, ging das Geschäft in Rauch auf, mit beträchtlichen Schäden für diese Gebiete, wie ich oben erwähnte.

Im Jahr 1583 besuchte der heilige Karl Borromäus das Mesolcina-Tal und war sehr erfolgreich, bekehrte viele, bekämpfte den Aberglauben und half den Katholiken, die dort sind, wie der Erzbischof in den Berichten erzählt, aber als der Heilige jene Täler verließ, wurden die Katholiken schikaniert, als hätten sie mit einen fremden Fürsten gegen das Bündnis verstoßen.

Dieses Tal ist kein Untertanengebiet, sondern übt jene Herrschaft aus, wie es auch die anderen Gemeinschaften dort kennen. Und schließlich gibt es Bellinzona, ein italienisches katholisches Land, auf das es aber die Ketzer abgesehen haben, die dort gerne ihre Pest einpflanzen wollen, wie sie es manchmal zu meiner Zeit versucht haben, obwohl sie mit Schande abgewiesen wurden. Diese Verrückten hören dennoch nicht auf, und wenn sie in Schwierigkeiten sind, dann werden sie noch hartnäckiger, so dass der Apostolische Nuntius größte Sorgfalt walten lassen sollte, damit sie diese verfluchten Bemühungen an den Grenzen verhindern. Ich hatte als guten Schutz die Aufmerksamkeit von Verbündeten gefunden, denn durch die Drohung der Gouverneure von Mailand, keinen Schritt ins Tal zu dulden oder ansonsten ihre Lieferung von Getreide mit Waffengewalt aufzuhalten, das heißt, sie würden erst für den Eifer Gottes und dann vor Hunger sterben, und die Schweizer Katholiken haben mir sehr geholfen.

Das Mesolcina-Tal steht unter dem Schutz von Kardinal Borromeo, ${ }^{223}$ der es im Gedenken an den heiligen Karl ${ }^{224}$ übernommen hat. Deshalb sendet er dort oft einige Oblaten hin, ${ }^{225}$ die viele geistliche Erfolge erzielt haben und noch immer erzielen. Deshalb ist es für den Nuntius ratsam, dass er mit diesem Herrn zusammenarbeitet, um gemeinsam diesem armen Tal beizustehen.

222 Vgl. Karl Fry: Nunzius Giovanni Antonio Volpe und die Konzilsverhandlungen mit den III Bünden, S. 40: „Auf der Septembertagsatzung 1560 sprach Planta in Baden, wohin er dem Nuntius über Altdorf nachgereist war, vor, und übergab ihm ein Schreiben an Borromeo zuhanden des Papstes und eines an den Kardinal Alessandrino, Michele Ghislieri, Generalinquisitor.“ 223 Gemeint ist Kardinal Federico Borromeo (1564-1631). Vgl. Stichwort „Federico Borromeo“, in: https://hls-dhs-dss.ch/de/articles/026396/2003-02-04/ (31. Dezember 2020).

224 Karl Borromäus war der Cousin von Kardinal Federico Borromeo.

225 Sehr wahrscheinlich meint der Autor hier die Benediktineroblaten, die nicht Mitglied eines Konvents sind und als „Missionare“ nach den Regeln des heiligen Benedikt von Nursia leben. 
Der Bund, den die Bündner mit den Schweizern haben, ist auf einen Hauptpunkt beschränkt, nämlich die gegenseitige Verteidigung und die Treue zueinander.

Mit den ketzerischen Kantonen sind sie enger verbunden, auch wenn es nur wenige Seelen sind, und besonders ist es so, dass sie es den Katholiken zu verbergen versuchen, um sie aus Eifersucht fernzuhalten.

Mit der Krone von Frankreich haben sie ein Verteidigungsbündnis abgeschlossen, das in der Zeit von Heinrich III. ${ }^{226}$ eingeschränkt wurde. Denn im Gegensatz zu früher, als sie dem König und seinen Verbündeten versprochen hatten, die freie Durchreise über ihre Pässe zu gewähren, haben sie es danach nur dem König vorbehalten, mit der Absicht, dass die Bitte der anderen Verbündeten nur dann gewährt werde, wenn es ihnen passen würde.

Mit den Venezianern haben sie, wie wir bereits sagten, den Bund aufgehoben.

Einige Gemeinschaften, die sich auf der italienischen Seite befinden, haben alte Abkommen mit dem Staat Mailand, mit der Verpflichtung, den Menschen nicht zu erlauben, die Pässe zu überqueren, und zwar weder direkt noch indirekt, wenn dies zulasten des genannten Staates geht, und dieses Abkommen haben sie 1604 erneuert.

Ich möchte noch hinzufügen, dass es in Graubünden viele Missbräuche in Sachen Gerechtigkeit gab, die bis in die Gegenwart reichen und etliche Beamte betrafen. Deshalb wurde eine tiefgreifende Reform im Jahre 1603 durchgeführt; aber diese wurde so plump umgesetzt, dass es zu viel Verwirrung führte. Und wer einmal einem Geschäft unterworfen war, der durfte in seinem ganzen Leben kein weiteres mehr haben. Das reicht aus, um über die Bündner zu schreiben.

\section{Anhang über die Walliser}

Ich habe einige Dinge über die Walliser gesagt, als ich über den Bischof von Sitten sprach, also habe ich wenig zu diesem Ort hinzuzufügen. Die Walliser sind Menschen, die in einem kleinen Tal leben, das sich von Ost nach West drei gute Tagesmärsche weit erstreckt, wenn man vom St. Gotthard aus beim Furkagebirge beginnt und bis nach St. Maurice geht. Das Tal ist durchgehend von der Rhone bewässert, die es in der Mitte teilt, und das Wallis ist von Bergen eingeschlossen, die sich etwa fünf Meilen um es herum befinden, und an manchen Orten ist es so eng, dass dort nur die Rhone fließen kann. Aber in St. Maurice, ${ }^{227}$

226 Heinrich III. (1551-1589) war von 1574 bis zu seinem Tod König von Frankreich. Er wurde von einem Dominikaner ermordet. Heinrich III. war der letzte Herrscher aus dem Haus Valois. 227 Vgl. Stichwort „Saint-Maurice (Gemeinde)“, in: https://hls-dhs-dss.ch/de/articles/002774/ 2016-12-23/ (31. Dezember 2020). 
früher bekannt als Aganno, ${ }^{228}$ kommen die Berge so nah zusammen, dass das Tal den Ort wie eine Festung umschließt. Es gibt dort eine Brücke mit zwei Bootsanlagen an der Rhone, und eine sehr große Festung gibt es auch noch, die im ganzen Wallis bekannt ist.

Diese kleine Provinz ist in eine obere und eine untere Provinz unterteilt. Die Vorgesetzten hießen früher Seduni und Viberi, die Untergebenen die Veragni, und weil sie Feinde waren und lange gegeneinander kämpften, wurden die Untergebenen von den Vorgesetzten unterworfen und gehorchen ihnen bis heute.

Die Walliser der oberen Provinz, die die Macht haben, werden in eine Republik von sieben Zenden oder Benzol unterteilt, die ohne ersichtlichen Grund so genannt wird. Sie stehen an der Spitze von sieben Stämmen und vertreten so ihren Ort in der Schweiz.

\subsection{Instruktion für Alessandro Scappi (1621-1628) 229}

Der nachfolgende Text besteht aus zwei Teilen, die im Geheimarchiv auch separat aufgelistet werden. Wer der Autor des Textes ist, wird in dem Schreiben nicht genannt.

Teil 1

Instruktion von Gregor XV. vom 12. Mai 1621 an den Bischof von Campagna, der als Nuntius für die Schweizer der sieben katholischen Kantone bestimmt ist. Sie enthält das von den Franzosen unterstützte Abkommen zwischen Graubünden und den Venezianern sowie das Abkommen zwischen dem Veltlin und den Spaniern mit den Sieben Festungen, die von diesen errichtet wurden, und handelt von Unterschieden zwischen den Konfliktparteien und anderen politischen Angelegenheiten.

Es ist eine wunderbare Sache, Eurer Herrschaft Aufträge oder Ratschläge zu erteilen, da Sie die Last ertragen müssen, die Sie für Seine Heiligkeit auf sich nehmen. Sie wurden als sein ordentlicher Nuntius den sieben Schweizer Kantonen zugeteilt. Da Sie bereits seit langer Zeit in großen Angelegenheiten die Gespräche mit Fürsten geführt haben und sich ihnen gegenüber als weise erwiesen haben, wissen Sie auch, dass zusätzlich zur üblichen Tätigkeit eines Nuntius jede Warnung ernst zu nehmen ist, und da Sie diese Anweisungen nun bei sich haben, in der nicht weniger steht als bei Ihren Vorgängern, sehe ich keine andere Möglichkeit, Ihnen mehr Informationen beizufügen, da in dieser Instruktion bereits alles enthalten ist, aber was schwieriger erscheint, ist, dass ich auch erklären muss, was die Anweisungen Seiner Heiligkeit für den Alltag sind, was die derzeitige Aufregung in Graubünden und im Veltlin gegenüber der Nuntiatur

228 Im HLS-Beitrag (ebd.) heißt es hingegen „Acaunum“ und auf Französisch „Agaune“. 229 Segreteria Stato, Svizzera, Volume 241, f. 81-101. 
betrifft. Da finden so beunruhigende und verwirrende Dinge statt, so unsicher, dass Warnungen allein nicht reichen. Aber aus all dem wird zumindest aus offensichtlichen Gründen ersichtlich, um welch wilde Nation es sich handelt, die hinter den Verdiensten und den Schätzen der Potentaten Europas gelenkt wird, und es sind schwierige Zeiten, in denen man nicht leicht einen Prälaten entsenden kann, der sicherlich seine eigene Vorsicht bei der Unterweisung und seinen Verstand als Ratgeber einsetzen muss.

Und als erste Anweisung werde ich, kurz gesagt, eine weitere Instruktionen $^{230}$ schicken, da - wie gesagt - in den bisherigen Anweisungen bereits alles mitgeteilt wurde, weil die Instruktion sehr vollständig ist, dank der sehr gewissenhaften Berichte der Nuntien, die aus ihrer langjährigen Erfahrung die Erkenntnisse gesammelt haben, um diese Angelegenheiten leichter behandeln zu können.

Wenn Sie sich nun zu Herzen nehmen, sich mit Bedacht und mit angemessener Begeisterung als Apostolischer Nuntius entsprechend einzusetzen, dann werden Sie die gesamte Nation Helvetien und das antike Rätien für Ihre Anliegen gewinnen. Die Schweiz und Graubünden sind ein Gebiet, das mit sehr großen und sehr reichen Bistümern und Klöstern und edlen Untertanengebieten beschenkt ist, und fast alle kirchlichen Orden blühten ins Unermessliche, und das gilt nicht weniger für die Waffen und auch für die Religion und die guten Werke, und so genießen die Menschen dort die einzelnen Privilegien, die sie von der Barmherzigkeit der Päpste und Kaiser sowie von den bewährten Regimentern erhalten haben. Doch dann wurde unter diesen einfachen Völkern die Pest der Ketzerei verbreitet, und das hat in gewisser Weise alle kirchlichen Dinge und die wahre göttliche Zugehörigkeit gestört und verdorben, indem sie die Seelen korrumpiert haben (... $)^{231}$ und so hat die Ketzerei auch die Politik umarmt und in eine böse Lage gebracht. Doch ein Teil wurde durch die göttliche Güte und durch die Arbeit der fürsorglichen Bischöfe und Prälaten gerettet, aber vor allem dank des Einsatzes des Apostolischen Stuhls und seines guten Dienstes zur Ehre Gottes. Zweifelsohne wird man in Zukunft sehen, ob die Nuntien mithelfen können, die Lage zu verbessern. Denn es kann nicht so bleiben wie bisher. Vielmehr müsste die pastorale Sorge gestärkt werden, und dann wird die Rückführung zur alten Ordnung ${ }^{232}$ wieder zunehmen, und die erlittenen Verluste werden dann rückgängig gemacht. Aber hierfür muss der Nuntius in diesen

230 Hier könnte es sich um die in Kapitel D. genannte Relation von Ladislao d'Aquino handeln, der einen sehr ausführlichen Bericht über die Schweiz schrieb.

231 Es folgt eine unklare Passage, die aber im Kontext des Textes keine Rolle spielt.

232 Gemeint ist, dass die Protestanten „wieder“ zur katholischen Kirche zurückkehren und so das Schisma aufgehoben wird. Der Autor dieses Textes geht also davon aus, dass die Protestanten noch zur Kirche gehören. 
Bergen wohnen, weil es vielen als ein starkes Zeichen erscheinen wird. Und wenn er keine Geschäfte hat und fast untätig ist, so soll er an den Ruhm der kleinen vor den großen Dingen denken, die man auch an den Höfen der großen katholischen Fürsten behandelt. Denn wenn man die Augen auf die Bekehrung der Ketzer richtet und ihrer Gottlosigkeit widersteht und in den früheren Gebieten wieder die Gerichtsbarkeiten einführt und vor allem die Prälaten und den Klerus mit der Förderung von Priesterseminaren unterstützt, oder in anderer Weise zur Heilung der Hungersnot der Priester und Missionen sorgt und den sehr nützlichen Dienst der guten Ordensleute fördert, um die ketzerischen Bücher zu verbieten; wenn man die Visitationen in den Diözesen, die Reform der Ordensgemeinschaften und die Stärkung ihrer Freiheit sowie die übrigen Kirchenbeamten fördert, und wenn Sie darüber hinaus als Nuntius auftreten, um die teilweise Uneinigkeit der katholischen Laien in diesen Kantonen anzugehen, und mehr den Franzosen gegenüber zugeneigt sind als den Spaniern, wie das eigentlich erwartet wird, dann werden Sie sich das Wohlwollen der Anführer in diesem Land sichern. Sie werden damit mehr für den Apostolischen Stuhl tun, als erhofft war, und so auch mehr Erfolg haben, ohne den Papst mit der Notwendigkeit zu belästigen, mehr auszugeben, als er ohnehin schon tut, um die Herzen der Menschen zu befriedigen. Und immer noch geht es darum, dass wir in der Eidgenossenschaft denjenigen, die sich mit anderen Fürsten verbinden, weiterhin die Ehrerbietung erweisen, damit der Nuntius gut arbeiten kann, aber es braucht sonst keine weitere nützliche Klugheit, weil ich keinen besseren und verdienstvolleren Apostolischen Amtsträger kenne als Sie. Ansonsten wird es mit der wahren Herrlichkeit nie vorangehen. Aus diesem Grund wissen Sie, dass all diese Dinge sehr gut und notwendig sind. Das sind mehr als bloße leere Worte, und Sie sollen sich auch nie gegen die Ihnen anvertraute Aufgabe stellen, damit die andere Seite keine Hoffnungen auf ihren Sieg hegt. In der Tat vertraue ich darauf, dass Sie alles unternehmen werden, diesen Menschen gegenüber mit Mitleid zu begegnen, und dass Sie Ihre Menschlichkeit in jenen Nationen aufzeigen, die es trotz allem wert sind, was hier nicht nur so aufgeschrieben wird, sondern ein allgemeines Anliegen der Kirche ist.

Für die gegenwärtigen Unruhen in Graubünden und im Veltlin gibt es zwei Gründe: Zum einen die Religion, zum anderen das Interesse des Staates. Der erste Punkt ist alt, und den gibt es aus mehreren Gründen, der zweite ist wichtiger als der erste Punkt, denn dieser wird fast nur als Vorwand des Reiches benützt, wenn wir über die Religion sprechen, und eines ist er sicher, wenn die Schweizer und die Bündner zusammen 300 tausend Scudi von der Krone von Frankreich erhalten sollten, dann sind sie geneigt, den Staat Mailand zu besetzen und Unruhen in jenem Staat zu fördern, den sie aber zuvor im Auftrag von Papst Julius II. unterstützt hatten. Es betrifft einen Teil des Veltlins und Grau- 
bündens, die im Jahr 1512 die Unterstützung der Schweizer nicht einfach als Untertanengebiete, sondern vielmehr als Verbündete erhielten. Nach dem Bündnis mit ihnen im folgenden Jahr wurde viel abgemacht. Doch danach, durch die Ketzerei infiziert, begannen die Bündner um das Jahr 1527 und in den darauf folgenden Jahren noch mehr, in das Veltlin einzudringen und so viele Anführer dort zu verpesten, dass es den Ketzern in Graubünden nicht schwerfiel, weiter zu gehen, da sie bereits so viele vertrauenswürdige Freunde und Anhänger hatten und sie dazu veranlassten, Richter ihrer Sekte dorthin zu bringen, und nach und nach die alten Ordnungen der Gesetze und der kirchlichen Dinge zu stören und die Freiheiten der Zwangsunterworfenen zu mindern, die sie zuvor als Freie und Verbündete behandelt hatten. Dann machten sich die Ketzer mit Gewalt daran, alle göttlichen und menschlichen Dinge zu untergraben, um wie vorgesehen die Unterwerfung all dieser Völker unter die Ketzerei sowie die Zerstörung der katholischen Religion überhaupt zu erreichen, und machten sich großen Mutes daran, ihr Gift durch dieses Tor in der Lombardei und in Italien zu verbreiten. Nur durch Zufall wurden sie in den letzten Jahren daran gehindert, da die Fürsten sich wehrten. Und so trachteten sie nicht mehr danach, den Geist des Klerus zu quälen und all ihre Gottlosigkeit weiter zu verbreiten. Aber sie erarbeiteten einen Plan, um den gesamten katholischen Namen in tausend unmenschlichen und tyrannischen barbarischen Handlungen auszutilgen, und schließlich dachten sie mit einer allgemeinen und grausamen Tötung daran, diejenigen aus der Welt zu schaffen, die nicht durch Flucht vor ihnen gerettet werden konnten; aus diesem Grund arbeiteten sie zu diesem Zweck zusammen, um das Tal durch ein großes Aufgebot an Männern zu regieren. Die Katholiken entdeckten den bösen Plan und, verzweifelt um ihr Leben bangend, ergriffen im Juli 1620 die Waffen. So haben sie mehr als 400 Gegner in Stücke gerissen. Darunter waren sowohl die Lehrer als auch die Prediger jener Sekte. Und dann, mit der frühzeitigen Hilfe der Spanier - denn inzwischen waren die Bündner von den Schweizer Ketzern begleitet -, standen im September rund 5000 Männer im Einsatz. Sie erreichten einen glücklichen Sieg in Tirano, wo sie rund 2000 Männer getötet haben. ${ }^{233}$ Der zweite Grund für die genannten Unruhen, von denen ich sprach, war das unehrliche Interesse des Staates, das zu den Kriegen führte, die zwischen dem König von Frankreich, den Schweizern und Graubünden stattfanden, und es ging darum, die Sforzas im Staat Mailand wieder zur Macht zu bringen, und so gründeten diese Menschen mit der Krone von

233 Die Schlacht bei Tirano wurde am 11. September 1620 bei Tirano im Veltlin zwischen den Drei Bünden, Bern sowie Zürich und Habsburg-Spanien ausgefochten. Sie endete mit einem Sieg Habsburg-Spaniens. Vgl. Friedrich Pieth: „Die Schweiz im Dreissigjährigen Kriege 16181648“, in: Schweizer Kriegsgeschichte, Heft 6, Bern 1916. S. 61-104. 
Frankreich im Jahr 1532 eine Liga mit Franz I., fast nach den vorher von diesen Nationen und den Herzögen von Mailand in einem Treffen festgelegten Vereinbarungen, das vorsah, dass die Bündner verpflichtet sind, das Veltlin den französischen Armeen sowie ihren Freunden und Verbündeten zu überlassen. [...] $]^{234}$

Teil 2: Namensauflistung ${ }^{235}$

\section{$[\ldots]$}

Und zumal Sie die reichlichen und nicht weniger umsichtigen Anweisungen Ihrer Vorgänger bei sich haben, kann Ihre Seligkeit auf die einzelnen Verhandlungen eingehen, die derzeit für Unruhe sorgen. In Graubünden und im Veltlin, die unter der Kontrolle Ihrer Nuntiatur stehen, gibt es Dinge, die so beunruhigend, verwirrend oder unsicher sind, dass die Ereignisse allein schon ausreichen würden. Aber daraus offenbart sich vor allem, dass es sich um sehr gefährliche Nationen handelt, die sich hinter den Bergen verstecken. Dort können die Potentaten Europas auch ihre Schätze bewahren. Deshalb ist es wichtig, dass in schwierigen Zeiten ein Prälat gesandt wird, der mit seiner Erfahrung bei der Erziehung und dem Verständnis helfen und beraten kann. Es gibt schon sehr viele Erfahrungen aus den fleißigen Beziehungen der bisherigen Nuntien. Und diese langjährigen Erfahrungen können dazu dienen, die Ausbildung pflichtbewusst und mit Freude anzugehen, um die Angelegenheiten besser zu regeln, so dass ich nur wenig anfügen werde. Sie dürfen sich sehr darüber freuen, dass Sie in den zerklüfteten Bergen und bei jenen Völkern sein dürfen, die meist stolz, rau und vermischt mit oder umgeben von hartnäckigen Feinden des Römischen Reiches sind. Es gibt durchaus viele Anzeichen von Frömmigkeit, und das große Vorhaben, den Glauben zu vermehren, ist ebenso möglich, um so unendliche Verdienste erlangen zu können, wenn Sie sich dazu entschließen, mit Bedacht und mit angemessener Begeisterung auf die Pflege der Apostolischen Nuntiatur achtgeben, die ganz Helvetien und Rätien mit sehr großen und reichen Bistümern betrifft.

$[\ldots]^{236}$

Da sie so viele Soldaten halten konnten, dass es ausreichte, jedem feindlichen Impuls zu widerstehen, beschlossen die Spanier, die das Tal bereits mit ihren Soldaten in ihrer Macht hielten, alle Bereiche dieses Tals zu schützen, und bauten dort acht Festungen. All dies hat dazu geführt, dass jetzt alle Fürs-

234 Die Instruktion geht bis f. 101. Darin werden die Rolle von Frankreich und Spanien sowie die Bedeutung der Protestanten und katholischen Orte erläutert.

235 Segreteria Stato, Svizzera, Volume 249, f. 137-161.

236 Es folgt eine Wiederholung der im ersten Teil genannten Informationen. Der zweite Teil dieser Instruktion ist in einem anderen Band im Vatikanischen Geheimarchiv aufbewahrt. 
ten neidisch sind, die sich an den Angelegenheiten Italiens beteiligen wollen, als ob die Spanier jene unter sich haben, die die Katholiken verteidigen und die das lange Tal besetzten, welches einzig für den Durchgang der Armeen über die Berge offen blieb, was in den Verträgen der vergangenen Bündnisse immer so umstritten war.

Der zweite Grund für die oben genannten Unruhen war, wie ich sagte, das Interesse des Staates. So kam es, dass sie nach den Kriegen, die zwischen dem König von Frankreich und den Schweizern und Graubünden stattfanden, sie die Sforzas in den Staat Mailand bringen wollten, und so einigten sich diese Völker mit der Krone von Frankreich, und im Jahr 1532 schlossen sie ein Bündnis mit Franz I., ${ }^{237}$ das fast den zuvor zwischen diesen Nationen festgelegten Abmachungen entsprach, und den Herzögen von Mailand wurde in einer Versammlung zugewiesen, dass die Bündner verpflichtet seien, ihnen den Pass zum Veltlin zu gewähren, damit die Armee der Franzosen und ihrer Freunde und Verbündeten dorthin gelangen könne, und aus dem Volk sollte ihnen auch Söldner für den König zur Verfügung gestellt werden, solange dies nicht dazu diene, den Staat Mailand anzugreifen. In jener Versammlung wurde auch festgehalten, dass jener Staat keine Änderung vornehmen darf. [...]

Es folgt eine genaue Beschreibung der Allianzen zwischen Graubünden, Frankreich, Spanien, Venedig und den Eidgenossen.

Da sich Frankreich alleine gegen einen Teil der Nation Graubünden unter Beweis gestellt hat, werden sie versuchen, mehr Waffen $\mathrm{zu}$ beschaffen, falls die anderen Fürsten ihnen zu Hilfe kommen werden; denn von diesen Völkern, die nichts anderes als ihre eigene Barbarei und die schrecklichen Berge verteidigen wollen, kann man wenig gewinnen und viel verlieren. [...]

Man muss die Zwietracht unter den Bürgern dieser Nation, die an einem einzigen Tag bekämpft werden könnte, nicht ernst nehmen. Das kann man am Tisch lösen. Es wird dem König leichter fallen, nach Lyon zu gehen, wenn das Veltlin nicht in Freiheit steht, und er wird sich an deren Unruhen ergötzen, denn er kontrolliert die Waffen aller gegen Italien. [...]

Und deshalb will ich für Ihr alltägliches Amt die vergangenen Anweisungen beifügen, und ich zweifle nicht daran, dass Sie mit den höflichen und freiheitsliebenden Umgangsformen zurechtkommen werden, um die Herzen dieser Nation zu gewinnen und sie trotz allem stärker an diesen Heiligen Stuhl zu binden.

237 Vgl. Stichwort „Franz I.“, in: https://hls-dhs-dss.ch/de/articles/029215/2006-01-05/ (31. Dezember 2020): „Mit dem 1521 mit Frankreich abgeschlossenen Soldbündnis erhielt der franz. König das Recht, jedes Jahr bis zu 16000 Schweizer Söldner anzuwerben.“ Die Jahreszahl, die der Autor in der Instruktion nennt, ist somit nicht korrekt. 
Und außerdem sollen sie Ihnen mit Ihrer Dienerschaft ein lebendiges Beispiel der kirchlichen Würde geben. [...]

Aus Rom, den 12. Mai 1621

\subsection{Bericht von Nuntius Ranuccio Scotti (1630-1639) ${ }^{238}$}

Die Gerichtsbarkeit der Nuntiatur in der Schweiz erstreckt sich auf zwölf Tagesreisen in die Länge und auf ebenso viele in die Breite. Sie umfasst in Oberdeutschland die fünf großen und ansehnlichen Bistümer Konstanz, Lausanne, Sitten, Chur und Basel, von denen das erste und letzte unter der Mutterkirche Mainz, die anderen unter jener von Besançon stehen. Auch das Bistum Como ist ihr beinahe ganz unterworfen, nämlich die Landschaften Veltlin, Lugano, Mendrisio, Bellinzona und andere. Keine unter den so vielen Nuntiaturen des Apostolischen Stuhls reicht an jene der Schweiz an Wichtigkeit und Ansehen. Sie hat die Aufgabe, den katholischen Glauben in jenem Land unversehrt zu erhalten, denn die Ketzerei legt von allen Seiten Fallstricke. Es ist die Aufgabe des Botschafters aus Rom, darüber zu wachen, dass die nahe Pest nicht die Völker ergreife, sondern die Ergebenheit dieser Nation dem römischen Stuhl erhalten bleibt und wachse.

Aus dieser unbedingten Selbsthingabe der Schweizer an den römischen Stuhl entspringt ihre große Hochachtung dem Nuntius gegenüber, in dem sie die Gewalt eines päpstlichen Bevollmächtigten verehren. Daher wird er bei seiner Ankunft in der Schweiz von geistlichen und weltlichen Abgeordneten an den Stadttoren unter einem Thronhimmel empfangen und unter dem Geläute aller Glocken und dem Donner der Kanonen bis zu seiner Wohnung begleitet. ${ }^{239}$

Kostspieliger als viele andere, weit umfassendere Nuntiaturen ist die bei der Schweizerischen Eidgenossenschaft. Aber es sind nicht der äußere Glanz, die Hofhaltung, die Uniformen oder ähnliche Dinge, die dies ausmachen und den großen Aufwand verursachen, sondern es sind die beträchtlichen Geldsummen für die Kosten der Gastwirtschaften, die bei gewöhnlichen Festtagen des Jahres fünfmal zum Einsatz kommen, sowie bei der Durchführung der Tagsat-

238 Zit. nach: Ludwig Snell: Geschichte der Einführung der Nuntiatur in der Schweiz, S. 147156. Originalschrift in: Helvetia Sacra e profana, relatione fatta da Monsr. Scotti, vescovo del Borgo etc. Macerata 1642. Snell hat seiner Übersetzung auch eigene Anmerkungen beigefügt. Der Text in dieser Arbeit ist eine überarbeitete Fassung.

239 Snell stellt in einer Fußnote an dieser Stelle den Ablauf des Empfangszeremoniells vor, wie es im 16. und 17. Jahrhundert in Luzern üblich gewesen sein soll. Vgl. Ludwig Snell: Geschichte der Einführung der Nuntiatur in der Schweiz, S. 147. 
zung. Die Bewirtung dauert fünf bis zehn Stunden, so sieht es die Sitte dieses Landes vor. Wer die Zuneigung und den Beifall der Schweizer für den Apostolischen Stuhl zu gewinnen gewillt ist, der soll es an Geschenken nicht fehlen lassen und sich ebenso eigennützig beweisen als freigebig. Denn auf die Gemüter der Schweizer macht nichts größeren Eindruck als der Anblick eines päpstlichen Gesandten, der von allem Eigennutz frei ist. Hinzu kommen noch die unaufhörlichen Reisen des Nuntius in alle seiner Obhut anvertrauten Gegenden, wozu sein Beruf ihn verpflichtet, damit die Gerichtsbarkeit der heiligen Kirche und ihre Freiheiten allenthalben gewährleistet, die Geistlichkeit gebessert, die klösterliche Zucht hergestellt und Bischöfe und Äbte zur Erfüllung ihrer Pflichten immerfort angehalten werden.

Nicht nur Geld, auch einsichtsvolle Klugheit darf dem Nuntius in der Schweiz nicht fehlen, will er seinem Amt mit Nutzen und Würde vorstehen. Denn da hat er nicht bloß, wie anderswo auch, die Gemütsart eines einzelnen Fürsten oder Günstlings zu bekämpfen, sondern die Leidenschaften so vieler Köpfe, die das Schweizer Gemeinwesen verwalten. Indessen wird er sich darüber, auf allerhand vertraulichen Wegen, die gehörige Kenntnis zu verschaffen wissen. Er muss aber in dem, was ihm vertraulich mitgeteilt wird, sich öffentlich höchst unwissend stellen, um ja das Zutrauen, das er genießt, und den Ruf der Unparteilichkeit nicht zu verlieren. Das soll aber ebenfalls mit Klugheit getan werden. Denn schweigt er zu viel, so läuft sein Ansehen Gefahr, missverstanden zu werden. Darum soll er, überall von Gefahren umgeben, sich im besonnenen Gleichgewicht halten.

Von der Schwierigkeit eines Amtes schließt man richtig auf die Geisteskraft dessen, der es würdig versieht. Um also das Andenken vieler Prälaten, die den Posten eines päpstlichen Nuntius in der Schweiz mit glücklichem Erfolg bekleidet haben, der Vergessenheit zu entreißen, will ich hier jene anführen, deren Namen ich in den Archiven oder in den Beglaubigungsschreiben aufgezeichnet fand. Aus der persönlichen Vortrefflichkeit der Botschaft wird der hohe Wert ihres Dienstes bemessen, den die römischen Päpste der Nuntiatur in der Schweiz mit ihrer Gründung bewiesen haben. ${ }^{240}$

1231 war Bischof Otto Apostolischer Nuntius in der Schweiz. Seinen Sitz hatte er in Basel. Der Name seines Bistums und Geschlechts ist ganz unbekannt. Dieses Amt bekleidete dann im Jahr 1233 Meister Philipp von Assist. ${ }^{241}$ Damals entrichteten die vorzüglichsten Klöster der Schweiz dem römischen Stuhl als jährliche Abgabe eine bestimmte Summe von Silbermarken.

240 Wie Snell feststellt, folgt eine unpräzise chronologische Auflistung der Nuntien in der Schweiz. Vgl. Ludwig Snell: Geschichte der Einführung der Nuntiatur in der Schweiz, S. 150. 241 Es ist keine weiterführende Literatur zu diesem Namen bekannt. 
Dann findet sich zwei Jahrhunderte hindurch keine Spur von irgendeinem Nuntius bis auf den berühmten Girolamo Frank ${ }^{242}$ im Jahr 1449. Zu eben dieser Würde gelangte im Jahr 1479 der Bischof von Anagni, Gentilis von Spoleto, ${ }^{243}$ der das erste Bündnis der Schweizer mit dem Papst verhandelt und abgeschlossen hat.

Eben dahin wurde im Jahr 1483 von Sixtus IV. der Schatzmeister der heiligen Kirche, Bischof Bartholomäus, mit dem Titel eines Legato a latere gesandt. ${ }^{244}$

Großen Ruhm erwarb sich auf diesem Posten der Bischof von Sitten, Matthäus Schiner, im Jahr 1510. Er erneuerte das Bündnis der Schweizer, Bündner und des Abtes von St. Gallen mit Papst Julius II., der jedem der Kantone ein Jahresgeld von tausend rheinischen Gulden aus dem päpstlichen Schatz anwies. Daraufhin wurde Schiner mit dem Kardinalshut beehrt, der die Schweizer und Bündner zu den zwei berühmten Feldzügen nach Italien überredete, um die Kirche in Parma und Piacenza wieder zu erobern. ${ }^{245}$ Der erste Zug bestand aus sechstausend, der zweite aus zwanzigtausend streitbaren Männern.

Leo X. sandte den Internuntius Goro Chersio ${ }^{246} \mathrm{im}$ Jahr 1513 und bald darauf den Bischof von Veroli, Ennio Filonardi, ${ }^{247}$ die beide $1515 \mathrm{zu}$ der Würde von Nuntien erhoben wurden.

$242 \mathrm{Zu}$ Hieronymus Frank, wie er auf Deutsch eigentlich genannt wurde, finden sich in Heinrich Bullingers Werken Spuren. Vgl. Heinrich Bullinger: Werke, S. 174.

243 Gentile da Spoleto, wie er auf Italienisch hieß, war von 1478 bis 1484 Bischof von Anagni. Vgl. Homepage des Bistums Anagni-Alatri: https://www.beweb.chiesacattolica.it/diocesi/diocesi/318/Anagni+-+Alatri (31. Dezember 2020).

244 Hier merkt Snell an, dass die „Eidgenossen an solchen Legaten keine besondere Freude hatten“. Vgl. Ludwig Snell: Geschichte der Einführung der Nuntiatur in der Schweiz, S. 151: „So sagten die Gesandten der Stände Luzern, Schwyz, Uri und Solothurn im Jahre 1650 dem Nuntius Boccapaduli, der ein sehr übermütiger und störriger Herr war, ins Gesicht: ,Ihre hohen Committenten werden den Heiligen Vater bitten, seinen Nuntius mit der Gewalt oder dem Titel eines Legaten von der Seite (nicht) mehr zu senden, sondern wie andere Fürsten und hohe Stände zu tactiren [sic!], indem die Herren Nuntien gemeiniglich ihrer Landes- und Gemütsart nicht gewohnt sind und auch keine oder nur schlechte Wissenschaft von den eidgenössischen Gebräuchen haben, woraus denn die unförmlichen Prozeduren, übereilte Urteile entspringen, die dem Staate große Angelegenheiten verursachen, auch der Religion unwiederbringlichen Schaden zufügen, ja ein Chaos oder Verwirrung sowohl in weltlichen als geistlichen Dingen erregen, nicht ohne das größte Ärgernis und Applaus der Acatholiken.““

245 Vgl. T. H. Neomario (Theodor Niemeyer): Geschichte der Stadt Rom, S. 1243: „Der Papst vergrößerte den Kirchenstaat durch Parma und Piacenza, welche zum Herzogtum Mailand gehört hatten. Die Schweizer, welche zur Befreiung Oberitaliens von den Franzosen das meiste beigetragen hatten, erboten sich, indem sie Abgesandte im Namen von 12 Kantonen zur Huldigung des Papstes nach Rom schickten, zum beständigen Schutz des Kirchenstaates.“

$246 \mathrm{Zu}$ diesem Namen ist nichts auffindbar.

247 Vgl. Pietro Filonardi Tibaldeschi: Famiglia Filonardi. 
Bald darauf erschien, vom entsprechenden Papst gesandt, Jakob Gamba$\mathrm{ra}^{248}$ und 1517 Anton Pucci, ${ }^{249}$ Kleriker der Apostolischen Kammer und Bischof von Pistoia und später Kardinal. Dann folgte 1518 Sigismund Dandolo, ${ }^{250}$ Apostolischer Kommissar. 1521 kehrte der oben erwähnte Ennio Filonardi nach Rom zurück, nachdem er, vereint mit dem Kardinal Schiner, zwölftausend Schweizer zur endgültigen Wiedereroberung von Parma und Piacenza angeworben hatte. Ihn kreierte Paul III. zum Kardinal.

Jakob Sadoleto, ${ }^{251}$ Bischof von Carpentras, wurde von Papst Clemens VII. in die Schweiz abgeordnet, und zwar im Jahr 1531. Während seiner Verwaltung griff die Ketzerei in der Schweiz immer weiter um sich, aber die fünf ältesten katholischen Kantone erkämpften in einer blutigen Schlacht ${ }^{252}$ über Zürich und die übrigen Protestanten einen ruhmvollen Sieg. Damals wurde der Sitz der Nuntiatur von Zürich nach Luzern verlegt.

Eben diese Stelle bekleideten zur Zeit Pauls IV. im Jahr 1545: Ottaviano Ruerta, ${ }^{253}$ Bischof von Ferrara, und unter Pius IV. wurde Anton Bulgio, ${ }^{254}$ Bischof von Como, entsandt, durch den der Papst mit den fünf ältesten katholischen Orten ein besonderes Bündnis schloss. ${ }^{255}$ Der genannte Prälat bewog die Schweizer, einen Bevollmächtigten zum Tridentinischen Konzil zu schicken und danach dessen Beschlüsse auch feierlich anzunehmen. ${ }^{256}$

Unter Gregor XIII. wurde Franz Buonomi, Bischof von Vercelli, 1580 entsandt. Dieser Nuntius hat in Freiburg die Gesellschaft Jesu eingeführt, zum großen Vorteil der katholischen Religion, da hier in der Nähe die Ketzerei der Berner drohte, die auch deswegen ergrimmt den eifrigen Prälaten gefangen zu

248 Seine Lebensdaten sind nicht bekannt. Er war Bischof von Albegna.

249 Antonio Pucci (1484-1544) war Teilnehmer am Fünften Laterankonzil und von 1517 bis 1521 Nuntius in der Schweiz. Vgl. Stichwort „Antonio Pucci“, in: https://hls-dhs-dss.ch/de/articles/017915/2011-12-15/ (31. Dezember 2020).

250 Auch über ihn sind keine genauen Daten bekannt.

251 Im italienischen Lexikon „Treccani“ steht zwar seine Biographie, doch fehlt jegliche Angabe, dass er als Nuntius in der Schweiz ernannt und entsandt wurde. Vgl. http://www.treccani.it/enciclopedia/iacopo-sadoleto_\%28Dizionario-Biografico\%29/ (31. Dezember 2020).

252 Gemeint ist die Auseinandersetzung 1531 in Kappel.

253 Dieser Name ist nicht auffindbar. In jener Zeit war Giovanni Salviati Apostolischer Administrator des Bistums von Ferrara (1520-1548). Es folgten Bernardino della Croce (1548-1559) und Gianantonio Volpi (1559-1588).

254 Auch dieser Name stimmt nicht, denn in jener Zeit war Cesare Trivulzio (1519-1548) Bischof von Como.

255 Vgl. Volker Reinhardt: Geschichte der Schweiz, S. 121.

256 An dieser Stelle fügt Snell in einer Fußnote an, dass die Eidgenossen misstrauisch ,gegen die Politik des römischen Hofes“ gewesen seien, und so hätten sie „dessen Aufforderung zur Beschickung der Synode von Trient lange unberücksichtigt gelassen“. Vgl. Ludwig Snell: Geschichte der Einführung der Nuntiatur in der Schweiz, S. 153. 
nehmen trachteten. Ebenso gründete er die genannte Gesellschaft auch in Luzern, ${ }^{257}$ unterstützt vom Papst, den beiden Kronen (Spanien und Frankreich) und der außerordentlichen Freigebigkeit der dortigen Regierung.

Unter demselben Papst wurde 1584 der Dominikanermönch und Bischof Niguarda, im darauf folgenden Jahr Baptist Santonio, Bischof von Tricarico, entsandt. Auf ihn folgte:

Ottavio Paravicini, Bischof von Alessandria, der bei der Krone von Frankreich den Unterhalt von 6000 Schweizern zu Gunsten des katholischen Bundes vermittelte. Als er noch in Luzern war, wurde er von Gregor IV. zum Kardinal erhoben.

Unter Clemens VIII. wurde Andreno Ludovico ${ }^{258}$ ernannt. Diesem verweigerten die Schweizer den Eintritt in ihr Gebiet, weil sie sich von den Legaten Paravicini und Gaetano ${ }^{259}$ beleidigt fühlten. ${ }^{260}$ Die Nepoten des Letzteren wurden in Altdorf verhaftet, gleichsam als Geisel für die seit der letzten Werbung schuldigen Geldsummen, die der römische Stuhl zu tilgen zögerte. Papst Clemens sandte den Bischof Johann, Grafen von Thurn (della Torre), der die Gemüter der bedeutendsten Staatsmänner in der Schweiz so zu beruhigen wusste, dass er als Nuntius anerkannt wurde und dieses Amt während der Lebenszeit von Papst Clemens mit dem größten Ruhme verwaltete. Viele Missbräuche hat er behoben, die Geistlichkeit und namentlich die Benediktinerklöster zum erbaulichen Wandel wieder zurückgebracht und letztere in zwei Abteilungen, der Schweizerischen und der Schwäbischen, aufgeteilt. Mächtig verhalf ihm zur Wiederherstellung einer Nuntiatur in der Schweiz der edle und fromme Ritter Melchior Lussi $^{261}$ von Unterwalden, einst Abgeordneter seiner Nation bei der Kirchenversammlung in Trient.

Unter Paul V. wurde 1606 Fabritius Verallo Nuntius, Bischof von San Severo, der nach zwei Jahren den Kardinalshut erlangte. Auf ihn folgte Ladislaus von Aquino, Bischof von Venafro, ein für die Ausbreitung der katholischen Religion eifriger Mann, den Paul V. zum Kardinal erhob.

257 Snell merkt an dieser Stelle in einer Fußnote an, dass sich Scotti zu irren scheint, „denn die Jesuiten waren längst vor der Ankunft des Nuntius Buonomi in Luzern“. Vgl. Ludwig Snell: Geschichte der Einführung der Nuntiatur in der Schweiz, S. 154.

258 Über ihn ist nichts erfasst.

259 Weitere Erläuterungen zu Gaetano sind nicht bekannt.

260 Hier fügt Snell in einer Fußnote an: „Die Urner erklärten damals: ,Sie möchten ihres Orts gern aller Legaten entbehren, ihre Landleute seien ihrer müde und unwillig; Sie machen ihnen viele Geschäfte und Neuerungen und Eingriffe, und nützen überhaupt dem Lande nicht viel““. Zit. nach: Ludwig Snell: Geschichte der Einführung der Nuntiatur in der Schweiz, S. 155.

261 Hier schreibt Snell den Namen „Lussi“ mit „i“. Üblicherweise wird aber Melchior Lussy geschrieben. 
1613 wurde Ludwig Conti, Bischof von Adria, Nuntius in der Schweiz. Diesem Prälaten verdanken es die Schweizer Benediktinerklöster, dass sie nun unmittelbar dem römische Stuhl und sonst keiner anderen Gerichtsbarkeit unterstellt sind.

1621 wurde unter Gregor XV. und mit nachgefolgter Bestätigung des wirklich regierenden Papstes Urban, Alexander Scappi, Bischof von Campagna, entsandt, der an Eifer und Tätigkeit keinem nachstand.

Auf ihn folgte der Erzbischof Ciriaco Rocci, nach dessen Beförderung zur Nuntiatur in Deutschland die Güte Seiner Heiligkeit und des Kardinals Barberini mich zum Nachfolger eines so würdigen Vorgängers bestimmte. Von mir kann ich nun weiter nichts sagen, als dass ich seit neun Jahren die erwiesene Gnade durch treuen Diensteifer dankbar zu verdienen suche. 
